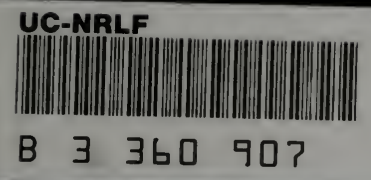




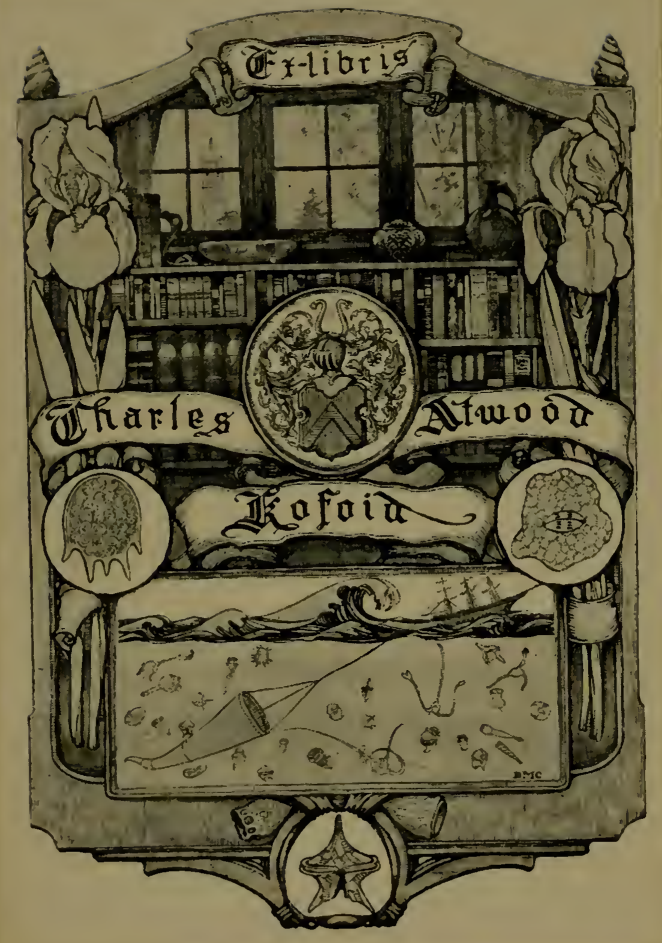




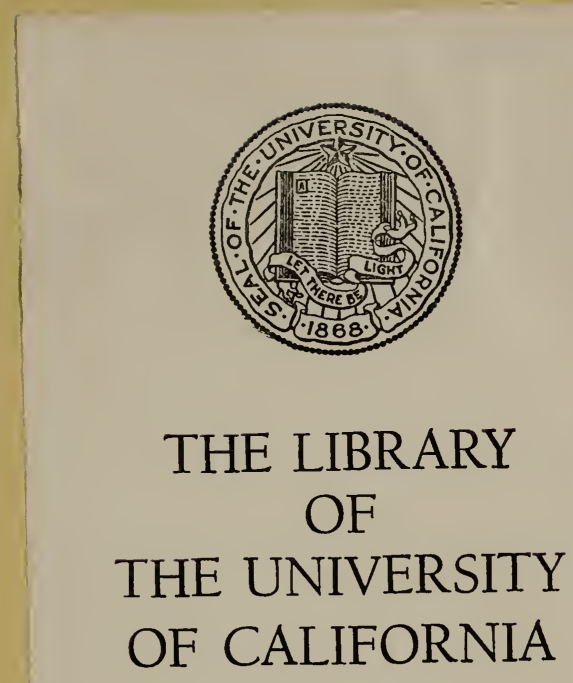

\author{
PRESENTED BY
} PROF. CHARLES A. KOFOID AND MRS. PRUDENCE W. KOFOID 



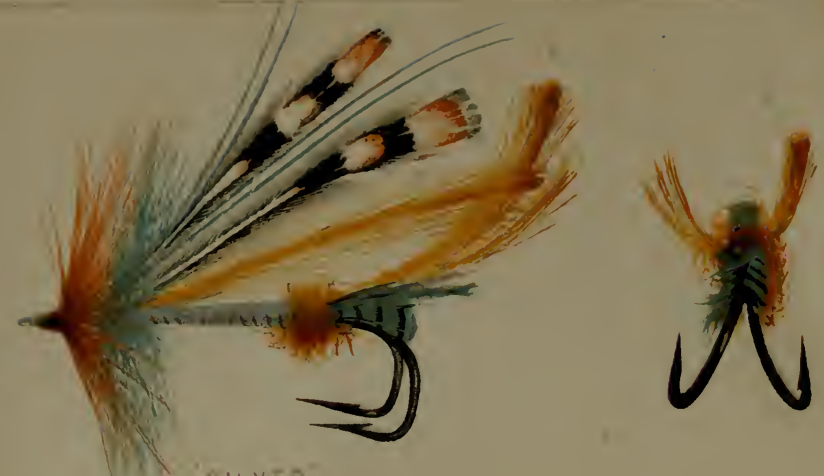

SILVER
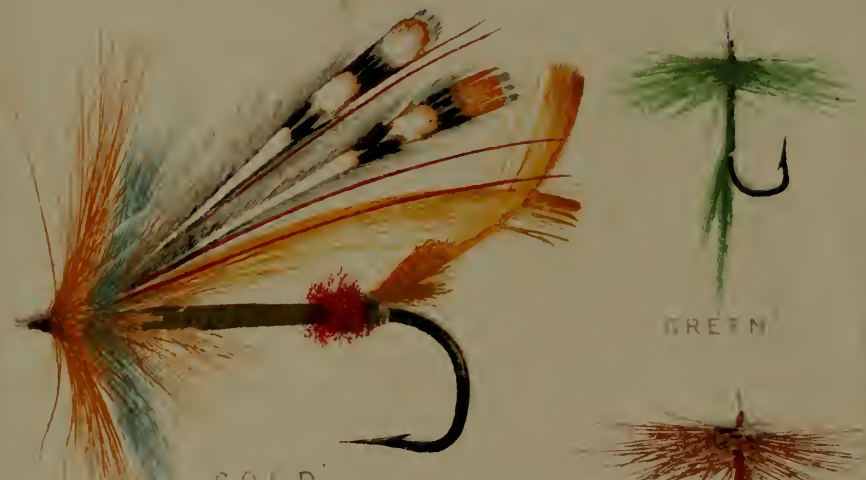

TRETM

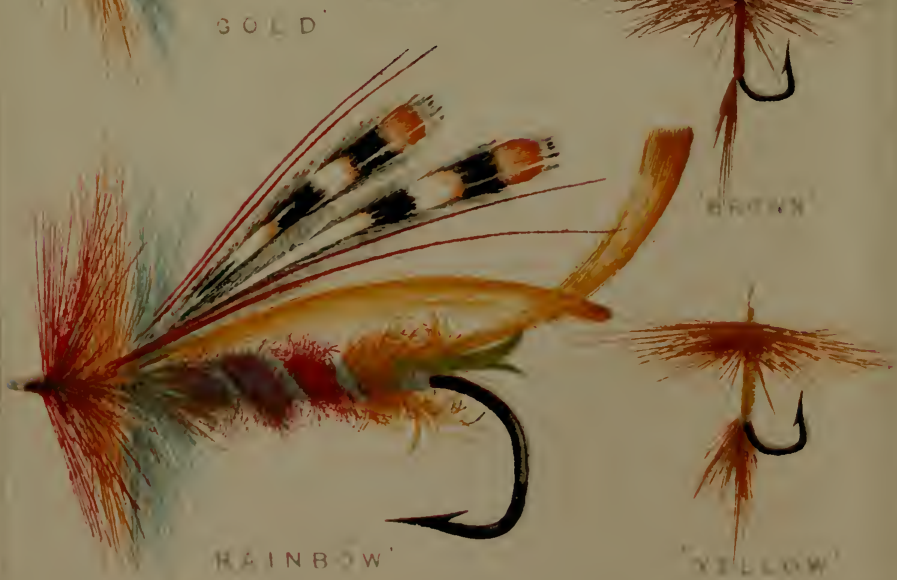




\section{THE MODERN}

\section{PRACTICAL ANGLER}

A COMPLETE GUIDE TO

FLY-FISHING, BOTTOM-FISHING \& TROLLING

BY

\section{H. CHOLMONDELEY-PENNELL \\ INSPECTOR OF FISHERIES}

AUTHOR OF "THE ANGLER-NATURALIST" “THE BOOK OF THE PIKE" ETC.

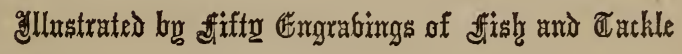

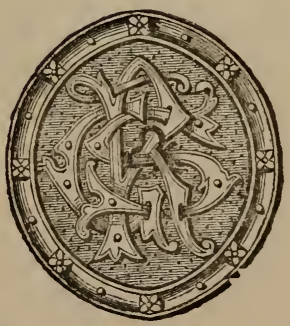

LONDON

GEORGE ROUTLEDGE AND SONS THE BROADWAY, LUDGATE

NEW YORK: 4 I6, BROOME STREET 


\author{
SAVILL, EDWARDS, AND CO., PRIXTERS, CHANDOS STREET,
COVENT GARDEN. \\ LONDON :
SAVILL, EDWARDS, AND CO., PRIXTERS, CHANDOS STREET,
COVENT GARDEN.
}

N :
RIXTERS, CHANDOS STREET,
ARDEN.

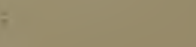

LONDON :
CO., PRIYTERS, CHANDOS STREET,
CONT GARDEN.

LONDON :
SAVILL, EDWARDS, AND CO., PRINTERS, CHANDOS STREET,
COVENT GARDEN. 


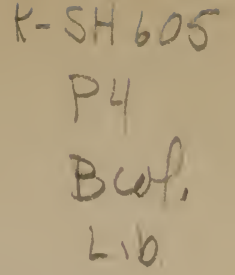

TO

JOHN FRANCIS WORTH, ESQ. OF WORTH, DEVON,

ONE OF THE MOST THOROUGH SPORTSMEN OF THE DAY WITH HORSE, ROD, OR GUN,

THESE PAGES ARE DEDICATED

BY

HIS SINCERE FRIEND,

THE AUTHOR. 


\section{OPINIONS OF THE PRESS.}

"The 'Modern Practical Angler' is the latest, though let us hope not the last, of Mr. Cholmondeley-Pennell's contributions to our angling literature. The purpose of the work is twofold : first, to supply the demand which exists for some general and complete angling manual, bringing the subject up to the mark of modern art ; and secondly, to introduce the author's views on the subject of fly-fishing, which not only differ widely from hitherto received canons, but, if accepted, will practically revolutionise, in the direction of simplifying, the whole system both of making and using artificial flies. Our readers will hardly need our assurance that the first object has been thoroughly and ably fulfilled. ... In regard to the second portion of the book, which relates to fly-fishing, the result of Mr. Pennell's teaching is 'the substitution of six typical flies-three for salnion and grilse, and three for trout, grayling, \&c. - for the whole of the artificial flies now used." This is indeed a 'revolutionary measure,' and one in which. every fly-fisher is directly and personally interested ; for who would not be glad to dispense if he could, once and for all, with the cumbrous assortment of furs, silks, and feathers with which the orthodox practice now loads his tackle-box, and the thousand-and-one patterns of flies enjoined by rackle-makers and angling writers as necessary for each variety of fish, river, and season? To the disciples of Mr. Pennell's school this will be all changed. His three typical troutflies, which are new both in principle and construction, can be made, he assures us, by the merest tyro ; and both these and the salmon-flies-dressed, of course, of different sizeswill readily stow away, with the materials for making them, in the compass of an ordinary bait-box. The 'glorious uncertainty' as to 'which is the right fly,' and the loss of precious time in experimental changes, are also obviated under Mr. Pennell's system, which we look forward with great interest to testing by the river-side on the first opportunity. The prospect seems almost too tempting to be realised; but it cannot be denied that the author's theories and conclusions are the legitimate deductions from an argument logically and even severely worked out; and we can hardly conceive that Mr. Pennell, whose 'fame is on many waters,' would peril his reputation by putting forward in so deliberate a manner theories which he had not himself thoroughly tested in practice.

"Mr. Pennell is not only well known as a senior angler, but as one of the straightest riders and straightest shots in England, and whatever he writes is well worthy of the consideration of Sportsmen."-Baily's Magazine.

"The book is adapted as a vade-mecum to all classes of anglers."-Land and Water.

" Mr. Pennell is so well and so favourably known as a fishing author, that anything which comes from his pen is sure to deserve and secure serious' consideration from an angler's point of view. What Mr. Pennell's politics may be we do not know, but in matters piscatorial he is undoubtedly an awful radical : he insists on the most complete revolution ir all things, and he is a philosophical radical to boot, for he gives reasons for the faith that is in him ..... we have no doubt that this, the latest addition to angling literature, will take a high place in the estimation of the public."-Field.

"Written by an angler of long and varied experience, the 'Modern Practical Angler' is certainly the best modern fishing guide that has come under our notice. The work is full of practical information."-Gentlenan's Magazine.

"The book is clever and handsome, containing much that will interest old anglers and instruct new ones, and also a little that will rouse some of those fierce yet pleasant controversies to which votaries of 'the quiet art' are fully as prone as their brethren of other sports, who do not deny being more noisy. Mr. Pennell has fished in many places, in many ways, with many men; he has an eye for natural scenery, and a knowledge of natural history ; and he has proved himself the posscssor of an elegant and sprightly pen both in prose and verse."-Scotsman.

"We have no need to certificate the author's thorough knowledge of a sport which, as he justly observes, is becoming every day more a matter of difficulty and of fine art .... Mr. Pennell covers ably the whole field of angling pursuit."-Daily Telegraph. 


\section{P R E F A C E.}

THE rapid advance of late years of theoretical and material knowledge has produced a corresponding improvement in the practice of most of the arts and sciences; and the professors of the gentle art, though in a quiet and unobtrusive way, have been by no means behindhand in the general progress. The result is, that the fisherman's library, for all practical purposes, consists only of some dozen books, all, or almost all, being the works of living authors. The names of Stoddart, Peard, Francis, and Stewart, as preceptors in the use of the rod and line; and in the cognate departments of ichthyology and angling belles lettres, those of Russel, Westwood, and Buckland, are household words wherever English anglers are to be found.

With such a phalanx of authors already in the field, however, it may be not unnaturally asked, Why is the present volume published? The answer is, that the admirable works of the writers referred to are, with one exception,* so far as the practice of angling is concerned, monographs, or treatises on particular branches only of fishing; and that there is a demand for some general and complete angling manual, bringing the

* "A Book on Angling," by Francis Francis, Esq Longman and Co. ${ }^{2} 5^{\mathrm{s}}$. 
subject up to the mark of modern art, and saleable at a price not beyond the reach of the masses. The present work is an attempt to supply this desideratum.

In regard, moreover, to the theory and practice of the most important branch of angling, viz., Fly-fishing, I have arrived at conclusions not only differing widely from hitherto received canons, but which, if accepted, will go far to revolutionize, in the direction of simplifying, the whole system both of making and using artificial flies.

The question of tackle, also, has for many years occupied much of my attention; and the details of this subject-especially as regards hooks-are entered into with a minuteness which may perhaps seem to require apology. The apology is, that the whole art of angling consists really of an aggregation of minutiæ, and that upon the difference between, say, a hook of one pattern and a hook of another, often depends, in effect, the difference between a good and a bad day's sport.

The present opportunity is taken of submitting to the judgment of anglers a new pattern of hook, constructed on mechanical principles, and the result of some thought and experiment.

In the department of Trolling-using the term in its widest sense-almost the whole of the tackle described is original, and might properly be called new, but that some of it has already appeared in the "Book of the Pike." Amongst the additions are an improved form of spinning-lead, an artificial trouting-minnow, new flights 
for spinning the eel-tail bait for Pike and Salmon, and, as I hope, a satisfactory solution of that long vexed problem, the "Preserved Bait" question.

In Pond and Float-fishing generally, modern practice and precept have not perhaps left much to be said that is in the strict sense of the term new; but on these subjects I may at least claim that nothing is put forward which I do not myself know to be true.

It happened to me, in fact, owing to a combination of circumstances, to have graduated in turn in every branch of fish-catching, from Sticklebacks to Salmon; and perhaps few men have wandered further over the United Kingdom in search of sport than $\mathrm{I}$ have, or dipped their flies into wilder or more varied waters. Lodging often for weeks together in shepherdis' huts and cabins, and sometimes with no lodging but the heather, and no companion but my rod, I have fished Scotland, river and loch, from Coruisk to the Tweed, and back again to the Ness. Ireland I know from the Bush to the Blackwater. I have taken Salmon from the Welsh Conway, and Trout from the grass-covered basin of Llyn Ogwen; and many a time has my creel grown heavy amongst the fairy foams and brawling shallows of the Dartmoor and Exmoor streams, or by the teeming waters of the Itchen, the Avon, or the Thames, on whose banks I have spent many of the pleasantest years of my life ... But I need say no more on this point-if, indeed, I have already not said too much. My book will be judged, not by who writes 
it, but by what is written in it; and I am not now addressing an angling audience for the first, though it may probably be for the last-time.

For the rest, no attempt is made in these pages at fine writing. Flowery periods and apposite quotations occupy space; and, I take it, if any one reads this book it will be with the desire of getting as much information as possible in the plainest and most condensed form.

It may be added that the Engravings of fish with which the several chapters are illustrated, have been taken from carefully selected specimens, obtained in every instance from the localities most celebrated for each particular species, and have been executed under my own eye.

WOODLANDS, WEYBRIDGE,

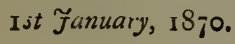




\title{
CONTENTS.
}

\section{PART I.-TACKLE.}

\author{
GE N E R A L R E M A R K S, P. I.
}

\section{CHAPTER I., pp. 5-15.}

HOOKS.

Imperfections of hooks; bend, over-fineness of wire and 'springing,' shank point, barb, p. 6.

Proper mechanical theory of-penetration, holding-power, strength, lightness, neatness, p. 9.

Existing lends of hooks-Sneck, Sproat, Limerick, round, Kirby, and their defects; ' hog-backed' hooks, p. 9.

New pattern of hook descriled, p. ro.

Hooks for trolling tackle-Triangles and double hooks, tail and reverse hooks. Lip-hooks, with gimp loops and metal loops; faults of existing patterns, new patterns described, p. $\mathbf{1 4}$.

\section{CHAPTER II., pp. I6-22.}

\section{SPINNING TACKLE: FLIGHTS, LEADS, AND SWIVELS.}

Flights-Loss of fish, \&c., with old-fashioned flights. New flights, flying triangles, p. 18.

Kinking - Causes of, defective leads ; the remedy, improved leads, p. 20.

Swivels-Number, arrangement ; double swivels, 'loop swivels,' p. 22.

\section{CHAPTER III., pp. 23-38.}

\section{LINES AND REELS.}

Trolling lines and dressing for, p. 26.

Reel-lines for fly fishing-Dressed line, silk and hair, spun cotton, p. 27.

Reel-lines for lottom fishing- 'Nottingham line,' p. 28.

Gut lines-Choice of gut, 'drawn gut.' Staining gut-Defective stains; one general stain recommended; ' red water' and other stains, p. $3 \mathbf{I}$.

Hair-Objectionable for every kind of fishing; staining : dyeing feathers, p. 33 . Gimp-Different qualities and sizes; method of staining, p. 34.

Reels-Wooden reels or ' pirns,' multipliers, plain reels, check reels, aluminium reels. A suggested improvement in reels, p. $3^{8}$. 


\section{CHAPTER IV., pp. 39-52. \\ RODS AND ROD MAKING.}

Observations on rod woods : Solid-Hickory, greenhart, ash, willow, fir, p. 43.

Hollow-East India, or mottled bamboo, white cane, Carolina cane, jungle cane, p. 45.

Rod rings.-Upright rings recommended for all purposes; 'pronged rings,' proper shape for bottom and top rings, p. 48. Ferrules-'Tube-cut,' ' hammered.' 'Brazing' of joints-To separate 'stuck' joints, p. 49. $A$ general rod described, p. $\mathbf{5}^{2}$.

\section{CHAPTER V., pp. 53-64.}

\section{MISCELLANEA.}

Knots for lines and gut-Lapping over ends, fisherman's knot; some new knots descriled, p. 55 .

New knots for Salmon and Trout drop flies, Ec., p. 59.

Varnishes-Green varnish; rod and tackle varnish, p. 60.

Bait-cans-Essentials of; new 'shoulder' bait-can; preserving live baits, p. 62. Disgorgers-Disgorger blades, a 'fishing knife,' p. 63 .

Landing-nets and gaffs-A new pocket-net described, p. 64.

\section{PART II.-FLY-FISHING.}

\section{CHAPTER VI., pp. $65-78$.}

\section{ARTIFICIAL FLIES.}

Present systems of artificial (Trout) fies- 'Colourists' and 'formalists'; both theories unsound in part, p. 70. Fishing up-stream, \&c., erroneous, p. 7 I. True theory of artificial Trout flies, and Application of to practice-form, colour, size, p. 76.

Three typical Trout fies described and recommended to be sulstituted for all others for Trout, Whitetrout, and Grayling fishing, p. 76 .

Theory of Salmon fies-The argument applied; three patterns of flies for Salmon and Grilse recommended to be substituted for all others, p. 77 .

Theory of Whitetrout flies, p. 77 .

Summary-Six fies only necessary for every description of fly-fishing, p. 77 .

\section{CHAPTER VII., pp. 79-86.}

\section{BROWN-TROUT.}

\section{ARTIFICIAL FLY-FISHING IN RIVERS AND LAKES.}

Salmon and Trout fishing contrasted, p. 79. River-fly-fishing-Casting ; 'switching,' p. 83 .

Drop-flies-Theory of; more than one a mistake. How to work tinedrop-fly,p. 84 . Striking and playing; when and where to fish, p. 86. 


\section{CHAPTER VIII., pp. 87-ro4.}

TROUT-FLIES.

Typical flies descriled-'Green,' 'brown,' and 'yellow'; new principle of construction. A colourless wax, p. 9o. Prevailing colours of natural flies. Colours of hackles; dyed hackles best. All flies should be carried in a box, p. 93 .

Selecting of flies-Size; colour. Fly rods and tackle. Fishing with the dry fly, p. 98.

Lake fly-fishing-Choice of flies; size, colour, \&c., p. 100.

Fishing with natural fies-'Creeper' and stone-fly fishing; blow-line fishing with the May-fly, p. I04.

\section{CHAPTER IX., pp. I05-II3•}

\section{WORM-FISHING.}

Modern and old systems contrasted. Proper times and places for worm-fishing, p. 106.

Existing tackles; theory of. New tackle descriled-Suitable for riverbottom fishing generally? p. III.

Trace. Best worms; management of bait, \&c., p. I1 3 .

\section{CHAPTER X., pp. II4-I29.}

\section{RIVER AND LAKE MINNOW-SPINNING FOR TROUT,}

Spinning with the natural bait.-The essentials of a perfect minnow tackle;

how to be combined in practice; a new minnow tackle descriled, p. II7. Artificial baits. New metal minnow descriled, p. II9.

Great Lake Trout; how, when, and where to spin for; tackle, p. I 22.

Lake-Spinning for Brown Trout; tackle, natural and artificial baits, p. I 24. Thames Trout-fishing, with the spinning bait and with fly; Tackle, \&c.

Decrease of Thames Trout, p. ז29.

\section{CHAPTER XI., pp. I30-I35•}

\section{WHITE-TROUT FISHING.}

Different species of White-Trout and their halitats, p. $13 \mathbf{1}$.

White-Trout flies - "Green," "brown," and "yellow" typical Trout flies, with the addition of tinsel, recommended also for White-Trout. Observations of fiy-fishing and spinning for. Rod, tackle, \&c., p. 134. 


\section{CHAPTER XII., pp. 136-I44.}

GRAYLING FISHING.

Grayling rivers and haunts.-The 'Grayling country;' spawning ; growthrate, and nomenclature, p. I39.

Artificial fly-fishing and fies. Uselessness of the great number of Grayling flies; typical Trout fies recommended to le substituted. Tackle, when and where to fly-fish, p. I 40.

Grasshopper fishing-best tackle, and mode of using; time, place, p. I44.

Grayling fishing with the gentle, p. I44.

\section{CHAPTER XIII., pp. 145-173.}

\section{SAL MON F IS H I NG.}

Outline of Salmon history and nomenclature, p. 148.

Fly-fishing: two principal difficulties, the 'rise' and the 'stroke'; casting and working the fly. Salmon haunts, p. I52.

Changing flies, and casting for second rise ; wading, \&c., p. I 54.

Salmon and Grilse fies: three universal flies described-'Silver,' 'gold,' and 'rainbow.' New method of construction-Head-hackles, \&c., p. I6o.

'Loops'; and how to fasten flies to casting-lines, p. 162.

Rod, reels, lines, and hooks. Gaffing, p. I66.

Spinning-Eel-tail bait and tackle, p. 169 .

Worm-fishing and tackle, p. $\mathbf{1} 73$.

\section{PART III._“TROLLING,”-OR PIKE-FISHING.}

GENERAL OBSERVATIONS, p. 174 .

C H A P T E R XIV., pp. 177-I99.

SPINNING.

Theory of spinning, Spinning fights-'The Author's patterns; directions for baiting, p. I80; details of construction, p. I82.

Traces-leads. Rod, reel, and reel-line for spinning and Pike fishing generally, p. 184 .

How to spin-Casting; 'Nottingham method;' striking; playing; landing, p. I9I.

Spinning-laits-Natural baits; Bleak, Dace, Gudgeon; the Eel-bait, tackle for and how to catch. Preserved bait. Sea-fish as baits. Artificial baits, p. 196.

When and where to spin-Pike haunts and spawning time, p. 199. 
CHAPTER XV., pp. 200-208.

TROLLING WITH THE DEAD GORGE BAIT.

Tackle and hooks-New leads; improved fastening for bait. The trace, p. 204. Working the gorge lait-and management whilst gorging. Gorge laits, p. 208.

\section{CHAPTER XVI., pp. 209-218.}

\section{LIVE-BAIT FISHING.}

Snap live-lait tackle-Defective tackles; essentials of a perfect flight. New pattern and trace described; mode of baiting, and baiting needles, p. 2 I 2. Floats; new system of, p. 2 I 3. Baits, and how to catch, p. 215.

How and where to use the live lait. Live gorge bait. Receipt for cooking Pike, p. 217.

\section{PART IV.-BOTTOM OR FLOAT-FISHING.}

\section{CHAPTER XVII., pp. 219-225.}

\section{GENERAL OBSERVATIONS.}

'Old' and 'new' (or 'Nottingham') methods of lottom-fishing, p. 220.

Ordinary float-fishing-Rods, lines, hooks, floats, shot, reels, \&c., p. 223.

Nottingham fishing-specialities of, and tackle, p. 225.

\section{CHAPTER XVIII., pp. 226-236.}

\section{BAITS, BAITING, AND GROUND BAIT.}

Baits-Worms; brandlings, lob-worms, where to get and how to preserve; Gentles, greaves, pith and bullock's brains. U'asp-grul's; easy method of taking wasp-nests. Pastes. Miscellaneous baits-Caddice: grasshoppers; meal-worms; earth-grubs, p. 232.

Ground laits - Theory and practice of ground baiting; gentles, paste, bran, bread, meal, greaves, grains, rice, worms, p. 236.

\section{CHAPTER XIX., pp. 237-244.}

\section{PERCH.}

Natural and artificial baits-Spinning and fly-fishing, p. 238.

Live-laiting, 'paternostering' and 'roving,' p. 242.

Worm-fishing in lakes, ponds, and rivers. Spawning season, p. 244.

The Pope or Ruffe, p. 244. 


\section{CHAPTER XX., pp. 245-254.}

\section{BARBEL AND BREAM.}

Habits of barbel and 'ground swimmers' generally. Bottom fishing-tackle and baits. Leger fishing and tackle, p. 248.

Ground baits and laiting-Worms and clay-balls; how to use, p. 250.

Halits and Haunts of Barbel-Torpidity in great cold, p. $25 \mathrm{r}$.

Different species of Bream-Carp Bream; White Bream, or Bream flat; Pomeranian Bream : their habitats, and how to be distinguished, p. 252.

Bream fishing-Tackle, baits. Ground baits. Spawning time, p. 253 .

\section{CHAPTER XXI., pp. 254-26r.}

\section{ROACH AND RUDD.}

Roach and Rudd are distinct species-how to be identified. A new variely of Rudd. Habitats of Roach and Rudd. Spawning season, p. 257.

Best baits and ground baits in running and stagnant waters, and how to use them. Tackle. Other species of the Roach genus, p. 261.

\section{CHAPTER XXII., pp. 262-27I.}

\section{DACE AND CHUB.}

The two species contrasted-Distinguishing marks, - habits and haunts, p. 265. Dace fishing-Baits; ground baits, tackle, \&c. Fly-fishing, p. 266.

Chul fishing with the fly: theory of Chub-flies. Useless multiplication of patterns: only one necessary. A new pattern descriled, p. 269.

Float-fishing-Caterpillars and grasshoppers; live minnows; pith and bullock's brains, p. $27 \mathrm{r}$.

CHAPTER XXIII., pp. 272-278.

\section{CARP AND TENCH.}

The two species contrasted-Alleged healing powers of Tench. Longevity and growth-rate of Carp. Habits and haunts of the two fish, p. 276 .

Carp and Tench fishing-Tackle, baits, ground baits, \&c., p. 278 .

\section{CHAPTER XXIV., pp. 279-288.}

\section{ON SMALL FISH PRINCIPALLY USED AS BAITS.}

Bleak-How to fish for with the fly, gentle, and cast-net-How to cook Gudgeon and Gudgeon fishing, p. 283 .

Stone Loach-Miller's Thumb. Minnous and Sticklelacks, p. 286.

All anglers should be Ichthyologists, p. 288. 


\section{AGENTS FOR SUPPLYING TACKLE.}

The tackle, \&c., described in the following pages may be obtained at most good fishing-tackle shops, but the following Manufacturers of long standing have been specially appointed agents, and have undertaken to make and supply it strictly according to pattern.

I have found some arrangement of this kind indispensable, in consequence of the frequent alterations, or socalled "improvements," introduced into the tackle sold under my name by inferior makers-the effect of such alterations being usually mischievous, and often destructive. I would therefore urge upon fishermen who may be inclined to try the flies, hooks, spinning-flights, \&c., herein recommended, to compare them closely with the illustrative patterns and diagrams, and to reject them if inaccurate.

H. C.-P.

\section{IIST OF AGENTS.}

\section{ENGLAND.}

(LoNDon.)

Mr. Charles Farlow, I9r, Strand, W.C.

Bernard and Son, 4, Church-place, Piccadilly; S.W.

Mr. Thomas Aldred, I26, Oxford-street, W.

Miss Phœbe Maria Jones, i I I, Jermyn-street, S.W.

Mr. John MacGowan, 7, Bruton-street, New Bond-street, W. 
Messrs. Eaton and Deller, 6 and 7, Crooked-lane, E.C.

Gowland and Co., 3 and 4, Crooked-lane, E.C.

Chevalier Bowness and Son, I2, Bell-yard, W.C.

Messrs. Bowness and Bowness, 230, Strand, W.C.

Alfred and Son, 54, Moorgate-street, E.C.

(Provincial.)

Winchester. Mr. J. Hammond, Great Minster-street.

Worcester . Mr. Frederick Allies, I3, St. Nicholas-street.

Shrewesbury. Mr. Henry Shaw, 45, High-street.

Manchester. Mr. John Chorlton, 8I, Piccadilly.

Cheltenham. Mr. James Ogden, 28, Winchcomb-street.

SCOTLAND.

Edinburgh . Mrs. F. Hogg, 79, Princes-street.

" . Mr. Phin, 8o, Princes-street.

Glasgone. . Mr. J. D. Dougall, 23, Gordon-street.

Aberdeen. . Mr. William Brown, 36, George-street.

Inverness . Mr. Hugh Snowie, 83, Church-street.

Kelso . . . Forest and Sons, Kelso.

\section{IRELAND.}

Dublin . . Martin Kelly and Son, 56, Lower Sackville-street.

Cork . . Mr. William Ashton Hackett, 38 , Patrick-street.

". . . Mr. William Haynes, 63, Patrick-street.

Castle-connell Mr. John Enright. 


\section{MODERN}

\section{PRACTICAL ANGLER.}

\section{PART I.-TACKLE.}

\section{GENERAL REMARKS.}

WE live in times in which, as we are constantly being told, the "schoolmaster is abroad," and certainly the dwellers in what the late Mr. Hood described as the "Eely-Places" have come in for their full share of educational advantages. No well-informed Pike or Trout is now to be ensnared by the simple devices which proved fatal to his progenitors in the good old days of innocence and Izaak Walton : and were we to sally forth with the gear bequeathed to us by our great-grandfathers of lamented memory we should expect to see the whole finny tribe rise up to repel with scorn the insult offered to their understanding. Owing doubtless to the rapidly increasing popularity of fishing of late years, there are 
but few waters on which the shadow of the rod or glitter of the bait is not more or less familiar, and as a consequence fish are everywhere becoming more wary and more difficult to catch. If, therefore, we would make as large baskets as we used, we must "subtilise" more and more our deceptive arts, so as to keep pace with the growth of fish-intelligence ; and to this end the most obvious, and on the whole the most important means, is to be sought in improving and refining to the uttermost every part of our fishing tackle. Other circumstances being equal, it may be safely asserted that the man who " fishes finest" will also catch most; and if we would ensure the presence of the greatest number of "fishdiners" we must offer them a recherché menu. The most primitive cookery and the coarsest bill of fare will, it is true, be sufficient to attract the very lean or very hungry; but we want to entice also the fat and well-flavoured gourmand, the fellow who has just been breakfasting on a souchet of water-shrimps, or making a prolonged luncheon on that bonne bouche of the fish-epicure, the dainty and succulent little May-fly.

It is with fish, in fact, very much as with ourselves: the more daintily a repast is served up the more we feel inclined to partake of it. Half-starved, or fasting, the lords, ay, and ladies too, of creation can relish anything-even the ponderous, antiquated joint, or unprepossessing pea-soup; but when once the edge 
of hunger is taken off we require something gustatory-highly-spiced entrées, jellies, creams, ices, - and finally, to stimulate the jaded appetite, man's original tempter, fruit, in which form and colour are called in to assist taste.

To sum up the argument, therefore, I say that to "fish fine"-finer if possible than any one else on the same water-and to tickle the piscine palate to the utmost, is the most certain way of making the heaviest creel. As it has been well paraphrased:- "Tell me what your tackle is, and I will tell you what your basket is."

Nor is it only as regards the basket that fine-fishing is to be commended : it is the only mode of killing fish that deserves the name of sport. To land a twenty pound Salmon or Pike by a single strand of gut, almost invisible as it cuts the water like a knife, is a performance to be proud of ; to lure "from his dark haunt beneath the tangled roots," the pampered monarch of the brook -to raise, strike, and steer him by a thread like gossamer through fifty perils by bank, bush, and scaur, and finally to lay the massive beauty gurgling on the green-sward with the microscopic hook still unshaken from his jaws, is a feat which taxes every nerve and the powers both of mind and body to accomplish. But what skill or pleasure either can there be in hauling out a miserable animal by sheer brute force, with a machine like a cartrope and a clothes-prop? There is no "law" shown to 
MODERN PRACTICAL ANGLER.

the fish, and not the slightest prowess by the fisherman. It is fish-slaughter-murder-anything you like-but it is not "sport." The essence of sport consists in the amount of skill, difficulty, or danger to be exerted or overcome in its pursuit. 


\section{CHAPTER I.}

\section{HOOKS.}

General observations-Mechanical imperfections of hooks, bend, overfineness of wire and 'springing,' shank, point, and barb. Proper theory of hooks-Points of a perfect hook, how to be attained : penetration, holding-power, strength, lightness, and neatness. Existing bends of hooks-Sneck, Sproat, Limerick, round, Kirby, and their defects; ' hog-backed' hooks. Nequ pattern described. Hooks for trolling tackle-Triangles and double hooks, tail and reverse hooks. Lip-hooks, with gimp loops, metal loops ; fault of existing patterns, new patterns described.

Too much importance cannot be attached by the fisherman to everything that concerns hooks. They are to the angler what the main-spring is to the watch, or the crank to the steam-engine-the very alpha of his craft. The whole art and paraphernalia of angling havefor their objects first to hook fish, and secondly, to keep them hooked. And yet, extraordinary as it may seem in such a mechanical age as ours, we cannot go into a tackle shop and buy a hook in which one or more glaring defects-or offences against the first principles of mechanics-cannot be pointed out. The most common fault of all perhaps lies in the shape of the bend. I have shown, when alluding to this subject in the Book of 
the Pike, how great is the difference in the penetrating powers of different bends. Between the two extremes it amounts to no less than cent. per cent. ; and yet even the best of these fall below the point of efficiency which ought to be attainable. Another obvious fault is overfineness in the wire, from which it results that when the point comes sharply in contact with a bone or other hard portion of a fish:s mouth, or even on the sudden jerk occasioned by striking softer material, it "springs" - that is, yields by a widening of the bend outwardsand so fails to penetrate. On the form of the shank of the hook, again, depends to a considerable extent in fly-fishing, the proper and even swim of the lure; and whilst the point and barb are the first portions of the hook to be brought into requisition in practice, it would seem that they are the last on which any theoretical consideration has been bestowed.

The theory of hooks, as based simply on mechanical principles, should probably run somewhat as follows :-

I. What are the objects to be aimed at in a perfect hook?

a. Penetration.

b. Holding power.

c. Strength.

d. Lightness and neatness.

2. How are these to be attained and combined?

Penetration.-Cateris paribus, the penetrating power of any hook will be greater in proportion as the angle of impact-the angle, that 
is, at which the point of the hook strikes the fish's mouth-coincides with the direction of the force applied (i.e. the pull of the line): or to illustrate this by a diagram :-

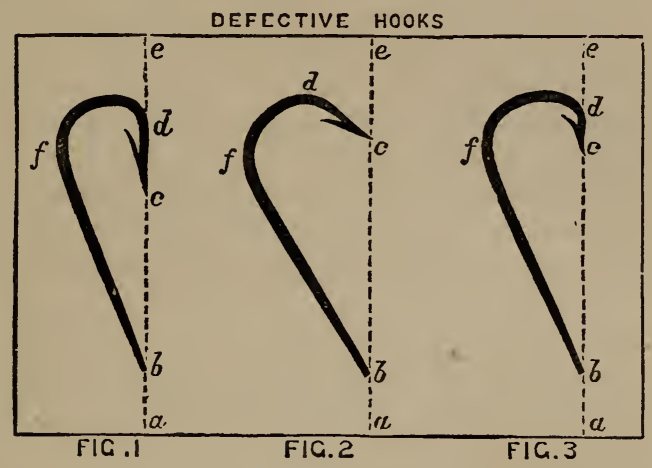

The dotted line $a$ e represents the direction of the applied force; the penetration will be greater as the direction of the line of the point $c d$, is coincident with that of $a e$. In figure $\mathrm{r}$ these two lines actually correspond, and if there were no other matters to be taken into consideration this hook, so far as penetration depending on bend is concerned, would be mechanically perfect. Figure 2 represents a hook in which the converse of the above principle is illustrated.

These principles hold good equally in the case of hooks the points of which are crooked or turned sideways, as in the Kirbys and Snecks, the penetration diminishing as the point is turned from the direction of the applied force; and accordingly this is the one particular in which the Limerick is superior to the other bends. The sproat and round-bends have also a similar advantage. In all these hooks the angle of impact, such as it is, is direct.

The above arguments are based, it will be observed, on the assumption that in all other respects except the bend, the honks under comparison are equal. But in fact hooks are divided into two broad divisions, the one possessing and the other lacking an element which has an obvious bearing on the penetrative power. I refer to the shape of the shank, whether straight or 'hog-backed' (curved). The substi- 
tution of a necessarily more or less yielding and elastic curve for a perfectly straight and rigid shank, cannot hut affect adversely the penetrating powers. As regards the penetration of the point itself, it is clear that, other circumstances being equal, the smaller the hole to be made the less will be the force required to make it; and also that a long straightly tapered point, like that shown in figure $\mathbf{I}$, will penetrate more easily than a shorter and "blunter," or bollowed-out point of the form represented in figure 3 . This latter principle, is merely, in fact, a converse application of the mechanical truism, that what is gained in speed is lost in power. If two barbs are of the same maximum diameter, and one is twice as long as the other, the longer barb will for practical purposes penetrate with half the pressure required by the shorter.

Again, with regard to the "point-side" of the barb ( $c d$ in diagram), it is obvious that in order to insure a firm and deep penetration this side must be of a proper length. The want of length in this part of the hook is one of the faults of the "Sproat-bend" which is exaggerated for sake of illustration in figure 3 .

Holding power.-To illustrate this I shall take a case which is both the most common in practice and will admit of a theoretical demonstration : that of the hook having penetrated quite through the lip of the fish, so that the point protrudes. In this case it is evident that, when once hooked, the nearer the point approaches the shank of the hook, the less chance must the fish have of escaping. This will be seen by carrying the principle to the extreme limit-and assuming that the point was so bent in after hooking as actually to touch the shank; the fish's lip would then be enclosed in a complete triangle, from which, of course, there could be no possible escape.

Strength.-It is obvious that those portions of the hook which are nearly or quite in the same line as the penetrating cr holding force, have little or no strain to bear. This is the case with the shank and with the short or point-side of the hook shown in the engraving fig. I. The strain, therefore, is thrown on the top side, and more especially on the angle $f$, and it is precisely in this point that the common sneck-bends have hitherto failed in practice. So marked has been this failure that, I have known three Salmon to be lost within an hour, with sneck houks, all by breakages at the angle in question.

Lightness and neatness.-The lightest form of hook, other points 
being equal, must evidently be that in which, whilst retaiming the requisite thickness of metal at the portion subject to strain, the parts not so subject-that is, the shank and "point-side"-are tapered away towards the ends. Hooks so tapered are also neater when employed for flies, and more convenient for general use.

The patterns of hook which at present most nearly fulfil the conditions indicated by a practical application of the foregoing theory are the sneck and sproat-bend hooks; the former is however marred by two faults, the turning to one side of the point, and the lack of strength above described; and the latter by the want of depth and power in the point-side, the hollowed out or blunted shape of the barb, and the curved or "hogbacked" form of the shank. Appearance, or neatness, is of course a matter of taste, but whatever other claims the sproat-bend has upon our suffrages they can hardly, I think, be urged on the score of beauty. The Limerick hook also has the disadvantage, though in a less exaggerated form than the "sproat," of being hog-backed, which, as I have shown, prevents the fly swimming straight and even, and gives it an inclination to turn in the water, like a miniature spinning-bait. The round and Kirby bends are very deficient in penetrating power, and disproportionately short in the shank as compared to their breadth of bend, either for appearance or use, more particularly in the matter of flies.

In the pattern of hook which is now being manufactured by Messrs. Hutchinson, of Kendal, under my name, I have endeavoured to hit the medium bciwcen 
theoretical and practical requirements, and to combine as nearly as possible the advantages of the various bends referred to, and especially of the sproat and sneck bends, whilst avoiding what I believe to be their faults.

Diagrams both of this hook and of the other hooks described, are appended, and by applying to them the principles advocated, my readers will be able to form their own conclusions as to how far the pattern I recommend fulfils the ideal sketched out. In this

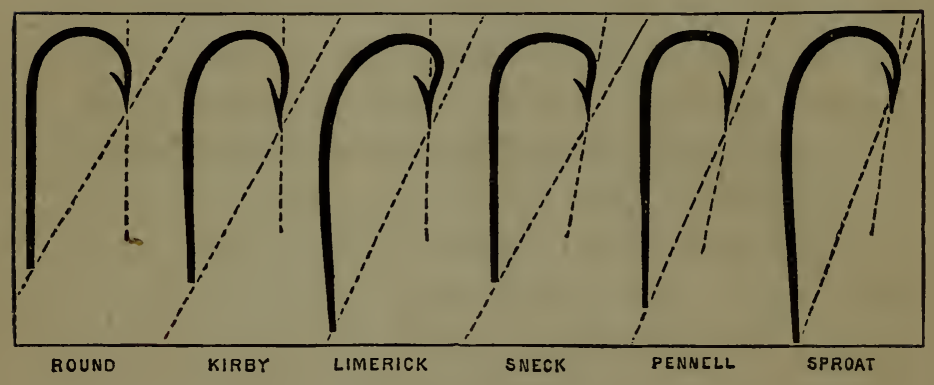

diagram the dotted lines show the directness or otherwise of the angle of impact, and in this point it will be seen that my hook is slightly inferior to the sproat-bend. In order however to obtain this extra-directness, both the depth and therefore strength of the hold, the shape of the barb, and generally the elegance of the whole hook have in the sproat-bend been sacrificed. In my pattern the angle of impact is quite direct enough to ensure penetration, whilst the slight additional " rank- 


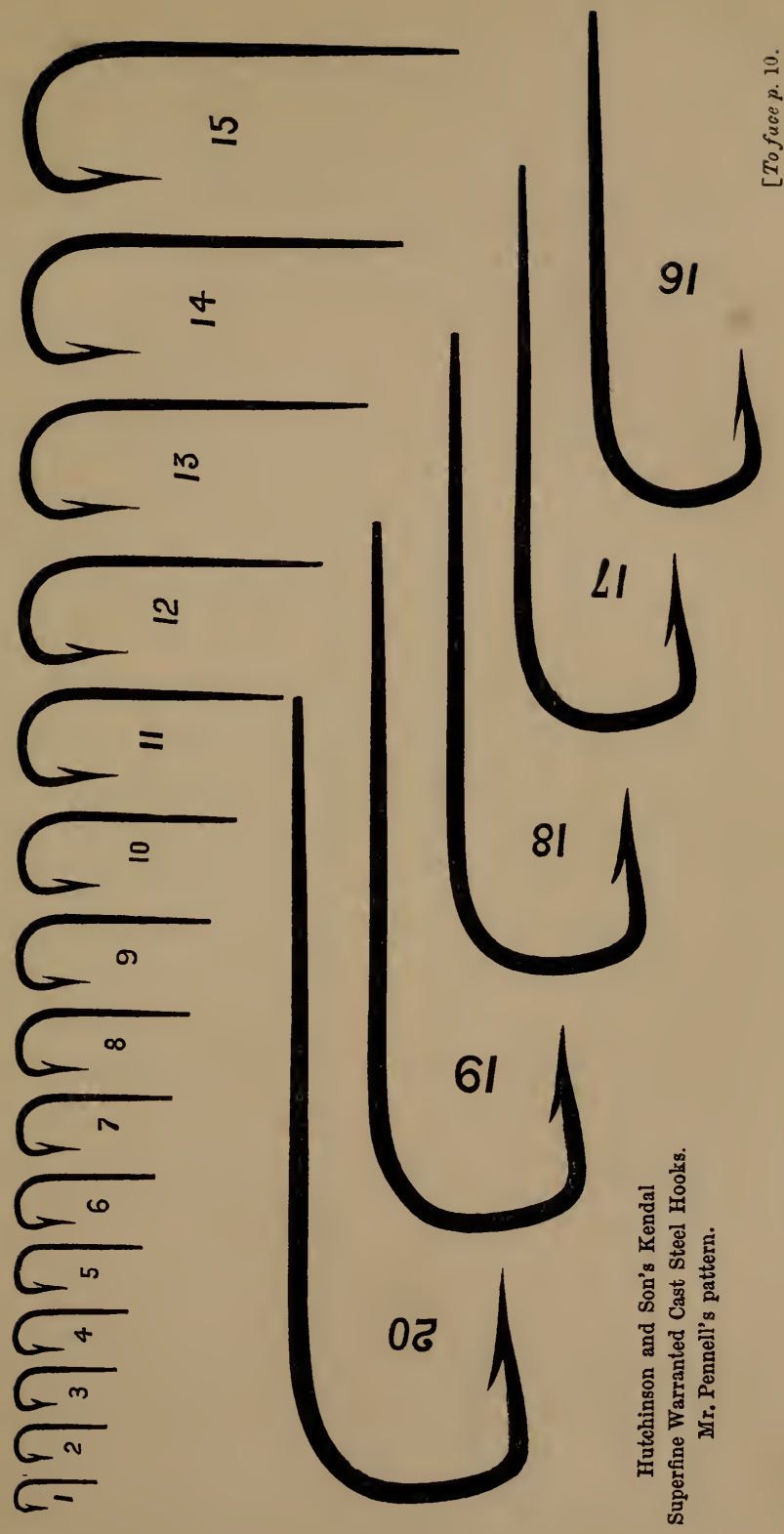



ness" of the point makes it less likely to miss hooking than if it were turned more inwards.

Fac-similes of the several sizes of my hooks are represented in the annexed plate, and the numbers given under each are those by which they are distinguished by the manufacturers.

Hooks used in Trolling Tackle.-Triangles AND Double Hooks.

Whatever is the best bend for single hooks is a fortior $i$ also the best for every description of triangles.

All triangles should invariably be brazed (i.e. soldered) together, so as to form a single piece. This has a very great influence upon their killing power, principally, no doubt, because triangles which are only whipped together are liable to slip or yield, when brought into sudden and violent contact with a fish's jaws.

Triangles of various sizes composed of my pattern of hook, as also double hooks for gorge-live-baiting and other purposes, are now being manufactured by Messrs. Hutchinson, the shank, in the larger sizes, being made a trifle shorter for the sake of neatness and lightness. The numbers correspond with those of the single hooks, according to the width of bend.

\section{TAIL-HOOKS.}

When my attention was first directed to the subject of Spinning-tackle, I found that one of the chief draw- 
backs of the old flights was that after a few casts the strain on the bait's tail was apt to work out the fixed hooks-set in the usual way point upwards-and thus to destroy the curve of the bait on which its spinning depended. This was combined with other minor defects which need not be recapitulated. In order to remedy these, I substituted for the small single tail hook a long-shanked round-bend hook with a smaller reverse hook lapped on to the end of the shank, so that when the latter was fixed in its place, the "pull" of the two hooks counteracted each other, and the bait both spun more brilliantly and lasted very much longer than under the old system. For readier manipulation these hooks were subsequently made in a single piece, and in this form are now very generally adopted by spinners. In the plate annexed fac-similes of the sizes most commonly in use are given for convenience of reference, the numbers being those of Messrs. Hutchinson.

In tail-hooks the round bend is preferable to any other, as it is more easily slipped under the skin of the bait and gives it a more perfect curve, and consequently a more rapid and regular motion. Directions for baiting, with other detailed instructions for the use of these hooks, will be found under the head of Pike-spinning.

\section{LIP-HoOKs.}

The lip-hook is a very important portion of the spinning-flight, as upon it depends the proper position 


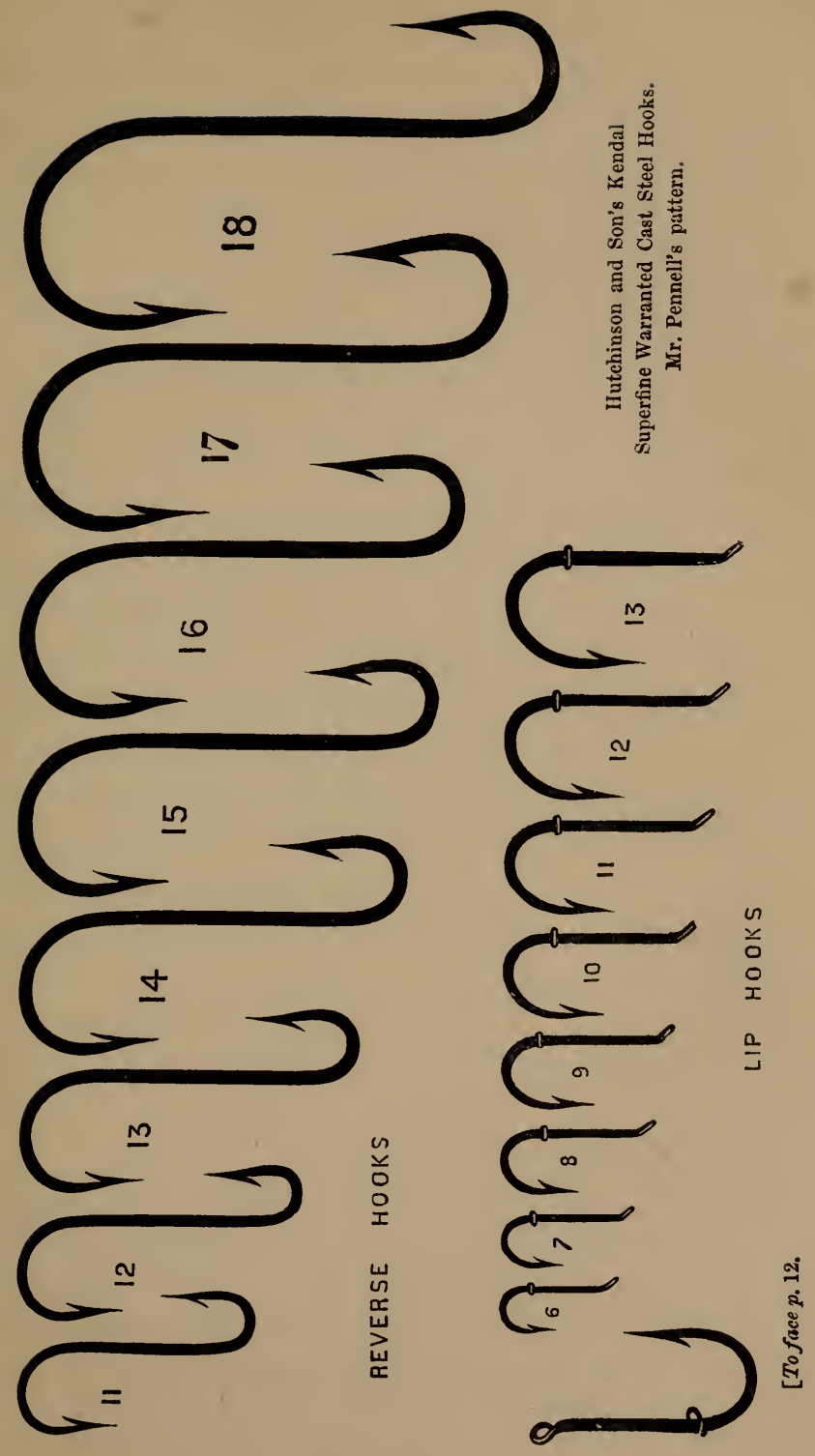



of the bait and flight. The chief objects to be aimed at in this hook are durability and neatness combined with ease in shifting when required, and complete fixedness or immobility at other times. The three last desiderata were all very fairly fulfilled by the old-fashioned liphook, composed of gimp loops whipped on to an ordinary lip-hook. The construction of this lip-hook is shown below (figure 2). The two little loops are formed by doubling a piece of fine wire or gimp (figure $\mathrm{I}$ ), and

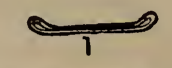
laying it on the upper side of the shank of the hook, and then lapping over all except the two ends. When complete, the end of the gimp or gut to which the flight is tied should be passed upwards through the lower loop, then twisted two or three times round the shank of the hook, and again passed upwards through the upper loop and drawn tight.

To shift the position of the lip-hook higher or lower, it is only necessury to loosen the coils round the hook by pushing the gimp upwards or downwards through the loops and then tightening from the other end.

In the other essential of durability, however, it was less satisfactory, and consequently various plans have been tried for some years to remedy this deficiency by making lip-hooks entirely of steel, one or both of the loops being brazed to the shank. Hitherto, however, these have been practical failures, as owing to the slip- 
periness of the polished steel the line could not be twisted round it tight enough to prevent its shifting its position with the slightest strain, such as that, for instance, which would be occasioned by its catching in a weed. It became a slip-hook, in fact, instead of a lip-hook.

The manner in which the loops were set also caused the gimp to stand out at each end in a manner that was both unsightly, and which tended to lessen the directness of the line of pull, at the point where it was especially necessary. I have lately, however, had a metal lip-hook made in which these

METAL LIP - HOOKS

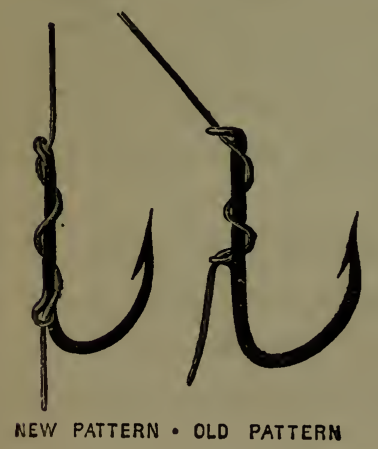
difficulties will I believe be found to have been overcome. By leaving the shank of the hook rough (unpolished) instead of smooth, the gimp no longer slips when once fixed in position, and by some slight changes in the position of the steel loops it is made to hang quite straight. The results of the two systems in regard to this latter point are shown in fac-simile in the engraving.

Diagrams of the several sizes of these lip-hooks likely to be really wanted in the construction of spinning tackle are given in the last plate (p. 12), with their numbers of reference. All lip-hooks should be made small rather 
than large, as they comparatively seldom touch a fish, and they show more than any others on the flight. It is also desirable to keep the bait's mouth shut as closely as possible. The hook figured in the woodcut at page $\mathrm{I} 3$ is about the number suitable for a medium-sized gudgeon. 


\section{CHAPTER II.}

SPINNING TACKLE : FLIGHTS, LEADS, AND SWIVELS.

Fligbts-Drawbacks to spinning: loss of fish ; causes of losses; oldfashioned flights, flying triangles, new flights. Kinking-Causes of kinking, defective leads; the remedy, improved leads. SwivelsNumber, arrangement ; double swivels, ' loop swivels.'

IN spinning, both for Pike, and for lake or Thames Trout, two great drawbacks were formerly experienced : one the large proportion of fish lost after being struck; and another the "kinking," or crinkling of the line, to which both sport and temper were not infrequently sacrificed. The average of fish lost after being struck with the old-fashioned tackle was computed at from fifty to sixty per cent.,- - an estimate which has been generally admitted to be under rather than over the mark.

\section{Flights.}

The above result was attributable mainly to the large number of hooks and triangles-the latter ranging from three to five-formerly employed on a good-sized flight. These were not only useless, but distinctly mischievous, both as regards the spinning of the bait and the basketing of the fish when hooked. Upon the bait they acted 
by impairing its brilliancy and attractiveness, rendering it flabby and inelastic. Upon the fish they operated only as fulcrums by which he was enabled to work out the hold of such hooks as were already fast. The great size also, and the defective bends of many of the hooks used contributed materially to swell the proportion of losses, as it should be recollected that to strike a No. 20 hook fairly over the barb, requires at least three times the force that is required to strike in a No. IO; and that this disparity is increased when the hooks are used in triangles. A Jack, say, has taken a spinning-bait dressed with a flight of three or four of these large triangles, and a sprinkling of single hooks-perhaps eleven or twelve in all. The bait probably lies between his jaws grasped crosswise, and therefore the points of at least six of these hooks will most likely be pressed by the fish's mouth, whilst the bait also to which they are attached is held firmly in his teeth. The wohole of this combined resistance must be overcome - and that at one stroke, and sharply-before a single point can be buricd above the barb.

The grand principle in the construction of all spinningtackle is the use of the fying triangle as distinguished from that whipped upon the central link. A flight constructed with flying triangles can never fail to be tolerably certain, in landing at least, a fish once struck. There are, however, many degrees of excellence in such flights, even in the item of "landing;" and as regards 
the "spinning," not one in a hundred of those that have come under my notice has been in the least calculated to make a bait spin properly.

In order to ascertain the best combination of hooks, \&c. for this purpose, I carefully experimented upon every part of the spinning flight and trace; including the number, shape, size, and arrangement of the hooks, leads, and swivels, with the various materials out of which a trace can be composed, in every case carefully testing theory by practice, and sparing no pains or trouble to obtain reliable results. The several arrangements of spinning flights which these experiments proved to be most suitable to the different varieties of baits and fish are given in the chapters devoted to each. Some of the flights have already been described in my former works and are now very generally used.

\section{KINKING.}

If the large proportion of fish lost was one great drawback to the popularity of spinning, "kinking," or the twisting up of the line into knots and loops, was certainly a still greater one. Trollers generally imagined that kinking was the fault of the running line, or its dressing; and all their attention was accordingly concentrated on these points, which, however important in other respects, had seldom anything to do with the real question. The vice lay not in the line 
but in the lead. No moderately well dressed line ought ever to kink with a lead constructed on proper principles.

The lead, however, was always fastened to the trace, by the latter passing through a hole in the centre, and the result was that it offered no resistance worth mentioning to the rotatory motion of the bait, the effects of which, instead of being confined to the trace below the leads, consequently extended upwards to the running line, and produced kinking. Kinking is in fact only another word for twisting; abolish twisting, and you abolish kinking also.

The seat of the disease being thus ascertained, the cure was easy. By a reference to the annexed diagram

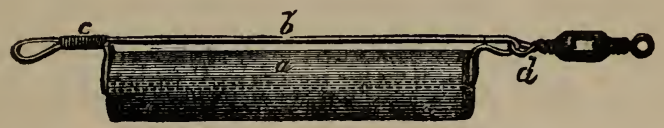

$a$. Lead. $c b$. Line of trace. $d$. End nearest bait.

it will be observed that the lead, instead of resting as usual on the line, hangs horizontally underneath it ; and it is in the application of this principle that the only permanent remedy for kinking is to be sought. By changing the centre of gravity the resisting power or vis inertice of the lead, is, for the purpose in question, more than quadrupled, without any increase of weight; the proper action of the swivels is insured; and all danger of kinking obviated. 
Since I brought the above subject under the notice of anglers, in I\$6I, I have had the satisfaction of seeing this principle adopted by the large majority of trollers, and its efficacy as a complete cure for kinking generally admitted. The engraving below represents the final result

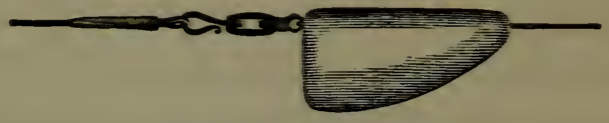

of my experiments to reduce the principle to practice in the simplest possible form. I think it will be found that the arrangement of lead as shown in the diagram meets whatever objections have been urged against this tackle, on the ground of its liability to catch in weeds, unsightliness, \&ic. In attaching the lead to the trace, all that is necessary is that at the point where it is to remain, viz, just above the swivel, it should fit the trace tightly, so as not to shift its position.

The lead is greatly improied by being varnished, or painted, a dark green, or weed tint, as lead is a very showy colour in bright water, and I have on more than one occasion known fish to run at and seize the lead, instead of the bait. An excellent varnish for this purpose is made with powdered dark green sealing-wax, and spirit of wine, mixed to about the thickness of thin treacle. 


\section{SwIVELS.}

From four to six swivels form the ordinary, and indeed necessary complement to each set of spinning gear, where the lead is suspended on the old plan; and these being distributed at intervals up and down the trace make a great show and stir in the water, frighten the fish, weaken the tackle, and are withal expensive. With the lead arranged as above a single really good swivel that works freely, fastened immediately below the lead, is usually sufficient for every purpose. The spinner is thus enabled to get a clear 2 or 3 feet of gut or clouded gimp between the bait and the lead-a very material assistance to fine-fishing. The danger of kinking, however, from the result of rust or otherwise is dininished by the use of a double swivel which I have had made for some years past with this object (vide cut). Blue swivels show less in the water than bright ones, and are less liable to rust. There are several swivels now made with a spring loop at one end, to or from which the loop of the line or trace can be attached or detached in a moment by the hand, and these are of great practical con-

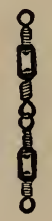
venience in the manipulation of almost all kinds of spinning and trolling trackle. One of the simplest forms is represented in the diagram at p. 20. Theoretically it might seem that there would be danger of the loop of the trace or line twisting out of these spring loops, but in practice 
I have never found the difficulty to arise, provided the loop is only just large enough to slip on to the swivel. Swivels work best and last longest when of medium or small size, like that represented, and they should always be well oiled before and after being used. 


\section{CHAPTER III.}

\section{LINES AND REELS.}

Trolling lines-Ancient lines, dressings for trolling lines. Reel-lines for Ay fisbing-Dressed line, silk and hair, spun cotton. Reel-lines for bottom fisbing-'Nottingham line.' Gut lines-Choice of gut, 'drawn gut'. Staining gut-Defective stains; Mr. Stewart's stain recommended red water-stain; other stains. Hair-Not to be recommended; for any kind of fishing; mode of dyeing; dyeing feathers. Gimp-Different qualities and sizes; method of staining. Reels -Wooden reels or 'pirns,' multipliers, plain reels, check reels, aluminium reels. A suggested improvement in reels.

\section{REEL LINES FOR TROLLING.}

VERY little seems to be known about ancient lines, whether for trolling, or any other fishing. We learn, however, that they were sometimes made of hemp, sometimes of horsehair, and perhaps also occasionally of byssus - a stringy substance by which certain species of mussels and pinnæ adhere to the rocks,- - but certainly not of gut. That they were finely twisted, however, the epithets “cuplokamos," “linostrophos," \&c., sufficiently indicate. Finally they were very short; often barely the length of the rod, which was itself shorter than ours.

Amongst our own predecessors in the gentle craft great differences of opinion existed as to the qualities 
which a trolling line should possess, and every conceivable variety of material has been at one time or other recommended for its composition, from "sheep and catgut," to "silver and silk twisted." Even amongst more modern authorities some peculiar divergencies are observable. Palmer Hackle (Robert Blakey), for instance, recommends horsehair, pur et simple; - a recipe which I cannot think likely to prove very successful, as it is within the experience of most trollers that, even with the addition of a proportion of silk, twenty yards of ordinary fly-line cannot be induced to run out through the rings of a jack rod. A few lines further on, however, Mr. Blakey explains that "there are other sorts kept by the tackle-shops, but-he has never tried them ;" and, therefore, he "will back a hair-line against them all at a venture." The bare material for a trolling line of genuine horsehair 80 yards long, would cost from 25 s. to $30 \mathrm{~s}$.

Three qualifications are essential to a trolling line: strength ; a certain amount of stiffening ; and imperviousness to water, without which no line can be prevented from swelling and knotting into tangles when wet and uncoiled from the reel. And here it may be at once admitted that these conditions are all very fairly fulfilled by the ordinary 8-plait dressed-silk trolling lines supplied by the tackle makers. Some discussion has recently taken place as to the merits of catechu, indiarubber, and other waterproof dressings, especially in 
securing greater durability, and I shall hope at a future opportunity to go more fully into this question with reference to a few experiments which I have carried out,--but I am satisfied that up to the present time no practical application of either of these dressings has been arrived at, or, at least, made public, which, having regard to the numerous points to be considered, will bear comparison with common 8-plait oiled silk, and I recommend the use of this line-of course of different sizes-for all sorts of Pike and Salmon fishing, paternostering, legerfishing, and Minnow-spinning.

It cannot be denied, however, that there is always some little uncertainty in the effect of oil dressings, especially when manipulated by amateurs; and I have on several occasions had lines returned after re-dressing -and that too from very careful hands-which for some reason or other seemed to become in parts almost immediately rotten, a result as far as I could judge, only attributable to the effect of the new dressing.

One great safeguard against premature decay we know; and that is, never to put by a line until it has been thoroughly dried. Attention to this simple precaution will save some expense, and not a few of those precipitate partings between fish and fisherman, which are so painful to at least one of the parties concerned.

From 60 to 80 yards will be found the most convenient length of trolling line for general use; as to substance, a medium rather than a very fine or very stout 
plait; and for colour the pale green tint which is now very properly preferred to the yellow, as showing less in the water. A heavy line will impair the "play" of the bait at any considerable distance.

\section{REEL LINES FOR FLY-FISHING.}

During the last few years it has become a not uncommon custom amongst fly-fishers to use for the fly the same 8-plait dressed silk line just described as most suitable for trolling purposes; and in windy weather the extra weight of such a line as compared with its bulk is an unquestionable advantage. Perhaps, however, the dressed line has made most converts owing to the equally unquestionable shortcomings of the mixed silk and hair line which was commonly the alternative. Nothing can well be worse than this line. It is expensive; wears out quickly; is never really strong even when new; "kinks" on the slightest provocation, and, owing to the protrusion of numberless points of hair, has a special inaptitude for running freely through rod-rings. For these reasons no one who values pocket or comfort should use a silk and hair line, whether twisted or plaited. Until recently I have myself for some years used the dressed silk line, and found it at least strong and smooth-running - two great advantages, it must be admitted,-but during the past twelvemonth a new description of line made of spun cotton has been sent to me for trial, which whilst inexpensive as compared with 
the dressed silk line, is equally strong and more durable. This line is what is termed "cable-laid"-twisted, that is, in the same manner as a ship's cable,-the principle of which is that whilst the cable itself is twisted, say from right to left, the separate ropes of which it is composed are twisted from left to right. The result of this is that the two twists counteract each other in their mutual inclination to kink, and when wetted the cable instead of swelling hardens and contracts. The spuncotton lines are made on the same principle, of sizes to suit all sorts of fish, including Salmon, and answer perfectly both for fly-fishing and ordinary bottom fishing.

They are not dressed in any way, but are stained a good neutral, or slate colour. Specimens were also sent me of the same lines dressed in various ways with indiarubber and tar for purposes of trolling. Neither of the dressings, however, properly effect their object; and if they did, would still be useless, as in a single day's spinning the whole of the dressing wears off. The Company,* however, informed me that at my suggestion they were about to try experiments with oil dressings, with what result I have not yet heard.

REel LiNes FOR BotTOM-FISHING.

A line of exceptional lightness, and with a disinclination to "kink" when wetted, is essential for the most successful and scientific method of bottom-fishing,

* "The Manchester Twine-Spinning Company." 
known as the "Nottingham style." Long casts have to be made with so light a bait and tackle, that unless the line is almost as fine as gossamer, and runs very easily, it will not pass through the rod rings without great trouble. It must also be "un-dressed," or it will sink instead of floating, and thus render it impossible to strike a bite effectively at long range. I have in my possession a line made at Nottingham which fulfils admirably all these conditions. It is composed of six or eight of the finest possible strands of silk, plaited somewhat in a square shape; and in thickness does not exceed that of ordinary "Holland thread," one hundred yards weighing exactly three-eighths of an ounce. And yet, fine as it is, it will lift a dead weight of between $6 \mathrm{lbs}$. and 7 lbs., which is double the strain that it is ever likely to be subjected to.

This line is îhe best that can be used on the reel for every description of bottom fishing, with the exceptions mentioned under the head of Trolling-lines.

There is a twisted silk line, sold in the tackle-shops, which is cheaper, but which kinks directly it is wet, rendering it useless for Nottingham fishing.

\section{GUT-LINES.}

Gut lines are to be preferred for every description of bottom and fly-fishing, and, especially in the latter case ; it is important that they should be carefully and evenly tapered from top to bottom. The three chief points to 
be looked to in selecting silk-worm gut, are roundncss, evenness of substance, and above all transparency; and in the case of very fine gut, to seeing that it has not been scraped, or artificially fined down in any way. Gut so treated is what is termed "drawn-gut." Its appearance is not so glossy as the natural material, and it frays and wears out almost directly when exposed to moisture and friction of any sort. Exceedingly fine, round, naturai gut is, of course, somewhat expensive, and not always to be obtained without some trouble, but it is essential in many kinds of fishing, and will in the end be found really much more economical than gut artificially fined.

\section{Staining Gut.}

Stained or clouded gut is much to be preferred to gut unstained, because it is less visible in the water. Different fishermen affect different stains, some preferring what is termed the "red-water stain," others a neutral or slate tint, and others a blue. The most important point in the staining of gut is to remove the gloss, which catches the light, and on a sunny day glitters through the water in a manner that must produce no little astonishment among the fish, and which would probably equally astonish the angler himself could he obtain a bird's-eye, or rather fish's-eye, view of his line.

In this cardinal point, however, all the ordinary stains used by the tackle makers signally fail; the tints of colour produced being moreover by no means the best 
obtainable. It is to be remembered that the fish sees the gut usually from below, and that therefore, especially in fly-fishing, the colour of the water hardly affects the question. A colour which without being glossy will assimilate best with the sky-tint for the time being is that which would be theoretically perfect if obtainable, but as the sky-tints change perpetually, dark alternating with light, and sun with shade, so as to make it impossible in practice to keep the colours actually matched, the next best thing is to employ a colour which harmonizes best with the largest number of the most commonly prevailing cloud-tints. This colour appears to be a sort of greyish-green, but I have never met with any single stain which will produce it. It seems to require the blending of several separate tints, and that may probably be the secret of the success of the following receipt, for which I was originally indebted to my friend Mr. W. C. Stewart :-

The first step in the process is to impart to the gut a lightish tint of the common " red-water stain." For this purpose take a teacupful of black tea, and boil it with a quart of water: keeping the gut steeped in the mixture until it has acquired the necessary tint. This process will sometimes take only half an hour or even less, and sometimes several hours, according to the strength and staining powrer of the tea: when sufficiently stained, rinse the gut well in cold water. When dry, takc a !handful of logwood-chips (obtainable at most druggists), and boil then in a quart of water till the latter is reduced to about a pint. Then takc it off the fire, and put into it a small piece of copperas, (sulphatc of copper) about the size of a hazel nut, powdered, stir the mixturc, and when the copperas is dissolved, which it will be in a few minutes, dip the gut into the mixture until it has got the dirty greyish- 
green tinge described. Very often a few instants' immersion will be sufficient, and in order to ascertain the exact amount of the stain, as well as to avoid overstaining, it is best always to keep a basin of water close at hand to rinse the gut in, the moment it is taken out of the dye.

This method of staining involves a little extra trouble, but it is trouble well bestowed, and will tell on the baskets. The removal of the gloss is I think due to the action of the copperas. Every description of gut used in fishing should be stained in this manner.

To produce the common stains already mentioned:-

Red-ruater stain.-Use tea-leaves as above described: or coffee, previously charred in a frying-pan and ground, will answer instead of tea.

Walnut-juice, I understand, produces a similar colour, but as I have never tried it, I cannot speak from experience.

Siate stain.-Soak the gut in a mixture of boiling water and ink. rinsing it well when stained.

Gut can be stained almost any colour by the use of "Judson's aniline dyes," or the "popular dyes," which are kept by most large chemists. Directions for use are given on the bottles, but the angler will find it convenient in every case only to use half the proportion of water recommended: and some of the stains have the effect of destroying the texture of the gut.

All gut stains can be reduced in intensity by boiling the gut in clean water. 


\section{HAIR.}

Horsehair cannot be used with advantage for any kind of fishing-line. I have already explained its inconvenience when employed in the reel, or running-line; and employed as a substitute for single gut it is equally a mistake, the latter being both finer, stronger, and, when stained as directed, much less visible in the water. This process of staining gut in fact takes away from hair the one real advantage it ever possessed, viz., that of not glittering in the water. It is a peculiar feature of hair that it will break on a long-continued strain, even though the actual weight be gradually rather lessened than increased. A strand of gut that will fairly lift a $5 \mathrm{lb}$. weight will commonly suffice to keep it suspended, if necessary; hair on the contrary will break in a few minutes on a strain less than that which it originally supported with ease. The best hair is obtained from the tails of stallions.

\section{STAINING HAIR.}

Stained hair is seldom used, the natural brown colour being usually preferred. Before it can be properly stained the greasiness must be removed by what is termed by dyers a "mordant." A good mordant for the purpose, as well as for the dyeing of feathers, is obtained by dissolving about a quarter of an ounce of alum in a pint of water, and slightly boiling the hair or feathers in it. 
The dyeing of feathers is, however, a very nice and complicated business, and even after much trouble the amateur can seldom succeed so well as persons who make dyeing their single profession. Moreover their dyes are in many cases secrets, not known even to the tackle makers who employ them, and from whom I advise all anglers to obtain their supplies of feathers ready-dyed.

\section{Gimp.}

The thicknesses of the various sizes of gimp required in fresh-water fishing, and the trade numbers, are shown in the annexed engraving, the sizes and numbers being those of the best gimp manufactured by Messrs. Kenning, of Little Britain, London.

000

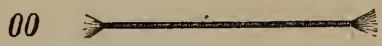

There are great differences in the quality and value of gimp, and it will commonly be found the wisest plan to obtain the

0
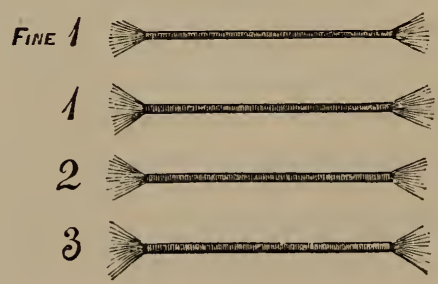
most expensive, as the difference between good and bad cannot be judged by the eye and is often not discovered until the discovery has cost the loss of a good fish. The best rough and ready test is the strength. 
The best gimp is commonly made on pure white silk-a yellow colour is generally an inferior quality.

\section{To Stain Gimp.}

Nothing can be worse, as regards fine-fishing, than the common glittering gimp ; indeed so great is the drawback that some authors have actually recommended the troller to take the trouble of lapping it over from end to end with waxed silk like the shanks of hooks. I therefore tried various ways of staining or clouding it, so as to remove the glittering appearance complained of without impairing the strength of the gimp, and the following will be found to answer every purpose so far as the finer requirement is concerned, though $\mathrm{I}$ am by no means sure that the gimp is quite so strong after staining, especially when put by for any length of time :-

Soak the gimp in a solution of bichloride of platinum-mixed in about the proportion of one part of platinum to eight or ten of water-until it has assumed the colour desired.

I find this stain is now very generally used in the tackle shops. Captain Robinson tells me that sulphide of potassium is a good permanent stain for both brass and silver gimp. He says :

SIR,--In your Book of the Pike, which I have lately read, bichlorate of platinum is recommended for staining brass gimp. This I failed to obtain in a county town, but being convinced of the importance of staining gimp, I thought of trying sulphide of potassium. As I find this gives a permanent stain to both silver and brass gimp, I take the liberty of mentioning it to you. Sulphide of potassium made by dissolving a little Lapis infernalis in water, mixing flowers 
of sulphur with it, and heating in a Florence flask. I believe quicklime in boiling water will also dissolve sulphur.

W. RoBInson.

Igth $\mathcal{F u l l y}, 1873$. Late Caplain Bombay Army.

\section{WINCHES OR REELS.}

Reels may be broadly placed in two divisions-metal and wooden. The latter I dismiss as being unsuited to anything but "Nottingham fishing," of which more hereafter. The former, as every fisherman knows, are divided into three classes :- " plain," "check," and "multiplying." Of these I think there can be no doubt that the "multipliers" combine the greatest number of disadvantages with the fewest recommendations, as they are expensive, very apt to get out of gear, and almost useless either for winding in a large fish, or for giving line to one of any other size.

The "plain" brass reel has at least the merit of bcingplain-in the sense of simpleness and inaptitude for getting out of order; but it has two great drawbacks, which exist also and to a still greater extent in the wooden reel, or pirn as it is called in Scotland, viz., that when the line is pulled out strongly either by hand, or by a fish, the wheel twists so rapidly as to "over run" itself, thus producing a sudden check, which at a critical juncture is very likely to cost the loss of the fish and the tackle. It is also, for another reason, very unsafe when playing a fish, as, should the pressure of the hand be for an instant removed from the line, the latter runs out so freely as to produce sudden slackness,-an evil perhaps 
greater even than the other, as nothing is more certainly disastrous than a slack line, and nothing more probable than the occurrence of the contingency referred to when fish have to be followed rapidly over broken ground. These are radical faults-vices would not be too strong a term-inherent in the principle of all "plain" reels, and inseparable from them.

They are, however, entirely obviated by the clicck system; and check reels should therefore be the only ones ever employed for any kind of heavy fishing, whether with bait or fly. With this reel the line is entirely independent of the hand, by which indeed it is very seldom desirable that it should be touched in any way. All that the hands have to do is to keep the point of the rod well up, and a steady strain on the fish ; and eyes and attention are thus left free to take care of their owner's neck-a practical advantage which those who have chased a salmon down the cragg'd and slippery channel of a Highland river, or a strong l'ike along the margin of a Hampshire "Water Meadow" will know how to appreciate. A check winch, in fact, does twothirds of the fisherman's work for him, and may almost be left to kill by itself; it acts upon the golden rule of never giving an inch of line unless it is takcn, and when really required pays it out smoothly and rapidly to the exact extent necessary, and no more. The even check prevents the line "over running" itself in the one case, or sticking fast in the other; and when it becomes 
necessary to wind up a fish, the check reel is in every way as direct and powerful a lever as the plain oldfashioned wheel. The point to guard against is having the check too strong.

I defy any man to fairly wind in a heavy fish with a multiplying reel. It is the old mechanical principle again of losing in power what is gained in speed; and a reel that gives four turns of the axle to one of the handle, loses exactly one-fourth of its strength for each turn-that is, has one-fourth only of the direct power of a check winch.

Beautiful reels for all kinds of fishing are now made on the chcck system ; some of plain brass, some of brass stained black, some-for the sake of lightness-of wood and metal combined, and some which are lighter than either, of aluminium. The saving in weight thus secured by the two last-named materials is very considerable, and they therefore present advantages to men who are not strong, and who may find the weight of a Salmon or trolling rod and reel tell upon their muscles, but for ordinary work and taking the chances of wear and tear and knocking about, I should give the preference to simple stained brass. Moreover, a heavy reel balances a long rod better than a light reel.

Within the last few years a considerable improvement has been introduced into the form of reels generally, by the substitution of narrow grooves and deep side-plates for the old-fashioned shallow-plated, broad-grooved 
winches. The advantages thus gained are increased speed and power; speed, inasmuch as the diameter of the axle on which the line is wound is enlarged; and power, because the handle being further from the axlc a greater leverage is obtained. Whilst speaking of handles, I would here most strongly recommend those attached to the side-plate of the reel itself, without any crank, as they obviate the constant catching of the line which takes place with handles of the ordinary shape.

One serious drawback, and so far as my experience goes, one only, is common to every reel hitherto made; namely, that the line is apt to get caught or hitched under the posterior curve of the reel itself, thus involving a constant trifling annoyance, and in the case of trolling and Salmon fishing, a serious danger. To obviate it I have had a small spring attached to the last of the lateral girders, or supports, and so arranged that when the

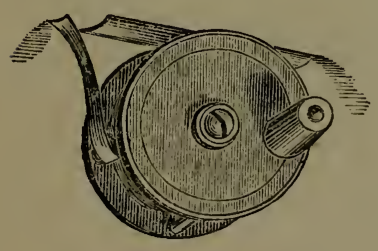
reel is in its place, the spring presses closely on the wood or fittings behind. This spring, of which a diagram is annexed, is very inexpensive, and can be attached with ease to any properly made reel, and I venture to think that no troller or fly-fisher who has once found the practical convenience of such an antidote to "hitching" will ever use a reel without it. 


\section{CHAPTER IV. \\ RODS AND ROD MAKING.}

Ancient rods-Observations on different rod woods. Solid woodsHickory, greenhart, ash, willow, fir. Hollow woods-East India, or mottled bamboo, white cane, Carolina cane, jungle cane. Rod rings - Upright rings recommended for all purposes, 'pronged rings,' proper shape for top ring. Ferrules- 'Tube-cut,' ' hammered.' 'Brazing' of joints - To separate 'stuck' joints. A general rod described and recommended.

WHATEVER ive may think of the skill of our forefathers in the gentle craft, it can hardly be denied that the implements they used were in every way vastly inferior to our own, and indeed, it may be added, generally such as to make any great display of what we understand as science out of the question.

Of the mechanical knowledge and ability which have led to these improvements, probably more have been lavished upon the rod than upon all the rest of the fisher's equipment put together, and if the fulfilling of every requirement which the most fastidious can demand be admitted as proof of excellence, we may very fairly congratulate ourselves on having arrived as nearly as may be at perfection in this one item at least. 
That in none was there more room for improvement may be gathered from the recipe for the construction of a trolling rod given by Juliana Berners in the brown old "Boke of St. Alban's," published about I486, wherein the implement is recommended to be of at least some I4 feet long ; the "staffe," or butt, measuring a "fadoom (fathom) and a half," of the thickness of an "arm-grete," or about as thick as a man's arm; and the joints being bound with long "hopis of yren" (iron hoops).

There are eight woods more or less universally employed by rod manufacturers ; four of which grow solid, viz., hickory, greenhart, ash and willow; and four hollow-East India bamboo, Carolina or West India cane. White cane, and Jungle cane.

Of the "solids" the most valuable, until greenhart came so much into fashion, was hickory. This wood grows in Canada, and is sent over in what are called in the tackle trade "billets," that is, longitudinal sections of a $\log$; each $\log$ being sawn from end to end through the middle twice or three times, so as to cut it up into 4 or 6 bars $\mathrm{V}$ shaped-having three sides. On their arrival in England the billets are transferred to the saw mills, where they are again cut up into planks ; and these planks are then put carefully away in a warm dry place and left for a year or two to season before being touched. After seasoning they are re-cut roughly into joints, sorted, and put away again for three years more,-some- 
times for as much as ten years,- - when they are finally worked up into rods.

The inferior billets, which are rejected by the larger manufacturers, arè cut up at once into joints and sold about the country by hawkers, who make it their regular business to supply the small country makers with wood for their rods. The same thing takes place as regards bamboo. After this insight into the ima pcnctralia of the rod-making trade, no one I fancy will feel inclined to grumble at having to pay a good price for a really good rod, or will be surprised at the comparative worthlessness of the rods turned out by inferior makers.

Hickory is the heaviest wood used in rod making, with the one exception of greenhart; and the purpose for which it is most commonly employed is the middle joints of rods, and for solid butts where weight and strength are required. In hollow butts it is never used, as it will not stand being bored.

Greenhart, which is an export from the West Indies, demands the next place, or rather I should have said the post of honour, in the rod maker's table of precedence. In all kinds of rods and in every different position it is to be found, whilst in some cases, as in the Salmon rod of Castle Connell, and many other Irish rods, it forms the sole material employed. Its speciality is, however, for tops; and here it is simply invaluable, as it is the only wood sufficiently stiff and at the same 
time elastic to admit of being used in such small bulk in a single piece. Thus in light trouting rods it will very often be found in slips a yard long and tapering off at the end to a substance little thicker than that of a stout darning needle, whilst a 7 -foot joint averaging about the circumference of a swan-quill, is the very common "lash" of a Castle Connell.

In consequence of its great weight, greenhart is only used for butts when they are very slender or tapered rapidly off from the handle, as in the rodsturned out by the Irish tackle makers.

Joints of this wood are hardly ever perfectly straight when fresh cut. They are bent or "warped" straight by hand pressure over a charcoal fire, and when cool retain, at any rate for a long time, their symmetrical shape, much as coes the originally straight walking-stick handle its crooked one after a somewhat similar process, -though I believe in this latter case the softening medium is water and not fire. Notwithstanding this "ductility" of some, indeed most, woods, there can be no doubt that the straighter a joint comes originally from the steel of the sawyer, the straighter will it remain in the hands of the fisherman. A joint that comes out straight from its seasoning hardly ever becomes permanently crooked afterwards, and per contra, one which is radically warped at the end of this process will as seldom be made really straight, or remain so for any length of time, however it may 
be twisted or bent over the charcoal of the tackle maker.

The other solid rod woods are ash and willow. The former, which in weight is between willow and hickory (willow being the lightest of all), is extensively used for hollow butts of bottom and trolling rods, as it bores well and is of good medium strength. It is also used for the solid butts of salmon rods. For middle joints it has been found too weak and yielding, the difference in strength between ash and greenhart being such that a top made of the latter would be as strong, or very nearly, as the joint next below it of the former.

Willow is a good deal used for the butts of common rods, as it "bores" more readily than any other wood; indeed its centre is little harder than the pith of a reed. In seasoning, both ash and willow require more care to. make them "usable" than do the heavier woods. Fir is also occasionally used for solid butts.

I now come to the hollow woods, or canes and bamboos. Of these by far the most valuable, indeed the only one which can be used properly in either trolling or fly-rods, is that grown in the East Indies-commonly known as the "mottled" bamboo-which has a considerable thickness throughout its length, and in the upper parts is almost solid. There is another East India cane, which is quite solid but lacking elasticity. It goes amongst the tackle makers by the expressive name of "puddeny." 
In the case of hollow woods there is, of course, no preparatory sawing or planing to be gone through, as the bamboo comes from its native jungle in pretty much the same state, barring the mottling, as that in which we find it in our rods; but even here the joints have to be "warped" as in the case of solid woods, and thoroughly seasoned, and much depends upon a judicious selection of the original stock and in subsequent careful matching and tapering of the various pieces of which the rod is composed.

I was never more puzzled than when admitted as a lad to the warehouse of a great London tackle maker to choose a cane to be made up for my "particular own." Well do I remember how my fingers glowed with pleasure and excitement as I lifted and poised one tapering beauty after another, uncertain among so many wooers which to take, and feeling, like the Captain in the Beggars' Opera,-

"How happy could I be with cither,

Were t'other dear charmer away !"

Like its schoolboy master, the rod built from the cane then chosen has since had many a narrow escape "by flood and fell," and not a few damaged "tips," ay, and "joints" too; but its main timbers are as sound as ever, and may yet be destined to wave death over many a pikey pool and glittering torrent when the hand that chose them is no longer able to do justice to their supple graces. 
But my pet rod is leading me into inadmissible digressions. To return.-The White cane, which comes principally from Spain and America, and is a fragile delicate creature compared to its swarthy Indian cousin, is used for roach rods,- "White cane roach rods," as they are temptingly described in the catalogues-and is fit for nothing else. For this one purpose, however, it is perfection.

The Carolina cane is also quite inferior to the East Indian. It is much lighter, and longer between the knots, and is employed only in the more common bottom rods.

Last on the list comes the Jungle cane, a Chinaman principally, but found also in many other parts of Asia. It grows as thick as a man's body, and is put to every variety of use by the Chinese, who amongst other things hollow out the pith and convert the skin into water-pipes. It is this skin or rind only which is of value to the rod maker, and that must be taken from a cane about as thick as a man's wrist. This is split up into narrow slips, and these slips when planed and smoothed down become the solid, grained-looking pieces of wood, so constantly forming the upper splices of top-joints. Some very beautiful rods, composed entirely of spliced cane, are manufactured by Mr. Thomas Aldred, of Oxford-street, London. Some of my readers who are in the habit of using bamboo and cane rods on the ground of their supposed much greater lightness, will perhaps be surprised to learn how small the difference in this point really is. I 
weighed a I 2 -foot solid ash and greenhart trolling rod against one of stout East India bamboo, and the weights were :-Solid rod, I lb. $5 \frac{1}{2}$ oz. ; Hollow rod, I lb. 4 oz.difference, $\mathrm{I}_{2}^{\frac{1}{2}} \mathrm{Oz}$.

At the close of every season, rods which have had a great deal of wear and tear should be re-varnished to preserve the wood; or, in the absence of varnish, well rubbed with oil (linseed is the best) before being finally stowed away.

\section{RoD RingS.}

Four considerations must regulate the question of rings: (I) That the material, especially of the top and bottom rings in trolling rods, should be hard enough to resist considerable friction; (2) that the top and bottom rings should be so shaped as to prevent the line catching round or over them; (3) that the rings generally should be large enough to let the line run through them with perfect freedom, and (4)-and this is by no means an unimportant point-that there should be enough of them on the rod to prevent the weight of the line "bagging" in the intervals, and yet not so many as unnecessarily to increase the wearing friction on the line passing through them, or curtail the length and freedom of the cast. For every description of fishing I recommend strongly the use of stiff or "upright" rings; the difference in weight is quite insignificant; and in addition to many other great practical conveniences, the rings last much 
longer without coming off or getting broken. In all general rods rings of the ordinary diameter, but made of steel wire, in the form shown in the engraving, will be found most convenient. Rings of this shape will not answer, however, for the bottom ring of all, as the line has a constant tendency to be catching round that ring in making a

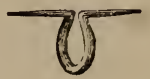
cast. The bottom ring should, therefore, be made in the form that is called "pronged," out of iron wire, twisted into a ring, in the form and of about the size shown in the woodcut annexed, with separate side-pieces brazed on. The perpendicular supports or arms being a good deal wider apart at the base than at

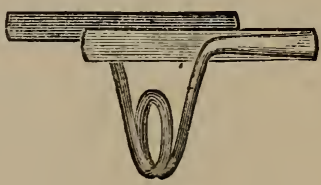
the apex, throw off instantly any curls of the line which may be inclined to twist round them. This will be found a really great practical advantage in every description of fishing, and especially in spinning.

Of even greater importance, however, is the form of the top ring, as this is both more liable to catch in the line, and proportionately more difficult to clear at the distance of from 12 to 20 feet from the fisherman; (the material, as in the case of the lowest ring, should be of steel wire). In order to remedy this catching of the line over the top ring, the great point is the avoidance of all projections over which the line can possibly hitch itself; 
and this condition will, I believe, be found to be fulfilled by the pattern of ring of which the engraving, enlarged for the sake of illustration, is a copy-

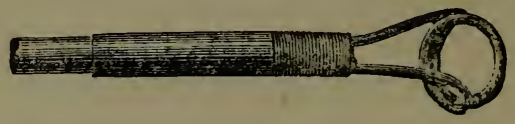

This is, in fact, to a certain extent, a modification or adaptation of the principle of the pronged ring recommended for the bottom joint. After being lapped over to within about half-an-inch of the ring, the wire is made to branch out in the shape of a $\mathrm{V}$, the upper points or sides forming a continuation of the ring itself. These sides act as a sort of guard to the ring to throw off the line, if it should curl over, much as the sloping sides of a gate, on a barge walk throw off the towing-line; whilst the position of the ring-that of inclining inwards towards the butt of the rod, instead of outwards from the foint - makes it almost impossible for the line by any effort of ingenuity to get above it so as to "hitch,"- - the head of the ring, in fact, forms an acute, instead of an obtuse angle with the rod.

\section{FERRULES.}

One word as to ferrules. These should always be "hammered," and not "tube-cut." To show the vast difference which there is between a good and a bad rod, even in such an item as ferrules, a bricf cxplanation of 
the mode of manufacturing the two descriptions of ferrule referred to, may be given.

Ferrules used for common rods, or tube-cut ferrules, are simply cylinders, of the same size at both ends, and cut off, 2 or 3 inches at a time, as required, from a piece of common soldered brass piping. These, of course, cost next to nothing, and break or bulge with the first strain put upon them. The ferrules used in really good rods are made, each one separately, out of sheet brass, hardsoldered or brazed; and then hammered out cold into the proper shape upon steel triblets-a process which though somewhat expensive and tedious makes the ferrule in the end very nearly as hard and strong as the steel itself.

A gentleman who does not wish his name published, but who has a large and practical acquaintance with the subject of rod-making, writes to me :-

I am inclined to think that the cases (referred to in your "Modern Practical Angler") where the brass ferrules of rods "bulge" and give way, are to be thus explained. The best tubing is mandrel-drawn, and I do not think any hammering would produce a density of metal so hard as that which results from welldrawn tubing : but it often happens (too often) that the tube and its correcter do not fit with that nice accuracy which is essential. In such case what does the ferrule-maker do? I will tell you, he anneals his tubing, and then with the furnisher adapts it to its fellow. For all practical uses its strength is then gone.

My own impression is that mandrel-drawn tube not tampered with, is (cæteris paribus) denser and harder than hammered tubing is, and no hammered tube could be so uniform.

I hope you will forgive this criticism of a work with which I am really charmed, but I shall be only glad to find that you accept it as it is meant, in all courtesy. 
The bottoms of all joints should be "double brazed" -i.e., covered with brass-not only round the thick part of the joint where it fits the ferrule, but also round the thinner end, or plug below it.

This is a very useful precaution, as it tends to prevent the joints swelling and sticking fast. If the joints are only half brazed or not brazed at all, the best way to avoid sticking is to grease or soap them before use. Joints which have become stuck, may in general be easily separated by being turned slowly round and round at the "sticking point" in the flame of a candle for some seconds, or until it is found that the joints will come apart. This process does not damage anything but the varnish of the ferrule.

\section{A General Rod.}

Considering the great diversities of tastes which prevail on the subject of the exact shape and material of which rods for different kinds of fishing should be made-some fishermen preferring hollow woods, others solid-some stiff rods, others pliable ones-it is impossible that I can within any reasonable limits give a detailed raisonne account of what is in my opinion the best description of rod for each description of fishing : nor if I should do so could I expect my brother fishermen to adopt my taste instead of their own. In other parts of the book, and wherever it seemed necessary-especially under the head of Salmon-fishing-I have made such 
observations as occurred to me: and all that I have proposed to myself under this head, is to give most general information in regard to rods and rod-making, as may enable those who are not already acquainted with thesubject to select their rods for different purposes with a knowledge of the qualities and capabilities of the various. woods of which they are made.

The following are the description and measurements. of the several joints of a general rod, which may be found convenient by those who do not care to carry a variety of rods about with them :-

\begin{tabular}{|c|c|c|c|}
\hline $\begin{array}{l}\text { Length of joints ; measured from top } \\
\text { of ferrule to bottom of plug. } \\
\text { (Butts ash : other joints and tops } \\
\text { greenhart.) }\end{array}$ & $\begin{array}{l}\text { Circumference at } \\
\text { bottom above } \\
\text { ferrule. }\end{array}$ & $\begin{array}{l}\text { Circumfe- } \\
\text { rence at top } \\
\text { below } \\
\text { ferrule. }\end{array}$ & $\begin{array}{l}\text { No. of Rings } \\
\text { (all of single } \\
\text { steel wire.) }\end{array}$ \\
\hline No. I Butt $3 \mathrm{ft} .2 \frac{1}{2}$ in. . & $\begin{array}{c}\text { Inches. } \\
3 \frac{5}{3} \text { at largest } \\
\text { part (be- } \\
\text { low winch } \\
\text { fittings) }\end{array}$ & $\begin{array}{l}\text { Inches. } \\
\qquad 2 \frac{5}{16}\end{array}$ & $\left\{\begin{array}{l}\text { I 'pronged' } \\
\text { ring just } \\
\text { below fer- } \\
\text { rule. }\end{array}\right.$ \\
\hline No. 2 Butt 3 ft. $2 \frac{1}{2}$ in. • & $\left.\begin{array}{l}3 \frac{1}{8} \text { (above } \\
\text { winch fit- } \\
\text { tings) }\end{array}\right\}$ & $I \frac{6}{8}$ & ditto. \\
\hline Ist Joint $3 \mathrm{ft} .2 \frac{1}{2}$ in. . . & $\mathrm{I} \frac{12}{16}$ & $1 \frac{10}{16}$ & 2 rings. \\
\hline $\begin{array}{l}\text { 2nd Joint } 3 \mathrm{ft} .2 \frac{1}{2} \text { in. . } \\
\text { 3rd Joint } 3 \mathrm{ft} .2 \frac{1}{2} \mathrm{in} .\end{array}$ & $\mathrm{I} \frac{6}{16}$ & $\begin{array}{l}\mathrm{I}_{16}^{3} \\
12\end{array}$ & $3 \quad$ \\
\hline Ist or "trolling" top $2 \mathrm{ft}$. Ioin. & $I \frac{1}{32}$ & $\ldots$ & $\left\{\begin{array}{l}5, \text { including } \\
\text { top ring }\end{array}\right.$ \\
\hline 2nd or "fly" top $2 \mathrm{ft}$. Io in. . & $\frac{11}{16}$ & $\ldots$ & $6 \%$ \\
\hline ing" top $2 \mathrm{ft} .3$ in. . & $\frac{11}{16}$ & $\ldots$ & 5 \\
\hline $\begin{array}{l}\text { 4th "minnow-spinning" top } \\
\text { I ft. } 3 \frac{1}{2} \text { in. } \\
\end{array}$ & $\frac{11}{16}$ & $\cdots$ & 3 \\
\hline
\end{tabular}

Total length of double-handed fly-rod... $\quad \ldots \quad$ I $5 \mathrm{ft}$. $\mathrm{I}_{2} \frac{1}{2}$ in. Total length of single-handed fly-rod ... $\quad \ldots \quad$ I2, 4 ,

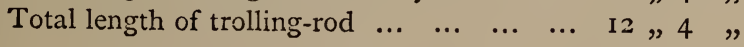


By changing the top joint of the double-handed flyrod for top No. 3 it becomes a suitable rod for worm or creeper fishing ; or by substituting top No. 4, for Trout minnow-spinning, or light paternosting. On a substitution of the stiff top for the two upper joints, it becomes a trolling and spinning rod.

On replacing the original joints, and taking off the large joint and butt, and substituting the smaller butt, a single-handed fly-rod is formed; and by a slight change of tops this can be made suitable for float or puntfishing. 


\section{CHAPTER V.}

\section{MISCELLANEA.}

Knots for lines and gut-Lapping over ends, fisherman's knot, some new knots described. Nezu knots for Salmon and Trout drop-fies. Varnishes-Green varnish, rod and tackle varnish. Bait-cansEssential points of ; the 'shoulder' bait-can, preserving live baits. Disgorgers-Disgorger blades, a ' fishing knife.' Landing-nets and gaffs-A pocket net described.

\section{KNOTS FOR LiNES AND GUT.-GUT-KNOTS.}

Everything, however minute, that conduces to "finefishing" should not be without interest to the fisherman who is not merely satisfied with doing a thing passably, or even well, but who wishes to do it as well as possible ; and of such minor mysteries of the gentle art there are none which are of more importance to the neatness -and therefore fineness-of tackle than the mode of knotting gut. In Salmon and other heavy fishing, moreover, this point frequently becomes a practical matter involving the loss or capture of fish-and those commonly the largest.

I make no apology, therefore, for considering this subject, in a book which it is my object to make complete and exhaustive of everything really essential to successful fishing. 
And first with regard to the very common practice of lapping the ends of the gut at each side of the knot. I am at a loss to explain the origin of this custom, which must be as troublesome to the maker as it is objectless to the user. Indeed it is worse than objectless: it is distinctly mischievous. It adds weight, so far as it goes, and clumsiness to what ought to be as light as possible; and it dots with opaque "splotches," at regular interva!s, what would otherwise be a transparent, gossamer-like strand from end to end. Indeed in bright clear weather I have frequently seen both Trout and Grayling rise at the knots on a fisherman's line who showed post (query propter?) no inclination whatever to meddle with his flies. It is hardly necessary to point out that for practical purposes the lapping of the short end of the gut outside the knot adds nothing whatever to the strength of the line.

For all fishing where exceptional strength is not required, the common single fisherman's knot, unlapped, is sufficient for every purpose, and the neatest

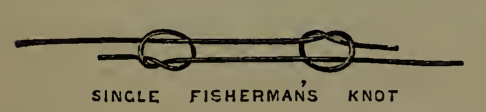
and strongest that can be used. It is made by tying a half knot round each strand of gut with the end of the other strand, in the form shown in the cut; then drawing both knots tight, and lastly drawing them closely together and cutting off the ends.

In the exceptional cases adverted to, when extra 
strength is really essential, as in the case of Salmon casting-lines and gut-traces used for Pike-spinning, a simple modification of the above knot will be found useful. It is tied thus :- Join the strands of gut in an ordinary single fisherman's knot, pulling each of the half knots as tight as possible; but instead of drawing them together and lapping the ends down on the outside, draw them only to within about an eighth of an inch of each other, and lap bctween them with light-coloured silk, or, still better, fine gut previously well soaked in water. This lapping relieves the knot itself of half its duty, and on any sudden jerk, such as striking, acts as a sort of buffer to receive and distribute the strain. It is one of the simplest possible forms of knot; and from its being much neater and nearly twice as strong, may be substituted with advantage for the ordinary whipped knot in Salmon casting-lines. As commonly tied I find that stout Salmon gut will break-at the knot-on a steady strain of from 12 to 15 pounds : tied as suggested, it will break at any other place in preference, no matter how great the strain may be. Facsimiles of the two knots, tied with the same strands of gut, are annexed.

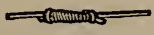

New knot.

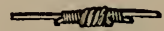

Ordinary knot. 
NEW KNOTS FOR GUT LOOPS AND DROP-FLIES.

\section{SALMON DROP-FLIES.}

Whilst on the subject of Salmon lines I may here mention a method of fastening drop-flies on Salmon casting-lines (when such flies are used) which I have found very successful. The object sought to be attained is, of course, that the fly should remain for the longest possible time standing clear from-in fact, almost at right angles to-the line, with the least amount of knotting or thickening, and the greatest facility for changing. To secure the first, it is necessary that the casting-line should be stiffened at the point of intersection. This is effected by joining the two halves of the line in a single fisherman's knot, leaving about half

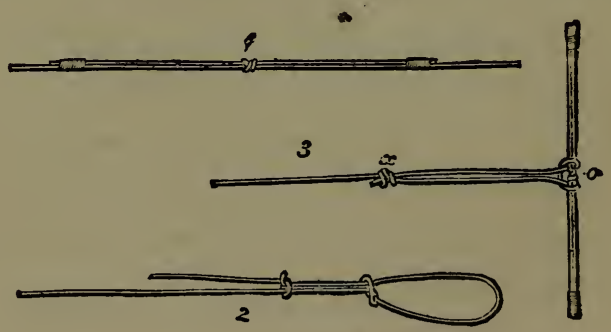

an inch over at each end. The knot having been drawn straight and close, these two ends should be lapped down to the line with a few turns of light coloured silk as shown in figure $I$ of the accompanying engraving; and the effect of this arrangement will be found to be 
that the casting-line at that point is trebly stiffened, with scarcely a perceptible increase of thickness or clumsiness. Over the central knot the loop of the drop-fly should be passed and drawn close in the manner shown in figure 3 .

For the tying of these loops, and all others used in fishing, I have, I believe, succeeded in hitting upon a new and considerably improved form of knot,-the ordinary loop being both clumsy and crooked (a serious drawback to the perfect set of the fly), and, in thick gut, very difficult to manipulate. My knot (fig. 2, and $x$ in fig. 3 ) is simply a new application of the principle of the ordinary single fisherman's knot, thus: a half-knot is made, about an inch and a half or two inches from the end of the gut, but not drawn quite tight; the end of the gut is doubled" over and passed back again from above through the opening; and then again, with this end, a second half-knot, embracing the main link, is made below the first. Both half-knots are then separately pulled tight, and drawn together. This produces the smallest possible knot, and one which will never draw and is perfectly straight. [I am indebted to the courtesy of Mr. Van Voorst for the use of the woodcut, which originally appeared in the Angler-Naturaiist.]

\section{TROUT DROP-FLIES.}

There are several ways recommended by angling authors for attaching the drop-fly to the casting-line, 
but most that I am acquainted with fail either in neatness or in strength, and all in rapidity. By one method, for instance, the drop-fly can be properly attached only whep the casting-line itself is made; by another, the knots of the casting-line have to be pulled asunder at the point of junction, and so on. My plan is as follows : Take the casting-line in the left hand a little above the intended point of junction, thick end upwards; then take the drop-fly, and with the same hand hold it along the casting-line, the fly end upwards; then, with the

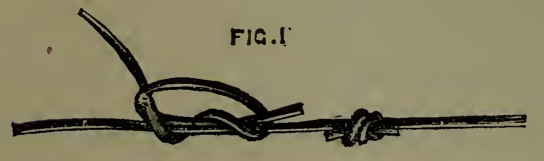
other end, make a knot round the casting-line, in the form shown in the engraving; drawittight, and

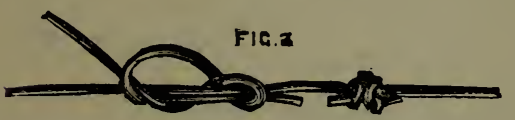
push it down on to the next knot of the casting-line below.

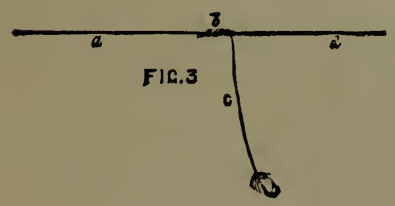

This knot, which in practice is the simplest possible, may perhaps be called a "double half-knot." The - only difference between it and the ordinary single half-knot is, that after the gut has been passed once round the main line, and through itself, it is passed round the line once more, and through the same loop again, before being drawn close.

The preliminary configurations of the knot are shown 
in figs. $I$ and 2 in an enlarged form. Fig. 3 is a facsimile of the actual knot when finished, as tied with fine gut.

\section{Knot for Fastening Reei Lines to Casting-} LINES, \&C.

An engraving of the simplest knot for this purpose is annexed, and the mode of tying it will probably be better understood from the diagram than from a verbal description. In the case of stiff or dressed lines the small terminal knot on the reel line can be omitted with perfect safety. This knot has the advantage of being both tied and untied with great ease and rapidity.

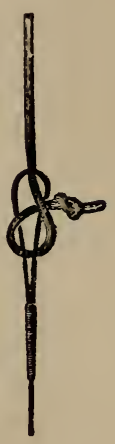

\section{VARNISHES.}

Grcen Varnish.-A most convenient and durable varnish for colouring leads used in all kinds of fishing is made from powdered dark-green sealing-wax dissolved in spirits of wine, or, better, in some of the spirit varnish for which the receipt is given below. This varnish dries quickly.

Rod and Tackle Varnish.-As a good varnish for rods, and generally for varnishing lappings of hooks, \&c., the following, used and commonly supplied for the purpose 
by most of the tackle manufacturers, will be found useful :-

Spirits of IVine, $\frac{6}{10}$.

Orange Shellac, $\frac{3}{10}$.

Gum Benjamin, a small piece, about $\frac{1}{10}$.

Allow the mixture a fortnight to dissolve before using. A varnish of some sort over the lapping is exceedingly valuable in all tackle, as it protects the silk from the effects of the water. In gimp tackle it is especially important, owing to the corrosion produced by wet brass and steel coming in contact.

This varnish dries almost immediately.

\section{BAIT-CANS.}

The most important point in a live-bait can is that it should be so constructed as to have the effect of keeping baits alive; and to this end it is highly desirable that it should have a double lid, for the purpose of keeping out the sun and keeping in the water. The abserce of this appliance will very frequently kill the baits in hot weather, and when the weather is cold its presence will preserve the legs of the carrier from a perpetual sprinkling of half frozen water. Another advantage of double lids is, that a small hand-net can be carried between the upper and lower one, which will save much time, and avoid the probability of poking out the bait's eyes with the operator's thumb-nail.

The above desiderata have already been to some 
extent fulfilled in the bait-cans sold at the tackle shops. But there is still a want, which, so far as I am aware, has never been successfully supplied-I mean the production of a can of such form and construction that it may be convcnicntly carried, when full, by a strap across the fisherman's shoulders. The want of such a can often makes the whole difference between comfort and discomfort in live-bait fishing. With the old can, the solitary angler has at best a choice of evils : on the one hand he may stop fishing and carry his can along with him, or, on the other, he may leave his can and continue his fishing operations, every step of which carries him farther away from his baits. Live-baiting, in fact, except from a punt or with an attendant, thus becomes much like a game of battledore, in which the fisherman, who is of course kept perpetually moving, forms a not inapt representation of the shuttlecock.

To remedy this inconvenience I have had

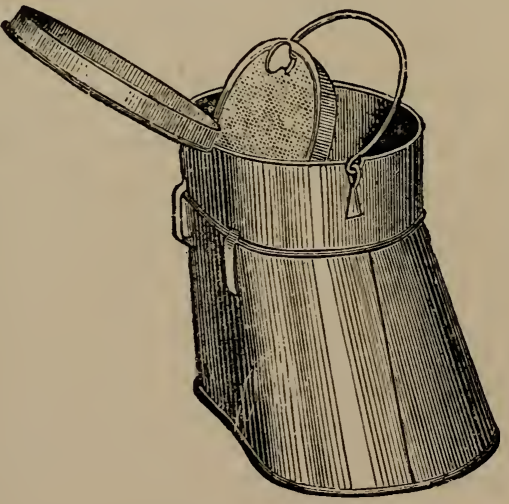

a bait-can constructed (somewhat on the principle of the ordinary pannier or creel), as shown in the engraving, which can be strapped comfortably over the shoulders and carried by the fisherman, without fear of his losing 
his baits on one side or his fish on the other, and getting wet through between them. The strap passes through the rings at the back, and over the shoulder.

To preserve baits alive for any length of time, they should be placed in some shady spot (in a running stream if possible), in a box not less than 3 feet square, with large gratings in several different places, and especially at both ends. The box, of which a portion ought properly to be out of water, should be kept clean and well scoured from slime and rubbish; and food, in the form of worms, gentles, or chopped liver, should be scattered into it every day or two. Dead baits should be removed from the box as soon as discovered.

\section{DISGORGERS.}

A disgorger is one of the most desirable, though not perhaps absolutely essential, items of a fisherman's equipment. In fly-fishing the use of a disgorger prolongs the life of the fly, and in every description of fishing shortens the time wasted in extracting the hooks, and saves the fingers. The most convenient way of carrying the disgorger is to suspend it by a short link from one of the breast buttons of the coat. In Pike-fishing especially, a disgorger is a sine quâ non, and the longer it is the better. The ordinary disgorger is too short for the purpose; and in consequence of the inconvenience experienced in extracting Pike-hooks with it, I had a " disgorger blade," if I may so term it-made, of course, 


\section{$\cdot$}



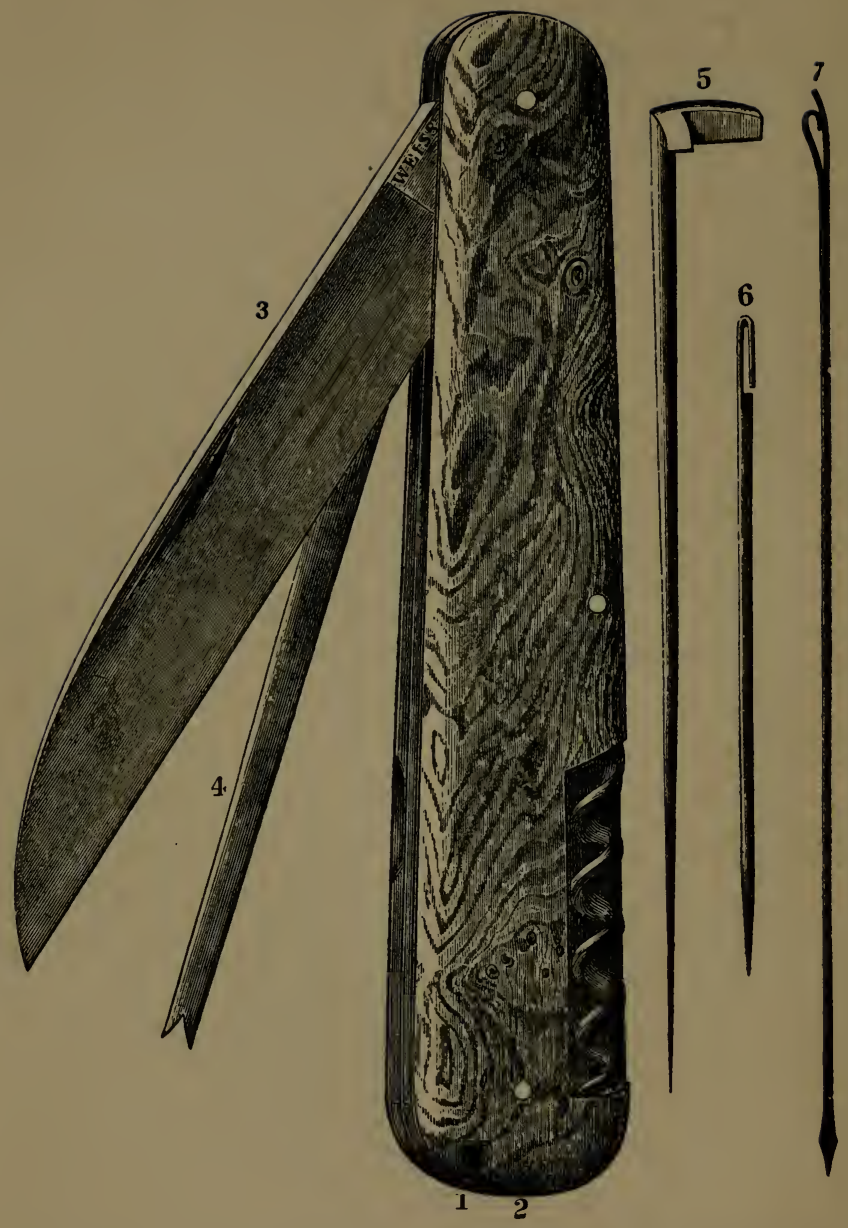

1. Box containing minnow-needle and baiting-needle.

2. Hole for pricker (marked 5).

5. Pricker, for loosening drop-flies, separating feathers, \&c.

3. Blade for crimping or other purposes. 7. Baiting-needle.

4. Disgorger. 
without edges of any sort-inserted in my fishing-knife, by which means the length of the disgorger was doubled, and its power and readiness for use very greatly increased. The advantage of this arrangement of the disgorger, in trolling as well as in other fishing, suggested the advisability of extending the principle so as to embody in the same knife the rest of the angler's implements, and thus spare him the necessity of collecting and stowing each article before starting for the river.

The engraving represents the form and arrangement of a fishing-knife which will, I believe, be found to contain all that is really required, viz. :- a powerful blade suited for crimping or other general purposes; a "disgorger blade;" a minnow needle; an ordinary baiting needle,-the last two slipping into a box in the handle of the knife,-a sharp-pointed pricker (a useful instrument for unpicking knots, loosening drop-flies, separating feathers, \&c.) ; and last, not least, a strong corkscrew.

\section{LANDING-NETS AND GAFFS.}

A gaff is generally the most convenient implement for use in Pike-fishing, when the angler is alone, or a net, if he has one large enough-say 2 feet in diameter-when attended. In Salmon-fishing also, except when there is danger of killing foul fish, a gaff is generally to be preferred, though even here I have found a large net to save time.

In Salmon-fishing, however, the fisherman is seldom 
without an attendant, and therefore no great difficulty

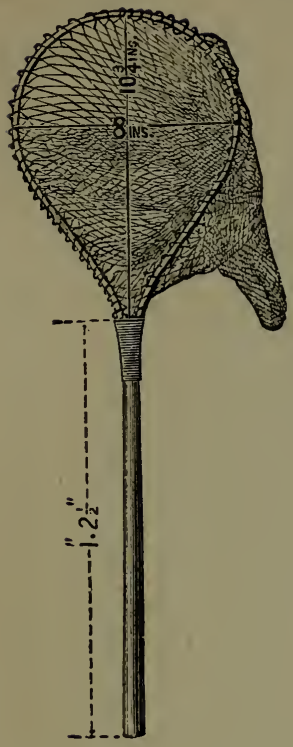
occurs whichever instrument is employed, and in Pike-fishing I have landed many hundreds of fish from boat and bank without either net or gaff. The case is different with the solitary Trout and Grayling fisher. The absence of a net often costs him the best fish of the day, whilst the nature of the work renders a net or gaff of the usual size an intolerable, not to say impossible burden.

The engraving gives a representation of a net suited for this fishing, which being made entirely of wood and weighing only 3 oz., can be carried without any inconvenience, whilst the handle, $\mathrm{I} \frac{1}{2}$ feet long, can be passed under a small strap attached to the coat, under and behind the left arm, and thence into the pocket, so as to be entirely out of the way. With this net, the measurements of which are given in the cut, a fish of 3 lbs. can be readily landed. The net should be made of dressed silk.

When wading with the fly, or worm-fishing for Trout, a net which the angler can carry with him into the water, and use without getting out of it, will be found a really great practical advantage, and save the loss of much time and many fish. 


\section{PART II.-FLY-FISHING.}

\section{CHAPTER VI.}

\section{General Observations.}

THE SYSTEM OF ARTIFICIAL FLIES.

Present systems of artificial fies- ' Colourists' and ' formalists'; both theories unsound in part. Fishing up-stream, \&c., erroneous. True theory of artificial fies-Application of to practice; form; colour; size. Three typical Trout flies described and recommended to be substituted for all others for Trout, Whitetrout, and Grayling fisbing. Salmon fies-The same arguments applied; theory of Salmon fies; three patterns of fies for Salmon and Grilse recommended to be substituted for all others. Theory of Whitetrout fies. Summary-Six fies only necessary for every description of fy-fisbing.

ENGLISHMEN are as a race decidedly conservative in their habits, and very slow to move out of the beaten track-phlegmatic is the term used by their continental critics,-and I shall be sorry if anything I am about to write should give offence to this in many respects excellent instinct. Conservatism, however, in the largest 
sense of the term implies contentment with what is; and if that were my condition in regard to the theory and practice of Angling, and especially of fly-fishing, this book would certainly not have been written. The measures which I am about to submit to the general parliament of anglers are decidedly radical-revolutionary would not be too strong a term,-for they aim at revolutionizing the fundamental principles of the flyfisher's 'constitution' - the very alpha and omega of his craft-I mean the system of artificial flies.

Trout fly-fishers may nowadays be divided roughly into two parties, which may be described as the "colourists," or those who think "colour" everything and "form" nothing ; and the "formalists," or " entomologists" as they have been sometimes termed, who hold, with the late Mr. Ronalds, that the natural flies actually on the water at any given time should be exactly imitated by the artificial fly used, down to the most minute particulars of form and tinting. The latter class includes probably the very great majority of anglers-both apostles and disciples-who have probably in most cases imbibed their opinions, until recently unchallenged, almost unconsciously and without ever questioning their soundness. The "colourists" are still but a section, though an increasing one, of the general fly-fishing community, and are represented by a few enterprising spirits in advance not only of their age, but also of the truth. The theories of both I hold to be dis- 
tinctly unsound; and if my reader will follow me in the next few pages, calling to mind, also, his own fly-fishing: experiences, I have little doubt that he will arrive at a similar conclusion. In fact the arguments of the two. schools are mutually destructive.

The position of the "formalists" is as follows :-

Trout take artificial flies only because they in somesort resemble the natural flies which they are in the habit of seeing; if this be not so, and if colour is the only point of importance, why does not the "colourist" fish with a bunch of feathers tied on the hook "promiscuously?' why adhere to the form of the natural fly at all ? Evidently because it is found, as a matter of fact, that such a bunch of feathers will not kill ; in otherwords, because the fish do take the artificial for the natural insect. If this be so, it follows that the more minutely the artificial imitates the natural fly the better it will kill ; and also, by a legitimate deduction, that the imitation of the fly on the water at any given time is that which the: fish will take best.

To the above argument the "colourists" reply:-

Your theory supposes that Trout can detect the nicest shades of distinction between species of flies. which in a summer's afternoon may be numbered actually by hundreds, thus crediting them with an amount of entomological knowledge which even a professed naturalist, to say nothing of the angler himself,. very rarely possesses; whilst at the same time you draw your flies up and across stream in a way in which no. natural insect is ever seen, not only adding to the impos- 
sibility of discriminating between different species, but often rendering it difficult for the fish even to identify the flies as flies. The only thing a fish can distinguish under these circumstances, besides the size of a fly, is its colour. We therefore regard form as a matter of comparative indifference, and colour as all-important.

Now in each of the above arguments there is a part that is sound and a part that is fallacious; and it is from the failure in distinguishing the true from the false, that what I believe to be the erroneous practice of both these opposite parties springs. Each argument, however, is sound so far as to be an "unanswerable answer" to the other:-It is clear-as stated by the "formalists"that colour is not everything in a fly, because if it were, a bunch of coloured feathers tied on anyhow to the hook would kill as well as an artificial fly, whereas by their practice the colourists themselves aamit that such is not the case. On the other hand, the argument of the "colourists," that from the way the artificial fly is presentcd to the fish it is impossible they can distinguish minutice of form and imitation, equally commends itself to common sense and common experience. This is the point, in fact, in which the entomological theory entirely breaks down. Because Trout take the artificial for the natural fly, the formalists argue that the one should be an exact counterpart of the other, ignoring the fact that the two insects are offered to the fish under cntively different conditions. The artificial fly is presented under water 
instead of on the surface; wet instead of dry; and in brisk motion up, down, or across stream, instead of passively floating. No doubt if the flies could always be kept dry and passively floating-that is, as they are seen in nature-the exact imitation theory would (though only up to a certain point) be sound enough ; but as in practice this is impossible, we are perforce driven to artificial expedients to extricate us from the "unnatural" dilemma. Thus at the very outset we find ourselves compelled to simulate life instead of death in our flies ; and for this purpose impart to them a wholly unnatural motion whilst swimming: again, because "fluffy" materials when wetted lose much of their strength of colour, fly bodies are constantly made of hard silk instead of soft dubbings; and as it is found that a naturally proportioned insect is deficient in "movement," an unnatural quantity of legs (hackles) are added to it-in the smaller species the wings being often omitted entirely. In short, we are launched upon an altogether artificial system, in which experience must to a great extent supersede nature as a pilot.

The colourists take advantage of this undeniable position to assail the whole system of "form" as a blunder, and in doing so themselves make a blunder still greater; they not only draw from correct premises an erroneous conclusion, but they draw a conclusion the very opposite of the logical one. For if it be admitted (a), that Trout do take the artificial for the natural fly, 
and $(b)$, that from the way in which the fly must be presented to them it is difficult to be recognised; the logical deduction is, not that form is of no consequence, but on the contrary that it is of the utmost consequence, and that the fly should be as "fly-like" and characteristic as possible, so that, notwithstanding its rapid and unnatural movements, it may be at once and unmistakably identificd as a fly.

I do not see any escape from this position, which if accepted puts the colourists as entirely "out of court" as by the previous argument are the formalists.

The superadded theory of the latter, that the imitation of the natural fly on the water at any given time is that which the fish will take best, falls as a logical sequence with the proposition on which it was based. As might be expected, this theory was never found to stand the test of practice, the experience of every fly-fisher teaching him that when a particular natural fly is on the water in abundance, Trout will commonly take better an artificial fly imitative of any other species. To this principle there is only one exception-namely, the case of " May-fly fishing with the dry fly." In this case, owing to the large size of the fly, it is possible to really simulate nature by presenting the artificial insect literally $d r y$, and floating passively. Thus the exception proves the rule.

Mr. Stewart, who has written one of the most able books of modern times on Trout fishing in clear water, founding on the same sound proposition as Mr. Ronalds 
-viz., that Trout take the artificial for the natural flyargues that because the natural $d r y$ fly usually floats passively down the stream, the artificial fly-zuct-should do the same. This is another analogical fallacy, the error of which would seem hardly to require an almost universally opposite practice for its demonstration. Ninety-nine men out of a hundred find it best to give a slight movement to the fly in the water.

I fear we must include in the same "unproven" category, and for the same practical reason, the theory that flies should usually be cast up stream, rather than down

To sum up the foregoing arguments therefore, the true rationale of the matter seems to me to be as follows:-

I. Whatever Salmon, ct hoc gcnus, may do, Trout certainly take the artificial for the natural fly.

2. But as the artificial fly is necessarily presented in an abnormal condition-namely, wet instead of dry, sunk instead of floating; and as the resemblance which wet feathers and silk under water bear to dry insectdown, fluff, and wings on the water, is imperfect,-(3) it is necessary for the purpose of hiding the counterfeit, and partly also to hide the hook, to give the fly an unnatural, life-like movement in the water ; adding to it also an unnatural quantity of legs (hackles) which open and shut, and move with the movements of the fly.

4. These "movements" and alterations, however, make it quite impossible for Trout to discriminate 
minutely between the various unnatural imitations of natural flies, whether in form or tint; (5) and render it doubly important that the imitation insect should be as characteristic and "fly-like" as possible in shape, lest the fish should fail to perceive the resemblance altogether.

6. General shape, gencral colour, and sizc, are all that can be distinguished by the fish. These are the points, therefore, to be kept in view in the construction of artificial Trout-flies.

The next step is to reduce these propositions to practice; and the argument seems naturally to take somewhat the following form :- If when presented to them in the only manner in which we can present them, nice varieties of imitations, and shades of shape and colour cannot be distinguished by Trout, the great mass of flies now used are obviously unnecessary, and where either the colour or outline is confused, are mischievous. It would be better on every ground to select two or three of the most favourite and distinctive families of flies, and imitate them only; not in their varieties, or even species, but, as it were, in their types,-and using those colours only which represent the prevailing tints in the selected families. What, then, are the most favourite families of flies-most favourite, that is, in the eyes of the Trout? Without question the Ephcmerida and Phryganida,-and for a very good reason, as with hardly an exception they are all bred in the beds, banks, 
and reeds of the waters over which they afterwards fly: To the first-named family belong, roughly speaking, the whole collection of the "duns," and "spinners," - the drakes, or May-flies, the dark mackerel, the sand-fly, and the March brown; whilst the latter includes the cinnamon, the grannom or green-fly, the willow-fly, and, more important than any, the stone-fly, or "water cricket," which in the early part of the year is so plentiful on many rivers. From these two great families, in fact, some of which are on the water every day of the year, fully three-fourths of the contents of most flybooks will be found to consist ; they therefore commend themselves as the families from which our typical flies should be made.

As regards form or shape no question can arise, as the selected families are all unmistakably and characteristically fies, in the proper sense of the term, having wings, legs, and, I think without an exception, "whisks," or hair-like appendages at the tail. These whisks are not only very "fly-like" and distinctive features, but are also easily imitated, and assist materially to disguise the hook, as well as to make the fly swim straight. This last is an important point, as the effect of the extra weight at the bend of the hook, unless counteracted by some additional "float," is to make the fly swim tail downwards.

The great majority of the most favourite river flies belong to the order Neuroptera, or nerve-winged insects, 
or less crude and imperfect-but the theory as ultimately elaborated, examined by the light of the theories of others, and worked out, tested and re-tested by myself during some twenty years' practical experience of fly-fishing on many of the principal rivers and lakes in the three kingdoms.

With regard to Salmon-fishing the arguments adduced against a multiplicity of flies apply, and with even greater force, inasmuch as it is not pretended by any one that Salmon-flies really imitate the colour or form of any known insects, but are rather spontaneous evolvements from the internal consciousness of anglers and tackle makers. They are certainly more numerous in their endless variety of colour and pattern than even Trout-flies, and are proportionately more useless, except to those who are paid for making or selling them. The result of my investigations is, that there is only one essential in the construction both of Salmon and Grilseflies, and that is brilliancy and strength of colouring; and that in proportion as they fulfil these conditions are their killing properties. Size is on the contrary an element constantly varying from local circumstances. A large river or lake usually demands a large fly, and vicc $v c r s \hat{a}$, and this again should be larger or smaller according as the weather is dark or bright, windy or calm. These are all points requiring the exercise of judgment, for in their combinations they present considerable 
variety; but the essentials of the flies themselves never vary. Nor is the rationale of this difficult to understand. The Salmon admittedly does not take the fly for any living insect, or food which he can have previously met with. Then for what and why does he take it? For its beauty and tempting appearance. Probably it has an appetizing effect. To borrow a familiar illustration from ourselves, how few schoolboys would have been flogged for stealing apples but for the fascination of their rosy cheeks?

In the Chapter on Salmon-fishing I have given three patterns of Salmon-flies which combine the real essentials as above described, in what my experience leads me to believe to be the most perfect form.

White or sea Trout, and their congeners, appear in their tastes, and habits of feeding, to be somewhat intermediate between Salmon and brown Trout; and the Trout-flies described, with a slight addition of tinsel, will kill them, both in still and running water, better than any others with which I am acquainted.

It will thus be seen that I propose to substitute six typical fies-three for Salmon and Grilse, and three for Trout, Grayling, \&c.-for the whole of the artificial fics now used.

That there are a great number of existing patterns of flies for each different kind of fish, most anglers are probably aware, but perhaps few have any very distinct 
notion of what the number really is. In a small collection of my own, consisting of so-called "standard" flies only, and those for Salmon and brown Trout alone, I find there are I 21 distinct patterns, or "species." But these are a mere drop in the ocean. Besides Salmon and Trout-flics proper, there are the endless varieties of flies for Grilse, Salmon-Trout, Bull-Trout, Grayling, \&c., the general total having been estimated by a recent writer at more than one thousand patterns. In fact their name is simply "legion." With most, if not all, fish may no doubt occasionally be killed, and with some, excellent baskets made; but yet painful as the admission must be to the accomplished student of angling entomology, and fiercely as it will be contested by many a gallant veteran of the old régime, it is nevertheless true that nine-tenths-or rather ninety-nine hundredths-of these graceful combinations of furs, silks, and feathers represent so much wasted time, money, and ingenuity.

Indeed when I think how great that ingenuity has been,-how much has been written, and charmingly written, for the last two centuries to teach how to make and use what $I$ have been exhorting my readers to discard as useless; and what a complicated and nicelybalanced system has been thereon elaborated, it is not without a pang of regret I have undertaken the ungracious task of writing what may perhaps eventually prove to be its epitaph. 
$\|$

$$
\text { . }
$$




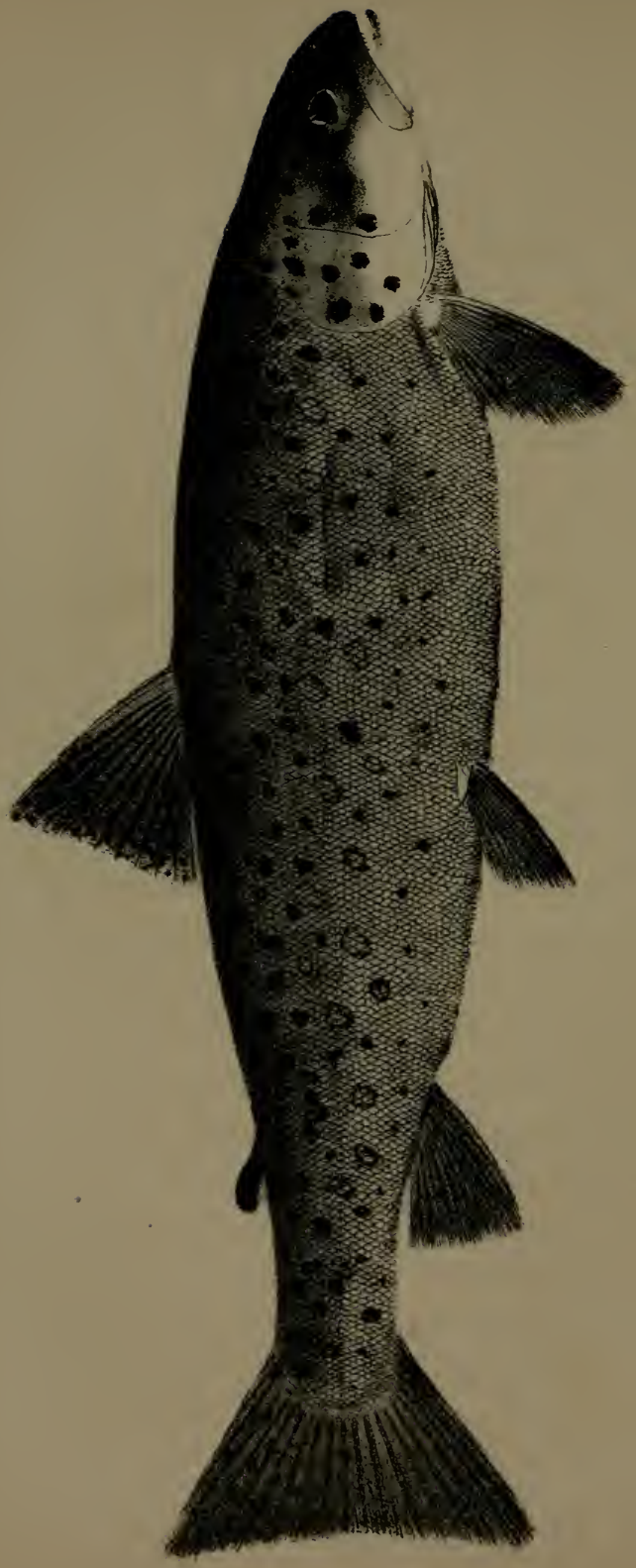

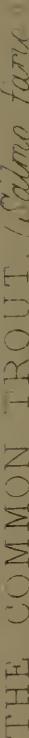




\section{CHAPTER VII.}

\section{BROWN TROUT.}

ARTIFICIAL FLY-FISHING IN RIVERS AND LAKES.

Salmon and Trout fishing contrasted. River fly-fishing-How, when, and where to fish. Drop-fies-More than one a mistake; theory of. Striking and playing.

IN thus placing Trout-fishing before Salmon-fishing, I invert the usual order of sequence. I do so deliberately, because, both as a sport, and as indisputably the most popular branch of angling, it seems to me to be entitled to precedence. With no assistance but his rod and no guide but experience, the Trout-fisher wanders down the bank of the untried lake or stream, selecting by intuitive perception the most likely casts, and if he raises a heavy fish has many a heart-quake and many a moment of breathless suspense, before he transfers the shining beauty to his creel. No Salmon-fisher, on the contrary, however skilful, can select for himself the places where he ought to fish, Salmon apparently being guided by the merest caprice in the choice of location, so that the very stone behind which the fly must fall to give a chance of 
success, has often to be pointed out by the local assistant ; whilst the tackle used is so strong, and generally the nature of Salmon casts so open, that with ordinary skill a fish once fairly hooked has little chance of breaking away. The chief glory of Salmon-fishing lies in the "rise"-which is certainly magnificent-and the only difficulty of the capture, as a rule, consists in the "stroke." So much is this the case, that I have known veteran Salmon-fishers, who, when Salmon were plentiful, made it a habit to resign the rod into the hands of an assistant after checking the first rush or two. But who ever heard of the Trout-fisher adopting such a practice? Not that I blame the Salmon-fisher; for though I never could bring myself to follow in this respect the example of men who were doubtless better anglers than myself, still, it must be confessed that there have been moments when I felt sorely tempted to do so. Wielding a 19 or 20 -foot rod for five or six hours consecutively is apt to tire even the strongest muscles; and as I have said, as a rule, the cream of the sport is over when the fish is fairly struck, and his first wild rush or two met and mastered. Still Salmon-fishing is a gallant game, fit for the persevering spirits and strong arms that play it; and it has, too, its gleams of triumph and excitement, the more intensely bright perhaps partly from their very shortness.

But to return to the first part of my subject,-Troutfishing. For the sake of convenience I shall divide this 
ARIIFICIAL FLY-FISHING IN RIVERS AND LAKES. 8I

into its several branches-River fly-fishing, Lake flyfishing, Worm-fishing, Minnow-fishing, Lake and River Spinning, Fishing with the natural fly and "creeper," and Fishing with the dry-fly.

\section{RIVER FLY-FISHING.}

There has been much excellent writing devoted to describing How, When, and Where to fish for Trout in rivers and streams; and this is one reason-want of space another-why I shall not go very minutely into those questions. It seems doubtful also whether anglers, as a rule, read, or if they read, remember so as to derive practical benefit from the detailed maxims and rules laid down on these subjects.

With regard to particular states of the atmosphere, for instance, some writers think the presence of ozone in a greater or a less proportion may probably make one day more favourable than another for fly-fishing. But what then? Nine men out of ten fish just the same, and make the best basket they can, whether they know, or think they know, the day to be good or bad; whilst as to "Where" to fish in any particular river, the only really available knowledge is to be gained by experience, and the most general instructions are all that can be given or recollected.

Again, as regards the "How." The proper movement of a fly-rod is very difficult to describe intelligibly, and I advise all tyros who do not understand the art tc get 
a lesson from some one who does. I can only attempt to give an outline, which may facilitate the acquirement of details.

\section{How To FısH.}

CASTING.

The flies and some of the line being in the water, and the rod held by one or both hands (in the latter case the right hand being above the left), the rod should be raised rapidly yet steadily, with a backward motion over the right shoulder, so as to fling the line wall out belind into the air; and then brought with a circular sweep round the head to the left, and propelled lightly forward, with force proportioned to the length of cast to be made. A short line will of course be best for the first essay. The shape of the curve described by the rod in casting is nearly that of a horse-shoe. In completing this movement the point of the rod must not be allowed to approach too near the water, but should be kept well up ; and even, at the moment the line is falling, a little upward springy movement of the point should be given. This has the effect of making the flies light softly, and before the line-two most important points.

As soon as the flies have touched the water, the rod should be gradually raised towards the perpendicular, the flies being kept in motion by gentle upward movements of the rod point.

Each cast will of course be only a repetition of the 
ARTIFICIAL FLY-FISHING IN RIVERS AND LAKES. $\delta_{3}$

above process ; but as skill is acquired, the fly-fisher will soon learn to cast the flies either over the right or left shoulder with one or both hands, and from any positioii.

"Switching" is another most useful method of casting, as by it water otherwise inaccessible, owing to trees or banks, can often be fished satisfactorily.

The modus opcrandi is as follows:-

By raising the rod to the full stretch of the arms the flies are drawn in until they are nearly below the angler's feet. Then with a very sudden, strong, circling movement of the rod they should be cast straight out again, up, down, or across, and the first process repeated. "Switching" requires practice, but it is well worth the trouble of learning.

As a rule the best mode of fishing rivers is to cast down and across the current, beginning under the further bank if possible, and ending under the near one. In spite of Mr. Stewart's able advocacy, most anglers have now arrived at the conclusion that fly-fishing up stream, always, or even generally, is a mistake in practice. In my general observations on fly-fishing I have pointed out one or two of the reasons which led me to consider it so in theory also. With a strong wind up stream it is sometimes a necessity, though, even then, I cannot but think an unfortunate one. 
WORKING THE DROPPER.

Some angling authorities recommend the use of three flies, and some even four.

The objections to this practice are many; but perhaps the most important are, that it is more difficult, especially in windy weather, to cast three than two flies; that it is more difficult to work them properly when they have been cast; and that when fish have been hooked there is more danger of entanglement in weeds, \&ic. Vexations, in short, are multiplied and efficiency impaired. The fact is that only one dropper can be properly worked, the perfect working of a drop-fly consisting in its skipping, or "dribbling" along the surface of the water amongst the ripples, and thus offering a sort of imperfect representation of a half-drowned insect endeavouring to rise from the water. Cross lines and others are more killing than any other form of fly-fishing, only because all their flies work in this manner. The point, however, is more important in lakes than in streams.

A description of an improved method of attaching the dropper, new knot, \&c., is given at pp. 57-S.

\section{STRIKING AND PLAYING.}

After striking, which cannot be done too rapidly, the point of the rod should be kept well up, and a steady though yielding pressure brought to bear on the fish, until he is killed. With a proper check reel, such as 
ARTIFICIAL FLY-FISHING IN RIVERS AND LAKES. S5 $_{5}$

that described in the chapter on Tackle, it is better when playing a fish, to remove the hand altogether from the line, so as to allow of its yielding freely to any hidden springs or rushes.

\section{WHEN TO FISH.}

I. Some rivers and lakes are early and some late, whilst there are a few, like the Devonshire "Otter," in which it is said the Trout rise best in a snow-storm. This of course is a very exceptional case ; but, taking the ordinary run of early and late waters, there are few months of the year from early spring to late autumn in which the Trout-fisher cannot find sport somewhere or other.

2. In all Trout fly-fishing, whether on lake or river, a moderate, rippling breeze and a chequered sky are great advantages ; principally, doubtless, because they help to conceal the counterfeit fly, and lessen the glitter of the gut.

3. A bright sun, a dead calm, or water that is very low and clear, are always bad, for the converse reasons.

4. Water that is thickcned by rain or other cause is always bad. It prevents the fish seeing the flies on the top, and brings down with it a quantity of ground-food which fixes their attention on the bottom.

5. The rise that precedes, and the fall that follows a flood whcn the woter has cleared, are generally favourable, more particularly after drought. 
6. The presence of any large quantity of natural flies on the water is usually exceedingly bad.

7. About sunrise and sunset are commonly the two best hours of the day in hot weather, as the fish are then on the look-out for the flies which oftener come out at those hours than at any other. In cold stormy weather, however, the converse rule often holds good.

8. As settled weather is very favourable, so changeable weather generally prognosticates uncertain sport.

\section{WhERE TO FISH.}

The best places to fish in any river are usually not where there are most fish, but where they can be most easily caught. These places are moderately rapid runs; scours, or "stickles," where the water is of a medium depth, and carries a brisk ripple or curl ; pools, with a current through them; and mill-tails, weirs, and eddies.

Deep, stagnant, lagoon-like reaches can only be fished with success when there is a good breezy ripple on them. 


\section{7}

\section{CHAPTER VIII.}

TROUT-FLIES.

Three typical fies described - 'Green,' 'brown,' and 'yellow'; new principle of construction. A colourless zvax. Prevailing colours of natural flies. Colours of hackles; dyed hackles best. All flies should be carried in a box. Selecting of fies-Size; colour; fly rod and tackle. Fishing with the dry-fly.

Lake fly-fishing.

Fisbing with natural fies- 'Creeper' and stone-fly fishing; blow-line fishing with the May-lly.

\section{Typical Flies : DRessing of.}

I HAVE explained in the preliminary chapter to this part, the reasons which lead, I think incontrovertibly, to the conclusion that for all practical purposes only a few typical flies, of the most common insect-colours and distinctive forms, are required for Trout-fishing, whether in lake or stream.

Such flies it has been further shown should naturally be three in number, embracing the three most common insect colours, green, brown, and yellow; and in form imitating the phryganida and eplemerida, which are the most favourite families of river flies, and the most distinctive and "fly-like" in their form. Several other desiderata with regard to colour, \&c., have also been pointed out.

The frontispiece shows the form and colouring of 
the three flies which I recommend as fulfilling the conditions indicated. They can be made of any size, from that used in the smallest and clearest of our Derbyshire streams to the largest sized lake-fly: nothing being required to be varied but the size of the hook, the length of the hackle, and the thickness of the silk with which the fly is tied. These flies are both simple in construction, and more easily and quickly tied than any flies hitherto made public, so far as I am aware. For the construction of an ordinary "March brown," for example, at least two feathers and three silks are required: in the brown fly shown in the plate, which is quite as good an imitation of the insect in theory, and a better one in practice, only a single strand of coloured silk, and a single hackle feather is used; and the other flies are made in the same way. The principle of their construction is as follows :-

A strand of common coloured sewing silk (not floss), of the required thickness having been waxed in the manner presently described, take two or three turns over the end of the hook-shank and gut; lay the hackle on the back of the hook, hollow side upwards, with the large end towards the hook-bend; lap over it with three or four turns of the silk; spin the hackle on over these turns (the same way round as the silk), leaving some of the hackle over; then fasten the hackle off with the silk, continuing to work upwards towards the bend of the hook, and lapping over the hackle until the body is of sufficient length; then fasten off the silk and cut the 
stem of the hackle off so as to leave the fibres in the $\mathrm{V}$-shaped form shown in the engraving. These latter form the whisks. By leaving and lapping over the stem of the hackle and the end of the silk, or by "stripping" the former and cutting the latter off close, the body can be made thick or thin as desired.

It will be seen that the body of the above fly is made of the same strand of silk with which the gut is tied on, and that the "whisk" is made of the same feather that forms the legs, or hackle. A fly thus constructed cannot break until the hackle or body silk is actually worn through, and will last twice as long as one made on the ordinary plan, where the hackle, wings, \&c., are constantly slipping or coming undone at the head. The saving in time in tying a fly (say a March brown) thus, as compared with the common method, is about 400 per cent. ; which I have proved by having frequently tied the fly on my plan complete in forty-five seconds, whilst in the ordinary method it cannot be tied by even a professional hand under three minutes. The whole process is, moreover, so exceedingly simple that a single lesson ought to be sufficient to impart it to the merest tyro.

The difficulty which gave me the most trouble to overcome was the body-silk. In order to use this for whipping on the hook, \&c., it was of course necessary to wax it ; but I found that the ordinary "cobbler's" wax quite destroyed the colouring of the yellows and greens. 
It was also necessary in some way to dress the silk with a waterproof coating to obviate the loss of colour to which flies tied with undressed body-silk are subject. The yellows particularly lose in this manner. After a good many experiments I hit upon a colourless wax, which fulfils both these conditions, and is moreover more convenient to manipulate than the ordinary cobbler's wax, which in cold weather becomes brittle and " chippy." A receipt for the colourless wax is appended :-

Receipt for Colourless Wax.-Burgundy pitch, I 20 grains ( $\frac{1}{4}$ of an oz.) ; white resin, 60 grains ; tallow, 20 grains. Having reduced the resin and pitch to a mixed powder and placed them in some clean receptacle (an egg-cup will be found very convenient), put them into an oven, and when quite melted add the tallow, stirring the whole thoroughly up together for several minutes. The wax, which when cold will be quite hard, will be ready for use in about twelve hours. The above quantities will make a lump of wax as large as a walnut.

The wax should be kept perfectly free from dust and dirt, and in using it for dressing the yellow flies, it is very desirable that the fingers of the tyer should also be quite clean.

For the body-silk of the brown fly the colourless wax over brown silk does not answer entirely, as the tint given by the brown silk is rather dead and " unfly-like." I find, however, that by waxing wery dark orange silk with ordinary cobbler's wax an excellent rich colour is obtained. The silk whilst frcsh waxcd should be drawn 
tightly between the finger and thumb; by this means the wax is almost removed from two sides of the silk, and massed on the other two sides, producing a mottled yellowy-brown appearance in the fly somewhat like that seen in the March brown and other principal brown varieties, as the stone-fly, great and lesser red spinner, dark mackerel, \&c., which are mottled with yellow or orange ribbings. The yellow and orange flies, on the contrary, as the cinnamon, yellow sally, fern, sand, and cowdung fly, are all either plain yellows or oranges, or if ribbed at all are ribbed with different tints of the same colours. The oak-fly is an exception.

With regard to the heads of flies, these can, on the above principle of tying, be made almost microscopic without any sacrifice of strength; but I advise the angler, notwithstanding, to have them dressed large. The heads of Trout-flies are usually made much too small-much smaller, that is, than they are in nature, and smaller therefore than is desirable; because it should be the aim of the fly-tyer rather to exaggerate than to diminish in the artificial imitation all the prominent features of the natural insect, so that on a quick glimpse the resemblance may be unmistakeable. This last observation applies also to the "whisks" or tails, in exaggerating which there is an additional advantage, inasmuch as the larger the whisk the better and straighter will the fly swim.

The following is the formulary for the three typical flies described :- 


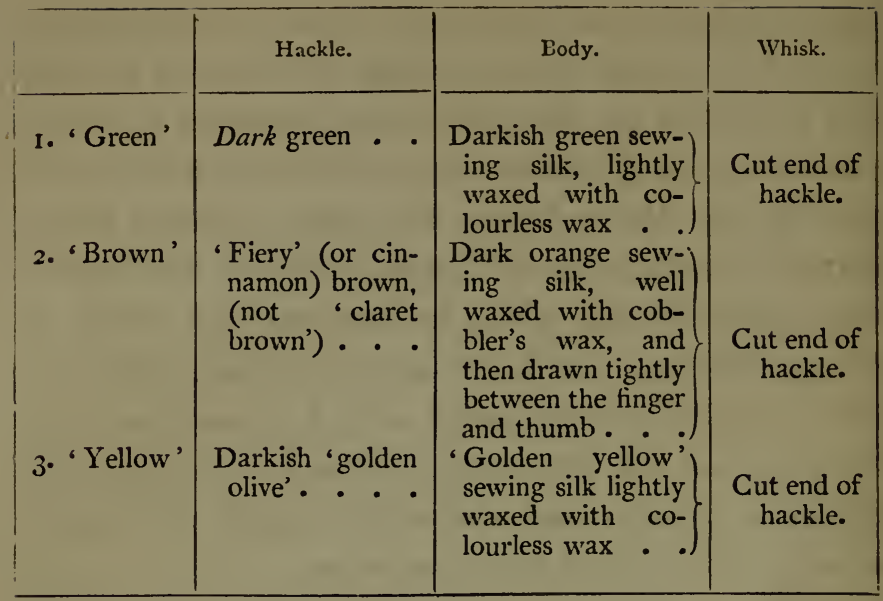

It is almost unnecessary to observe that the colour of a hackle can only be judged by holding it between the eye and the light-the position also in which it is perceived by the fish. The cinnamon or "fiery brown" hackle when thus examined becomes shot with smoky yellowish lights, and the golden olive with transparent golden yellows. The green hackle also, if properly dyed, should, when thus examined, assume a lighter and more liquid tint of green. Natural coloured hackles do not present these beautiful effects, and therefore for all flies hackles artificially stained are to be preferred. For small flies "neck" hackles are preferable to "saddle" hackles, as they are softer in the fibre, and thus show more movement in the water.

Floss silk will not answer at all for dressing these 
flies, as it loses all glossiness and strength of colour. For convenience in tying them several different thicknesses of sewing silk are requisite, from ordinary sewing silk-which is of the proper thickness for small flies-to silk of about the substance of holland thread, which is the size most suitable for lake flies.

All flies should be carried in a box, instead of being pressed together in a book, a process which robs them of half their elasticity and play of hackle, and to which they should never be subjected even for a moment. This is a most important point. Tackle makers think that the fly regains its full elasticity as soon as it is wet, but I have convinced myself by repeated practical experiments that this is not the case.

\section{Selection of Flies.}

\section{SIZE.}

It is a curious fact, but nevertheless an indisputable one, that the size of the flies to be used in any given river or lake generally depends, within certain limits, not upon the size of the fish, but upon the size of the water, modified by the condition of the wind and sun. There are occasional exceptions to this rule-as to most others -but in the absence of local knowledge or guidance, which on this point is often useful, the fisherman acting upon it will find himself right in nineteen cases out of twenty.

In most Trout streams, properly so called, in either 
portion of the United Kingdom, the best sizes of hooks are Nos. 2, 3, or 4, (vide plate), a larger or smaller size being used as the day is more or less dark or windy, or the water high or low. In the Derbyshire streams, No. I or 2 will generally be found the best sizes. Smaller hooks are sold in the tackle shops, but I have not included them in my patterns because I regard them as practically useless, No. I being small enough for every purpose usually required.

\section{COLOUR.}

In small rivers and streams I recommend the use of the "green," as the tail-fly, or stretcher; and the "brown," as the bob-fly, or dropper to begin with, both of course dressed small to suit the size of the water: if either fly does not appear to kill, substitute the yellow as the dropper, and the best of the others for the stretcher; in larger waters the same flies of a larger size.

In deep lagoon-like reaches of river water, with a breeze on them, and especially in Scotland or Ireland, I recommend commencing with the "yellow" as the dropper, and the "green" as the stretcher. If either of these flies does not kill substitute the "brown."

Local Anglcrs will probably, and that almost without an exception, tell the fly-fisher that no flies but local ones are of any use on their lakes or streams, but this opinion is usually based on a very slender experience, 
limited most likely to that gained on some half a dozen lakes or rivers in their own neighbourhood.

Local prejudices are, however, by no means confined to professional fishermen. Even first-rate amateur performers are often imbued with the notion that no flies but those they have been accustomed to consider the correct thing on particular rivers and streams will kill in them. I remember once fishing the most famous Trouting loch in Scotland, in company with two of her most celebrated (and justly celebrated) anglers, and when I showed them the flies I meant to use, they assured me that they "would never kill fish in Loch Leven!" At the end of the first day, however, my basket, which included seven Trout weighing I4lbs., was found to be heavier than both theirs. This result I attribute of course solely to the flies, not, be it well understood, to the fisherman.

I will not go so far as to say that there may not be exceptional occasions-or even exceptional rivers, though that I should much doubt-on which some local pattern of fly may not prove more killing than the three typical flies I recommend ; but I am quite satisfied that taking the average of waters and weathers, and the great saving of time in the avoidance of experimental changings of flies, my patterns-which have been tested frequently against the best local flies on half the principal Trouting waters in the British Islands-will kill more fish in the course of the year than any others at present generally known. 
FLY-RODS, LINES, HoOKs, \&c.

As regards fly-rods it is difficult to give any opinion upon a matter which is so much one of taste, and dependent to a great extent on the strength and height of the individual angler. As far as my experience goes, a twelve-foot rod inclined rather to stiffness thar to pliancy will be found the most generally efficient weapon. It is also convenient to have a hollow butt, so that one or two shorter tops-one for Minnow spinning, and one for worm-fishing-may be carried in it.

The single-handed fly-rod contained in the general rod described at page $5 \mathrm{I}$, will be found to answer the above description. A square ring of india-rubber slipped half way down the butt will throw off the rain-drippings, which would otherwise run down the rod on to the angler's hands and sleeves.

Full observations on the subject of Reels, Reel-lines, Gut-lines, and how to stain gut, hooks for flies, nets, \&c., are given in the preliminary chapters on tackle.

\section{Fishing with The DRy-Fly.}

The object of the dry-fly is evident from its name-it is made to float dry on the water like the natural insect, thus affording the solitary instance of the "formalist" or entomological theory being carried to its legitimate result. The peculiarities in the construction of the fly to enable it to fulfil this rôlc, are first its wings, which generally consist of the whole tops of feathers (mal- 
lard, generally), set nearly back to back, and pointing upwards and outwards; and secondly, its body, which is composed almost entirely of materials unabsorbent of water, such as mohair and hackles.

The method of using the dry-fly on the Stour and a few other rivers, where its use is best understood, is very peculiar. A large fish, say, is known to inhabit some particular hole or eddy. The spot is watched by the angler until he sees the fish rising, and then the fly is cast so as to fall a foot or two above him, and allowed to float (dry) passively over him. On the fly becoming wet, which happens after every cast, it is dried by being rapidly thrown to and fro, or "spread" in the air, when it is ready for another cast; but this is seldom made until the rise of a fish is seen, or his haunt known. Some fishermen who use the dry-fly consider it is not properly dried without a little crack or "flick" taking place at the end of the spread; but this "flick," though doubtless very artistic, often whips off the fly. A stiff rod with a tolerably pliant top is the best for the purpose. The dryfly being presented to the fish in the same way as the natural fly, is most killing when the particular natural fly imitated (which is commonly the May-fly) is on the water. Smaller flies are made, but it is found difficult in practice to "float" them; and, indeed, the whole process is cumbersome, and is only worth practising on rivers where the fish are very large and wary, or cannot be taken in any other way. 
Mr. Ogden, of Winchcomb Street, Cheltenham, is the most celebrated manufacturer of "dry-flies," of which he makes a speciality. I have now before me a fly of his that I have used several times, and which has survived a good deal of "flicking." It is still fit for work, and floats like thistledown.

\section{LAKE FLY-FISHING.}

Almost all the remarks already made on the principles of river Trout-fishing both as to the "How" and the "When," apply also to Trout-fishing in lakes. The case is different, however, as regards the "Where," and on this point a few observations may be offered.

The best spots for fly-fishing in lakes are usually outfalls of streams, rocky patches and banks, the edges of reed-beds, and generally the sloping shores at the point where, without being shallow, the water is not too deep for the bottom to be seen. The use of a boat is commonly a great advantage in lake fishing, as by its means not only can a greater range of water be fished, but it can be fished in a much shorter time. Moreover, such spots as the margins of reed-beds, and submerged banks, which are as stated usually amongst the best casts, can rarely De commanded from the shore, even with wading-a practice, by the way, which in lakes is apt to lead to awkward results, unless pursued with great care.

The boat should be allowed to drift before the wind, 
the flies being cast out in front and at the bow and stern, according to speed.

A ripple on the water is almost a sine quâ non in lakefishing, and a good curling breeze an advantage. When the water has been quite calm, however, I have sometimes caught fish by throwing the flies into the centre of the circle caused by a " rise."

\section{Selection of Flies.}

SIZE.

The considerations which regulate the size of flies to be used on any given lake are in many respects similar to those given under the head of River Fishing ; and on this point the opinion of a local practitioner may usually be taken with advantage. Loch flies, however, as a rule, are considerably larger than those applicable to streams; the sizes most commonly used varying from No. 7 to. No. Io (see frontispiece).

\section{COLOUR.}

For some reason which I have not succeeded in fathoming, the Yellow fly always seems to kill best in the position of dropper, or bob-fly, and the Green when employed as the stretcher, or tail-fly. The Brown can be used in either position; but I have found it best, especially on new waters, to try the Yellow and Green first, reserving the Brown as a change in case of necessity..

For lake fishing a light double-handed rod from 
I4 to 16 feet long will be found most convenient, as, whether the angler is fishing from the shore or the boat, it enables him to work his flies better than a shorter rod, and to command a greater reach of water. The general rod described in the chapter on Tackle embraces a double-handed fly-rod designed for this purpose.

\section{Fishing With Natural Flies. \\ “CREEPER" AND STONE-FLY FISHING.}

Creeper and stone-fly fishing is confined to the Border and Lowland Scotch rivers; at least, I never remember to have met with it elsewhere, and it may therefore be regarded as a branch of the art rather local than general. The creeper is the larva of the stone-fly (Scottice Mayfly), in which condition it passes most of the winter and spring months, living under stones in shallow water, from whence it may generally be readily obtained in quantities sufficient for angling purposes. It will live for a day in any perforated can or bait-box, even if kept in the pocket, and for a longer time in a little water. The mode of baiting and using the creeper is as follows. Put the upper hook through the shoulder, and the lower hook through the tail of the creeper, so that it may hang straight on the line; when baited, use it precisely in the same manner as the worm described in the next chapter, always selecting rapid rather than still parts of the stream. The bright weather and low clear water, which 
are best for worm fishing, will also be found most favourable for the creeper. The stone-fly usually remains in its larval or "creeper" condition until the middle of May, and from early in April until this time heavy baskets may oíten be made with it. When in season, the creeper is commonly from an inch to an inch and a quarter long.

The rod, line, and hooks recommended for wormfishing, and described in the following chapter, omitting the shot or sinkers, and setting the hooks a little closer together, will be found the best tackle for creeper-fishing.

About the middle of May the creeper changes from the larval into the fly state, casting its tortoiseshelllike covering, and unsheathing its wings, of which, however, it makes but little use. Mr. Stewart, whose excellent chapter on the subject should be studied by all Border anglers, considers that the fly is even more deadly than the creeper. He advocates the use of two flies as the bait. Except, however, on very large rivers like the Tweed, I confess I think the large one is to be preferred, both because it is more easily put on and kept on the hooks, and because it presents a more natural appearance in the water. The fly is nearly the same length as the creeper, and the tackle used for one should be used for the other. In fact, when the creepers are changing the angler will often find it convenient to fish indiscriminately with either the one or the other. 
Trout take the stone-fly best under water, and close to the edges of the stream or pool, even under hollow banks, if the fly can be got there. This point is laid much stress on by Border anglers, and with good reason, inasmuch as the natural spots to find the fly are close to the banks, from which they are washed; and it is here consequently that the Trout come to look for them. A dark full water is more favourable for the effective use of the stone-fly than one that is low and clear; but in both states good baskets may be made with it. The flies should be collected in a box the night or early morning before they are to be used; the best places for finding them being under the stones above, but near the water's edge; and where most cast-off shells are seen, the fly will probably be found to be most numerous.

Colonel Campbell tells me that he has had great success on the Border streams, with this fly used with blow-line tackle (as described on the next page).

A method of natural-fly fishing is also much practised on the Peterel, and doubtless on many other neighbouring streams, in which two flies-the generic names of which I could not ascertain-are used upon a small double hook.

The season for stone-fly fishing begins about the middle of May, and ends about the middle of June.

\section{BLOW-LINE FISHING WITH THE MAY-FLY.}

Besides the fishing above described the only really effective method of using the natural fly for Trout is 
with the "blow-line;" and the place to see blow-line fishing is in the Lakes of Westmeath. Indeed, this beautiful chain of waters seems to be the natural habitat of the art. Each lake in its turn, as the fly appears on it, becomes for a few days a centre of attraction to the angling community, and many a boat which, as Pat says, is only safe provided you do not "cough or snaze," is then dragged from her moorings-perhaps at the bottom of the lake-and pressed into the service. The art of blow-line fishing, though in its principles exceedingly simple, demands much nicety of execution in practice, and, as indeed its name implies, it cannot be pursued at all without the assistance of that most inconstant element, the wind. Weather, however, proving propitious, the tackle is easily adjusted. A skein of floss silk prepared for the purpose, and attached to the end of a light running-line, is substituted, so far as the actual casting is concerned, for the "reel-line," and to this, instead of the ordinary flycollar, is fastened a single small hook whipped on a strand of fine gut. The hook is baited with a Mayfly, and as the boat drifts the wind carries out the floss silk, which ought to be so managed by the aid of hand and rod that only the hook and fly should actually touch the water. Near the edges of the reeds will usually be found the greatest quantity of Ephemerida, and as a corollary the greatest number of Trout. The exact time for this fishing varies a little, as the spring 
has been cold or genial; and the several lakes vary also inter se, which is a great convenience to the fisherman; but from the middle to the end of May is commonly about the time. The Westmeath lakes, when the fly "is up," will well repay a visit, as the fish, which are at this time in the highest condition, run from two to five, and sometimes ten pounds, and take the natural fly freely; and if the angler puts Dr. Peard's charming little book, "A Year of Liberty," into his portmanteau, he will need no abler or more agreeable guide.

An analogous system to that above described is pursued occasionally on some streams in England; but on others it is strictly prohibited, and on many hardly considered fair fishing. The circumstances of the two cases, however, are entirely different. 


\section{CHAPTER IX.}

\section{W O R M - F I S H I N G.}

Modern and old systems contrasted. Appropriate times and places for worm-fishing. Existing tackles; the theory of a perfect worm tackle New tackle described-Suitable for river-bottom fishing generally? Trace. Best worms: management of bait, \&c.

For the present scientific method of worm-fishing for Trout we are chiefiy indebted to Mr. Stoddart and Mr. Stewart. This branch of the art was, until late years, principally confined to rivers in a state of partial floodrising or falling. The performer, armed with a short stiff rod and extra coarse tackle, walked down the river or stream, fishing the pools and likely runs in front of him, and hoisting out bodily any unlucky fish which the purblinding condition of its own element was mainly instrumental in transferring to ours. Now all this is changed, and worm-fishing for Trout is a branch of the gentle art requiring much nicety and skill in its successful performance, and rapidly becoming second only to fly-fishing and spinning in the estimation of anglers.

We have learnt that the real time for the use of the 
worm is not when rivers are swollen or swelling, but when they are low and bright,-June and July in Scotland, and July and August in England, being the two best months-at the time, in short, when fly-fishing is, from the nature of the case, least attractive and most unremunerative. Instead of short rods and coarse tackle, long, light weapons, and the very finest gut, are in requisition, with which the worm-fisher enters the river, and wading as nearly up the middle as he can, fishes before him the swift runs and shallows, and the broad bed of the stream itself; often going far towards filling his creel without ever setting foot on the bank. Wormfishing, as above described, is certainly a very deadlyprobably the most deadly - mode of Trout fishing generally sanctioned by the canons of the art; and it is not at all to be wondered at that on some much-frequented waters its use is prohibited.

But there are thousands of miles of river and stream in the wilds of Ireland and Scotland, and some few still in England, where from year's end to year's end the fly of the angler rarely falls, and on which the breed of Trout is only improved by a little thinning out now and then. Here is the legitimate domain of the worm-fisher, and thus pursued worm-fishing is a sport which need fear comparison with none.

As regards the tackle to be used in worm-fishing, I cannot better explain the views which I would commend to the reader's consideration than by quoting a 
letter which I addressed to a contemporary periodical in January, I 867 :-

\section{"NEIV WORM TACKLE FOR TROUT.}

"I see in your last number a letter from the Prince de Vismes, asking me to explain through your columns the principle of the two-hook Trout worm tackle, to which I incidentally referred in a recent communication on the subject of the relative advantages of the various bends of hooks. It gives me much pleasure to comply with this request.

"The easiest way of explaining the form of the tackle will be by a diagram, but before doing this it may perhaps be desirable to preface my remarks by a few observations on the views hitherto prevailing on the subject of Trout worm tackle.

"With one exception, no writer on fishing that I an acquainted with has ever suggested the use of more than a single hook. On looking through the modern school of angling authors, I find the following recommendations and instructions on the subject:-Bowlker, in his 'Art of Angling,' recommends a single No. 5 or No. 6 hook ; Mr. Stoddart advises, in his 'Angler's Companion,' single hooks, sizes No. IO, I I, or I2, 'according to the dimensions of the stream, its condition, and the kind of Trout inhabiting it.' Mr. Bailey, in his 'Angler's Instructor,' suggests a single No. 7 ; Otter's 'Modern Angler,' a No. 5 ; 'Glenfin' ('The Fishing Rod, and How to Use It,') a 6 or 7 ; 'Ephemera,' Hewett Wheatley, and some other authors, either simply recommend 'a single hook,' without naming the size, or omit the question altogether whilst Mr. Moffat, whose 'Secrets 
of Angling' burst upon the world since all the foregoing works appeared, of course hits upon a combination the very worst possible, and one which would be tolerably certain to lose three out of every four fish run-i.e., one small hook, extra fine in the wire! The 'member for Finsbury,' as this author, with the detestable slang which some modern writers appear to think funny, calls the Trout, would certainly let Mr. Moffat into at least one angling secret with which he is at present unacquainted, if he were to appear on the banks of the Tweed, or the Spean, armed with such an apparatus.

"It will thus be seen that a 'single hook' for Trout worm-fishing has been hitherto universally recommended by angling authorities, with, as

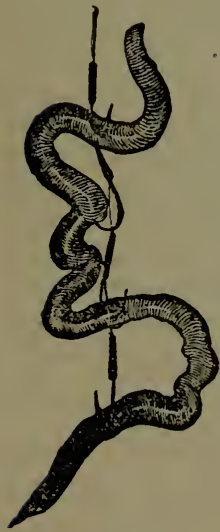

4-hook Tackle (Baited). I before stated, a solitary exception, and that is Mr. Stewart, who, in his 'Practical Angler,' boldly deviates from the beaten track, and gives a diagram (of which, for the sake of clearness, a facsimile is appended) of a tackle composed of four small hooks, in lieu of the conventional single large one. I give Mr. Stewart the greatest credit for the originality of this idea, which belongs to him alone; at the same time, I am not surprised at its proving, as he himself admits, only a modified success. Mr. Stewart says that with this tackle he found he could kill larger fish, but fewer in number, than with the single hook, and that this experience was confirmed by others. He attributes, and I have no doubt correctly, the diminution in 
the numbers of fish run, primarily to the circumstance of its being impossible properly to conceal so large a number of hooks in a single worm, and to their being consequently seen by the fish. This was the principal drawback to the four-hook tackle. As a minor inconvenience, Mr. Stewart also mentions that, from the number of hooks often fixed in the fish's mouth when landed, a certain waste of time necessarily occurred.

"These being the incidental disadvantages of $\mathrm{Mr}$. Stewart's plan, its advantages were, (I) that the worm was more quickly baited than with the single hook, (2) that it lived much longer-with the large single hook it dies almost directly-(3) that it presented a much more natural appearance to the fish, and (4) that, owing to the superior penetrating tendency of small over large hooks, much fewer fish escaped after being once hooked, whilst it became possible to use the fines could not be safely done with large heavy hooks. This of itself is an advantage the importance of which can hardly be over-estimated in Trout fishing in clear streams.

"As regards the other point-the killing powers-my own experience of the tackle was that when fishing properly $u p$ stream, and with a shortish line, hardiy any fish escaped at ail, whilst with the large single hook, I think the experience of most of my brother anglers will bear me out when I say that fully 50 per cent. of runs were 'missed.' On the other hand, I fully recognised the practical force of the objections mentioned by Mr. Stewart, and accordingly I endeavoured to construct a tackle similar in principle but different in detail, which should combine all the foregoing advantages, without 
being open to the drawbacks. After various experiments, I arrived at the conclusion that a tackle consisting of two hooks instead of four, and these a trifle larger and thicker in the wire, fulfilled the required conditions, and also combined one or two material improvements in other points. Annexed is a diagram of this tackle,
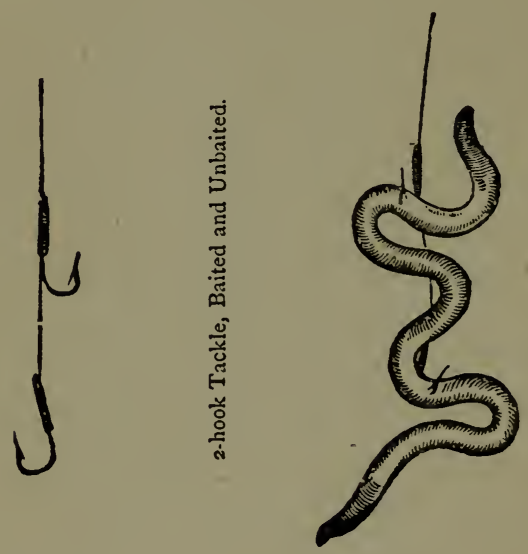

baited and unbaited. The size of the hooks, \&c., can be varied slightly according to the size of the stream, or of the worms.

The worm is here shown in a curled-up position in order to contrast more readily with Mr. Stewart's tackle, but in actual work it is recommended that the worm should, on the contrary, hang as straight as possible on the hooks, which gives it a more natural appearance, and is in every way much the more killing method. 
"The great advantages, in several points, of Mr. Stewart's tackle over the old large single hook have been already explained. The following are the advantages which I believe will be found to belong to the two-hook over the four-hook tackle:-(I.) It is baited in less than half the time. (2.) The worm lives much longer. (3.) Its appearance is much more natural and lively. (4.) The hooks are comparatively unseen. (5.) They are "disgorged" in half the time.

"In killing powers I do not think that there is any appreciable difference, but if there is, the extra size of hook and strength of wire which can be employed in the two-hook tackle ought to give it the advantage. It is also, of course, more easily made.

"In order to bait this tackle, I put the upper hook quite through the worm, laterally, about half an inch below the head, just above the knot, and the second hook similarly about an inch below it, according to the size of the worm, as shown in the engraving.

"It will be found that the worm, especially when unscoured, is very apt to wriggle itself off the hooks, or into pieces, and the most effectual remedy for this inconvenience, and one which a very little practice will make easy, is to put the two hooks through the worm as expeditiously as possible, and then drop the worm instantly into the water; the cold partially numbs it, and prevents it twisting off.

"Thus much as to worm-fishing for Trout. I am by 
no means clear, however, that this tackle will not be found equally advantageous in all kinds of worm-fishing, either with a float, as for Barbel, Bream, Perch, \&c., and especially in running water. If Trout, which are in many respects a very shy fish, will take it readily in the finest and brightest water, there seems to be no reason why other and bolder fish should not do so; and if they will, I cannot but think, for the reasons above mentioned, that it must entirely supersede the present single-hook system."

The trace for worm tackle should consist of about two yards of the finest stained gut; one or two shot, according to the depth and rapidity of the stream, being placed on the line some 14 inches above the hooks. The object of this is to weight the bait, so as to bring it close to or touching the bottom without checking or sticking fast; but in broad shallow water no sinkers at all will be found necessary. A longish rod is most convenient for the purpose.

With regard to baits, any weil-scoured worms which are not much larger nor smaller than that represented in the woodcut will do ; but for worm-fishing for Trout, as for most other species of fresh-water fish, the brandling, or dunghill worm, is distinctly the best,--probably owing to its peculiar pungent smell and red colour. For the purpose of rapid baiting the most convenient manner of carrying the worms is in a wide-mouthed bag attached to the button-hole. A worm that is disfigured or dead 
should never be kept on the hooks. This is perhaps the most important point of all. The name of the worm indicates where it can best be found. Before use it should, if possible, be placed in a damp moss for two or three days.

After being cast up stream as far as the length of rod and line will conveniently admit, the bait should be allowed to be carried back with the current nearly to the angler's feet. If in its passage the line comes to a suspicious stop, the nature of which is not obvious, or if a fish evidently takes the bait, the line should be allowed to remain for three or four seconds motionless, when the angler should strike,-not very hard, as the hooks are small,-but still firmly and decidedly.

In worm-fishing for Trout, perhaps more than in any other kind of fishing, the short-handled pocket net described at page 64 will be found an invaluable auxiliary. 


\section{CHAPTER X.}

RIVER AND LAKE MINNOW-SPINNING FOR TROUT.

Spinning with the natural bait.-The essentials of a perfect minnow tackle; how to be combined in practice; a new minnow tackle described. Artificial baits. New metal minnow described: Lake Spinning for Trout-The Great Lake Trout ; how, when, and where to fish for ; tackle. Lake-Spinning for Brown Trout. Best mode of fishing; tackle, and baits. Thames Trout-fishing, with the spinning bait and with fly. Decrease of Thames Trout.

\section{SPINNING IVITH THE NATURAL BaIT}

BEFORE dealing with the question of how to spin with the Minnow, a preliminary consideration is the tackle most suitable for the purpose. In this, in fact, as in most other works of fishing, the tackle is really the most essential part of the matter, so far as the angling instruction is concerned; one reason amongst many being that forms of tackle can be readily illustrated and conveyed by written descriptions, whereas skill and experience, except in their results, cannot.

What, then, is the best Minnow tackle?

In order that we may arrive at a satisfactory answer to this question, we must first ascertain what are the 


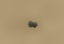

\section{.}




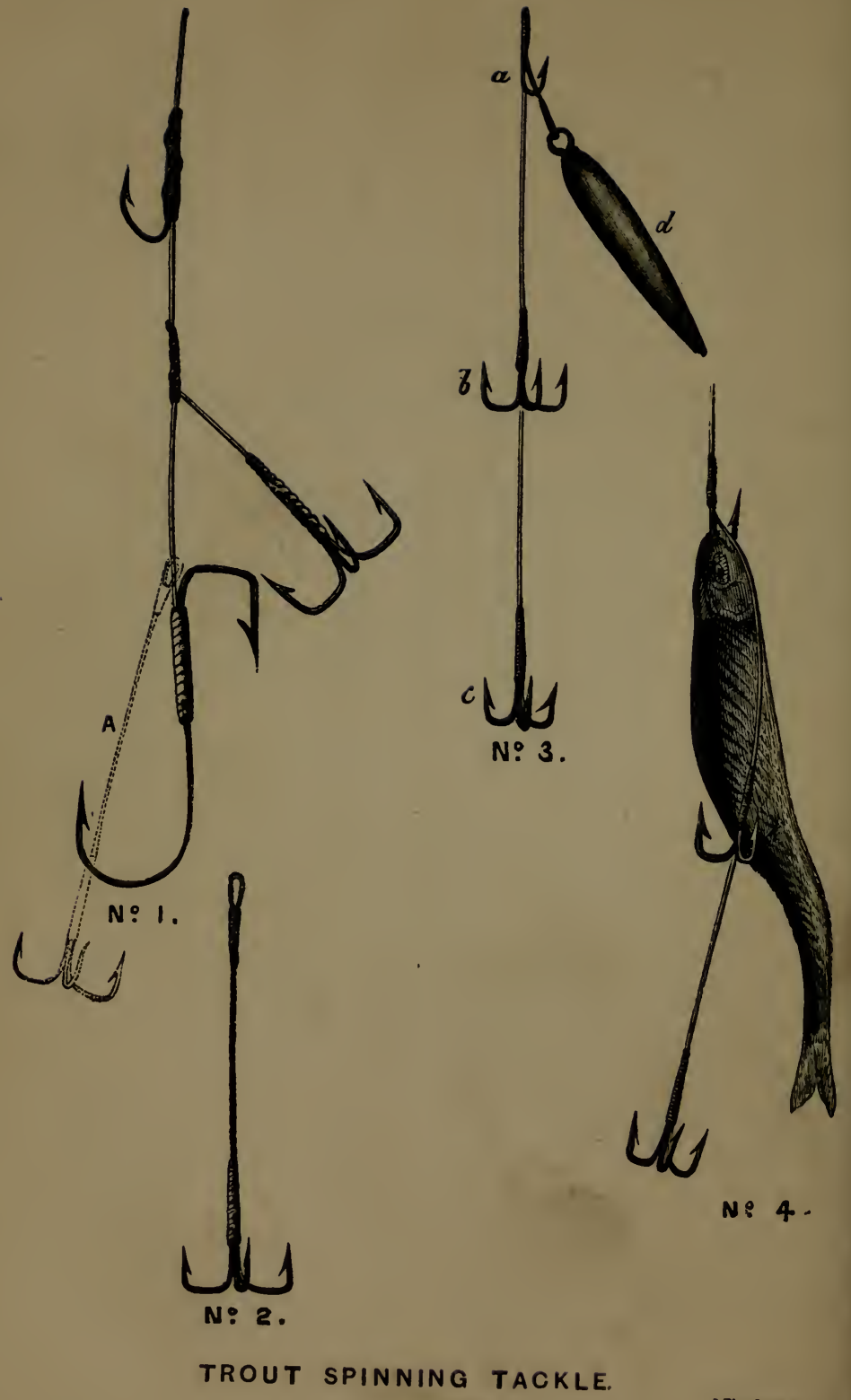

[To faoe p. 115 
TROUT RIVER AND LAKE MINNOIV-SPINNING. II5

qualities essential in such a tackle-I mean those which all spinners would endeavour to combine if they could. They may, I think, be epitomized thus :-

I. As to hooks: (A) an arrangement which will give a brilliant spin to the bait; (B) which will most certainly hook any fish that takes it; (C) and which will least often let him escape afterwards

2. A trace fine, strong, and clear of ali encumbrances.

3. A lead so placed as to sink with the greatest rapidity and least disturbance or show in the water.

4. The utmost simplicity of application in the whole tackle.

That these are the essentials of a perfect Minnow tackle, I think no experienced Minnow-spinner will probably dispute, I therefore assume their concurrence so far, and at once direct attention to the diagram of the Tackle in which I believe them to be realized (figure 3 of Plate).

In this figure $a$ represents the lip-hook (whipped to the main link and not moveable); $b$, a fixed triangle, one hook of which is to be fastened through the back of the Minnow ; $c$, a flying triangle hanging loose below its tail ; $d$, a lead or sinker attached on to the shank of the lip-hook, and lying in the belly of the Minnow when baited. 
Directions for Baiting.-Having killed the Minnow, push the lead well down into its belly; then pass the lip-hook through both its lips, the upper lip first, and lastly insert one hook of the triangle $(b)$ through its back, just below the back fin, so as to crook or bend the body sufficiently to produce a brilliant spin. Figure 4 shows the position of the hooks, \&c., when baited.

That this arrangement of hooks fulfils the primary condition of "spinning," is of course capable only of ocular and not of verbal demonstration, but I can only say that when properly baited (and nothing is easier than to bait it properly), I have never seen any tackle which was in this respect superior to it. With regard to its hooking and holding qualities, these depend upon simple mechanical considerations which are at once obvious to the experienced eye, and the Minnow-spinner who has followed the arguments in the preliminary chapters on the relative powers of flying versus fixed triangles, will probably not have much hesitation in coming to an affirmative conclusion.

(2.) As to the arrangement of Lead, and (3) general Fineness: The lead, which lies in the bait's belly, not only puts the weight exactly in the place where it is most wanted, but gets rid of the clumsy and complicated "nose cap" with which Hawker's (originally Salter's) spinning flight and other modifications of it are disfigured.

Several sizes of the tackle are necessary to meet variations in the size of the Minnows used.

The trace should consist simply of 4 or 5 feet of fine 
picked stained gut, with a small double swvivel at the end, to form the junction between the trace and the reel-line. This tackle is principally intended to be used in streams and small rivers which can be commanded by the rod with a line of the same length, or where the angler can wade. It is also well suited for trailing in lochs where very small baits and fine tackle are requisite; but if used for the latter purpose, as in Thames Trout-fishing-viz., by throwing out and drawing in, a lead like that described at p. 20 will have to be added, to prevent the line kinking.

\section{ARtificial Baits.}

Theartificial substitutes for Minnowsare numerous, from the graceful "nymphs" and "water-witches" of Hewett Wheatley, to the "kill-devils" and "Satanic tadpoles" of contemporary nomenclators. As compared with the natural Minnow, baited and used as above described, I am satisfied that there is no artificial imitation hitherto made public which is worth mentioning. Hewett Wheatley, who in the last generation gave more attention to this particular subject than any other writer, comes to an opposite conclusion; but only for one reason-namely, that owing to the imperfect hooking powers of the natural Minnow tackles then in use, and the comparative perfection in this respect of his own artificial baits, the former missed so many more fish than the latter. This reason no longer exists, as the arrangement of 
hooks in the natural Minnow tackle figured in this chapter, is, both practically and theoretically, nearly perfect. Therefore, my advice is always to use the natural Minnow when obtainable.

But although the fish killed thus will be both more nu-

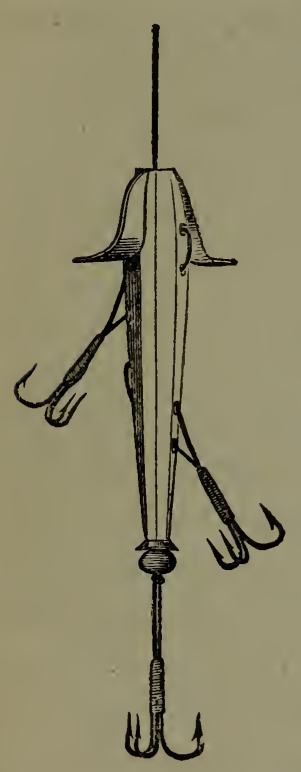
merous and larger than with the artificial Minnow, it frequently happens that natural bait is not to be procured; and when this is the case an artificial bait may be advantageously used.

Up to the present time no artificial bait has been brought out equal to the simple brass Minnow of Mr. Wheatley. The best of these I have adopted as a basis for the Minnow figured in the engraving: the latter has, however, been altered, and as I think considerably im. proved in several important respects both as to shape and "rig." It is madehexagonal or octagonal instead of round, so that the sides and angles catching the light gain an additional brilliancy and glitter in the water; and one-half of the Minnow is coloured a bright metallic green, to represent the back of the Minnow. This Minnow is also made in white metal as well as in brass, so as to give a"more perfect imitation of the white belly of a real fish. The round protuberance at the 
tail of the Minnow is a glass bead slid down tightly on to a knot in the gut, which is thickened by lapping at: the point to make it fit close. The bead thus prevents the friction of the Minnow fraying the gut below. TheMinnow can be so adjusted that the trace and tailhooks may either spin with it, or remain stationary. In the former case, the gut, when it passes through the Minnow, must be thickened by lapping round it, so that it may fit close.

The trace for this artificial Minnow, and the mode of using it, are identical with those already described for the natural bait. The trace is, however, only suitable for "Minnow fishing," properly so called, and not for spinning. in large lakes or rivers.

A long lightish stiff rod, with stiff rings, is most convenient for Minnow-spinning. The rod embraced in the general rod described at p. $5 \mathrm{I}$, and similar to that used in Trout worm-fishing, but with a somewhat stiffer top, will answer the purpose well.

In Minnow fishing a small sharp gaff is more convenient than a net, because the hooks are very apt to get entangled in the meshes, and not unfrequently get broken with the struggles of the fish.

\section{LAKE SPINNING FOR TROUT.}

There are two species of non-migratory Trout: one, the common Brown Trout (Salmo fario), to be found in almost all the considerable lochs and pools in Scotland 
and Ireland, and in many of those of England, especially of Cumberland and Westmoreland ; the other, the great Lake Trout (Salmo ferox), an inhabitant principally of the larger and deeper waters. In such lakes it is to be found distributed over almost the whole of Scotland and Ireland. It occurs, to my knowledge, in Lochs Awe, Ericht, Lochy, Garry, and Laggan, and has been recognised in Loch Shin, in Lochs Loyal and Assynt, and amongst the Orkney and Shetland lakes. In Ireland it appears as an inhabitant of all the best known and largest lakes, as, for example, Loughs Mask, Erne, Melvin, Corrib, and Neagh; and it is the Ulswater Trout and Grey Trout also of the English lake districts. The habits as well as the size of the two species are somewhat different ; the common Brown Trout being caught, as a rule, under five pounds in weight, and being principally a day-feeder; whilst the great Lake Trout usually averages from five to fifteen pounds in weight, and feeds principally at night.

To begin with the great Lake Trout:-The rod, reel, line, and trace recommended for Pike-spinning, are also suited to this method of fishing ; as the great Lake Trout is one of the most powerful fish that swims, and in his manner of running at the bait and showing fight, is aptly described by his specific name-Forox. As, however, the Trout is a quicker sighted fish than the Pike, another foot or two of stained gimp or gut should be added to the trace between the lead and the flight. The latter should be 


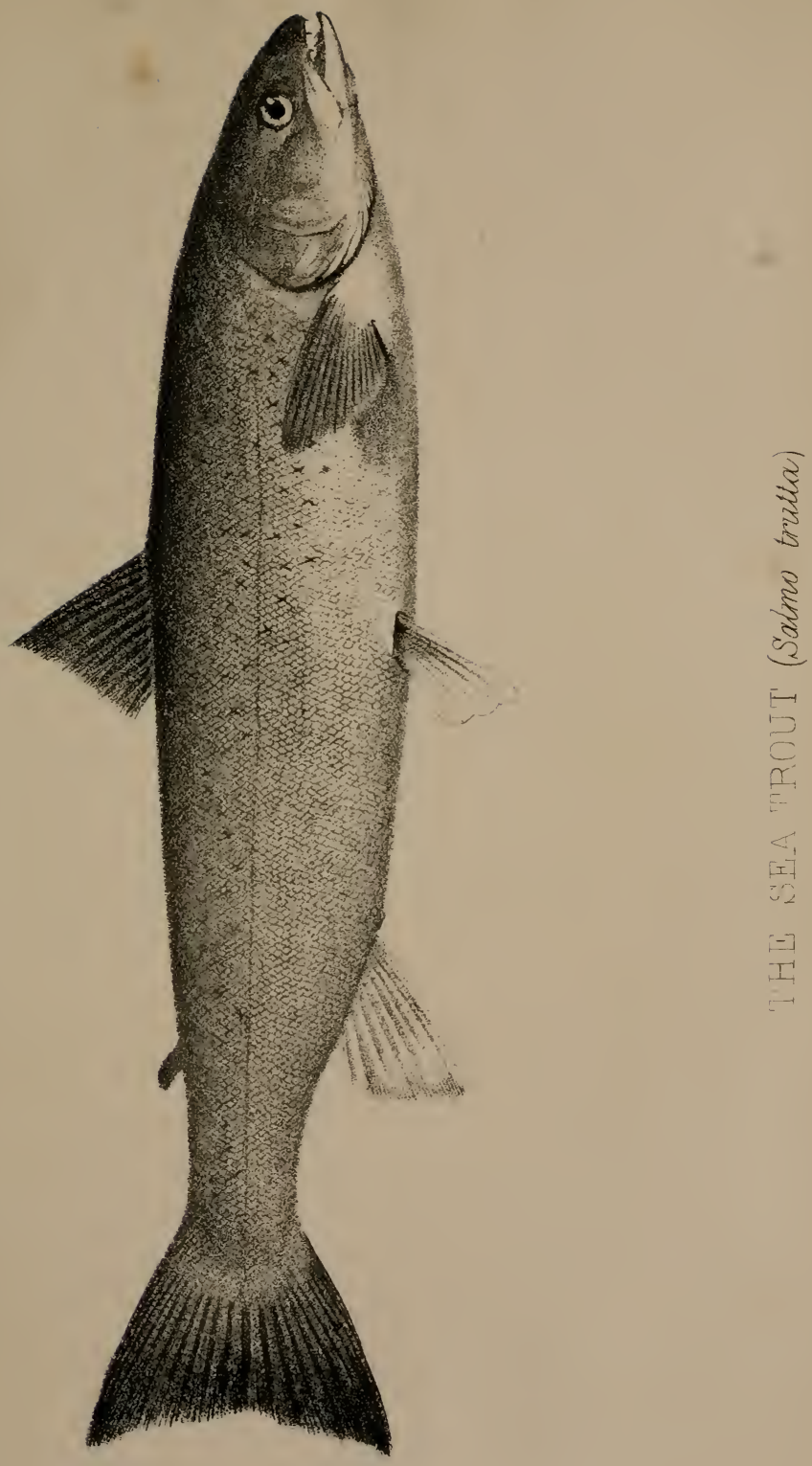



TROUT RIVER AND LAKE MINNOW-SPINNING. I2I

selected according to the size of the bait used. For my own part I have always given the preference to small rather than large baits, and the flight of hooks recommended for Thames Trout-spinning (fig. I, Plate, p. I I6), baited with a small Trout, will commonly be found the most killing bait and tackle. (For directions as to baiting, see chapter on Pike-spinning.) Although the tackle is this similar, the mode of using it differs entirely: as a rule, in spinning for Trout or Pike in rivers, the bait is worked by the movement of the hand and rod combined, the line being drawn in at each cast; in lake-spinning, on the contrary, the bait is almost invariably trailed behind the boat, the rod doing the work alone.

The secret of success in spinning for the great Lake Trout lies principally in four points-time, depth, speed, and place, thus-

Time.-As a rule, begin fishing at the time when other people are lecving off-that is, about six o'clock P.M. From this hour until midnight Lake Trout may be caught.

Depth.-Instead of weighting the tackle to spin the bait at some 3 feet from the surfacc, lead it so as to sink to within about the same distance from the bottom, be the depth what it may. Both for this purpose, and in order to keep the bait at a distance from the boat, it is almost indispensable that from 40 to 60 yards of line should be let out from the reel.

Specd.-Let the boat be rowed slowuly, rather than 
at a brisk, lively pace. A large Lake Trout will seldom trouble himself to follow a bait that is moving fast away from him; consequently the bait must possess the speciality of spinning, at all events moderately well, or it will not spin at all.

Place.-The place to trail over is where darkness and light seem to meet in the water-that is, where the bank begins to shelve rapidly, say at a depth of from 9 to 15 or 20 feet, according to the nature of the basin : a much greater or much less depth is useless. This is a rather important point, as thereupon it depends mainly whether the bait is ever seen by the fish it is wished to catch.

The food of the Lake Trout consists of small fish. These are not to be found in any great depths of water, but, on the contrary, on the sloping shores of the lake, up which therefore the Trout naturally comes at feeding time in search of them, stopping short of the shallows.

The Ferox is himself poor eating, but shows magnificent sport, and fights like a bull-dog.

With regard to the ordinary brown Lake Trout, though they may not unfrequently be taken at night when trolling for the Ferox, they are rather day than nightfeeders, and usually take best before noon.

In very large waters, where the size of the Trout is in keeping with that of the lake, the tackle and bait above described will answer every purpose. In smaller waters, however, and under ordinary circumstances, a 
finer trace and flight, though of the same pattern as Fig. I, and smaller baits should be used. The trace in this case should be constructed with two yards of stout, round, stained gut between the lead and the flight. If as small a bait as a Minnow, or very small loach-an excellent bait-is used, the same trace and lead, but the flight recommended for Trout-spinning in streams. (fig. 3, Plate, p. I 6 ) must be substituted.

In every other respect,- - that is to say, except in time, tackle, and size of bait,-there is no difference in principle or practice between lake trolling for Brown Trout and for great Lake Trougt.

Loach-or more accurately "stone loach" - can generally be caught by wading up a shallow burn, armed with a fork, and turning over the stones. The loach, which has an ostrich-like habit of thinking its body hidden when its head is, permits itself to be "speared" without much difficulty.

In all sorts of spinning, whether in lake or river, a good breeze is usually an advantage. In the case of very large sheets of water, I have, however, on more than one occasion, made very good baskets of Brown Trout in a dead calm, and with a bright sun over head.

\section{ARtificial Baits.}

No artificial bait with which I am acquainted is nearly so good for lake trolling as a natural one. The spoon 
appears to have lost for Brocon Trout what little attraction it ever possessed. The best-or more accurately the least bad-artificial bait that I know is one I had made a year or two ago with tin, and mother-of-pearl on each side, made exactly to imitate a Bleak in size, shape, and colour. The spin was given by the tail, which was crooked, forming the continuation of the centre piece.

\section{Thames Trout-Spinning.}

Spinning for Thames Trout is probably, judged by the standard of difficulty, the highest branch in this department of fishing. Amongst the best localities for Thames Trout may be mentioned Weybridge, Sunbury, Penton Hook, the Old Windsor Water, Marlow Weir, and some deep pools above Oxford. In the vicinity of Weybridge very few fish were killed during the last season, though some of the keenest and most successful Trout fishers reside in the neighbourhood, and devote much time and patience to the pursuit. I hardly know to what to attribute the falling off in the take of Thames Trout of late years, notwithstanding the efforts made by the Thames Angling Preservation Society for increasing the breed and stocking the water. It is certain, however, that such a falling off has actually taken place, and of the Thames and its quondam leviathans, it may now be said, with only too much 
TROUT RIVER AND LAKE MINNOW-SPINNING. I25

truth-apparcnt rari nantes in gurgite vasto-not only they are not caught, but they are not seen. Fifteen years ago, when the Marlow Fishing Association was in its zenith, I remember that one of its most prominent members thought nothing of taking two or three goodsized Thames Trout in an April morning. Thegentleman in question, Mr. H. R. Francis, was certainly one of the most accomplished anglers who ever threw fly or bait in the Thames; but there are many first-rate spinners and fly-fishers still to be found occasionally in their old haunts, and none of them would, I think, be sanguine enough to anticipate such'a basket for the Ist of April, I 870. The same number of fish per week would now be a good take for any one. The lower weirs and pools have fared no better, and yet the capabilities of the river are precisely the same now as they were then. Nor does "over fishing" explain the deficiency, because there are now, and always must have been, more Trout bred or turned.into the Thames every year than the water can feed. I confess I am perplexed, and when a disease cannot be diagnosed-as doctors phrase it-it is very difficult to prescribe for the patient. There are, however, one or two points in which I think there can be no doubt that the Thames Angling Preservation Society might sensibly improve the Trout fishing. At present, when the stock Trout are turned in at the weirs, they have no proper "hides" or resting-places except the weir holes themselves, and are probably, in the vast 
majority of cases, swept away by the stream, and carried into unsuitable, perhaps Pikey, waters. I would place in the gravelly streams and shallow waters below the weirs a considerable number of blocks of stone or bricks - say about a foot high; and these blocks scattered over the bottom would afford some protection to the fish, and some inducement to them to remain where they were placed, and where they could be found again. As the weirs and the shallows below them are quite out of the course of heavy navigation, no practical inconvenience would be felt on that score. Another point is to abolish entirely all "set" and night-lines. Under the pretence of catching eels, these lines are now constantly fishing some of the best spawning grounds in the Thames, and there can be little doubt that Trout are frequently killed by them. If simultaneously with this prohibition the setting of eel-pots was sanctioned, the exchange would be hailed as a boon by the fishermen, the Trou? would be safe, and a quantity of useful food now lost to every one secured.

Whilst referring to the Thames and its regulations, another point suggests itself, with regard to which some steps will have to be taken before long. I allude to the question of the supply of baits for Pike-fishing. A very small casting-net is now only allowed to be used, and this, except in shallow water, is next to useless. Baits, however, must be got if the fishermen are to get their livelihood, or visitors their day's 
fishing; and consequentiy great has been the expense to which the former have been put to obtain the necessary supplies, frequently from distant places. I know in this neighbourhood (Weybridge) one fisherman who alone was obliged to obtain during the past season $23 \frac{1}{2}$ dozen of bait from Farlow and Bowness, of London, at an expense considerably exceeding a shilling the dozen ; and this too when the river is really swarming with small fish of every description. The plan I would propose is this (of course without interfering with the cast-nets now allowed):-Let it be a portion of the duty of the wholly paid bailiffs to catch and keep a proper supply of bait; and let them supply them to the fishermen or other persons at, say, $\sigma d$. per dozen. This will obviate all fear of poaching, the fishermen will get a proper supply of bait, and the Thames Angling Protection Society will reap an income which will go far towards paying the cost of the staff of . keepers. But this is a digression. To return to Troutfishing.

The rod, reel, and line recommended for Pike-spinning will answer every purpose in spinning for Thames Trout.

The trace and flight should also be similar in construction; the material of the trace, however, in all cases being single gut, and made up "finer" than when used for Pike. The lead should also be lighter, to correspond with the bait.

In the engraving at p. 116 , a diagram (Fig. $I$ ) is given 
of the size of flight which will generally be found most suitable for Trout on the Thames. It is also a very useful flight for Pike in hot summer weather when the water is low and bright.

Directions for baiting are given in the chapter on Pike-spinning.

Unlike Jack, Trout are very frequently in the habit of "taking short," as the puntsmen phrase it-that is, seizing the bait by the tail instead of by the head, or from laziness or shyness making their dash a little behind rather than before it. In order to meet this peculiarity, and to render the killing powers of the above flight as deadly in the case of Trout as they are in that of Pike, I use for Trout-spinning an additional flying triangle, tied on a separate link of twisted gut (see Engraving, fig. 2), which can at pleasure be attached to or disengaged from the ordinary flight by being passed over the tail-hook from the point. This triangle flies loose from the bait in the position indicated by the dotted outline A (fig. I), and will be found to act as a powerful argument against any sudden change of mind or loss of appetite on the part of a pursuing Trout. The size of the hooks, length of gut, \&c., drawn in the engraving, are of the proper proportion for a flight of the size shown. They should be enlarged or diminished proportionably as flights of a larger or smaller size are used. Elasticity, or it may be paradoxically described "stiffness," is absolutely essential to the proper action of this 
"tail triangle," and therefore the only material of which the link can be made, if it is to be of any use, is gutsingle or twisted, the latter being the better of the two.

The bait which finds most general favour is a Bleak, which from its shape and glittering scaling has a light and brilliant effect in the water. If a Minnow is used, it should not be a small one, and in this case the flight already described under the head of "Minnow-spinning" may, be substituted with advantage. The Thames Trout fisher will often find, however, that he will kill more fish with the fly, especially amongst the rough water and foam of the weirs, than with a spinning bait. The fly for this purpose should be large and gaudy, so as to show up through the foam. The "gold" fly described in the chapter on Salmon fishing (and Plate, p. 88) dressed on a very small-sized grilse hook-say a No. I 3 of my sizes, will be found as killing a fly as any for this purpose. For fishing the quieter parts of the stream, a much smaller fly is required, and for this purpose either of the Trout flies already described can be advantageously used. Thames Trout frequently run as large as Iolbs.; specimens of $\mathrm{I} 5 \mathrm{lbs}$., and even larger, not being by any means unknown. The season begins on the Ist of April, and ends on the Ioth of September. 


\section{CHAPTER XI.}

\section{WHITE-TROUT FISHING.}

Different species of White Trout and their habitats. Theory of White-Trout fies - "Green," "brown," and "yellow" typical Trout flies, with the addition of tinsel, recommended also for White-Trout. Observations of Ay-fishing and spinning for. Rod tackle, \&c.

UNDER the name of White or Sea Trout are often included in ordinary parlance several species which are properly distinct, as the Salmon Trout and Bull Trout (Salmo trutta and Salmo eriox), and also others the specific positions of which are undetermined or disputed. One cause of the difficulty which an angler, who is not aiso a thorough ichthyologist, finds in identifying the various species of migratory Salmonide, is the great variety of local names often applied to one and the same fish. On the Tweed for instance, the Salmo criox, which is of course most widely known by its proper name of Bull Trout, is simply "The Trout ;" on the Coquet it commonly goes by the name of "The Salmon," and it is believed to be identical with the Sewin or Sewen of 
Wales. To anglers, by far the most interesting species is the Salmon Trout.

Salmon Trout fishing when good is perhaps, at any rate for a time, the most fascinating of all fishing. Indigenous in many of our best Salmon and Bull Trout rivers, and frequently abounding in streams which produce neither the one nor the other, there is no fish that swims which rises more fearlessly to the fly, or when hooked, shows for its size such indomitableEnglish pluck I was about to say-but at any rate such determined and enduring courage. In fact, the bright graceful Salmo trutia is the most game and mettlesome, if not, on the whole, the most beautiful fish known to Europe, or probably to the world.

Although the Don, the Spey, Tay, Annan, Nith, and many other Scotch waters, as well as a few English rivers produce the Sea Trout in tolerable abundance, Ireland must be considered as its home par excelience. Many of the streams and lakes on the west coast of Ireland produce Sea Trout in an abundance, rare if not unknown, in the sister Island.

Salmon Trout are migratory, and in this respect resemble the Salmon more than the Brown Trout; otner of their habits, however; seem more allied to the latter species, and, as remarked in one of the earlier Chapters of this book, the fish would appear to stand in its habits and instincts somewhere about midway between the two. So with regard to the flies 
used for their capture; in size and shape they more commonly bear a resemblance to natural insects, a resemblance which cannot be sacrificed without loss of efficiency; in colours, on the other hand, for some of the most killing artificial White Trout flies no natural prototype could be found. Under these circumstances the arguments in the preliminary Chapter on fly-fishing apply with full force to White or Sea Trout, and the three typical flies already recommended for Brown Trout (including the plain hackle-wing) dressed with a very slight variation, will be found at least as killing on lakes and rivers as any of the numerous local or gencral flies.

From what has been said, it would naturally be inferred that colour bears a more important part in White than in Brown Trout fishing. In fact, as "natural imitation" recedes in importance, colour advances, and the "salmon sympathies," if I may so express it, of Sea Trout are principally shown, so far as fly-fishing is concerned, by the fact, everywhere recognised in practice, that they usually prefer in flies a certain amount of actual glitter as well as strength of colour. Therefore, in dressing the three flies for White Trout the addition of a little tinsel is desirable-to the Yellow, gold tinsel, and to the Brown and Green, gold or silver according to fancy. The tinsel should be applied sparingly, as its effect is weakened by excess. Three complete turns round the body are ample; the tinsel being of course broad or narrow as the fly is large or small. Oc- 


\section{.}




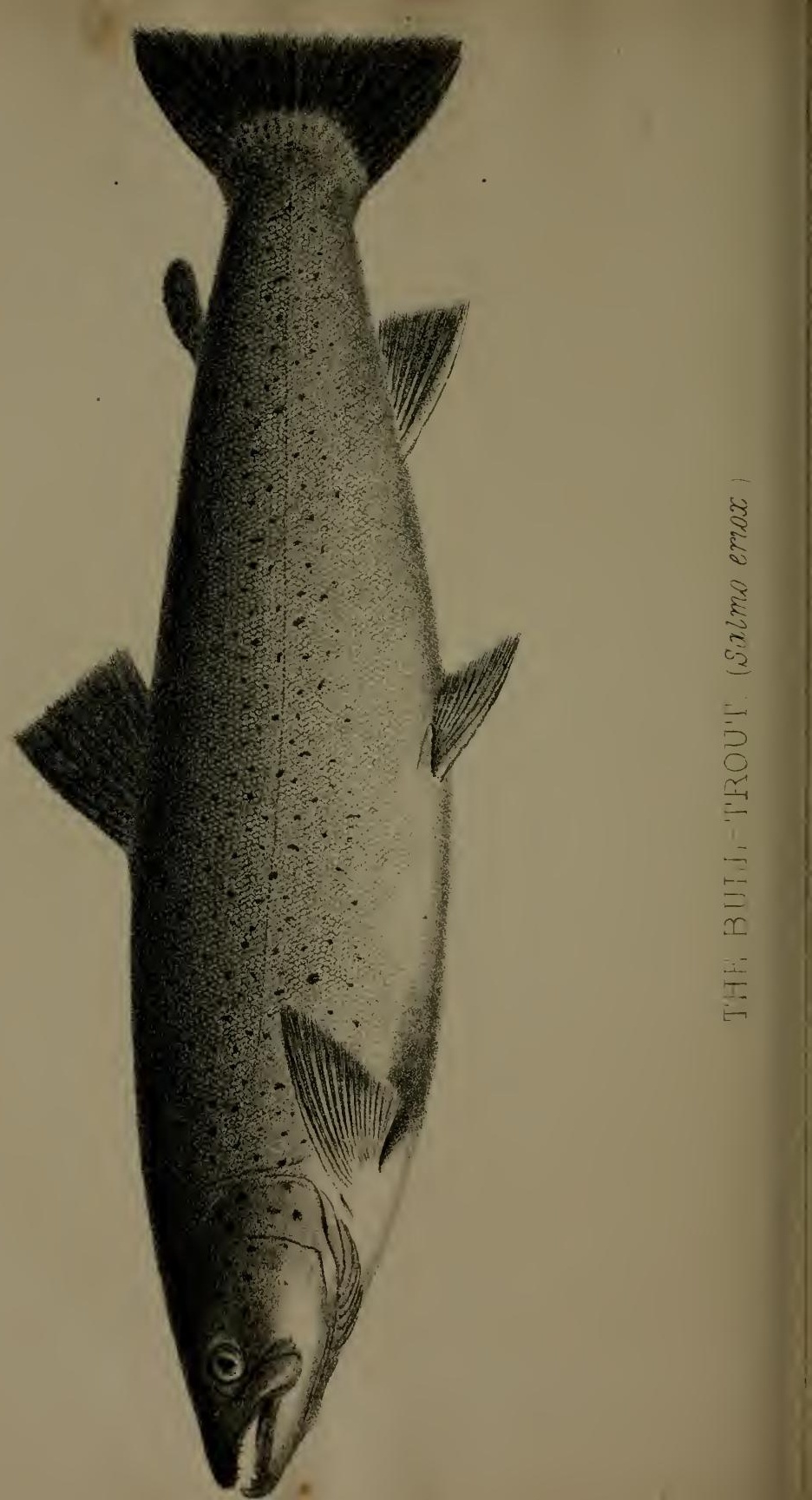


casionally in very lạrge waters the silver or gold flies recommended for Salmon, and dressed small, will be found very killing.

As in lake fishing for the ordinary Brown Trout, I advise the use of the Yellow fly as the dropper, and the Green as the stretcher to begin with; the Brown being reserved in case a change seems desirable.

The limits within which the sizes of White Trout flies vary, although influenced to some extent by the common considerations of water and weather, are narrower than those applicable to Brown Trout ; and White Trout flies are rarely required to be dressed on hooks smaller than No. 8, or larger than No. I3, (vide Plate, p. I I). But size is still a point of great importance, and as it is desirable to exactly suit the size of the fly to the fish and to the water, the White Trout fisher should keep by him all or nearly all the intorncitiate sizes.

In the case of White, as in that of Brown Trout, too great stress can hardly be laid on the importance of carrying the flies loose in a box. From the moment they are dressed they should never be squeezed or pressed, as in a fly-book, for instance, as they thereby lose much of their crispness and vitality.

All the larger sized flies for White Trout should be dressed with a loop, both as lasting much longer, and, by the method herein proposed (see Chapter on Salmon fishing), swimming much better. For the best method 
of attaching the dropper, staining the gut, \&c., see preliminary Chapters on gut and knots. The method of working the flies, and the other observations as to the How, When, and Where of Brown Trout fly-fishing and minnow-fishing, apply also in almost every case to the Salmon Trout. Both this fish and Bull Trout will occasionally take the worm, but it is at best an uncertain bait.

The observations in the Chapter on spinning for the common Brown Trout, Salmo fario, in lakes are applicable also to spinning for White Trout: a very small bait should be used. Spinning for White Trout is however very uncertain work, especially in lakes. I have usually had the best sport in a strong breeze. In streams the natural minnow used as described in the Chapter on Minnow-spinning will sometimes fill a good basket with Sea Trout. The double-handed fly-rod, similar to that already recommended for Brown Trout fishing in lakes, will generally be found to answer best for White Trout fishing.

When in full season, and tolerably fresh from the sea, the White Trout is bright and silvery, but as autumn spawning time approaches, the fish begin to lose their brilliancy of scaling, and acquire a reddish or blackish tinge. The most common weight is from one to five pounds, but specimens have been taken as heavy as twenty pounds. Last autumn I hooked and played for some time a Sea Trout which must have exceeded 
ten pounds; but having only a light single-handed flyrod I could not exercise that wholesome pressure on his movements which is so desirable, and after three-quarters of an hour of alternate somersaulting and "suiking" he eventually broke me. 


\section{CHAPTER XII.}

\section{GRAYLING FISHING.}

Grayling rivers and baunts.-The 'Grayling country'; spawning; growth-rate, and nomenclature. Artificial Ay-fishing and fies. Uselessness of the great number of Grayling flies; typical Trout fies recommended to be substituted.

Grasshopper fisbing-best tackle; time, place, and mode of using. Grayling fishing with the gentle.

\section{GENERAL REMARKS.}

WHILST yielding to the Trout in courage and dash, the Grayling is yet a beautiful and mettlesome fish - a foeman not unworthy of our steel-and if the former is the handsomer, the latter would by many be considered the prettier species of the two. The Trout has, so to speak, a Herculean cast of beauty ; the Grayling rather that of an Apollo-light, delicate, and gracefully symmetrical.

Except in the Clyde, where the fish was introduced about ten years ago, there are no Grayling, so far as I am aware, either in Ireland or Scotland-and even in England the fish is still local, and comparatively speaking, even rare. The following are amongst the streams which produce the Grayling in more or less abundance. 


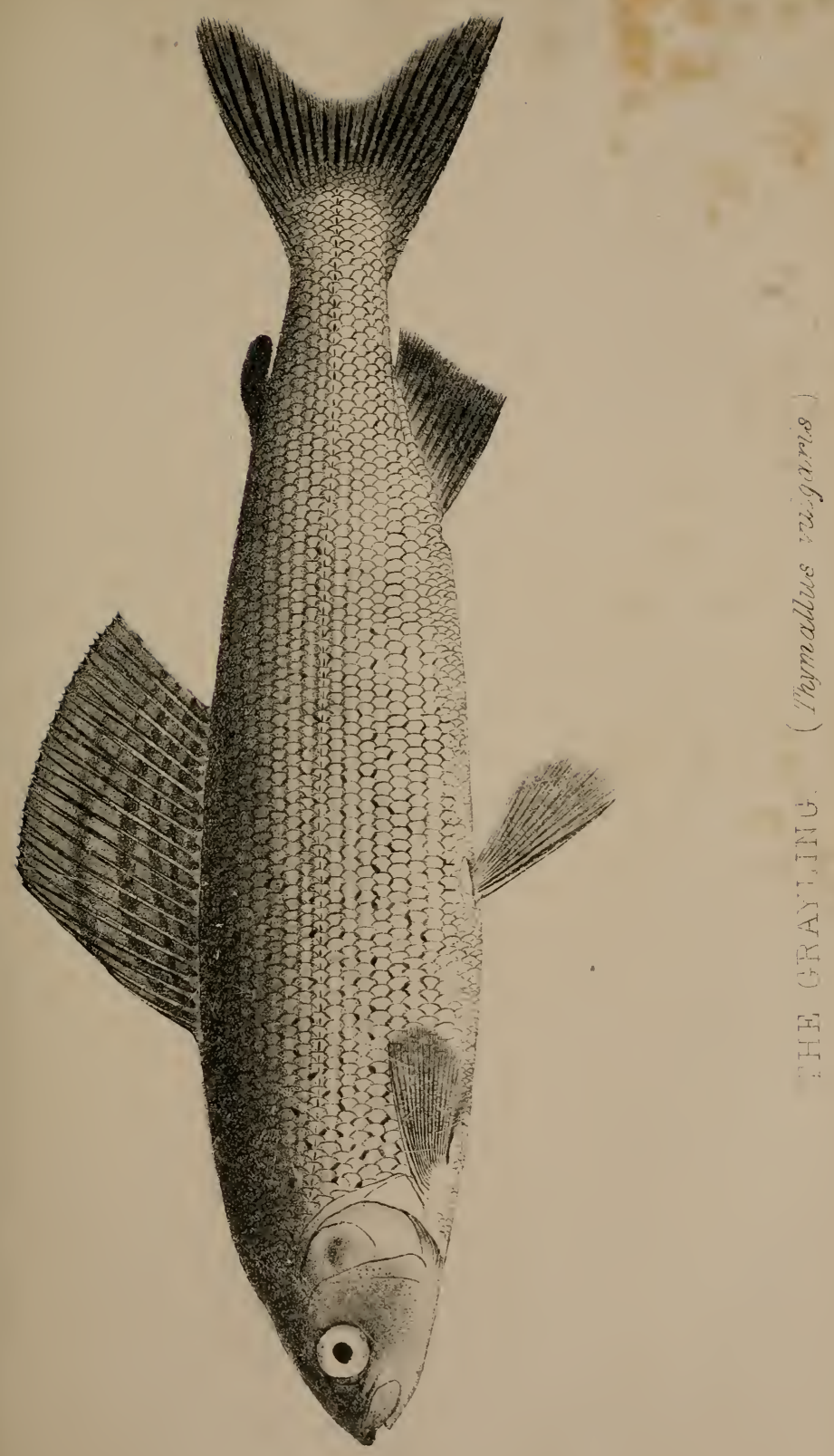




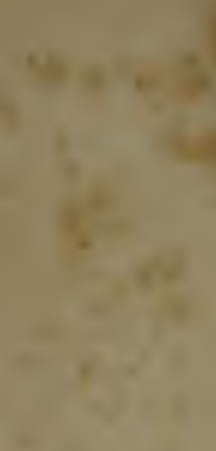

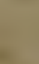$$
\text { N. }
$$$$
\frac{5}{2}=
$$$$
-4
$$$$
\text { and }
$$$$
4=
$$$$
\text { p. }
$$

.

\section{.}


In Hampshire and Wiltshire-the Test, Wharf, and both the Avons ; in Herefordshire-the Dove, Lug, Arrow, Wye, and Irwin ; in Shropshire-the Teme and Clun, Corve and Onny ; in Staffordshire-the Hodder, Trent, Dove, and Wye; in Derbyshire-the Dove; in Merionethshire, the Dee; in Lancashire-the Ribble; in Yorkshire-the Derwent, Ure, Wharfe, and Whiske ; and in Cumberland, according to Heysham, the Esk and the Eden.

The Wye, Dee, Lug, and Teme are the only Welsh rivers holding Grayling that I am acquainted with. Leintwardine on the Teme may be considered as the centre of the Grayling country ; and from Leintwardine to Ludlow is the best piece of Grayling water in the kingdom ; so far as my experience goes.

The cause of the non-existence of Grayling in Irish or Scotch rivers is probably to be found in the "rock, stone, and scour," which are their most common characteristics, whilst the Grayling appears to thrive best in rivers, the beds of which are composed partly or wholly of sandy gravel or loam ; and instead of dashing torrents and rapids in uninterrupted succession, affects waters in which shallows and "stickles" alternate with gentler currents and deep sluggish "lanes" or channels of stream.

The spawning months for Grayling are April and the early part of May, when they come up to the gravelly scours in shoals-in this respect resembling dace. The 
spawning process occupies from three to four days, after which the fish return to their own haunts, and are then unfit for food until about August; during the intervening months the spawned fish rarely take the fly or bait, and if caught in May or June should be returned to the river. The Grayling season begins in August and properly ends with December, as after Christmas the fish begin to get heavy in spawn, a condition in which a good sportsman will not kill them, although it cannot perhaps be truly said that they are actually unfit for the table until after the spawning has taken place. When I last fished the Teme, the limit of size under which the Leintwardine Club wisely prohibited the taking of Grayling was Io inches. I hear, however, that the club rules have been recently revised.

One year old fish are locally termed "Pinks"; at two years, when they weigh about $\frac{1}{4}$ lb., they become "shot" or "shut" Grayling ; and afterwards "Grayling." The "Pink" Grayling have neither spots nor lateral lines observable. "Shot" Grayling have spots, but no wellmarked longitudinal lines as seen in the full-grown fish. At three years old the Grayling weighs about $\frac{1}{2} \mathrm{lb}$. in average waters, and is supposed to continue growing at about the same rate, viz. $\frac{1}{4} \mathrm{lb}$. per annum, until reaching its maximum weight, which may probably be considered under ordinary conditions from 4 to 5 pounds. A Grayling weighing half a pound spawns, but a "Shot" Grayling does not. 
The mouth of the Grayling is exceedingly tender ; and consequently both striking and playing, the fish requires to be handled carefully. For the same reason, and also from the peculiar character of the banks, a net is almost a necessity in Grayling waters. The light pocket-net described in the chapter on tackle, will be found the most convenient for the purpose.

Grayling but seldom take the minnow, either natural or artificial, or the worm. The three most killing ways of fishing for them being with the artificial fly, with the artificial grasshopper, and by float-fishing with gentles.

\section{FLy-Fishing.}

Fly-fishing for Grayling begins in earnest in August-that is, about a month earlier than either the grasshopper or gentle fishing-and continues through September and October. Fair bags may not unfrequently be made as late as November, but a warm day, and the middle hours of it, are then desiderata. Indeed, as soon as the weather becomes cold, the warmest hours of the day, say from 12 till 2 or 3 o'clock, will usually prove best for the fly. The flies locally used for Grayling fishing are not quite so numerous as those for Trout-the only reason being, I believe, that the localities themselves are fewer; but still the Grayling fisher's repertory will commonly contain from ten to twenty varieties, good and bad, the greater part of which are wholly unnecessary, and in their 
effects on the basket mischievous. Perhaps the most killing of the list are the August, Whirling, and Blue Duns (light and dark) ; Silver-twist, blue ; Red and Green Insects; Willow, Orange, and Sedge or Cinnamon fly One or other of these will kill all through the season; but if the Grayling fisher will substitute for them and their congeners the three flies, Yellow, Green, and Brown, which I have recommended for Brown Trout (vide, frontispiece), and use them steadily throughout the season, he will probably find reason to congratulate himself on the exchange.

The arguments which have been adduced on this subject as applicable to Trout flies, as well as the observations on Trout fishing generally in streams, and how it is to be done, Rod, Tackle, \&c., apply equally to Grayling fishing and flies. The finest possible stained gut should be always used for both flies and collar.

Comparatively few heavy Grayling are taken with the fly, the haunts of the large fish being chiefly the long slow-running deeps which are most unfriendly to this mode of fishing. In the rapids and "stickles," small Grayling may be taken, but these scours are not really good either for the fly, grasshopper, or gentle. The best spots for all three are steady running streams, and tails of pools, for the fly about three, and for the grasshopper about four feet deep. The grasshopper can, however, be frequently used with advantage in water which is much too slow for the fly. 


\section{GRASSHOPPER-FISHING.}

The lure known by the name of the artificial grasshopper, is really a rough imitation of a caterpillar, and not of a grasshopper. The best are imitations made as follows. Whip a strand of fine stained gut on to a No. Io or No. I I hook ;* making the silk lapping extend as far as the bend of the hook. Take a lightish lead, bored, of about an inch in length; cut it down at one end to the length of the lapping (about three-quarters of an inch), taper it off at the thick end a little with a knife, and then run it over the shank of the hook, with the heaviest end towards the bend of the hook: pinch it so as to fix it firmly in its place; and make a few transverse " nicks" with the knife to cause the dubbing to stay on : then lap the lead all over with light green worsted; and make a few turns over this body with yellow silk, waxed with colourless wax. It is an improvement to the appearance of the grasshopper to run a narrow slip of straw down each side of the body under the yellow ribbing.

The form of the grasshopper is shown in the engraving (figure I). Grasshopper. Float. It should be baited for use with three or four large

* If a No. I I hook is used, which is on the whole the best size of bend, a small piece of the end of the shank should be nipped off, as the grasshopper would otherwise be too long and large for ordinary purposes. 
gentles put on the hook so as to make a bunch and partly cover the bend and point. The trace should consist of three yards of fine stained gut.

The grasshopper is worked by "sinking and drawing," as it is termed: that is, the bait is thrown in and allowed to sink till it touches the bottom, and is then steadily drawn up again about a foot or a foot and a half, and allowed to sink as before. The stream is usually strong enough to shift the bait as much as is desirable, but if the water is too still for this, the result can be arrived at by "drawing" the bait a little to right or left with the rod. The great point is to be quite sure that the bait touches the bottom before drawing up, and in order to assist the eye in judging this point, it will be found of the greatest advantage to have a sinall moveable white mark on the line, placed a foot or a foot and a half higher up the line than the highest point which ought to be submerged. It is, in fact, a miniature float, always kept out of water, and the most convenient form is this. Take a small white feather, and cut off about half an inch of the hollow quill, and three-quarters of an inch of the solid white part of the feather-stem, just thick enough to fit neatly into the hollow quill cap (A), as shown in the engraving, figure 2 ; the cap passes over the line and is shifted according to the average depth of the water fished.

A run will of course be perceived as the bait is being drawn up, when a smart stroke should be given, and the 
fish held tightly. Otherwise from its non-fighting propensities a large Grayling is very likely to get off : the hook also is a good deal encumbered with gentles. When first struck, the larger Grayling appear to me to fight as an Eel does-pulling tail backwards, instead of running down, or away head first as other fish generally do; and I hardly ever remember seeing a hooked Grayling spring out of water.

The best spots for grasshopper-fishing have already been described. Where the water is deep enough, a short line worked almost perpendicularly near the bank will be found most successful; but by throwing out a considerable distance, excellent water otherwise inaccessible can often be reached. The cast may be made over hand like a fly to a distance of some ten yards, but care must be taken to allow the line to spread well behind, or otherwise the bait will perform various eccentric flights into the water or bushes. A longish light rod, say fourteen or fifteen feet, is most convenient for grasshopper-fishing: and the "General Rod," reel, and line recommended for worm-fishing for Trout (p. I 12) will be found to answer the purpose excellently.

As a rule, fish caught with the grasshopper are twice as large as those caught with the fly. September, October, November, and December are the best months, and the best days are usually quiet warm days succeeding frosty nights-in fact, grasshopper-fishing never fairly gets into play until after the first sharpish frost. 
From about eight A.M. until four P.M. is commonly the best time of day. I have been informed that grasshopper-fishing was first introduced into Shropshire about forty-five years ago by the late Mr. Jones, fisherman, of Ludlow ; whose son, also residing in Ludlow, is, or was when I last fished with him, as deadly a Graylingkiller as I ever met.

\section{GENTLE-FISHING.}

Before the introduction of the artificial grasshopper, it was the custom, in Shropshire at any rate, to fish for Grayling with gentles only for bait and ground-bait, used in the same manner as we now use them for Roach, and with similar tackle. Fished in the

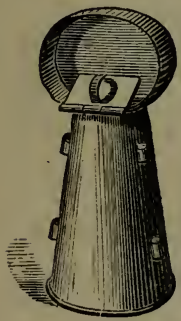
"Nottingham style" they will still be found a very killing bait (vide Chapter on Roachfishing).

In the above and every description of gentle-fishing a tin box like that shown in the engraving, with a tray in front of the opening, and which can be suspended from the button-hole, will be found a really great practical convenience and saving of time. This box was, I believe, the ingenious invention of Messrs. Dawson, Bell Yard, Temple Bar. 


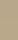




\section{CHAPTER XIII.}

\section{SALMON FISHING.}

Outline of Salmon history and nomenclature. Fly-fishing: two principal difficulties, the 'rise' and the 'stroke'; casting and working the fly. Salmon haunts; changing flies, and casting for second rise; wading and waterproofing.

Salmon and Grilse fies: three universal fies described - 'Silver,' 'gold,' and 'rainbow.' New method of construction-Head-hackles; 'loops'; how to fasten flies to casting-lines. Rod, reels, and lines. Gaffing. Hooks for Salmon fies. Spinning jor Salmon-The Eel-tail bait and tackle; how to dress and use. Worm-fishing tackle, boc.

\section{OUtline of "Salmon History" and}

\section{NOMENClatURE.}

A History of the Salmon, in the proper sense of the term, is beyond the scope of this work, and I have moreover already dealt with the subject in detail in the "Angler-Naturalist." A few facts, however, which I shall put as briefly as possible, are desirable, if only to enable the fisherman to know what Salmon he may put into his creel and what he ought to return to the river. The general terms used in Salmon nomenclature may also perhaps be useful.

The young of a Salmon remains one, two, or three years in the river before migrating to the sea: during 
this period it is a "parr." Just before migrating it changes its golden and brown coat for a silver one, and becomes a "smolt," at which time it weighs from one to two ounces. The smolt returns from the sea a "grilse," commonly in from five to ten weeks, but sometimes more, and having increased in weight from two to ten pounds. Sometimes, however, the smolt does not come back as a grilse, but returns in the spring of the following year as a small Salmon.*

The smolt, whether it comes back in the grilse or Salmon state, and the mature Salmon also, spawn usually about November or December, and go back to the sea as a spent-fish, or "kelts," in February or March; ordinarily returning during the following four or five months as "clean" fish, and increased in weight from seven to ten pounds.

Shortly before spawning, and whilst returning to the sea as "kelts," Salmon are considered "foul fish"- unfit for food-and their capture is then illegal. "Foul fish" before spawning are, if males, termed " red fish," from the orange-coloured stripes with which their gill-covers are marked, and the golden orange tint of the body; the females are darker in colour and are called "black fish." After spawning the males are called "Kippers," and the

* The circumstance of the non-return of the Smolt in all cases during the first year, and the theory of the spawning of Salmon in alternate years, is now very generally received amongst naturalists. It was first propounded by the author in the Times in $186_{3}$, and subsequently in the "Angler-Naturalist," published during the same year. 
females "Shedders," or "Baggits." The History of the Salmon-Trout and other migratory Salmonidæ has never been quite so decidedly established; but in many points it certainly, and in most others probably, is nearly identical with that of the Salmon. The colours of the Salmon-Trout and Bull-Trout before or after spawning are also nearly the same as those of the Salmon, and their condition may be ascertained accordingly.

The above names may perhaps be conveniently presented in a tabular form :-

NAMES OF SALMON IN DIFFERENT CONDITIONS AND STAGES OF GROWTH.

Parr . . . . Before taking its migratory dress. Smolt . . . . After taking ditto.

Grilse . . . . Smolt, on first return from the sea, during the same year.

Salmon . . . Smolt, not returning till year following ; or Grilse after its first trip to the sea, and at all subsequent stages.

Clean fish . . . Fish fit to eat ; neither just going to spawn, nor just after spawning.

Foul fish . . . . Vice versâ.

Fresh-run fish . . Salmon recently ascending rivers or lakes from the sea.

Red fish . . . Male Salmon just before spawning. 
Black fish . . . . Female Salmon ditto.

Kippers . . . . . Male Salmon just after spawning.

Shedders or Baggists Female Salmon ditto.

Kelts or Spent fish . Male or female Salmon returning

to the sea after spawning.

Well-mended Kelts . Salmon which (after spawning)

have partially recovered their condition in the fresh water.

Both grilse and Salmon can always be at once distinguished from the Salmon-Trout and Bull-Trout, by the spots. After the smolt stage, these latter fish invariably have spots on the sides, below the lateral or side-line; the line, that is, longitudinally dividing each side of the fish into two halves. Salmon and grilse never have such spots.

Grilse can be distinguished from Salmon, (I) by the tail being forked, whereas in the Salmon it is always nearly square, and ultimately convex; and (2) by the scales, which in the grilse come off even with the slight pressure of the hand. Fresh-run Salmon-i.e., Salmon just fresh from the sea-carry on their bodies the parasites commonly called " tide lice," these drop off aiter a few hours' contact with the fresh water, but the marks, something like miniature leech-bites, remain for a day or two. The longer the Salmon remains in fresh water the less brilliant becomes its colour. 


\section{FLY-FISHING.}

Although, in common with many Trout-fishers who are also Salmon-fishers, I prefer good Trout-fishing to any other sport with the rod, it must be admitted that there are points in which Salmon-fishing carries off the palm -and carries it off too not only from Trout-fishing, but from every other sport which these islands afford. Perhaps I could not with truth say that I prefer fishing to shooting, or shooting to hunting; they are a glorious trio, to each of whom in turn I have sworn allegiance; and if like Paris I had a golden apple to bestow, it should be given to Fishing only because she has been in a special sense my mistress-" the fairest and most loving wife"-in many a wild and lonely spot where but for her gentle companionship and solace, I should have felt myself in every sense of the word alone. But though it would perhaps be impossible, honestly, and " unbiassed by self-profit," to award the palm of superiority to either of our three national sports as a whole, I unhesitatingly assert that there is no single moment with horse or gun into which is concentrated such a thrill of hope, fear, expectation, and exultation as that of the rise and successful striking of a heavy Salmon. I have seen men literally unable to stand, or to hold their rod, from sheer excitement.

And indeed in this very excitement-in the impetuosity of spirit it engenders-lies almost the only real 
difficulty of Salmon-fishing. Two causes combine to make the moment of striking a critical one: In the first place the Salmon is so large and bright, and in the second so comparatively slow-moving, owing to his bulk, that the eye almost certainly perceives him in the water befure he has actually taken the fly; when a premature stroke, an almost instinctive tightening of the muscles and line, at once snatches the fly from the fish, and the fish from the creel. The art is to resist for a moment the inclination to strike; only for one moment, but long enough to allow the fish to take and turn down again with the fly; and then strike if you will : not a slight hesitating blow like the tap of a lady's fan-for there is often a long line and a heavy strain on it between the Salmon and his would-be captor-but a strong, steady, determined stroke bringing the line up as flat as a knife, and driving the tapering hook-point well in over the barb.

Next to the number of Salmon lost through striking too quickly, are those lost from striking too feebly. I repeat, therefore, strike strongly and hard, as I have described, and repeat the stroke by way of making sure. If the tackle will not stand this strain it is a clear proof that it is not fit for Salmon-fishing. A weak stroke is worse than useless, because whilst it fails to make the hook penetrate, it provokes the fish to a sudden violent effort to rid himself of it, and thus lessens the chance of his hooking himself.

If the above mode of striking is adopted, not more 
than one fish in five which fairly take the fly in open water ought to escape. I kept a register for some time of my losses and takes, and I found this to be a fair average.

Having mastered this point, the tyro who knows anything of Trout-fishing will find that there is very little to learn in the art of Salmon-fishing which a few hours practice under a good master will not suffice to teach him. The principles of casting and working the fly are in fact almost identical, allowing for the difference in size and weight of the tackle employed. All the movements, that is to say, and particularly that given to the fly in the water, are somewhat slower than in Troutfishing. The method of casting - the principles which should guide the Salmon-fisher in selecting the size of his fly-the general condition of wind, weather, \&c.are also similar, and for all these the reader is referred to the chapter on Trout-fishing.

Salmon, however, depend more on the condition of the water than do Trout, and there are many rivers in which the chances of taking a fish are almost nil, unless there is a "fresh" in the river.

As regards the "where" to fish for Salmon in any given river, this can only be acquired by local experience. Sometimes what to the natural man appears a most lovely cast, hardly holds a fish from one end of the season to the other, whilst in the uninviting lagoon-like looking hole below, a rise may be predicted with certainty. Even particular stones are not unfrequently haunted by Salmon 
with a pertinacity which is very remarkable. In the Conway, for instance, I have often had pointed out to me a stone, the little eddy behind which was almost invariably tenanted by a Salmon. Such is also the Red Stone below Makerston on the Tweed, and there are many similar instances.

Why Salmon should evince such strong predilections for particular spots is a question which has never been satisfactorily answered; but that they do so evince them is beyond a doubt; and whilst such is the case, the Salmon-fisher who does not want to waste his time will never, if he can help it, try a new water without some local guide who knows the casts, and what are and what are not the spots most likely to hold Salmon.

A gaff is sometimes necessary for the safe and expeditious landing of Salmon, but it requires to be used by an experienced eye and hand, and in the early spring months, when the kelts or spawned fish are dropping down the river, a net, (which should not be less than two feet in diameter,) will both save the fisherman's time and probably the lives of at least some "doubtful" fish. In fact, on many early Salmon rivers a net is almost a sine $q u \hat{a}$ non, and the use of the gaff should be discouraged in every way.

Another important point in Salmon angling is "fishing for a second rise." If a Salmon through his own or the angler's fault has missed the fly, he will, if properly managed, frequently rise a second, and sometimes a 
third or even a fourth time, and be hooked after all. When a Salmon has risen, instead of immediately throwing again, the best plan is for the angler to sit down quietly on the bank for a few minutes, and then carefully cast over the fish again, beginning a few yards above the actual spot where the rise took place, and bringing the fly gradually down over it. If the fish does not rise, a short interval should be allowed as before, during which the fly should be changed for one of another colour, and afterwards the same process repeated. Some good fishers advise changing the fly the first time of recasting, and a second or even third time afterwards; but my experience is in favour of the system here described, which is both simpler and less troublesome. If a Salmon will not rise either to the original or to a new fly, the chances are much against his rising again at all at that moment. He may do so, however, at another time of the day, and in view of this contingency the casting over him of a number of flies a great many times is less likely to attract than to disgust him.

\section{WADING.}

Wading is often necessary in Salmon-fishing, and indeed in Trout-fishing also. Where the fisherman has to wade deep, as is often the case in Salmon-fishing, fishing trousers fastening round the waist will often be found a great convenience: they are also much less dangerous than either wading stockings or leather boots. 
In the event of a sudden immersion these latter fill with water, and thus act as plummets, loaded with which even a strong swimmer may very easily be drowned. Wading trousers, on the contrary, take so long to fill that they practically act as floats during a time which is generally sufficient to enable a swimmer to reach the bank; and they give of course a non-swimmer a proportionately better chance than he would otherwise have.

If leather boots are used, the best dressing that I am acquainted with, as also for shooting-boots, is a coat of the green-looking waterproof paste manufactured by Messrs. Strawson, of Crewkerne, Somersetshire ; and for merely keeping the leather pliant when not in use, tire following will be found an excellent mixture :-

Waterproofing for boots toc.-Burgundy pitch, 1 oz.; bees' wax, 2 oz.; turpentine 2 oz.; neatsfoot oil, I pint. The turpentine should be added just before taking the composition off the fire.

\section{Salmon and Gritse Flies.}

For the arguments bearing upon the question of what a Salmon-fly ought to be-the rationale, that is, of Salmon-flies-the reader is referred to the general introductory observations on fly-fishing, Chapter VI. The figures in the frontispiece represent the three flies therein alluded to dressed of three different sizes, so as to exhibit in the most convenient form-the arrangement of wings, hackles, \&c.; No. I being tied on a double hook, showing with the foreshortened diagram annexed to it the proper angle of "set" for the latter. 
No alteration whatever is required in the dressing, from the smallest Grilse to the largest Shannon flies, except that the hooks, hackles, and wings must be proportionally larger or smaller.

The speciality of these flies it will be seen consists in the arrangement of hackles, which are, in fact, double, embracing a "shoulder" hackle, and what may perhaps be best described as a "head hackle ;" the body of the fly being made a trifle shorter to admit of the additional set. The hackles commonly used in Salmon-flies are so small, and necessarily so much compressed and pushed out of position by the wings, that when in the water they present very little appearance of movement or life in the water.

I shall here make no attempt at giving a code of instructions for Salmon-fly making : it has been already done as far as accurate verbal description and woodcuts can do it, by several living authors, and very thoroughly and completely by the late Mr. Blacker, in a charming little volume illustrated by the actual fies. This, however, is a monograph, and however beautiful or interesting as a work of art, is too laborious and studious for an age in which so much has to be done in every twentyfour hours that even minutes are jealously economized. Anglers of ordinary leisure will find it most convenient to have their flies dressed at the tackle-maker's, and if they wish to know how to make a fly themselves-a most useful knowledge in emergencies-a few lessons 
from a practical fly-tier will be worth volumes of precept. It is, however, an art requiring much nicety and delicacy of manipulation, and not to be acquired in any degree of perfection without practice and a certain natural aptitude.

As with Trout-flies so with Salmon-flies, none should ever be put into a fy-book or be otherwise compressed. The elasticity of the hackle fibre is impaired by pressure, and all the fresh "crispness" of the fly is lost. If as soon as made flies are put into a box with others, they will bear any amount of tossing or tangling without injury, and a round tin box, equal in bulk to an ordinary fly-book, will contain quite as many flies and collars as any flyfisher need wish to take with him to the river side.

I have already referred to this more than once, but it is in my opinion a point of such great importance that too much stress can hardly be laid upon it. This will be better understood when it is recollected that the whole art of fly-fishing as we practise it, is based on the principle of simulating life, rather than death; and that between a fly new and crisp, and one which has been long flattened in a fly-book, there is almost as much difference when they are in the water as between a living and a dead insect.

The extra, or " head hackle," should be about the same length in the fibre as the body of the fly from head to butt. As, however, the size of hackles is limited, in very large flies it is impossible to carry out this pro- 
portion strictly; but with a little trouble hackles of an inch and a half long in the fibre can easily be obtained by feather-dyers and tackle-makers, and up to this size anglers using the flies recommended should insist upon the proper proportion being maintained. These hackles not only possess an amount of transparent, almost prismatic, colour which no other part of the fly displays, but, as they are worked through the stream, open and close with every movement of the rod or fly, and give the appearance of life to what would otherwise look only like a bar of dead silver or gold or colour.

The principal wing-feathers in all these flies are the black and white neck hackles of the jungle cock, and the next in importance feathers from the golden pheasant known as "toppings"-perhaps the two feathers which experience has proved to be on the whole most killing for Salmon in the greatest variety of combinations. If the expense of golden pheasant toppings in the wings is objected to, the best substitutes are golden orange hackles.

These colours have also the advantage not only of being in themselves strong and glowing, but of harmonizing with the body colours of each of the three fliesa harmony which the hackles complete. As the harmonies of sound depend upon the combination of certain natural "intervals" furnished by the harmonic chord, so in forming harmonies of colour the natural or prismatic arrangement, as displayed by the solar spectrum of the 
optician, must in every case be taken as the basis. Thus in the gold-fly - the prevailing colour of which is intended to be a rich golden orange-red, orange, and yellow are the three predominant colours-orange (the gold of metallurgists) in the prismatic arrangement passing into red on the one side and yellow on the other. In " the Rainbow" the same model is closely followed, the whole of the prismatic colours being combined in the body and shoulder hackle in their proper sequence. In No. 3 , which is a silver-bodied fly, no harmony of colour is strictly speaking possible-silver (or white brightened) not being a colour but rather a negation of it. In a more general sense, however, both white and black harmonize with all the other colours.

It will be seen that the "silver" fly is tied on a double hook. This is a plan which I first saw practised by Dr. Peard, the accomplished author of "A Year of Liberty," to whom I was also indebted for the original flies on which, with the exception of the extra hackle, and some modifications of colour, the pattern-flies here given are based. The addition of the second hook perceptibly influences for good the proportion which losses bear to runs. It is also rather an improvement than otherwise to the fly, so far as neatness goes, and helps to sink it a trifle lower in the water-another advantage, in my opinion. The hooks are set at rather less than a right angle.

The following is the formulary for these flies :- 


\begin{tabular}{|c|c|c|c|}
\hline 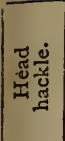 & 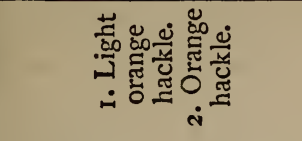 & 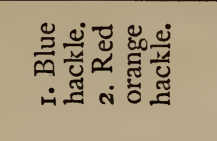 & 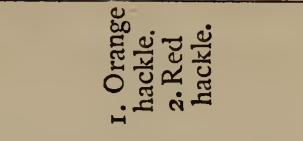 \\
\hline$\sum^{\infty 00}$ & 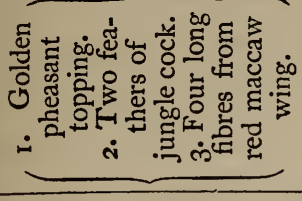 & 莣 & \\
\hline 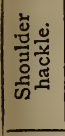 & 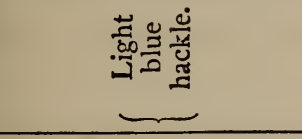 & 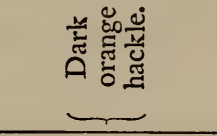 & 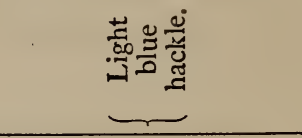 \\
\hline $\begin{array}{l}\dot{\vec{\partial}} \\
\text { ค }\end{array}$ & 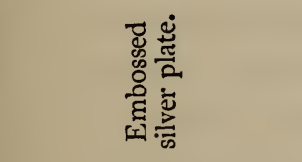 & 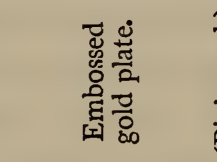 & 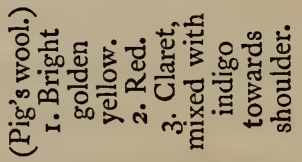 \\
\hline$\stackrel{\Xi}{\Xi}$ & 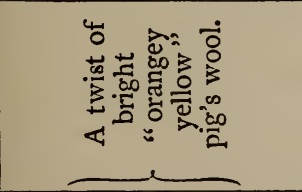 & 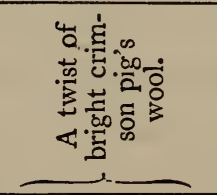 & 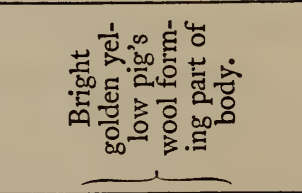 \\
\hline $\overrightarrow{\tilde{\pi}}$ & 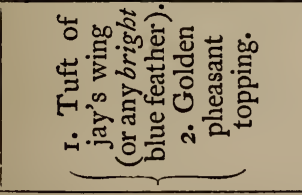 & 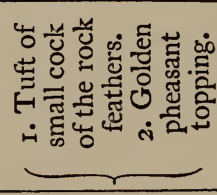 & 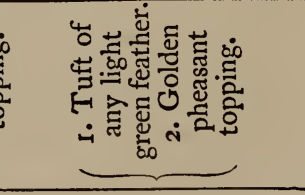 \\
\hline$\dot{g}$ & \multicolumn{3}{|c|}{ 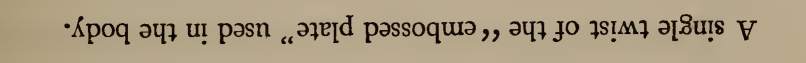 } \\
\hline & 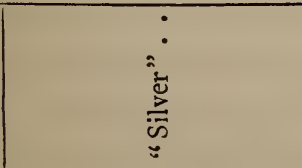 & $\begin{array}{l}: \\
: \\
3 \\
0 \\
0 \\
0\end{array}$ & 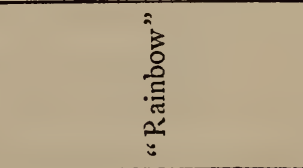 \\
\hline
\end{tabular}


The "tag," and the head of ostrich or peacock here usually added to Salmon and Grilse flies, are neither useful, nor, to my eye, ornamental. The latter moreover almost always gives way before the rest of the fly, and the space which it occupies tends to prevent the desirable strength being given to the "fastening off." A head finished off in the manner shown in the engravings of the above flies both looks neater, because more suitable and workmanlike, and saves labour to the flydresser.

It is seldom-I may say never, except in large waters like the Shannon-that two Salmon-flies, or one Grilse and one Salmon-fly can be used with advantage. The bob-fly or dropper in lake Trout-fishing is often the most killing fly, because when properly worked it skips along the ripple like a real live insect endeavouring to rise after a partial immersion ; but the Salmon-fly, which is apparently not taken for a fly at all, kills best under water. If White-trout, however, are in the river, a Whitetrout fly, as the dropper, may often be used with advantage. A clescription of two new methods of attaching drop-flies has been already given.

The collar should be of the strongest picked Salmongut, stained as already directed for Trout-gut, and the strands knotted in a single fisherman's knot (described at p. 54), with a lapping of thin gut insidc, or between the knots, instead of the ordinary silk lapping outside. This mode of lapping relieves the knot itself of half its duty, 
and on any sudden jerk, such as striking, acts as a sort of buffer to receive and distribute the strain. It is moreover simpler, much neater, and nearly twice as strong as the common double knot. Tied with the latter a couple of feet of very strong Salmon-gut will break-almost always at the knot-on a steady strain of from $\mathrm{I} 2$ to $\mathrm{I} 5 \mathrm{lb}$; t tied on my method it will break at any other part in preference. The gut-lapping has also the advantage of being transparent, whilst silk is of course opaque.

All Salmon-flies should be dressed with gut-loops, not only with the double object of strength and durability, but for the purpose of making the fly swim straight when attached to the casting-line. This last object, however, is not accomplished with the ordinary mode of knotting on the fly-viz., by forming a half-knot at the extremity of the casting-line, and then "reeving" it in and out through the loop. When thus attached the fly presents a sort of broken-backed appearance, and must of necessity swim head downwards instead of horizontally.

The following method will be found entirely to obviate this defect, whilst it is at the same time neater and stronger and equally simple:Pass the end of the casting-line through the fly-loop from above; then over the loop; then up again through it from below;

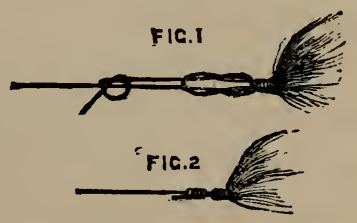
and finally tie with it a half-knot round the main line, 
in the form shown in the diagram, fig. $\mathrm{r}$. Then draw the last-made knot tight, and slip it up to the loop, drawing the main line also tight as shown in fig. 2, which is a facsimile of the knot as tied on a small Grilse-fly. In fig. I the loop is exaggerated in length for the sake of illustration.

The gut should always be well moistened before the knot is tied.

THE RoD.

Salmon-fishers have almost all their peculiar fancies about rods. Some pin their faith to the swishy, spliced, and somewhat top-heavy weapon which takes its name from Castle Connel ; whilst others, going to the opposite extreme, will fish with nothing more pliant than the oldfashioned, untapered, four or five ferrule-jointed rod of the past generation of London makers. The latter would doubtless bring against the swishing rod the charge of top-heaviness, whilst its owner would consider that the extra top weight and "play" of his rod did duty instead of muscular effort. He might probably put his argument thus:- "In every cast your stiff rod has to be worked with twice the movement of arm that mine requires:" to which the reply would be, "Yes, but then my rod is so lightened towards the point, that it is no effort to me to work it." For my own part I think that, like the chameleon philosophers, both are wrong and both are right; in other words, that each rod 
possesses a valuable principle of its own, but carried to a mischievous excess in the two extreme types I have referred to. In a Salmon-rod power is preeminently necessary, and greenhart gives it. Lightness is another essential element, and the oldfashioned evenly-tapered hickory rod admirably fulfils the condition.

At most London tackle makers, however, and at many of the best provincial makers also, a rod may now be obtained which combines in the greatest attainable perfection both of these qualifications. In these rods tl:e upper joints are made of greenhart and the butts commonly of ash ; and without being so swishy as the pattern which finds favour at Castle Connel and generally throughout Ireland, they have pliancy enough to be pleasant handling, as well as stiffness sufficient for hard practical work. When properly proportioned they are quite free from top-heaviness, and yet will strike and "double up" a fish fast enough to please the veriest butcher, whilst possessing that perfect graduated play from butt to point which connoisseurs delight in. These rods are generally made in three joints, with ferrules, and vary in length from $I 7$ to 21 or 22 feet. I append the measurements of a rod of my own made on this. principle, which has been admired by some good Salmonîshers :- 


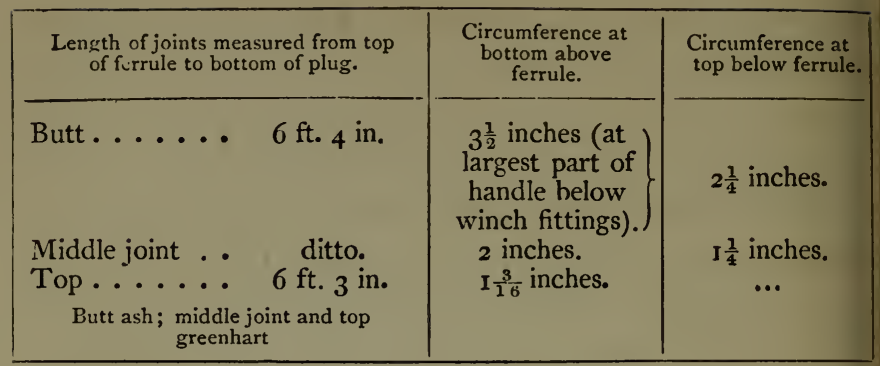

The length of this rod when put together is I 8 feet 6 inches. Very strong and tall anglers may wield, and very broad waters sometimes demand, a longer weapon, but for all ordinary purposes I think 18 or I 9 feet will be found the most convenient length. In order to insure the greatest comfort and efficiency, the rings, \&c., of Salmon rods as of all others should be stiff, and of the shape and construction shown at pp. 47-8.

\section{The ReEL ANd Line.}

A reel similar in pattern to that recommended for Trout (pp. 37-8), but capable of holding from 80 to 100 yards of stout casting-line will be found best. For an I 8 or 19 foot rod, such as that described, a reel of four inches in the diameter of the plate gives on the whole the best balance. Further observations on the reel, as, well as on the method of preventing the line "hitching" round it, will be found at pp. 35- 8 .

A heavy as well as a strong reel-line is very necessary 
in Salmon fishing, as it enables the fisherman to throw his heavy fly more readily against the wind. The weight $\mathrm{s}$ in fact also an advantage in other respects. The ordinary eight-plait dressed silk line, or the spun cotton line described in the chapter on tackle (pp. 26-7) will be found the best, the latter being about one-third of the price of the former.

\section{The GafF.}

A straight sharp point is the only real essential in a gaff. All other matters are comparatively unimportant. As the gaff has always to be carried by an attendant, one with a 6 or 7 foot solid handle is most convenient. In gaffing a Salmon there is an art which needs some little practice and presence of mind to acquire. Unskilful gaffers make a sort of dive or snatch at a fish. The proper plan, on the contrary, is cautiously but quickly to lower the gaff until the point nearly, but not quite, touches the fish's opposite side below the shoulder, and then give it a sharp, sudden jerk (not stroke) inwards, which drives it home. Snatching, diving, and striking at Salmon with the gaff result in frequent hitchings of the line, and abortive scratches and cuts being inflicted on the fish, which, though impotent for purposes of capture, yet produce sufficient smart to frighten him into a final and despairing rush, which is frequently fatal-I mean to the basket. So obstinately stupid on this point are often even professional attendants, that I 
have frequently gaffed my Salmon myself with one hand, holding the rod in the other, rather than entrust either to their tender mercies.

\section{Hooks.}

In the shape, weight, and especially in the strength of the larger sizes of hooks, described at page I I, I have had particular regard to the requirements of the Salmon-fisher, and I believe these hooks will be found to combine these essentials in a greater degree than any of the existing patterns (vide chapter on hooks).

\section{SPINNING FOR SALMON.}

There are some rivers, principally large and deep ones, in which Salmon will take a spinning bait at certain seasons of the year. The Clare-Galway river debouching into Loch Corrib is an example. In this river in September and October, when a little freshet is coming down, an Eel-tail is perhaps the most attractive bait. Diagrams of the best tackle for spinning with the Eel-tail, and of the same when baited and ready for use (both of the actual size) are annexed. The flight consists of a No. I 6 hook whipped on strong Salmon-gut, with a pierced shot pressed tightly on to the top of the hook-shank, as shown in the cut. The object of the shot is to assist in forming a presentable head to the bait, and to keep the latter from 
slipping up and down. The trace should consist of fine stained Salmongut, but in other respects, the tackle, with the rod, reel, and running line, should be similar to that recommended for Pike (vide chapter on Pike-spinning). In order to bait this tackle, take an Eel of from about II to I4 inches in length, and skin it* to within 4 inches of the tail, cutting off the skin and flesh neatly at this point. Then cut off with a sharp pair of scissors the turned over portion of the skin half-way down. Next insert the hook in the centre of the flesh at the upper end of the bait, and run it through, as one would threddle a worm, until the point is brought out about an inch and a half from the tail end, curving the bait

* To Skin ax EeL. - Having killed the Eel, make a circular incision through the skin below the pectoral fin. This is best done by passing the blade of a sharp penknife under the skin, bit by bit, in a circular direction. Then pin the head of the Eel down to a table with a steel fork, and having got hold of the edge of the skin with the finger nails, and turned down a little way, take hold of it with a dry cloth, and it will generally pcel off with ease.

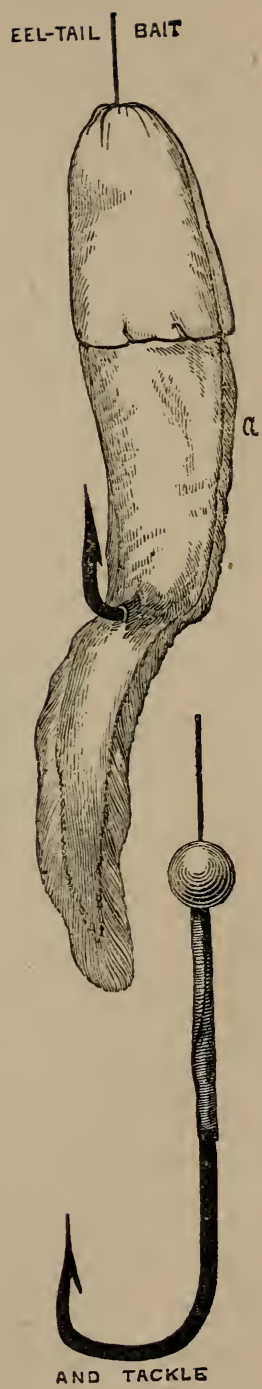


as represented. Having adjusted the bait neatly with the fingers, turn the loose skin up again, and with strong waxed silk or fine twine tie it tightly round above the shot; then turn it down again, and stitch the edges down with a needle and strong waxed silk or holland thread. The bait is then complete. It will be found to improve the shape of the head if one-fourth of an inch or so of the spine is cut out with a penknife at the point where the shot is to rest. The Eel-skin with which somewhat more than half the body of the bait is thus covered, is of a light bluish tint, which seems to be particularly attractive to Salmon. It is also, of course, exceedingly tough, and increases the durability of the bait. The Eel used for this bait is the better for being kept two or three weeks or even longer in plenty of dry coarse salt, which renders the skin both tougher and bluer, but it will do very well fresh. If the Eel is salted it will be found best to soak it in water for some hours before baiting, to make it plumper and more filled out. As the process of baiting an Eel-tail requires some little nicety, I recommend the angler to bait his tackle before starting for the water-side. Two baits, or three at the outside, will generally be found more than enough for a day's fishing, barring of course losses by breakages.

The best mode of spinning for Salmon is almost identical with that pursued in spinning for Pike, which latter is fully described in the chapter devoted to that subject. Not only in rivers but in lakes also, both Trout 


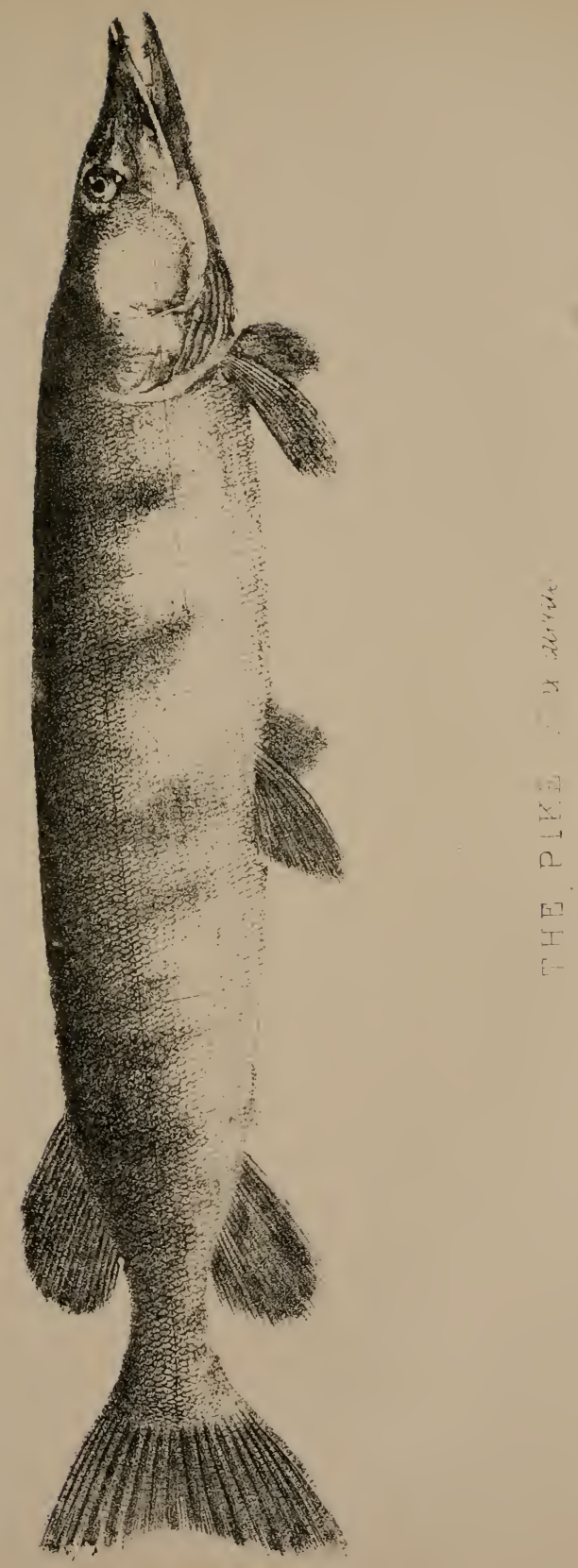



and Salmon may be taken by the Eel-bait. Salmon will also in some waters take the Parr-tail, and occasionally the Minnow; but I believe that if Salmon will take spinning bait at all the Eel-tail will in nine cases out of ten be found the most killing, besides being much the least trouble; as, when cnce baited, it is almost everlasting. Eels also sufficient for the purpose can almost always be procured by setting a night-line for them, either in ponds or rivers. The spinning bait for Salmon should be worked more slowly and gently than that used in Pike fishing, and the line should be sufficiently leaded to carry the bait nearly to the bottom of the rizer. No general rules can be given as to the state of water, or the season when Salmon will best take a spinning bait. Different localities differ on these points. In the Tweed, for instance, April, May, and sometimes March, are considered the best months, and according to Border canon, Tweed fish rarely take the spinning bait when the water is discoloured, or beyond its ordinary spring size. In the Clare-Galway river, Ireland, on the contrary, the Eel-bait comes on principally late in the season, and I have known fish killed by it in October when the water was too much discoloured for the fly.

\section{WORM-FISHING.}

The above observations on the differences of water and season for the spinning bait in different localities, 
apply according to most authorities to a considerable extent to worm-fishing also. For example, Mr. Stoddart lays it down that worm-fishing "can be practised with success only when the river is clean and small," and yet in Ireland I have known seven clean Salmon taken before breakfast out of "The Leap" on the river Bush, in April, when the water was all but in actual flood and hopelessly thick for the fly.

The mode of fishing as commonly practised is extremely simple: a large single hook, say No. I4 or I 5, is whipped on to two or three yards of Salmon-gut. A supply of lob-worms having been obtained, and, if feasible, previously scoured, the hook is passed through the middle inch or two of two or three of them, according to their size and the size and state of the water, the last worm being so put on that no part of the hook or barb is left visible. Sufficient large split shot should then be fixed to the line about $\mathrm{I} \frac{3}{4}$ feet above the bait, to take it well to the bottom, but yet they should not be so heavy as to prevent the stream carrying the bait freely along with it over the stones.

The bait is then worked very much like the worm bait for Trout, except that the angler, having selected a pool or run in which he knows that there are plenty of Salmon, generally remains at the same place, shifting his ground a few paces at a time higher or lower. The usual symptom of a bite is a stoppage of the bait, followed by a very gentle twitching. Sometimes, however, 
though in my experience rarely, the Salmon takes the bait in a more reckless fashion, resembling rather the run of a Trout. Having taken the bait, the Salmon wiil frequently remain nearly or quite motionless for some little time, and then move steadily away. This is the moment to strike, and as the bait is invariably actually swallowed or pouched, there is little fear of the fish being missed. Should the fish move away at once after biting, line and time must be given him to pouch the bait. To provide for the contingency of any sudden moves or rushes on the part of the fish, and against that of any sudden check on the part of the angler, it is a wise precaution always to keep a yard or two of spare line loose in the hand between the bottom ring and the reel. This precaution will not seldom save the loss of a fish.

The rod used for fly-fishing for Salmon, but with a somewhat stiffer top, and also the reel and line, will answer every purpose for this kind of worm-fishing.

But there is another method of worm-fishing for salmon, unpractised, so far as I am aware, and at any rate 'unpreached,' by any angler or angling writer, which, according to my experience, is as superior both in its practice and results to the system above described, as spinning is to gorge baiting.

This method consists of applying to Salmon the system of fine fishing already advocated for Trout, with three trifling differences only in tackle and bait. 
I. Instead of a "brandling" or other small worm, the bait should be a lob-worm, large or small, according as the river is high or low, coloured or clear.

2. The hooks and trace should be similar in every respect to the Trout tackle, but with hooks one or two sizes larger (only) as the bait is a large or small one; and instead of a small shot or two to weight the trace, a sinker should be used of sufficient weight to carry the bait lightly down to the bottom of the run or pool. A number of small paternoster leads (smoked to prevent their glittering) are most convenient for this purpose, and they should be attached to the main trace, about two feet above the hooks, by means of a horsehair loop, which will both admit of a ready change of leads, to suit the varying depths of the different casts, and, where a "foul" occurs, which it frequently does, will, as a last resort, break at a less strain than the main line, and thus save the latter. The lob-worm should be put on quite straight, like a Trout worm, the upper hook near the knot, and the tail hook lower down. The thicker the hooks are in the wire, the better. The stroke, a gentle one, should follow immediately on a bite, or more often on a suspicious stoppage being perceived. 
I have repeatedly caught Salmon with this tackle in bright sun, and in the clearest and finest water, and after all other methods of fishing, including the ordinary worm practice had failed; a slightly clouded water is however, best. It is of course most important, especially in the former case, that the angler should carefully keep out of sight; and, if possible, always below the spot which the bait is fishing. This is almost a sine quâa non with this mode of fishing-than which I know nothing can be more truly "sporting" and sportsman-like. The very fine hooks and tackle which must be used, and the nice manipulation of the line and bait required to insure success, entitle it to a front place in the Angler's Arcana. 


\section{PART III. \\ “ TROLLING,"-OR PIKE-FISHING.}

\section{GENERAL OBSERVATIONS.}

THE term "to troll" or "trolling" had no doubt its derivation in the Welsh words "troell," a wheel or reel, "trol," a roller, and in its less specific application means to move circularly or in a rollicking kind of way. In a general sense, therefore, any bait which is moved or worked in the fashion indicated might without inaccuracy be termed a trolling bait, and hence the word has been of late years frequently applied to all linds of spinning, whether for Pike, Perch, Trout or other fish. In its more strictly legitimate sense however, trolling has, since the time of Hobbes, who was christened the Father of trollers, been considered as especially applicable to Pike-fishing, and even, by way of an imperium in imperio, specifically to the method otherwise known as gorge-bait fishing. If the suffrages of modern anglers were collected, I think it would bc 
found that the large majority, rejecting the very restricted and the very latitudinarian interpretations, accept the word trolling as descriptive of Pike-fishing generally, and of no other kind of fishing; and in this sense I have used the expression in the heading to this part of my subject, the several kinds of spinning applicable to Salmon, Trout, and Perch, being dealt with in the chapters devoted to each fish.

In the "Book of the Pike,"* I have endeavoured to give a complete History of the fish, from the earliest times. There is no other species which has in itself so much character, if I may use the expression, and, perhaps consequently, so many curious anecdotes and quaint apocryphal legends clustered around it, almost from the dark ages down to our own days. I shall not here attempt to give any history of the fish, beyond noticing such of its habits and instincts as have a practical bearing on the art of Trolling. The space at my disposal moreover does not admit of ichthyological or anecdotal digressions. For the same reason, my observations will be confined as far as possible to describing what is in my opinion the best form of tackle for the various kinds of Pike fishing, without entering minutely into the arguments pro and ion., or

* The "Book of the Pike: a Practical Treatise on the various Methods of Pike-fishing, with an Analysis of the Tackle employed. Also a History of the Fish, \&c." London: Frederick Warne and Co., Bedford Street, Covent Garden, price $5^{\text {s. }}$ 
into a detailed examination of the numerous tackles, most of them now obsolete, which have at various times been advocated by other authors. These are given in detail in the "Book of the Pike"; and I am under the less necessity to repeat them, inasmuch as the tackles therein recommended have now been very generally adopted by trollers. 


\section{CHAPTER XIV.}

\section{SPINNING.}

The rationale of spinning-Early mention. Spinning Flights-The Author's patterns ; directions for baiting; details of construction. The trace-Best materials and knots; leads. Rod, reel, and reelline for spinning and Pike-fishing generally. How to spin-Casting; 'Nottingham method;' striking; playing; landing. Spinning baits-Natural baits; Bleak, Dace, Gudgeon; the Eel-bait, tackle for ; setting of Eel-lines; sea-fish as baits. Artificial baits. When and where to spin-Pike-haunts and spawning time. Receipt for cooking Pike.

THE only mode of snap-fishing with the dead-bait worth consideration is "Spinning,"-a branch of trolling which in the majority of cases as much surpasses in deadliness all other methods as it is unquestionably superior to them in its attractiveness as a sport, and in the amount of skill required for its successful practice. It will occasionally happen, no doubt, that in particular waters, or states of water, the live bait will kill more fish, or that a river may be so overgrown with weed as to be impenetrable to anything except a gorge-hook ; but such contingencies are comparatively rare, and taking the average of waters and weathers throughout the year, it may be safely assumed that the spinning-bait will 
basket three fish for two taken by any other legitimat method.

To this result several causes combine. The piquan effect of an apparently wounded fish upon a Pike's appe tite; the concealment of the hooks by the bait's rotary motion ; and last, not least, the great extent of wate: which may be fished in a given time. Add to this the almost universal applicability of spinning to all countrie: and climates, and it must be admitted that it fully justi. fies the high position in piscatorial precedence awardec it by most modern authorities.

The first distinct mention of spinning for Pike-as we understand the meaning of the word "spinning" - that ] am acquainted with in our Bibliotheca Piscatoria occurs in Robert Salter's "Modern Angler," the second editior. of which was published in $18 \mathrm{r}$, the first edition being probably therefore a good deal older. Spinning for Trout, however, has been known and practised at any rate since the time of Walton, who says that the Minnow should be so put on the hook that "it must turn round when 'tis drawn against the stream."

\section{SpinNing Flights.}

Bearing in mind the principles-already pointed out in the Chapters on Tackle, p. 16-which should rule in the construction of all spinning gear, I devoted a good deal of time and attention, some years ago, to making a perfect flight of hooks for this purpose, and the diagrams 
in the annexed plate, taken from the "Book of the Pike," show the result of my experiments. These flights represent the three sizes which will be found most convenient for all ordinary baits-that is, from a Gudgeon of medium length up to a fair-sized Dace. I never spin with very heavy baits myself, but for those who do, flights of the pattern of No. 4 should be dressed proportionally larger. No. I is figured in the chapter on Trout spinning (p. I 5 ), and will be found a very useful flight with a small Gudgeon or Bleak, when the water is low and bright. The upper triangle in No. 4 is, it will be observed, attached to the lip-hook, so that it must always hang near the shoulder of the bait. The under triangle hangs lower down near the tail.

The question of the relative size and proportion of the hooks to the bait is, of course, of great importance, as, if the hooks are too small, the Pike very probably escapes being struck by them, and if too large the bait will not spin. I should therefore recommend all spinners who may use this tackle, to keep at least the three smallest of these exact sizes of flights in their trolling case.

Directions for Baiting.-First, to fix the tail hook: insert the point by the side or lateral-line of the bait near to the tail, and passing it under a broadish strip of the skin and through the end of the fleshy part of the tail, bring it out as near the base of the tail-fin as practicable. Next irsert the small reversed hook, in such a position as to curve the bait's tail nearly to a right-angle. Finally, pass the lip-hook through both its lips, always putting it through the upper lip first when the bait is a Gudgeon, and through the lowver one first with all others. This is very important in securing a really brilliant spin. 
The flying triangle, or triangles, should not be booked into the bait in any way, but be allowed to fly loose in the position shown in the engraving.

The upper, that is, the shoulder portion of the body of the bait, should lie perfectly straight; and great care must be taken that the gimp or gut is tightened sufficiently to prevent any strain on the lips of the bait, and yet not so tight as in any degree to bend or crook its body. If these directions are not exactly attended to the bait will not spin.

Observations on the best form of hooks, tail-hooks, lip-hooks, and triangles, will be found in the chapter on that subject, (pp. I I-I 5).

Upon examining the results arrived at with the foregoing flights as contrasted with those obtained from any of the flights previously in use, I find that whilst with the best of the latter the average of fish lost after being hooked, was about half; with the former the proportion has only been one in six, or about 16 per cent., thus giving a clear gain to the basket of four fish out of every twelve hooked.

The following is a register of the actual number of runs, and number of Pike lost by me with this tackle when fishing the Hampshire Avon, during four consecutive days in August, $186_{3}$, the water, it should be observed, being in the worst possible condition for spinning, and full of weeds :

$$
\begin{aligned}
& \text { No. caught. No. lost. }
\end{aligned}
$$

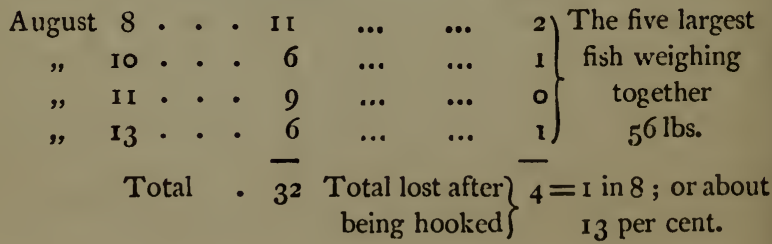




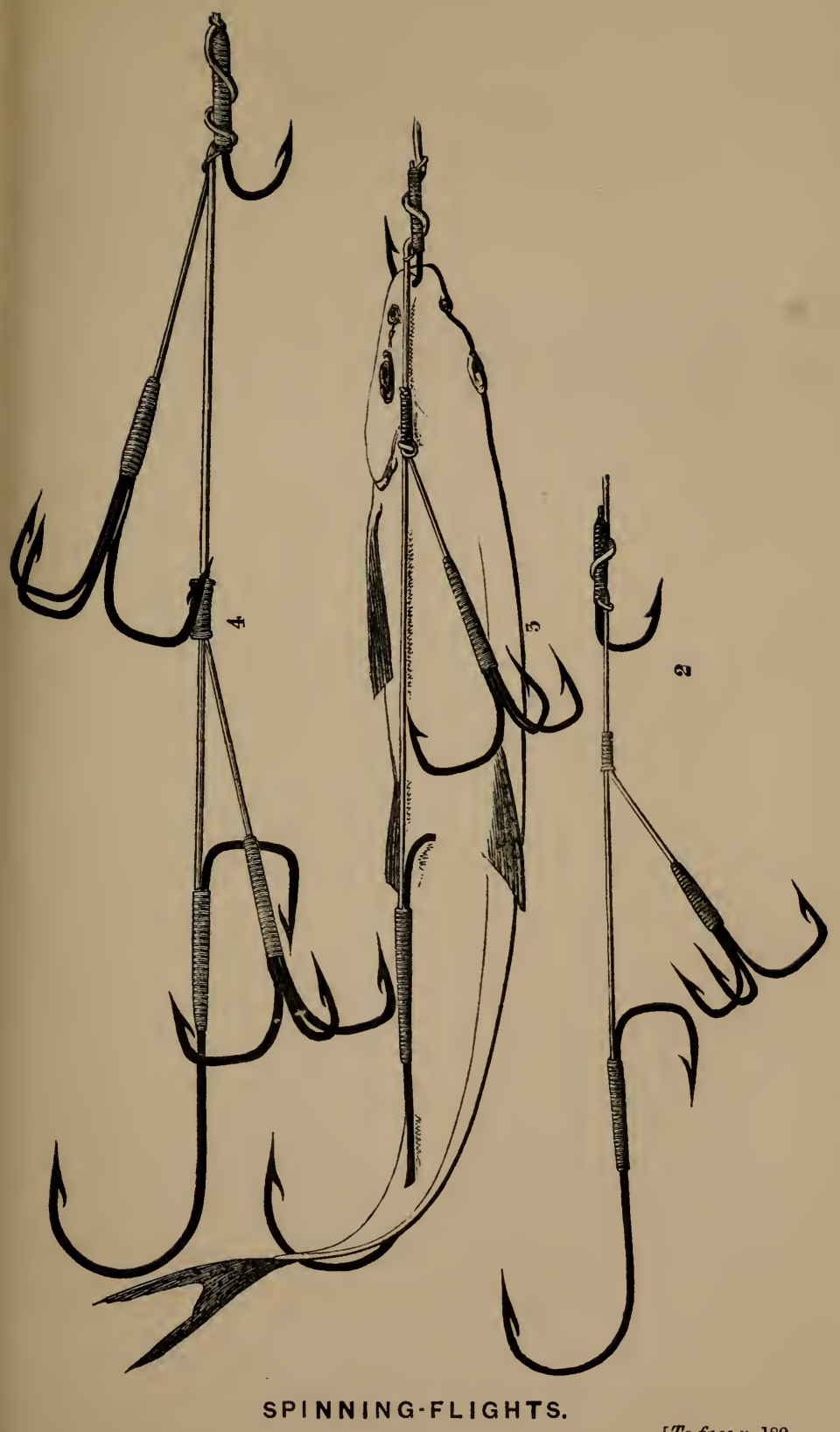

[To face $p .180$. 

Mr. Frank Buckland, who was fishing at the same time, and who also used my tackle, did not miss a single run.

The next point is the material on which the flight should be tied, the object being, of course, to secure the greatest amount of finencss compatible with the required strength. And as nothing could well be worse for finefishing than gimp in its natural state, so when stained in the manner pointed out in the preliminary chapters (p. 34), nothing can well be better. It becomes, in fact, almost as invisible in the water as gut itself; and is, therefore, recommended strongly to be used under ordinary circumstances both for trace and flight.

With regard to the material of which the short link for the Flying triangle in spinning flights should be made, this depends upon considerations different from those which govern the choice of the material for the central link. The one absolute essential is, that the substance-be it gut or gimp-by which it is attached to the central link of the trace, should be to a certain extent, to use a paradoxical expression, stiff and clastic, so that the triangle may always stand out in its proper position at the shoulder of the bait. Without this precaution there can be no certainty that a fish will be hooked. Ordinary gimp very fairly fulfils the purpose whilst it is new and stiff, but when it becomes flabby, which will occur after it has been used for a 
short time, the cortainty of hooking a fish is materially reduced. I, therefore, had made some twisted "gutgimp," as it may be called- - that is, treble gut twisted, covered with fine wire-which I find combines every necessary quality.

In order to cause the link of the flying triangle to stand well out from the bait, it should be tied round the central link in a half knot, as shown in the diagrams, before being lapped. This is of importance. The gimp wire can be unwound from that portion of the gut which is required for tying the knot.

With the exception of the lip-hook, I generally cover the lapping of the hooks used in spinning flights with silver tinsel, which perhaps increases somewhat the attractive effect, and blinds the eyes of the fish as to the character of these glittering appendages.

The next, and almost equally important portion of spinning gear is-

\section{The Trace.}

This should be made of one of two substancesstained gimp, as before stated, or single gut.

For very fine fishing I commonly make my own traces of five or six lengths of the thickest salmon gut (stained) that can be obtained-two above the lead, and threc below,-and when properly tied and managed, I speak from experience in asserting that such a trace will hold anything of the Pike species up to twenty pounds, and I 
have little doubt that in open water that weight might be doubled, or even trebled with safety. But properlyticd and handled, mark: for it is a great mistake to assume, as I have often heard fishermen do, that because a single-gut casting line will kill a Salmon-the gamer fish of the two- $\dot{a}$ fortiori, it will kill a Pike of equal size. With the same rod, and in the same water, it will do so no doubt. There is, however, a wide distinction to be drawn between a stiff three-joint trolling rod, and a twenty foot "Castle Connell," and a vast difference between a clear Highland Salmon river, and the weedy, often foul waters, usually tenanted by overgrown Pike. The stiffness of the rod renders the line liable to sudden jerks and strains, whilst the sharp blow which is absolutely necessary for properly striking a fish, is the most trying ordeal to which any knotted tackle can be subjected. But the thing is to be done, notwithstanding. Two essentials only besides good management are required-a rod-top of the proper stiffness, and the peculiar description of gut knotting described at page 55 .

\section{LEADS.}

For observations on the subject of leads generally, and for a description and diagram of the pattern which is recommended to be used for all kinds of spinning traces, the reader is referred to the preliminary chapter, pp. 18-20. 


\section{RoD, REel, ReEL LINE, \&c.}

In the same chapters will be found a description of the rod, reel, running-line, and hooks suitable for Pike fishing. In the matter of Trolling rods tastes usually differ widely, but the rod contained in the "general rod" described at page $5 \mathrm{I}$ is, I think, as perfect a spinning rod as can be used. If greater strength or stiffness is required, the butt may be made solid instead of bored, and one or two shorter tops may be added. My experience leads me to give the preference to ash or hickory, and greenhart, for any Jack rod under thirteen feet in length. Beyond that, the difference in weight, slight as it is, tells decidedly in favour of bamboo. The rod suitable for spinning is also suitable for all kinds of Pike fishing. If very large live-baits are used, a somewhat shorter top may be substituted for that described.

\section{How to SpIN.}

The rod and tackle being arranged as described, and the bait hanging about two yards from the top of the rod, the spinner unwinds from the reel as much line as he requires or thinks he can manage, allowing it to fall in loose coils at his feet; and then, giving the bait one or two pendulum-like movements, swings it vigorously out in the direction in which he wishes to cast, at the same time letting go the line altogether, and permitting the bait to run oui to the full extent. After allowing a 
few moments (according to the depth of the water) for the bait to sink, he lowers the point of the rod to within a foot or so of the surface, and holding it at about right angles to the bait, begins drawing in the line with his left hand, making with his right a corresponding backward movement of the rod, between each "draw." The object of this movement of the rod, which to the spinner soon becomes a sort of mechanical see-saw, is to prevent the bait being stationary whilst the left hand is preparing for a fresh "draw"; and in order to accomplish it satisfactorily the best plan, as well as that most convenient for casting, is to hold the rod firmly with the right hand just below the lowest ring, letting the line pass between the upper joints of the middle and forefinger, and resting the butt of the rod firmly against the hip. In spinning from a punt an agreeable change of posture is obtained by standing with the right foot on the side or well of the boat, and partially supporting the elbow and rod on the knee. The "draws" or pulls, and the corresponding movements of the rod, must of course be varied in length and rapidity according to the depth of water, size of bait, and other circumstances, but a good medium speed, when the left hand is carried well back, is about forty "draws" per minute; and a cast for every two yards of stream fished is the allowance which on the whole will generally be found the most advantageous. In spinning for Salmon a slower and gentler movement is necessary. 
The bait should not be taken out of the water until brought close $u p$ to the bank, or side of the boat, as it is not at all an uncommon circumstance for a fish, which has perhaps been following it all the way across, to make a dash at it at the last moment, when he appears to be about to lose it.

The proper play of the rod, which is one of the most certain tests of a good spinner, is highly important, not only to prevent the stopping of the bait between the draws, but in order to give it its tull glitter and piquancy. It produces a more "lifelike motion," as it were, than that imparted by the mere pulling in of the line by hand, whilst for some reason or other-probably the greater elasticity of the lever used-the spin of the bait is also far more rapid and brilliant.

The loss of attractiveness in the bait caused by the substitution of a mere mechanical motion for this combined movement of the hand and the rod, is in my opinion one fatal objection to what is termed the "Nottingham style" of spinning.

To test the fact that such a loss does actually take place, the following simple experiment will suffice;drop the spinning bait into the water, and wind it in as fast as possible, on the Nottingham plan (that is, by the reel only), keeping the point of the rod stationary; then draw the bait through the water at the same pace, using the rod only, and it will be found that whilst a 
rapid spin is gained by the one, the effect of the other is little better than a "wobble."

These are the obvious theoretical objections to the Nottingham style, as a system, which must occur to any one accustomed to the Thames method of spinning. It is much to be doubted, however, whether practically it would be found even feasible with the small baits and very light leads and traces constantly used on the Thames and other fine waters. With such a bait and trace, weighing together exactly I oz. 2 scruples, I have made a cast of forty-two yards (measured), which I should say would be entirely out of the question if the same bait were thrown from the reel. The weight of the bait and trace used by Mr. Bailey, and of which I obtained patterns from him, is $3 \frac{1}{8} \mathrm{oz}$., or nearly three times as much.

With regard to the direction in which to cast a spinning bait, opinions differ somewhat. In stagnant waters no difficulty can of course be felt, as the simple and obvious rule is to cast over the place in which the fish are most likely to be ; but with rivers the case is different, and the cast straight across stream, and that straight down stream have both their advocates. As in many other matters I believe that the truth lies midway between the two extremes, and that putting aside exceptional circumstances, which of course make their own rules, the best direction in which to cast with the spinning bait over running water is diagonally- 
that is, in a direction rather slanting down and across the stream.

The depth at which the spinning bait should be worked depends entirely upon the state of the water with reference to weeds and other circumstances. It will be generally found, however, that in hot weather the fish lie near the surface, and in cold weather near the bottom; so that the bait should be spun "shallow" or "deep" accordingly.

The next question of importance is striking, as more Pike are probably lost by a failure in this point than by all the other casualties of spinning put together.

It is therefore strongly recommended to all spinners, as the very alpha of their craft - and notwithstanding the opinions to the contrary expressed by many angling authorities-to strike, - and that the moment they feel a run. All other rules, such as "giving the fish time to turn," "waiting till he shakes the bait," \&c., \&c., are useless, and indeed generally impossible in practice.

Again, the Pike, with many other predaceous species, shows a great reluctance to quit his hold of a prey once seized. Most of us have probably witnessed this tenacity in the case of both Eels and Perch ; and the Stickleback, as is well known, will let itself be pulled out of the water by its hold of a worm. On one occasion for the sake of experiment, I fastened a large cork to a string, 
and drew it across a Pike-pond, giving it at the same time an irregular, life-like motion. It was quickly seized by a fish of about 2 lbs., which made a most determined resistance, running out the twine as if really hooked, and only relinquishing its grasp of the cork when within arm's length. The experiment was repeated several times with a similar result.

This illustrates a fact of great importance to Pikefishers, and one which is of especial significance in the case of spinners : namely, that Pike will constantly show considerable fight, and even allow themselves to be dragged many yards, by the obstinacy of their hold, without ever having been pricked by a hook-shaking the bait out of their mouths when almost in the net.

I say once more therefore-Strike,-and strike hard; and repcat the stroke until a violent tearing struggle is fclt; such a struggle almost invariably beginning the moment a fish really feels the hook, and being easily distinguished from that sluggish resistance, sometimes absolute inaction, experienced when he is only "holding on." It is generally large unwieldy Pike which act in this fashion, and an attention to the above suggestion will not unfrequently save the loss of the best fish of the day.

In the majority of instances, neither time nor circumstance admits of any rules as to the direction of the stroke being adopted, and in such cases the simplest and safest plan is to strike straight upwards. 


\section{Playing.}

The golden rule in playing all fish is to keep a strong and even strain upon them from the first to last, and get them into basket with as little delay as possible. The maintaining of a sufficiently heavy strain is particularly necessary in Pike-fishing where stiff rods are used, and flights containing several hooks, as the sudden slackening of a foot or two of line is sufficient to restore such a rod to the straight position from which it has been comparatively little bent, thus removing the strain altogether.

Should a fish run under or into weeds, there is but one plan to be pursued; -instantly tighten the strain upon him to the very utmost that rod and line will bear : by this means the line will frequently act as a knife and cut its way with the fish, through all obstacles. But whether the expedient fails or succeeds it is the only one that can be adopted: if once the fish passes under the weeds without carrying the line straight over him, the latter forms an angle at the point where it strikes the obstacle, and all power over the fish is instantly lost.

\section{LANDING.}

There are many conflicting opinions in regard to the landing of the Pike, as on all other angling matters.

Nobbes suggests that you " put your fingers in his eyes." -adding "some will adventure to take him by the gills, 
though that hold is neither so secure nor so safe for the Fisher, because the fish in that heat of passion, may accidentally take revenge upon his adversary, by letting him blood in the Fingers, which way of phlebotomizing is not esteemed so good."

The justice of this latter observation will probably commend itself to Pike-fishers without any very elaborate argument. Indeed most of us would probably object to attempting practically either one or the other of Nobbes' ingenious methods. If neither a landing-net nor a gaff is accessible, by far the best and safest method of landing a Pike is to grasp him as tightly as possible behind the shoulders, and either lift or throw him on the bank.

In spinning, the gaff has a great advantage over the net, inasmuch as it prevents the straining, and often breaking of the flight, by the struggles of the fish in the net. A Pike-fisher will generally find it both more profitable and more amusing to gaff his own fish.

\section{SPINNING-BAITS.}

To commence with the fresh, natural baits. Of all the natural Pike-baits ordinarily used, the best, both as regards perfection of spinning and durability is incontestibly the Gudgeon, and I believe that taking the average of waters and weathers, it is also, of such baits, the most killing all the year round. In clouded water or very dark weather, a Bleak or small bright Dace or Chub may, from their glittering scaling, possibly possess 
an advantage, as being more readily seen; and in cases where the Pike are known to be of exceptional size, a bait of one or other of the two last-named species, and larger than a Gudgeon, may be desirable. As a general rule it is always safe to use a small bait when the water is low and bright, and a larger one when it is full or clearing after a flood.

These observations are limited, as pointed out, to a comparison of the baits commonly recommended in angling works and used by Trollers. There is, however, a Pike-bait that is not recommended by any author, so far as I am aware, but which is well worthy of the attention of Spinners: I refer to the Eel. It has been found by experience that Pike in stews prefer Eels to any other fish as food, and also fatten upon them more rapidly, and a consideration of this fact first led me to try the Eelthough doubtless it has often been tried before-as a spinning bait for Pike. It appeared only probable that the food which was most popular in a stew would also be most popular in the open river or lake. This deduction has certainly been justified by the result of my experiment; for since I have used the Eel-bait I have caught both a greater number of Pike, and those of decidedly a larger average size than $I$ ever took in the same waters, either stagnant or running, with any of the ordinary baits. I have also tested the one against the other on the same day and water, and the advantage has always been unmistakably with the Eel-bait, whether 
employed whole or in part only. A whole Eel 8 or 9 inches long makes a capital bait, and it can be used on the tackle shown in figure 4 of plate. Owing, however, to the giving way of the lips after a few runs, the whole Eel is a less convenient bait than the tail part only, out of which an artificial head can be formed that never wears out. Indeed I have fished with a bait so made for two days consecutively, taking a good many fish on both, and the bait was still fit for work at the end. This is owing to the extraordinary toughness of the Eel skin, on which the teeth of the Pike make little or no impression.

The eel-tail bait and tackle when used for Pike spinning is, with two exceptions, dressed and baited exactly in the same manner as that described for spinning for Salmon (p. 167). The exceptions are: first, that the bait and hook are commonly about double the size; and secondly, that this greater size renders the addition of a flying triangle necessary to insure hooking a fish run. The best sized eel for making the bait is from I I to 14 inches in length, but one a little longer or shorter will serve the purpose. For a large sized bait, about 7 inches (when the bait is complete) is the best length. The hook used should be a No. 20 of my pattern (vide p. 10), which is $3 \frac{1}{2}$ inches long in the shank, or one-half the length of the bait. In smaller baits somewhat smaller hooks should be used-the same proportion bctween the longth of the hook and bait being always pro- 
scrved. This is important to insure a good spin. The flying triangle for the large sized bait described should

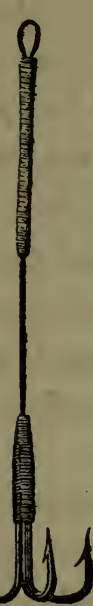
be a No. IO or II, the link to which it is attached being of stout gut-gimp as already described, and the total length of gimp and triangle about $2 \frac{1}{3}$ inches (diagram annexed). This makes the flying triangle hang at the right place, by and below the shoulder of the bait. The gimp should be finished of with a small loop of about the size represented. The flying triangle is fastened to the bait as follows:-The skin having been cut off about $I_{2} \frac{1}{2}$ inches from the flesh, and turned down and sewn in the manner directed at p. 168 , make a small slit in the turned down skin near the middle of the side of the artificial head: pass the loop end of the gimp upwards through this hole, under the turned down skin, and bring it out through another small hole made at the "nose" of the bait close to the main link of the flight; the main link should then be passed through the loop of the triangle, and the latter drawn down again to its proper position.

This bait has the great advantage of being, able to be used salted. Instead of becoming soft and flabby as other baits do when "pickled," the Eel on the contrary grows tougher, and if placed in plenty of coarse, dry salt, either in a jar or other receptacle, will keep, within my 
own experience, for five or six weeks, and probably for much longer. Before being used the Eel should be allowed to soak in fresh water, if possible for ten or fifteen hours, to restore its plumpness and pliancy.

It will be found most convenient to make up the Eeltail bait before starting for the river side, as the manipulation is troublesome and requires some nicety. When once made, however, it is almost everlasting, and thus, in fact, effects a great saving of the angler's time in baiting. The salted Eel-tail in my opinion is not only by far the best preserved Pike bait, but it fulfils every requirement that the most exacting can demand, and thus satisfactorily solves that vexed problem, the great Preserved Bait Question, which has been so longdiscussed in the columns of the sporting press, and in which the comfort of the Pike spinner is so vitally concerned. In a pickle-jar or a small bait-kettle, the troller can thus carry with him enough spinning baits to last him easily for a week, and these can be kept and used again if not wanted.

Another advantage of Eel-bait is that it can be obtained at almost any pond, river, or canal by merely setting a night-line baited with worms on No. IO or I I hooks. The great point in the management of Eellines consists in taking them up sufficiently early-before or about sunrise, say : if they are allowed to remain long after the sun is up, the major part of the Eels will get off the hooks. 
Another way of making the Eel-bait is to cut out from just below the neck of the Eel 3 or 4 inches of the thickest part of the body, the head and tail being then sewn together with strong silk or holland thread. This bait can be used on the same flight as the whole eel ; but it does not wear nearly so long as the tail bait above mentioned.

When fresh-water bait cannot be procured, either of the following sea-fish can be used-zohen quite fresh-as substitutes:-Basse, Grey Mullet, Herring, Sprat, and large Whitebait.

\section{ARTIFICIAL BAITs.}

So far as my experience goes, artificial baits-and I have tried not a few-are entirely inferior to natural baits for Pike fishing: they should only be used when the latter cannot be obtained. The "spoon-bait" was tolerably killing when it first came out, but it seems to have gradually lost its attractiveness, at any rate on waters where it has been much used, and is now generally inferior even to the ordinary run of artificial baits.

\section{When, AND WHERE TO SPIN.}

In some respects the discussion of the first part of this subject may be considered unnecessary, as, practically, men who have once taken to spinning rarely care much for any other method of Pike fishing, and with slight exceptions the spinning bait may be used with advantage from 
the Ist of June to the end of February - that is, during the whole season when Pike should be taken. The only circumstances under which the preference is to be given to the live bait or gorge bait, is, for the former, when the water is too much discoloured by flood; and, for the latter, when too much overgrown with weeds to make spinning practicable. Nor do I believe that there is any rule as to the state of the wind, weather, or water, by which the most experienced Pike fisher can really prognosticate what will be a good day for spinning and what for trolling, or even whether the day will prove good for Pike fishing at all. To this view I have been gradually led by a careful observation of the condition of weather and water existing on days on which I have had the best and the worst sport, and I cannot say that I have ever been able to make out that there was any rule or system whatever traceable in the result. In this opinion I am confirmed by Captain Warmington of Fordingbridge, a most experienced "spinner," who kept for many years an exact register of the state of the wind, water, barometer, \&c., on the days when he had been Jack fishing. without, as he assured me, having been able to arrive at any results whatever-the results, in fact, were altogether contradictory and unintelligible. My own experience is that in very severe cold it is of little or no use fishing for Pike: they seem to become torpid or sulky from cold, and will not take except under extreme provocation. The only chance 
under these circumstances, in most waters, is the live bait; but even this method-in which the pleasure of the fisherman is so much sacrificed to that of the fish-will often fail. The presence of melted snow in the water, however small the proportion may be, will almost invariably prove fatal to Pike fishing, as to every other description of fishing without exception.

Probably a good breeze from whatever quarter it may blow is favourable for Jack fishing, and particularly for spinning; whilst with regard to Water the only rules which can be considered to have any general significance are that a full fresh stream, the rising that precedes a flood, and the clearing that follows it, usually give heavier baskets than a water that is low or bright.

As regards the Where of spinning:-The haunts of Pike vary considerably at different times of the year, and also vary with the nature of particular waters; but it usually prefers a still, unfrequented spot plentifully supplied with weeds and flags, selecting if possible a gravelly or sandy bottom. The neighbourhoods of reeds, docks, bulrushes, and the broad-leaved water-lily are its favourite resorts; and of these a flooring of lilies, with from four to six feet of quiet current over it, and a wall of reeds at the side, springing from the bottom, is the best-

" A league of goss washed by a slow broad stream That, stirr'd with languid pulses of the oar, Waves all its lazy lilies and creeps on. ..." 
Indeed it may be said that the reed and the lily are to the Pike what the hollybush is to the woodcock. In lochs and meres it commonly frequents the most shoal and weedy parts, small inlets, and little bays, or the mouths of streams where minnows or other fry congregate; and in rivers, back-waters and dam-heads, eddies between two streams, or in fact any water that is weedy, of moderate depth, and not too much acted upon by the current.

As a general rule, Pike will be found during the summer in or close upon the streams; and in winter, after the first heavy flood, in the large eddies and deeps.

The Pike spawns sometimes as early as February, but more commonly about March or April, according to the climate, forwardness of the spring, and other local circumstances,-the young females of three or four years old taking the lead, and the dowagers following. For this purpose they quit the open waters in pairs, and retire into the fens, ditches, or shallows, where they deposit their spawn amongst the leaves of aquatic plants; when the spawning process is complete the fish return again into the rivers, and are then for some weeks in a state of partial stupefaction, and unfit for food. In rivers they begin to be in condition again about June, but in still waters the recuperative process is much slower. On the Thames, within the City jurisdiction, which extends up to Staines, Pike-fishing is illegal between the Ist of March and the 3 Ist of May. 


\section{CHAPTER XV.}

TROLLING WITH THE DEAD GORGE BAIT.

Tackle and books-New gorge leads described; improved mode of fastening tail of bait; trace for gorge baiting. Working the gorge bait-How to distinguish a 'run'; management whilst gorging. Best gorge baits.

As the only dead-bait Snap-tackle of any value to the angler is that used in Spinning, so the only dead-bait Gorge-tackle which can be similarly described is that employed in the method of Pike-fishing commonly known as "Trolling."

TACKLE : HoOKs.

Although Trolling is by no means so exciting or artistic a mode of fishing as spinning-and all gorgetackle should on general considerations be avoided as far as practicable-yet it is often an exceeding useful adjunct in the Pike-fisher's vade mecum, as he may not unfrequently meet with waters so weedy, or overrun with bushes or stumps, that a spinning-bait cannot by possibility be worked. The gorge-bait is then in its legitimate province-a province to which I confess I, for one, should be disposed to confine it. 
TROLLING WITII THE DEAD GORGE BAIT.

It is curious that whilst so many portions of the Fisherman's equipment have of late years undergone such a complete transformation, the gorge-hook, except in the matter of finish, has been literally stationary. In fact in a most essential particular it has retrograded instead of advancing-I refer to the length of the wire shank or "arming" attached to the leaded hook. This is a most important point, for two reasons. First because the modern system of elongating the hooks by a stiff coil of twisted wire destroys to a considerable extent the life-like play and elasticity of the bait; and secondly, because this unnatural stiffness and rigidity is constantly the cause of the Pike refusing to pouch it.

The cause of the modern innovation is plain enough ; it is to assimilate this length of the hook to that of the bait, so that there may be something solid on which to fasten the bait's tail, and thus prevent it slipping down the gimp and doubling up. Even with this assistance, however, the process of baiting is tedious enough : to be effectual it must be done very carefully; and what can be more trying than pottering with numbed fingers over the complicated miseries of needle and silk in a biting east wind, or when, perhaps, the only propitious hour of a winter's afternoon is visibly gliding away? Moreover, if the hook be not exactly of the right length of the bait's tail, there remains the contingency either of having nothing to lap it to, or of leaving a thick 
stump of brass wire protruding where most certain to be seen.

With these facts and experiences vividly in my recollection, I one day set about thinking how this tackle could be improved,- the object being of course to get rid of the superfluous wire shank, at the same time finding a simple and effectual manner of fastening the bait's tail without it. Rather by good luck, I believe, than anything else, I succeeded in hitting upon a plan which not only fulfils these conditions but also gets rid altogether of silk or needle and saves the trouble and delay which they entailed.

The shape of the tackle and of one form of the lead will be seen on a reference to the annexed plate.

Figure No. I represents the gorge-hook, \&c., unbaited, and No. 2 the same when baited and ready for use. Figure 3 is a smaller size of the hook; and the loop A shows the position actually occupied by the gimp after being passed through the tail of the bait, and tied.

In this tackle it will be seen ( $I$ ) that the wire arming of the hook is cut off close to the end of the lead, thus materially reducing the unnatural rigidity of the bait before alluded to ; and (2) that the shank of the hook (C) is left bare for about half an inch above the bend. This is the portion of the hook which lies in the throat of the bait when adjusted, and the object in cutting away the lead is to prevent that unnatural and unsightly-looking enlargement of the throat and gills 
I

. 


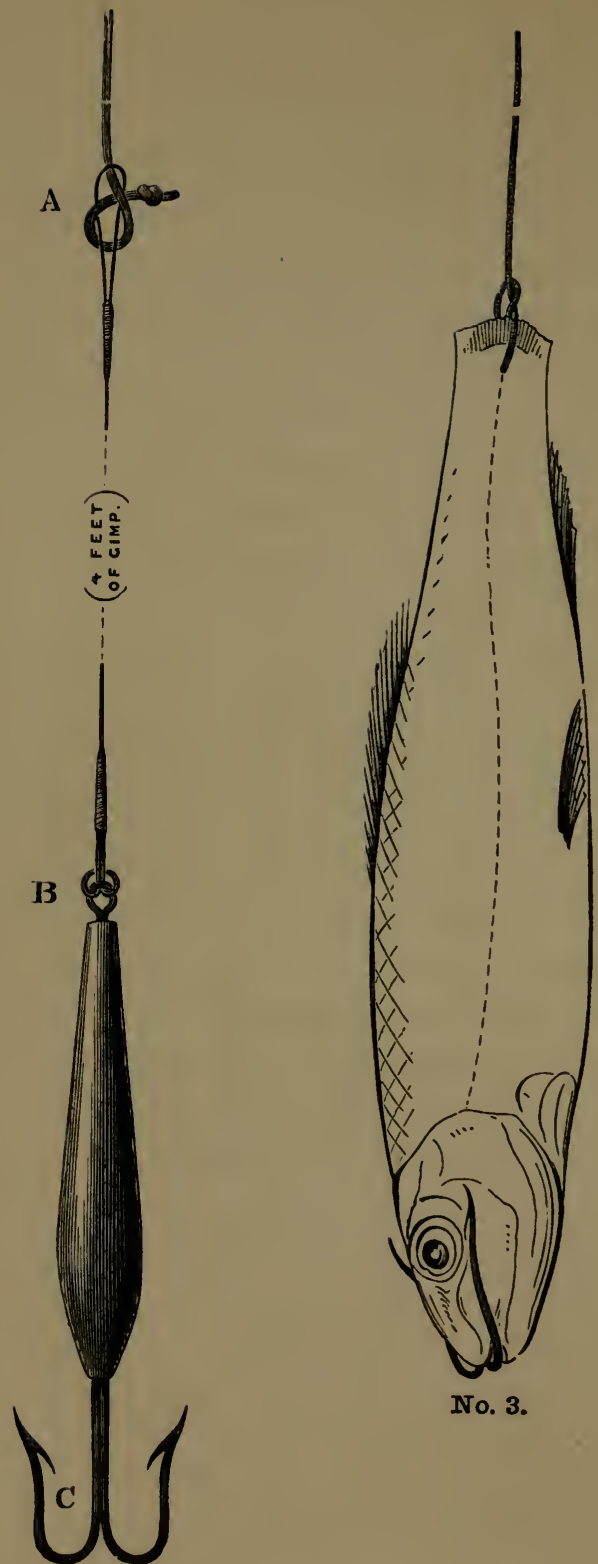

No. 1.

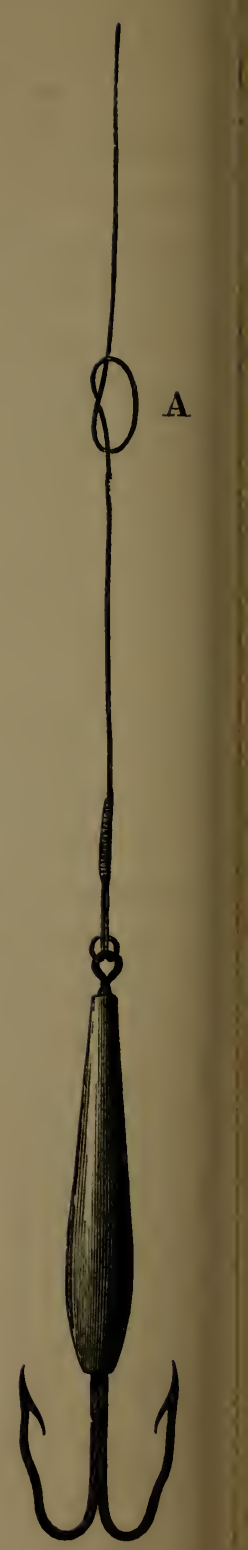

No. 2.

[Tofiuce p. 203. 
which occurs with the ordinary hook, and which renders it necessary to tie the gill-covers down to prevent their catching or tearing in the weeds. It also avoids the necessity of sewing up the lips of the bait to prevent the hooks slipping or shifting.

This is a decided saving of time and trouble, and, moreover, makes the bait last longer by being less strained. The darting and glancing motion which it should have is also increased by the placing of the lead in the proper place-the belly.

A still better method of weighting the gorge bait is by forming the lead of pierced shot, simply threaded on the gimp attached to the hooks, and graduated in size so as to resemble the solid lead in shape. A weight of this kind has the advantage of being quite soft to the teeth of the Pike when seized, and thus gets rid entirely of the "lead stiffening" in the bait's belly.

Perhaps, however, the greatest advantage incident to this tackle, used either with the solid lead or pierced shot, is the saving of time and annoyance in fixing the tail when baiting. This is accomplished as follows :-

First cut the tail-fin of the bait off close to the flesh; then with a baiting needle pass the gimp in at the mouth and out again by the tail of the bait as usual, taking care to bring it out as nearly in the centre of the tail as possible: then pass the baiting needle laterally through the bait's tail, at about a quarter of an inch from the extremity, drawing the gimp through after it ; and finally pass the end of the gimp through the loop thus made at the extremity of the bait (see figure 2 of plate) and draw it tight. A sort of half knot is thus formed which never slips, and which can be untied in a moment when a fresh bait is required. 
This arrangement is the simplest possible-such as any schoolboy could manage without difficulty at the first trial. Yet simple as it is (and for that reason only, valuable) it will be found practically to make the whole difference in the convenience and efficiency of a Trolling bait.

The precise bend of the hooks used for gorge-fishing is of comparatively little consequence, although the neatest is perhaps that shown in the engraving, fig. 3 . The one essential is that their points should stand sufficiently out from the sides of the bait's head-the barbs pointing upwards-to insure hooking, and yet not so far as to be unsightly or catch in the weeds.

\section{TRACE FOR GORGE HoOKS.}

No link of gimp, separate from the trace, is required in this arrangement ; as the trace, which should consist simply of about four feet or so of fine stained gimp, can be looped on to any hook in the manner shown in the engraving (fig. I, B). Swivels also are merely encumbrances. When a fresh bait is to be put on the hooks, the gimp should be unhitched at its junction with the running line. The simplest and most efficient fastening for this and all other traces and casting lines, is shown in figure $I(A)$.

\section{Working THE GoRge BAIT.}

The word "troll," taken as explained by its derivatives, 
expresses the sort of circular movement which should be given to the gorge bait, and for the purpose of producing this it is a common and very good plan to cut off a pectoral fin on one side and a ventral fin on the other. A good many Trollers also cut off the back and anal fins to prevent their catching in the weeds, but I believe this to be a mistake, as the stripping off of all its fins reduces the bait too much to the condition of "King Log," and considerably curtails the variety of its gyrations in the water. Moreover the inconvenience which it is intended to obviate is usually more imaginary than real.

The major part of the movements of the bait being produced by itself when sinking head-foremost, the part of the Troller is principally to keep on raising it, every second or two, to the surface, and generally to take care that its conduct approaches as nearly as circumstances will permit to the laws of perpetual motion.

Short casts rather than long ones are to be recommended, as the bait can thus be made to enter the water in a downward-darting direction instead of flat on its side, or perhaps tail-foremost.

I am not usually an advocate for any Medo-Persic laws with regard to fishing up stream or down stream; but in trolling with the gorge bait it is essentially necessary to adopt the former method, to cast, that is, somewhat in front of and above you, and work the bait 
downwards towards you-and for a very simple reason : namely, that the slope of the zuceds with the current makes it impossible to work it properly in any other way. This plan has also the merit of bringing the bait into contact first with the Pike's jaws instead of his tail. The bait should be kept as much as possible in the runs and gullies between weed-clumps, or at the margin of weed-beds in pools, and being brought well home to the boat or to the troller's feet before being lifted out of water for a fresh throw. Each time that the bait is left to sink after a "lift," a proportionate quantity of the line should be pulled in with the left hand and allowed to coil on the ground; the action being slower than, but of the same nature as, that required in Spinning.

\section{How to distinguish a " mun."}

Upon a fish seizing the bait, the first notice which the Troller receives of the fact is the stoppage or check of the line, very often hardly to be distinguished from that occasioned by a weed, and followed generally by a few savage little tugs or wrenches which are produced by the jaws of the Pike in his efforts to kill his supposed victim. Sometimes, however, the bait is taken by a heavy fish with a rush and jerk that well-nigh twists the rod out of the Troller's hand.

\section{Management of Pike whilst Gorging.}

The first step to be taken on perceiving a fish, or a 
suspicious 'check,' is to slacken the line, letting out a few yards from the reel if there is none already unwound, and seeing that all is clear for a run. The next point is to ascertain indubitably that it is a fish; because although it is perhaps comparatively seldom that a fish is mistaken for a weed for more than a few seconds, it by no means unfrequently happens that a weed or stump is mistaken for a fish; and nothing less than a wasted five minutes will convince the agitated Troller that such is the case.

Most of my readers will probably remember Leech's. charming sketch of the old gentleman, who has got a ' run' of this sort, standing, watch in hand, instructing his young companion, " never to hurry a Pike, Tom. He has had ten minutes already; I shall give him another five to make sure "-whilst his hooks are palpably to be seen stuck fast in a submerged stump.

When however the nature of the retainer which your bait has received is thus doubtful, a little judicious tightening or a few slight pulls of the line will generally elicit signs of vitality should a Pike be at the other end of it. If "no sign" is made, the demonstrations may be gradually increased until the point is satisfactorily settled one way or other. Should the seizer-being unmistakably a fish-remain passive or moving quietly about within a small compass for more than three or four minutes after taking, a slight jerk (or "stirring" as Nobbes has it) may be given at his mouth, which if 
dexterously administered will probably have an effect of hastening the dénouement.

Sufficient time should always be allowed to a Pike to gorge the bait-five or even ten minutes if necessary; the fact of his having "pouched" will most commonly be indicated by his moving off towards his favourite hannt immediatcly afterwards. If he then remains quiet without moving away again, the line should be gradually tightened (not struck, although Nobbes says a "gentle stroak will do him no harm ") and the fish landed.

\section{BEST GORGE BAITS.}

Any of the ordinary Jack baits can be used with gorgetackle; but a Gudgeon is commonly the most killing in clear water, and a Dace or other bright fish in water that is swollen or discoloured.

The best method of extracting the hooks from the fish when killed is to make a small slit in the belly of the fish at the point where the gorge-hook is felt to be, and, after disengaging the trace from the reel line, draw the bait out head foremost through the orifice. 
209

\section{CHAPTER XVI.}

\section{LIVE-BAIT FISHIN G.}

Snap live-bait tackle-Defective tackles; essentials of a perfect flight. New pattern described; mode of baiting. Floats; new system of floats. Minnow needles : Trace described. Baits, and how to catch ; bait-can. How and where to use the live bait. Live gorge bait.

\section{Live-BaIt Fishing.}

Snap Live Bait.

A GREAT variety of patterns of live-bait tackle are given by various authors; some of them tolerably good, others (and they are the majority) execrably bad-whilst a few are simply impossibilities, as no live bait could survive their application more than a few minutes. A good example of the last, termed the "Bead hook" will be found in F. T. Salter's "Angler's Guide and Complete Practical Treatise, \&c.," 2nd edition, temp. I8I 5.

A really efficient live-bait snap-tackle, and one which has been extensively used for many years by Pike-fishers on the Thames-having been the invention, I believe, of one of the best and most popular fishermen on its banks*_-is figured in Otter's "Modern

* H. R. Francis, Esq., M.A., author of the "Fly-Fisher and his Library." 
Angler," of which an engraving, reduced to $\frac{1}{4}$ th the actual size, is appended.

Even this, however, ought rather, perhaps, to be described as the least faulty, than as the most complete of the patterns which have been published. Baited thus : the single lip-hook is passed through the upper lip of the bait, and the small hook of the triangle is fixed into the skin near the back-fin. From this it results that the bait is suspended in a most unnatural position in the water, standing in fact on its tail, except at the moments when it rights itself by a muscular effort. The effect is, of course, that it cannot "travel" properly, and instead of roving about freely in every direction, is confined to a comparatively small space, having moreover a constant tendency to rise to the surface rather than to remain swimming at mid-water. Of minor imperfections it may be observed that any hooking of the lips is always objectionable, as it tends, by interfering with the functions of respiration, to shorten the existence and lessen the vitality of the bait, and this is one reason why all livebait tackles which consist only of a single lip-hook are bad.

What is wanted in a live-bait tackle is-

(I) That the hooks should be suspended in a position in which they will be most certain to strike when the bait lies crosswise in a Pike's mouth ; (2) that the lips of the bait should not be interfered with in any way; and 
(3) that when on the hooks its natural position should be nearly horizontal, and with the head pointing rather downwards than upwards to prevent its rising to the surface.

Bearing these conditions in mind, I have after a good many experiments constructed a tackle in which I believe it will be seen that they are all fairly fulfilled; and as I have now for some years been in the habit of using it, I can safely say that I have found the conclusions arrived at on theory fully borne out by the results of practice.

This tackle is shown in the annexed plate,-figure I representing the arrangement of hooks in the flight, and figure 2 the same when baited. In baiting, the gimp is passed under a good broad strip of skin with the baitingneedle* (in two separate stitches if necessary), and pulled through until the shank of the small hook $(a)$ is brought close up to the side of the bait below the skin : this keeps the large flying triangle $(b)$ at a proper distance and in its correct position under the shoulder of the bait.

It is of importance, to secure the full killing powers of this or any other tackle, that the proportion between the size of the hooks and the bait with which they are used should be preserved. The bait shown in the engraving

* The best baiting-needles, whether for Minnows or larger bait, are those in which the eye is in this shape. 
-a small Dace-is of the proper size for those hooks; but by an error of the draughtsman the hooks are made to hang too far below the bait. The gimp between the lip-hook and triangle should be one-third of an inch less. This method of fastening the gimp under a strip of skin is much better both for the longevity and liveliness of the bait, than the passing of a hook through its lips, and on humane considerations is also to be preferred; as, whilst experiments have demonstrated that the bodies of fish are capable of feeling but a very slight amount of pain, it is well known that nothing causes so much suffering as any interference with the organs of breathing.

The hooks should be tied on about a foot and a half of fine stained gimp, with a loop at the other end which can be most conveniently attached to the upper portion of the trace (composed of two or three feet of stained gimp) by means of a "hook swivel" (figure 3), which will also have the effect of keeping the lead in its proper place. A lead of the shape drawn is neater and shows less in the water than one of the ordinary bullet form, and is therefore to be preferred. Both lead and float should be painted of dark green, or weed tint, with the same object. Green sealing-wax varnish prepared as already directed will be found the most convenient mixture. Strike very sharply the moment a fish takcs, and repeat the stroke (as recommended in Spinning) until a violent struggle is felt. 


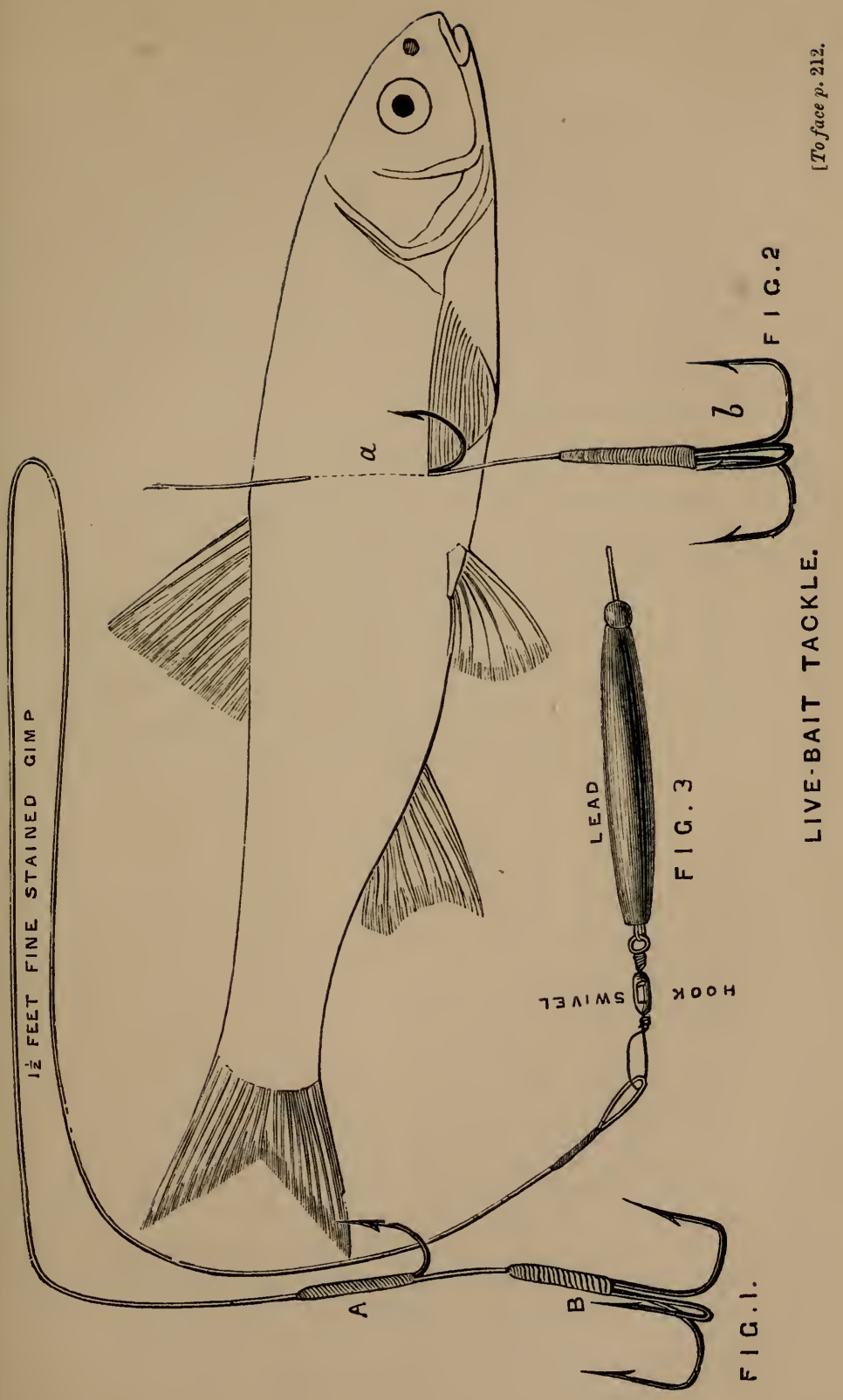



In lieu of one large float, it will be found a good plan to employ a number of much smaller ones, say four or five, strung on the line at a foot or so apart : cork balls varnished green and varying in size from a bantam's to a pigeon's egg are most convenient. The merit of this arrangement is that whenever the bait makes a plunge the corks yield to him, and enable him to rove about over a much larger area and at a greater variety of depths than he can with the ordinary single large float, which is, likewise, both more easily seen by the fish, and more liable to stick in weeds and roots than its smaller substitutes; another advantage is that the corks prevent the running line from tangling with the bait and trace. The cork nearest the bait (or two together if one is not buoyant enough) should be just sufficient to keep the bait up when absolutcly at rest, and no more.

\section{Live Baits.}

With regard to live-baits a good deal must of course depend upon the state of the water. Should it be vory bright and clear, a Gudgeon, which is also a very tough fish, will generally be found the best, and in extreme cases even a Minnow used with a small float and a single gimp hook passed through its upper lip or back may sometimes be employed with advantage.-In this case the smallness of the bait nullifies the objection to a single lip-hook. Bigger baits and with brighter scaling should be used as waters are more swollen and discoloured. It 
should always be borne in mind that with snap-tackle, whether spinning or live-bait, the larger the bait the greater are the chances against fairly hooking a fish. And this is a rule to which, from the necessity of the case, no tackle can be an exception. Four or five ounces is about the maximum weight of any bait which can be properly worked on live-bait snap-tackle ; where bigger baits are necessary (and in some waters, as for instance Slapton Ley, fish of half a pound and upwards are very commonly used), recourse should be had to live-bait gorge tackle, which will be described presently.

Probably the best live bait of all for thick or clouded waters is a medium-sized Dace, as its scales are peculiarly brilliant, and the fish itself by no means easily killed. In case of waters in which the Pike are overfed, or obstinately insensible to the attractions of the ordinary baits, I should recommend trying them with live Gold-fish; with which I have more than once caught Pike under circumstances leading me to believe that if instead of one or two baits, I had had as many dozen, remarkable results might have followed. If Goldfish are not forthcoming, small Carp form a very killing and long-lived bait.

Under the head of Ground-baits, will be found an account of the best methods of attracting the different descriptions of bait within reach of the cast-net. Attention to these will save the angler much time and trouble. In casting for Gudgeon the presence or absence of the 
fish, which can commonly be detected by the eye, is the best guide to be followed. This guide failing, however, "raking" is often an excellent expedient (see Gudgeonfishing.)

A live-bait can, which will be a convenience to livebait fishers, when unaccompanied by an attendant, is described in the general Chapter on Tackle (p. 60); where also will be found directions for preserving live bait.

\section{How and where to use the Live Bait.}

The "How" of live-bait fishing is simple enough. In warm weather, and generally throughout the summer, the bait should swim at about mid-water; in cold or wintry weather at about one-third from the bottom,those being the positions respectively occupied by the fish at such periods. The bait should not be left too long in one place, but be kept gently moving about, or "roving," as the old writers have it, either by force of the current or with the aid of the fisherman's hand and rod. If baits run short it will generally be found the better plan, instead of going on fishing with a specimen that has lost its activity and attractiveness, to keep bright, lively baits on the hook whilst they last, and then to use up the dead ones again, either with the Spinning or Gorge Tackle. A three-quarters defunct live bait is certainly "a delusion," but rarely a snare so far as the Pike is concerned.

In ponds, and sheets of water of small extent, the 
live bait, and especially the gorge live bait, is generally more killing, all the year round, than any other method of fishing; and there are some rivers, and large lakes too, though they are comparatively rare, in which Pike will not take freely anything except a bait that is alive. These waters of course make their own rules.

Under usual circumstances and in ordinary rivers the period when the live bait is most killing is after the fish have been swept by the first winter floods into the eddies and deeps, and where the water is full and slightly discoloured.

The "spring snap-hook" is a perfectly useless contrivance.

The "Paternoster" will be described under the head of Perch-fishing.

\section{Live-gorge Bait.}

The Live-gorge bait may be used in all the places and under the various circumstances referred to as being most suitable for snap live-bait. The rules as regards time for pouching, \&c., are the same as those given under the head of 'Trolling with the dead-gorge bait,' and the tackle (float and trace) is identical with that recommended for live-bait snap fishing, in everything except the hook and the mode of baiting.

These are so simple that an explanatory diagram is superfluous :-Instead of the flight used with the snap live bait, the hooks consist of a common double or single 
hook on gimp; with the aid of the baiting-needle the gimp is inserted under the skin of the bait, just behind its pectoral fin, brought out again near the end of the back fin, and drawn carefully through until the shank of the hook is hidden under the skin. The loop of the gimp is then attached to the hooked swivel on the trace, and the arrangement is complete.

The disadvantage of this tackle as with all other Gorgebait tackle is, of course, that the Pike has the opportunity of rejecting after taking it if he thinks proper. On the other hand the hooks are less seen than those used in snap fishing, and the fish consequently is less likely to be frightened by them. Its most useful province is when in a lake or other large sheet of water the fisherman wishes to carry on two kinds of fishing at once, say for Perch and Jack. He can then leave his Gorge-bait to take care of itself whilst he wanders away with his other rod, returning at intervals to see if he has had a run. When the rod is thus left, 20 or 30 yards of line should also be left by its side carefully uncoiled, so that it will run out easily if the bait is taken. It must be added, however, that this "leaving-the-rod-to-fish-for-itself" mode of operation is not many degrees removed from Trimmering, which ought to be the abomination of all Pike fishers. 


\section{Cooking Pike.}

So many fine Pike are wasted for want of a little knowledge on this subject that I am tempted to append a receipt for filleting Pike, which I obtained from Mrs. Robertson, the obliging landlady of the Bat and Ball Inn, Breamore. Cooked in the ordinary methods Pike can hardly be regarded as a very gustatory dish : dressed as directed in this receipt, I think it will be generally admitted to be a really excellent one. The sauce, it will be seen, plays the part of Hamlet in the affair :-

Cut the fillets, and after covering them with plenty of egg and breadcrumbs, fry them over a brisk fire till thorougbly browned. Then pour over them a gravy made thus:

After removing the fillets, lay the hone and trimmings in a stewpan with two shalots and a small bunch of parsley, stew them for one hour, and strain the liquor, which add to the following sauce. Put two ounces of butter over the fire; when melted, add the above liquor, and also one tablespoonful of flour, one teaspoonful of soy, one dessertspoonful of anchovy, one of Worcestershire sauce, and a little salt. 


\section{PART IV.}

\section{BOTTOM OR FLOAT FISHING.}

\section{CHAPTER XVII.}

\section{General Observations.}

'Old' and 'new' (or 'Nottingham') methods of bottom-fishing-Ordinary float-fishing-Rods, lines, hooks, floats, shot, reels, \&c. Nottingham fishing-specialities of, and tackle.

"BotTom FIshinG," whatever the term may have originally conveyed, does not now always mean fishing on the bottom. Several branches of angling, such as paternostering, which comply with this condition, are excluded ; and others, as for example float-fishing in midwater, which do not comply with it, are embraced. The expression bottom-fishing in the angler's dictionary has come to imply simply rod-fishing with a float; and if we were to exclude Pike, Trout, and Grayling from the category, float-fishing and bottom-fishing might be said to be synonymous. 
Bottom-fishing is divided into two classes: the old style, or ordinary bottom-fishing, and the new style, or "Nottingham fishing." These two methods of floatfishing differ mainly in their details of manipulation. And as by one or other of them are principally taken all coarse river and pond fish, except Pike, a preliminary description of each system will save repetition in the succeeding chapters.

\section{- Ordinary Bottom Fishing}

Is practised with a rod, line, and float; split shot being attached to the line at a distance of from one to two feet above the hook to sink the bait, and partially sink-Anglice, "cock"-the float. Sometimes a reel and running-line are used, and sometimes not ; but the íormer plan has this advantage, that whilst a reel and runningline are never really in the way, their absence is often attended with serious practical inconvenience and loss of fish.

RoDs.

All sorts of rods are used according to the fancy of the angler, but the general rod already described (p. 5 I) con . tains all that is necessary; and indeed by a change of butts and tops embraces varieties of length and stiffness adapted to every description of bait and circumstance.

\section{LINES.}

The best and cheapest reel line for ordinary bottom 
fishing is a fine undressed spun cotton line, of the manufacture described at p. 26 . The lower, or 'floatline,' should invariably consist of single gut, stained as directed at p. 30, and as fine as it can possibly be used with safety. This point is perhaps of more importance in bottom fishing than in any other kind of angling, because in this mode the fish have more time for examination before biting. They are able, as it were, to take a leisurely survey of the position and of the arrangements prepared for their benefit. Hair should never be used in any kind of fishing, because gut can be procured which, when stained, is both finer and stronger than any hair. It is also transparent, whilst hair is opaque. Some observations on this subject will be iound in Chapter III.

\section{Hooks.}

As regards the hooks, for the reasons already given in the chapter devoted to that subject, I recommend for all kinds of bottom fishing the patterns of hook therein described; and the sizes mentioned in this part refer to the several sizes of those hooks as shown in facsimile at p. II. The proper sizes for each fish and bait are given under the separate chapters.

\section{FLOATS.}

The best and most durable floats are made of porcupine quill ; for the finer description of fishing, of a single quill simply, and where larger floats are required, 
as in the "Nottingham style," of porcupine and goose or swan quill combined, the upper half of the float being composed of the hollow quill. This float, of which I believe I was the originator, unites the advantages of being exceeding strong, unconspicuous, and of giving probably a greater supporting power, bulk for bulk, than either of the ordinary combinations of corks or quills. It can be made of any size, up to a foot long, which is the best length for heavy Nottingham fishing, and either to fasten with caps at both ends, or a cap at the top, and a ring at the bottom. The former method has an advantage in making the float less liable to slip-a common occurrence which involves either a frequent "re-plumbing," or the probability of fishing at the wrong depth. Even with the double caps as fastened in the ordinary way, the float, especially after repeated striking, is apt not uncommonly to shift its position by degrees; and in order to make this impossible I pass the line round as well as through the lower cap-in other words, twice through-loosening the coil when the position of the float is to be shifted, and drawing it tight when it is fixed in its proper place. If this method is adopted, caps of gutta perchà should be used instead of quill caps, as the latter would wear and fray the line.

The above expedient will be found of considerable practical advantage in all fishing where accuracy of plumbing is essential. 


\section{SHот.}

The shot should be sufficient to submerge about threefourths of the length of the float; and their position on the line should be regulated according to the nature of the water. In still water, the bulk of the shot should be about two feet from the bait, a single small shot being placed midway, to insure the bait itself sinking with tolerable certainty and rapidity. In rivers where the stream is deep or strong, it will commonly be found most convenient to place the shot about a foot above the hook with a single shot midway as before.

The object being to "cock" the float, and at the same time sink the bait to the required depth, these points being attained, of course the further the shots are away from the bait the better. A few medium sized shot show less than a number of small ones.

\section{"Nottingham Fishing."}

One portion of what is known as Nottingham fishing is the throwing from the reel-trusting, that is, to the weight of the bait and float, and the impetus given by casting, to draw off from the reel, as the line is thrown, as much of the latter as may be required for each cast. For the reasons already given with reference to the application of this method of casting to Pike fishing (p. 185), I consider it in every way a mistake in theory, and, as applied to light float tackle, usually an impossibility in practice. 
The other principle of Nottingham fishing is an excellent one, and the practice of it is rapidly spreading over all parts of the country, and for every description of river and pond bottom fishing. Its result is to enable the angler to fish "swims" at considerable distancessometimes as much as twenty yards-away from him, and at the same time to add to the length of the swim itself, by allowing the bait to travel over a greater extent of ground than is possible under the ordinary method. This result is attained by the use of a largish float, and a running-line which combines strength with the greatest possible lightness and fineness, and therefore, of course, runs through the rod-rings with the utmost facility. In pond fishing the Nottingham method gives the angler the advantages of being able to make much longer casts, and consequently to fish finer and further off. A proper Nottingham line of fifty yards long should not weigh more than one-fifth of an ounce, and is strong enough to land the largest fish which the angler is likely to meet with (see observations on lines, p. 28). In casting, the line should lie in loose coils on the ground; and when a long cast is to be made it will be found convenient to draw the line in, not through the lowest ring, but through one or other of the rings next above it-an arrangement by which, owing to the diminution of friction, a light bait can be thrown to a greater distance.

With the foregoing exceptions, the tackle, \&c., already 
described for ordinary bottom fishing, as well as the general observations on its use, and the remarks elsewhere made on baits and ground-baits, are applicable to Nottingham fishing. 


\section{CHAPTER XVIII.}

\section{BAITS, BAITING; AND GROUND BAIT.}

Baits - Worms, brandlings, lob-worms, where to get and how to preserve; two-hook tackle. Gentles, greaves, pith and bullock's brains. Wasp-grubs; easy method of taking wasp-nests. Pastes. Miscellaneous baits-Caddice; grasshoppers; meal-worms; earthgrubs.

Ground baits-Rationale of ground-baiting ; gentles, paste, bran, bread, meal, greaves, grains, rice, worms.

\section{WORMS.}

THE best worm for every description of angling, except Barbelling or Bream-fishing, is usually the brandling or dunghill worm, found in old rubbish and manure heaps. In common with all other worms brandlings are better scoured and kept as recommended for Trout fishing (p. II2). Of other kinds of worms, the reddest are the best. For Barbel, Bream, and Chub, the tail end of a lob-worm, about 2 inches, is, for some reason-probably because it is larger-a better bait. Lob-worms can frequently be obtained in the same spots as brandlings-in kitchen-gardens, and generally in any moderately damp, heavy soil. Lob-worms also come out in great numbers on dampish, low-lying 
lawns at night, and may be then gathered on and round the edges of the grass, borders, \&c., in great numbers. I have repeatedly picked more than a quart full of solid worms in this manner in half an hour. Some lawns, however, are much more prolific of worms than others. About ten o'clock at night is generally the best time for lob-worm gathering.

When the tail of a lob-worm is used, the worm must be broken about the middle-longer or shorter, according to circumstances-and the hook, if a single one, inserted at the point of breakage, the worm being then "run up" the hook until the shank is somewhat more than covered.

To bait with a whole worm take the hook by the shank in the right hand, and the worm, head upwards, in the left ; enter the hook-point a little below the head, and after passing it through a trifle more than the length of the shank, bring the point out again, and run the worm up on to the shank and gut; then again insert: the point and barb only about two-thirds down the worm in the direction of the worm's head; and finally, pull theupper portion of the worm down over the hook-shank till it touches the tail part. This is the best method. both of concealing the hook and giving a natural appearance to the bait, in every kind of fishing where a. single hook only is used. 


\section{GentLes.}

The finest gentles are obtained from the liver of the sheep or bullock. They should be placed in moist sand to scour and get rid of a pinky-brown discoloured patch which they have when first taken from the liver. In moist sand they will keepfresh and in good order for several days. In the winter months, if it is desired to keep them for a longer time, they should be put into a large-mouthed bottle two-thirds full of earth, the bottle being corked up and placed in a cellar or other cool situation. No gerreral directions can be given for baiting, as this of course varies with the size of the hook. Carrion gentles (see ground baits) can be used when liver gentles are not obtainable.

\section{GREAVES,}

Or the refuse of the fatty materials out of which tallow is made, are a good bait for Barbel, Bream, and Chub, and occasionally for Roach. The greaves, after being broken up with a hammer, should be boiled gently for about half an hour, long enough before they are wanted for use to allow of their getting cold and hard. The whitest pieces are the best for bait, and these can be most conveniently disposed so as to hide the hook by being cut into broadish strips or slices. 


\section{“Pith” AND “Bullock's Brains.”}

This bait is a modern discovery, but it is the most deadly of all baits for Chub fishing in winter. The "pith" is used as the bait on the hook, and the brains for the ground bait, and I shall therefore describe them both together. They are prepared thus :-

Having obtained from a butcher some brains from a freshly-killed bullock, cow, or sheep, first thoroughly clean and wash them in cold water, and then boil them for fifteen minutes, changing the water once during the process. When cold they are ready for use.

The "pith" is the spinal marrow of a bullock or cow, and should also be obtained quite fresh. The pith requires to be boiled for about three minutes to prepare it for use. The brains and marrow from one bullock will be sufficient for an ordinary day's fishing. In order to make the brains sink readily, and also in order to separate the particles, or make them fine, some fishing authorities recommend that the brains should be chewed by the angler as he uses them. This process, however, though effectual, is not relished by most persons, and the best substitute is to squeeze the brains in the hand whilst under water. The brains should be thrown in from time to time, in pieces about the size of a walnut, a few yards (according to stream and depth) above the spot which is covered by the bait. 
The pith when used for Chub or Barbel, should be cut up as required, into pieces about the size of a largish hazel-nut, and baited on a No. 9 or No. 1o hook. (See plate, p. I I.)

\section{WASP-GRUBS.}

The young of the wasp in its immature state as found in the comb, is a good, though very delicate bait for Roach, Dace, Chub, Bream, and Grayling. It may be easily obtained throughout the summer and early autumn months by digging out the nest: the adult wasps, it is hardly necessary to say, having been previously destroyed. For this purpose the following is the best receipt I am acquainted with, and as wasps are great enemies to the orchard and fruit-garden, I commend it also to the attention of farmers :-

Procure a strong solution of cyanide of potassium (prussic acid) and having thoroughly wetted therewith a doubled piece of lint about six inches square, place the lint at the mouth of the hole, so that the wasps cannot well obtain ingress or egress without settling on it. Every wasp crawling over or alighting on the lint will be instantaneously killed, and twenty-four hours will commonly be found sufficient to enable the comb to be dug out without difficulty.

PASTES.

Having tried most of the pastes described in Angling manuals, the result of my experience is that there is no 
paste so good as a simple one of white bread-crumb, and made thus: put a lump of crumb into a pocket-handkerchief, and having twisted it up, dip it in water, giving it a few squeezes whilst immersed so as to eject the air, and substitute water. Then wring the crumb as dry as may be in the handkerchief, and taking it out, work it for a minute or two in the hands, which should be clean.

Wools, dyes, and flavourings, whether with sugar, honey, or essential oils, are useless or mischievous. Paste is a good pond bait in summer for Roach and Rudd, and not a bad one occasionally for Carp-but this exhausts its rôle.

Paste should be put on in a pear shape so as to cover the shank as well as the bend of the hook. When using paste, a few small pellets thrown in from time to time round the float are useful.

A paste made of cheese is sometimes a killing bait for Barbel and other kindred species.

\section{Miscellaneous Baits.}

Caddice, grasshoppers, meal-worms, and earth-grubs generally are occasionally killing baits for all the beforementioned coarse fish, but they are so difficult to obtain in any quantities that they are seldom worthy of much consideration. The meal-worm, which is perhaps the least troublesome, breeds amongst the refuse sweepings of flour mills. The caddice (or as its name is sometimes 
abbreviated-"cad-bait") is the larva of the phryganea, of which there are many species, furnishing several of the insects most popular for imitation by the artificial fly. In the larval state it is found in the banks of most streams amongst gravel, decayed reed-roots, and other aquatic débris. It is enveloped in a shell or case, generally cylindrical, resembling commonly a piece of dead stick or rush, and from this it is of course necessary to disencumber it before use.

\section{GROUND BAITS AND BAITING.}

In every description of bottom fishing ground bait, or a substitute for it, can be used with advantage. Anglers, however, often make a great mistake in ground baiting, by so surfeiting the fish with food that they have no need or appetite to attack the hook-bait, which, in comparison, must always present a more or less unnatural appearance. On this account also it is generally better in rivers to fish a little below rather than actually over or above the ground bait, because by so doing there is a greater chance of the unsatiated fish which are working up stream towards the ground bait, coming first into contact with the bait on the hook.

As a general rule, to which, however, there are several exceptions, it may be stated as the rationale of ground baiting, that the bait used on the ground should be of the same description as, but inferior in quality to, that used on the hook. 
Bearing in mind this rule, it will hardly be necessary to explain that of the ground baits which I am about to enumerate the majority are also used as baits for the hook-some simply, some in combination with others. To begin with,

\section{GentLes.}

"Carrion gentles" are generally used for purposes of ground bait, being smaller, more easily procured, and otherwise inferior to the liver gentles, which should be used on the hook, thus carrying out the cardinal principles of ground baiting already indicated. Carrion gentles can be obtained from any carcase or offal ; they are, I believe, generally procured for the tackle-shops from the dealers in horse-flesh. They should be mixed with moist sand, as, if kept in any quantity, pure and en masse, they are apt to scald, as the expression is ; that is, they become so heated that many die. Carrion gentles, simply or in combination with other baits, are the best ground bait all the year round for Roach, Dace, and Bleak, and are also a very good bait for Bream or Barbel. In ponds or still waters I should advise their use for either of the fish named, without other admixture, on all occasions when they can be procured.

\section{PASTE}

Is to be recommended for use principally in the same kind of water as that suitable for gentles. A few pellets 
of the same paste used on the hook may be thrown in round the float from time to time.

\section{BRAN, BREAD, AND MEAL.}

Wet bran mixed with carrion gentles, or worked up with soaked bread, is a very good ground bait, either for Roach, Dace, or Bleak ; in fact, when used by itself, it is the most certain mode of attracting Bleak to any given spot that I am acquainted with. In water where there is a current, the addition of soaked bread, in about equal parts, or meal sufficient to give the bran weight and consistency, is essential. Or a handful of meal squeezed under water in the hand, and thrown in from time to time, may be used by itself; as may also soaked bread which is first squeezed dry in the hand. The best meal for the purpose is made from wheat, ground up with the husk, such as that employed for the coarser kinds of brown bread. This should be moistened sufficiently to make it cohere in lumps, but not sufficiently to make it sticky. Bran is a great addition to both the above-named baits, as it is light and easily carried down gradually by the current, so as to entice the fish upwards.

\section{GREAves.}

Prepared as already described, greaves is a very good ground bait for Barbel and Bream, especially in combination with some or all of the foregoing. 


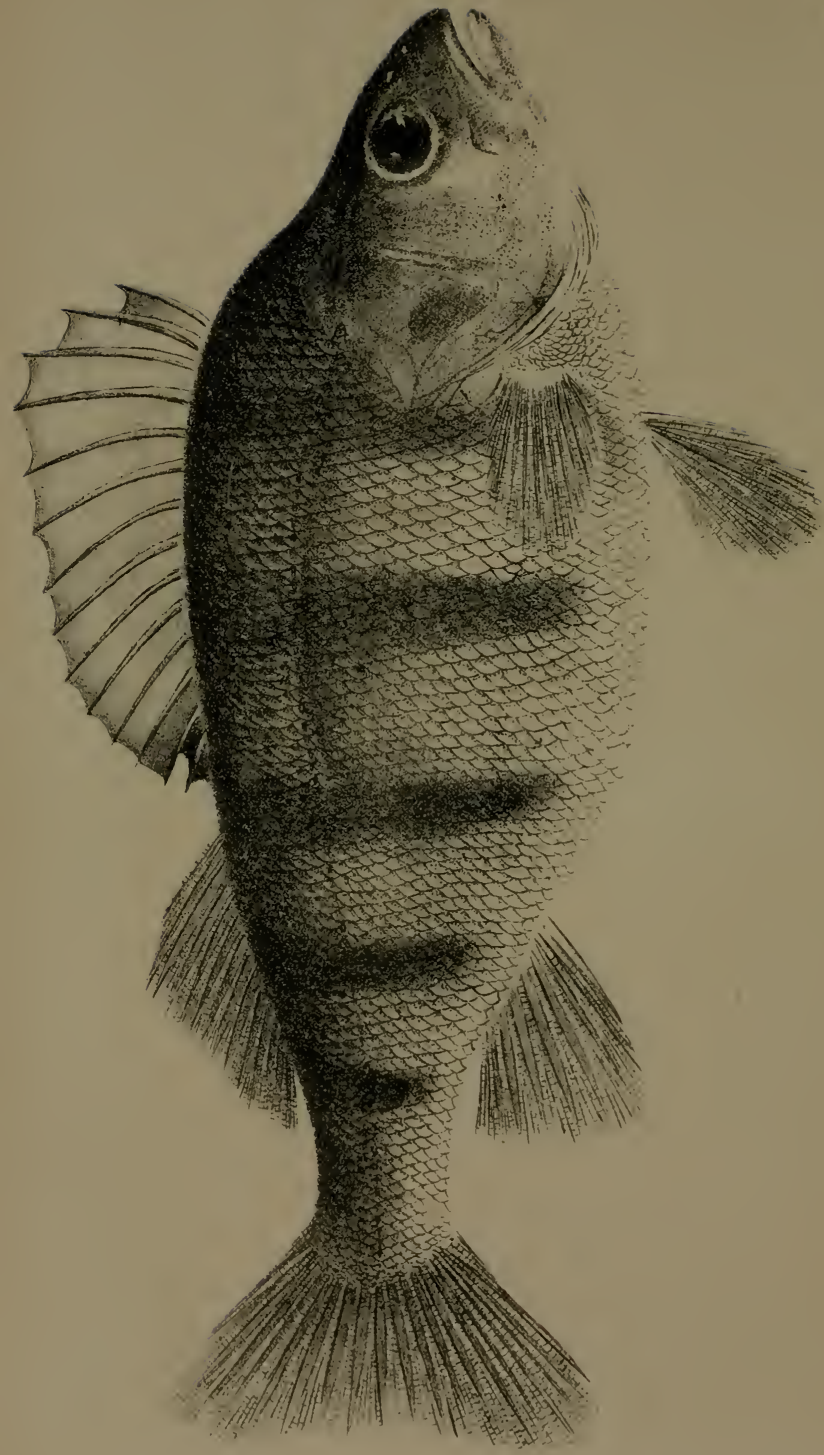

政 


\section{GRAINS.}

Brewer's grains or malt is a coarse, sour ground bait, with which I never had much success.

\section{RICE.}

Boiled rice used in the positions described for gentles, is the best ground bait for Minnows; and by bearing in mind what has been said as regards the attractiveness of bran for Bleak, and gentles for Roach and Dace, much trouble will be spared to the angler when procuring supplies of live-bait with the casting-net. A stillish curve or eddy of river about two feet deep will be found the best description of spot both for the application of this principle of baiting, and for using the cast-net effectually.

\section{WORMS,}

If not the best, form one of the two or three very best ground baits for Barbel, Bream, Chub, Perch, Carp, and Tench. Authorities differ as to whether they should be used whole or "chopped."

Mr. Francis Francis, who has written some of the best chapters on bottom fishing with which I am acquainted, recommends "broken" worms; whilst Mr. Baily, of Nottingham, in his clever little manual, is strongly in favour of the "whole" system, at any rate so far as previously baited swims for Barbel are concerned. Whole worms are, I think, preferable in all cases where swims are baited any considerable time before being fished, 
and broken worms where only a few hours intervene, or where the two processes of ground baiting and fishing commence simultaneously.

For the latter purpose it is not necessary that the ground bait should retain its vitality for any length of time, and an ordinary lob-worm may in this case be broken certainly into two pieces, with advantage. "Chopping" on the other hand, or breaking the worm into a number of small pieces, is certainly bad, as thereby one chief element of attractiveness, life, is taken away. A divided worm is for some time more lively than a whole one.

As a rule, worms, when employed as ground bait in gentle currents, or in ponds and still water, are best used by themselves simply, but in deep or strong water it is necessary to enclose them in hollow clay balls, so that the balls may carry the worms to the bottom before bursting, or being washed open by the action of the stream. The application of these rules will be explained more in detail in the chapter on Barbel fishing.

I cannot do better than conclude these observations on ground bait with a rule which should never be forgotten: after ground baiting, plumb the exact depth, and arrange the tackle so that it may not be necessary to make a disturbance when fishing commences. 


\section{CHAPTER XIX.}

PERCH.

Omnivorous instincts of Perch-Natural and artificial baits-Spinning, Ay-fishing. Live baiting, 'paternostering' and 'roving.' Wormfishing in lakes, ponds, and rivers. Spawning season.

The Pope or Ruffe.

THOUGH fishing for Perch properly belongs to-indeed heads-this division of my subject, yet by its habits of feeding and the methods of angling employed for its capture, it might justly claim honourable mention both under the category of fly-fishing, and, taking the word in its widest sense, of trolling also. Thus, for example, in the great lakes Perch will often take a spun Minnow or a bright fly in preference to any other baits, whilst both in lake and river the deadly qualities of a live Minnow or small Gudgeon are well known to all Perch fishers.

In the case of lake-spinning for Perch it would seem that the usual rule in regard to the superiority of natural over artificial baits is reversed. Whether from the greater facility with which small artificial baits are procurable, or from some other cause, I have certainly caught and seen caught, far more Perch by the arti- 
ficial than by the natural spinning-bait. Formerly a "spoon" about three-quarters of an inch long was very killing in many waters; but as with Pike and Trout so with Perch, this bait seems latterly to have lost much of its attractiveness. A stone Loach, a Minnow, or a very small Gudgeon, are all good spinningbaits, and should be used both in lakes and rivers with the tackle described for fine lake spinning (p. 123), or for river Minnow-spinning (p. I 16), as the case may be.

With a gaudy red fly dressed on, say, a No. Io hook, I have also had good sport, but its legitimate province is confined to large shallow lakes, and then is only practically worth consideration in bright hot weather and a dead calm. The flies may be either "trailed" or cast by hand; the former plan being usually best until the position of a shoal of fish is ascertained, and the latter afterwards. As already observed, however, both the methods of Perch-fishing above described, are only really much worth considaration in the great lakes, where they often come in very opportunely to fill what would otherwise be a blank day, the most impracticable weather for Trout being commonly the most favourable for Perch. It certainly does occasionally happen that good baskets may be made with the spinning-bait in rivers. I have done it repeatedly in the Kennet, below Hungerford, but then the fish of this river-in my opinion the best Perch water in England-run very large, averaging from one to two pounds, and, owing to strict preservation, are compa- 
ratively little fished for. The Hampshire Avon is another beautiful river, which produces in parts Perch quite as large as those of the Kennet, but they are not so numerous.

The most killing bait for Perch in rivers, and not unfrequently in lakes also, as in Windermere for instance, is the live Minnow, and the best method of using it is with what is termed a "paternoster." The paternoster is made and used thus : to the end of about 4 feet of stained gut attach a lead, and at the distance of say 3 and 15 inches above it respectively, two hooks, Nos. 8 or 9, tied on gut lines 4 or 5 inches long. These should be attached in the same manner as that recommended for fastening on drop flies (p. 58), so as to stand out at right angles to the main line.

The tackle is baited by passing each of the hooks through the upper lip (only) of a live Minnow, or small Gudgeon. The rod and line recommended for Trout Minnow spinning (p. I I9) will be most convenient for this purpose, but any stiffiish rod with a line that runs tolerably freely will do. As, however, a long line cannot be used in paternostering without loss of efficiency, danger of fouling, \&c., a longish rod, not too heavy, is a desideratum. In deep holes, under steep banks, and under weirs, are the haunts in which the greatest execution will generally be done with the paternoster; and from October to January large deep eddies, or back-waters, into which, especially after a flood, the 
Perch are swept. Such spots abound on the Thames and most large rivers. In the Thames, the best Perch water I know is just below the paper-mills at Temple, near Marlow. Here, after the first heavy flood, the Perch collect in astonishing numbers; and I remember on one occasion, when fishing this pool with the late Tom Rosewell and Mr. H. R. Francis, killing some twelve dozen Perch with the paternoster in a few hours. The water was then still slightly clouded from floods.

The Weirs are the great places for the paternoster in summer, as the Perch then collect in the rapids and rushes of water to scour and brace themselves after spawning. The modus opcrandi is as follows:-The rod and tackle being arranged as described, and the lead hanging 6 or 7 feet from the top of the rod, the baits, if the water to be fished is within the length of the rod, should be gentiy dropped or lowered down till the lead rests on the bottom; if, however, the desired spot is further off, the baits, after a slight pendulum-like movement, are lightly cast-or rather "swung"-into it, and the line drawn in until it is stretched straight between the lead and the rod-top. Every half minute or so the position of the bait should be shifted a foot or two by lifting the lead and drawing in line; a sharp twitch will indicate a bite, when the point of the rod should be instantly lowered a little so as to slacken the line somewhat, and prevent the fish prematurely pricking himself. The attack being repeated, and-as it usually happens- 
in a more vigorous manner, the line should be quietly but rapidly tightened, and a vigorous "lift" (not stroke) given almost at the same instant with the rod. Striking is not desirable in paternostering, first, because the Perch is a very delicate-mouthed fish, and the rod a stiff one; and secondly, because by this means both baits will almost inevitably be lost. A chief element of success in paternostering-as indeed in all live-bait fishing-is, that the baits should be fresh and really lively.

Leads of a pear-shape are preferable to bullets, because from their shape less liable to catch in stones, sunken posts, \&c. They should always be painted with green varnish (p. 59), which makes them less conspicuous.

In water where there are many Jack it is often a good plan to attach a third hook (No. I I or I2) tied on fine stained gimp, about 2 feet above the lead, baiting it with a Gudgeon. Many good fish are caught in this way. In bottom fishing from a punt it is usually an excellent plan to put out a paternoster, which may not only add to the weight of the creel- "on its own hook," as the phrase goes-but by killing any Pike or Perch which may be roving in the neighbourhood, add to the chances of a good take of other fish. The proximity of either of these predaceous species sadly disturbs the appetite of the grami- or vermi-nivora, and a sudden stoppage in the biting of the latter is constantly attributable to this cause. 
Another method of fishing for Perch with Minnows, sometimes used also for Trout and Pike, is what used to be called by the old writers "roving." It consists simply in substituting an ordinary gut-line, single hook, and float for the paternoster, and baiting with a live Minnow hooked through the upper lip. This method is, however, very inferior to the paternoster for either Perch or Pike; and for Trout is not to be named with either fly, worm, or spun Minnow fishing.

Besides Minnows and small Gudgeon, the only live bait that Perch take freely, both in rivers, lakes, and ponds, is the worm-a brandling being much the best. It may be used either in the ordinary or "Nottingham style," in the mode already described in the preliminary chapter on "Bottom or Float-fishing." The hook, single, should be from No. 6 to 8 or 9, according to the average size of the Perch in the waters fished. I cannot but think, however, that the two-hook tackle recommended for Trout, p. I Io, may probably eventually supersede the single hook for all kinds of worm fishing, at any rate in running waters, and not impossibly in pond fishing also. At the same time, I have myself tested the tackle in this department of angling sufficiently to put the above forward as more than an opinion-an opinion, however, in favour of which strong prima facie arguments exist, and which I should be very pleased to find confirmed by that of any other anglers, who may be inclined, for the sake of experiment, to 



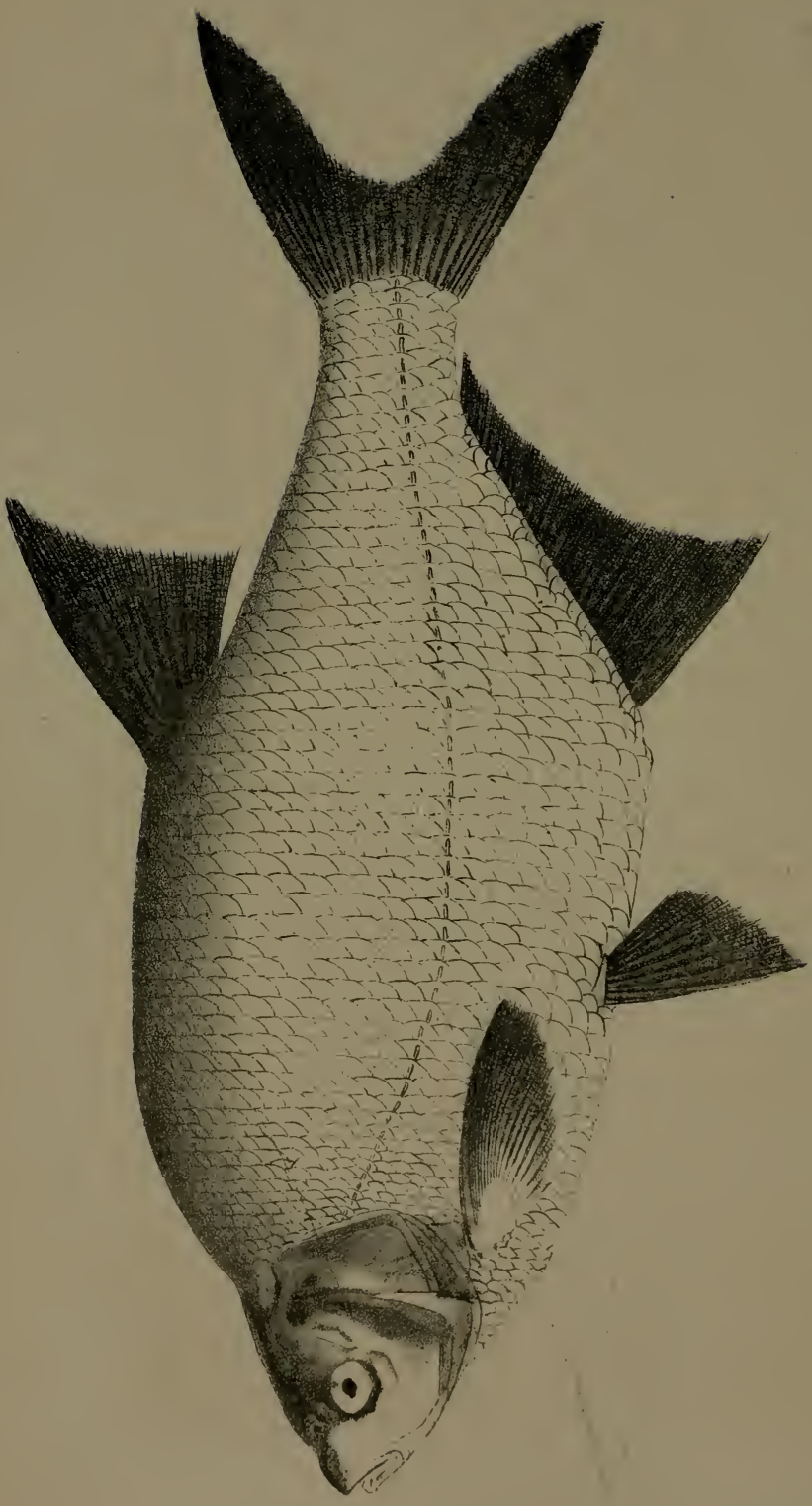


give the tackle a trial. In river Perch fishing, the worm should just dribble along the bottom; in ponds, it should float about 8 inches or a foot above it ; and in lakes a little more, according to the depth.

It is usually advantageous not to strike too soon in fishing for Perch as compared with other species. The Perch rarely quits a bait, especially a worm, when he has once attacked it; indeed, if allowed, he will frequently "gorge" or swallow it entirely; but this, again, is an inconvenience in another direction. The best general rule is to let the float be carried well under water before striking.

In rivers and streams the "Nottingham plan" will often be found the most killing mode of worm fishing for Perch. As in other cases, a few broken worms thrown in occasionally as ground bait will assist in attracting the fish.

Perch most commonly swim in shoals, so that when one is caught others may be expected to follow. In Windermere I have watched these shoals, and found them to consist not infrequently of many hundreds. In Slapton Ley, Devonshire, they can hardly be said to be in "shoals," as the whole water swarms with them, and I have frequently caught them there literally as fast as I could bait. As a rule, however, they are quite insignificant in the matter of size, very few of those that I caught or saw exceeding a few ounces in weight. They are smaller than even the Windermere fish. Perch are 
the only English species of scale fish which have been clearly proved to be bi-sexual, that is, to contain in each separate individual the means of reproduction complete-in other words, both milt and roe. They spawn towards the end of April, or beginning of May, casting their eggs in strings like festoons of pearls about the weeds and rocks. That they increase rapidly is not to be wondered at when it is considered that as many as 280,000 eggs have been counted in a single specimen, weighing half a pound.

\section{The PoPe OR RUfFe.}

The only other species of the Perch family known to exist in this country is the Pope or Ruffe, a gregarious fish, which though resembling its congeners in many points of habit and structure, is in an angling point of view altogether inferior. The bait and tackle recommended for Gudgeon-fishing will be found also the most successful in taking Pope ; and indeed it is in Gudgeonfishing that the Pope is most frequently captured. I have seldom met with specimens exceeding 4 or 5 inches in length. 


\section{CHAPTER XX.}

BARBEL AND BREA.I.

Habits of barbel and 'ground swimmers' generally. Bottom fisbingtackle and baits. Leger fisbing and tackle. Ground baits and baiting -Worms and clay-balls; how to make and use. Spawning-time. Haunts of Barbel-Torpidity in great cold.

Different species of Bream-Carp Bream; White Bream, or Bream flat; Pomeranian Bream : their habitats, and how to be distinguished. Bream fisbing in rivers and ponds-Tackle, baits. Ground baits. Spawning-time.

\section{BARBEL.}

THE Barbel is so named from the barbels or beards with which its nose and upper lip are furnished, in order to assist it in feeling its way about in deep, and consequently more or less dark waters; and probably also for the purpose of enabling it to detect the nature of the substances with which it comes in contact. Of the species provided with these barbels-Carp, Tench, Gudgeon, Roach, and Turbot, all find their food principally at the bottom. The barbels, in fact, afford a correct index to the habits of the fish which are thus furnished, and teach the angler that in fishing for them his bait must always be on or close to the bottom. This rule holds good with 
especial force in the case of the Barbel, which not only lives and feeds on the bottom, but procures its food most commonly by "rootling" with its nose amongst the gravel and stones, very much as a pig turns up a field with its snout.

Bottom fishing either by the ordinary method, or in the Nottingham style, are now the fashionable modes of Barbel fishing. The tackle being that already described, but somewhat stronger than usual, as the Barbel is a very hard fighter, not seldom running from five to seven, and even occasionally to ten pounds weight. The best baits are the tail of a lob-worm, greaves, and gentles-their "order of merit" on the average of waters being very much that in which they are here placed. When gentles are used, five or six will not be found too many for the bait; the hook being passed laterally through the first four or five close to the tail, so as to form a bunch, and the last being reserved to cover the point of the hook, which should be a No. 5, 6, or 7 , according to size and depth of water and other circumstances. For the wormtail or greaves a No. 8,9 , or Io hook should be used. The method of baiting with worm-tail and greaves is described at pp. 226-227.

The bait should swim just clear of the bottom ; when it drags along the ground the line is apt to come into contact with the noses of intending biters before the bait, thus risking the dilemma either of so arousing their suspicions as to make them change their mind, or, if 
they are still inclined to take the bait, making it almost impossible for them to do so without turning round and following it. This is an important point. In Barbel, as with other fish, except, perhaps, occasionally with Bream, it is best to wait to strike until the float disappears, or moves steadily and decidedly away.

In all light waters, and often in deep and heavy ones, the Nottingham method of barbelling will be found the most killing, as well as the most lively; but there is another system formerly very generally practised by Thames anglers, and which is in some sense the speciality of Barbel fishing. This is termed "legering," or "leger-fishing." The tackle consists of a large hook, say No. I I, whipped on to two lengths of very strong picked gut and attached to the running line, which is again passed through a flat oblong lead, of the shape and usually of about the size of that figured in the engraving. The lead is prevented from running down the gut by the junction knot, but otherwise works freely up and down the line. No float is used, and the bites are distinguished by

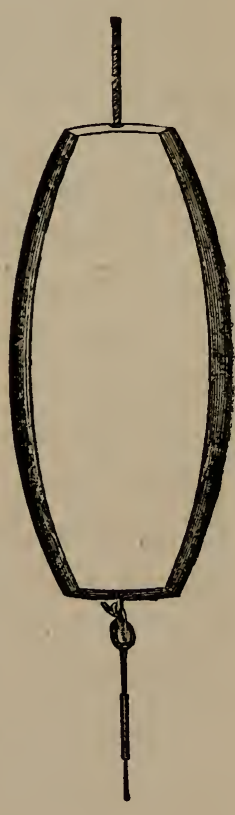
the touch.

The bait being cast to the desired spot, the runningline is kept stretched tolerably tight between the point 
of the rod and the lead, which of course rests on the bottom. A few slight twitches indicate a bite, and a decided tug the moment for striking, which it is important should be done sharply, as the lead has often to be moved by the stroke before its effect reaches the fish. There is also generally a considerable pressure of stream on the line Owing partly to this and partly to the weight of lead to be worked, an ordinary Jack-rod and spinning-line are the most convenient implements for leger-fishing. The rod for Jack contained in the general rod described at page $5 \mathrm{I}$, will answer the purpose well.

Legering is most effective in deep, strong eddies, and rushes of water where an ordinary bait would not reach the bottom, or could not be effectively worked. For any other water the Nottingham method is to be preferred.

The bait may be either a whole lob-worm or the tail of one. In the former case the point of the hook should be inserted in the head of the worm, and then, by a process like that of passing a bodkin and tape through a hem, be 'run' through the whole of the worm except about an inch of the tail.

The same ground baits are used as for float-fishing, but opinions differ as to whether the ground baiting should take place before or during the sport, and whether the ground bait should be worms or greaves. My own experience leads me to give the preference, especially 
for legering, to worms for all kinds of Barbelling, and I prefer the swim to be baited beforehand (if possible twenty-four hours). Still I have had excellent sport with both kinds of baits, and both systems of using them. 'Ground baiting as you fish' has, however, this advantage, that if Barbel do not come on to bite at one swim there is no disappointment felt in moving to another. A fisherman-especially a professional fisherman-hates quitting the hole into which he has thrown so much time and so many pints of worms. If it is intended to fish the same swim a second day, the ground should be re-baited on quitting.

The mode of preparing and using greaves forground bait is described at p. 227. If worms are used for baiting a Barbel swim in anything but dead water or a very slow stream, I recommend their being enclosed in hollow clay balls of about the size of a man's two fists. These, if the swim is to be fished at once, should be thin enough/ to break almost directly they touch the bottom, and the worms, of which a couple of handfuls are enough to begin with, should be broken into two pieces. If the swim is to be baited twenty-four hours or more beforehand, a quart of worms is not too much-two days, two quarts. In this case-say a twenty-four hours' ground baitingthe worms should be used whole, and enclosed in ciay balls, of which a few ought to be thin enough to break or wash open almost immediately they touch the ground, the majority being strong enough to resist the action of 
the stream for several hours. A few worms should be allowed to protrude half their length or so, here and there, through the outside of the thicker balls. The object of these dispositions is to avoid glutting the fish at one time, and then leaving them without anything to attract or amuse them for the rest of the twenty-four hours interval between baiting and fishing.

On the other hand it is most important that the solidity and number of the clay balls be so adjusted that their contents should be consumed some hours before the swim is to be tried with the rod and line-that the fisn, in fact, should be allowed an interval to regain their appetites.

These are the principles which must guide the angler in "previous ground baitings," whether for Barbel or other fish. Their application, which differs of course according to the circumstances of each individual case, is a matter often requiring both nicety and judgment, upon the display of which the success of the bottom fishing will in a great degree depend.

The Barbel spawn in May or June, and as soon as they have recovered a little strength make their way into the swiftest streams they can find, such as weirs, mill-tails, \&c., to scour and brace themselves; beginning to get into condition again in a few weeks, and being in the best season for the angler until September and October, when the frosty nights drive them from the streams and shallows into the deeper waters. Here they 
will be found until the spring; and in these quiet deeps and eddies they are to be caught, if anywhere, during the winter months. At this period, however, especially if the sveather is very cold, it is of comparatively little use to fish for Barbel, as they lie in a sort of semitorpid condition, and refuse to move. So inanimate are they, that the fishermen not unfrequently provide themselves with hoop landing-nets, which they place near the fish, and with a pole literally push them in ; and I have known shoals to collect under the shelter of a sunken punt, or other tidal obstruction, lying so closely one over the other as to present the appearance of a solid mass.

\section{The Bream.}

There are two species of Bream which are more or less generally scattered throughout the waters of Great Britain,-the common, or Carp Bream (abramis brama), and the White Bream, or Bream-flat (abramis blicca) The latter I have caught occasionally, but it is a miserable, bony fish, rarely exceeding one pound in weight, and almost as worthless for angling as for eating. In colour it is silvery, or dusky, instead of golden, but the most certain distinction is to be found in the teeth, situated in the throat, and which in the Bream-flat are placed in two rows on each side, numbering three and five respectively, whilst those of the Carp Bream are placed in one row only on each side, numbering five. In order to examine the teeth properly the jawbone 
must be taken out and the flesh and skin carefully removed.

There is a third species which has been occasionally identified by naturalists - the Pomeranian Bream, (abramis buggcnhagii). I am acquainted however with but four spots in which it has been found, and it is so rare as to be only of interest to the ichthyologist. In shape it is thicker and longer in proportion than the other two species, and has its throat teeth in two rows on each side, numbering three and five respectively.

The common Bream, though a very indifferent fish for the table, is well worthy of attention in an angling point of view, as where it exists at all it is usually found in great numbers, often of a large size, and is a ready biter.

All the baits used for Roach, Perch, or Barbel will kill Bream, but by far the best river-bait is the tail of a lob-worm used with the Nottingham or ordinary floattackle,-in the case of rivers precisely as described for Barbel fishing. The gentle is another good bait.

The observations on ground baiting for Barbel are also equally applicable to Bream. The latter, however, is a pond as well as a river fish, which the former is not; and for pond-fishing for Bream some slight modifications of baits and tackle are often requisite. Thus, if worms are employed the hook should be a size or two smaller, say a No. 8 ; the worm itself, the tail of which is to be used, should be also rather slenderer, or a whole worm 


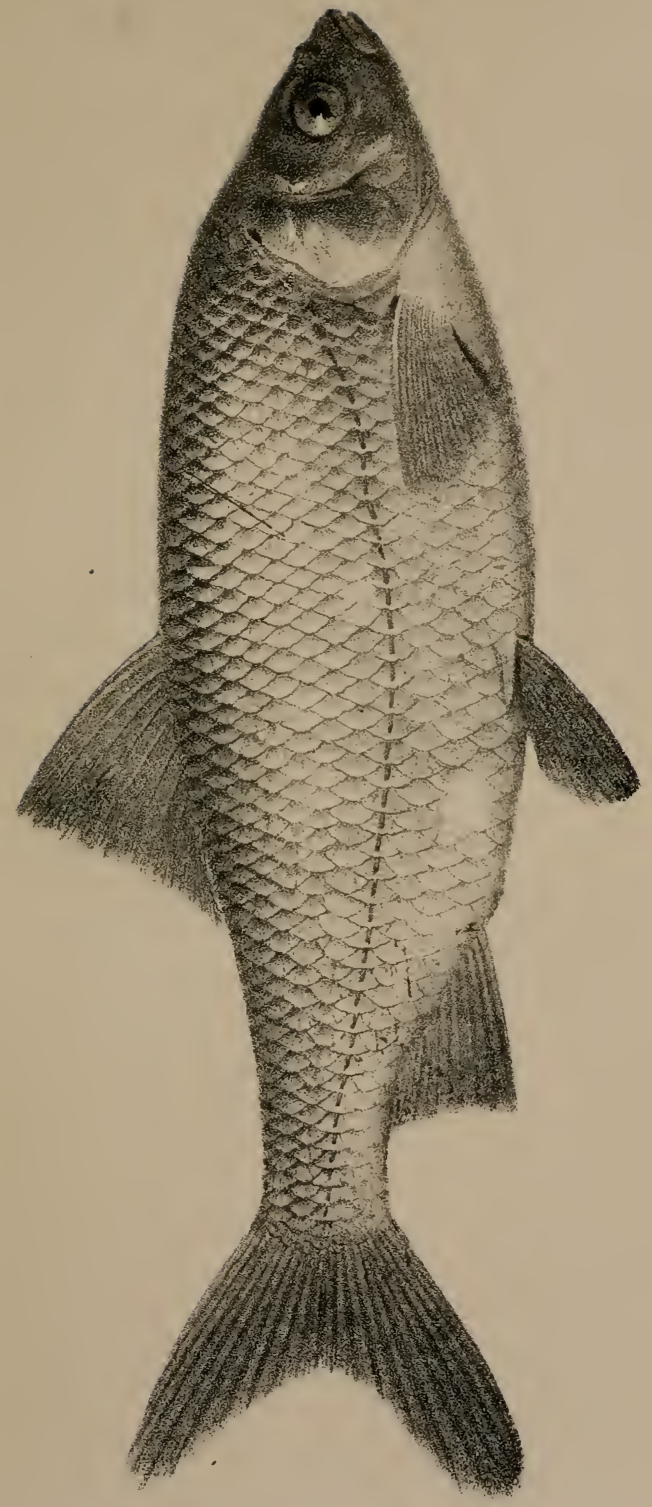

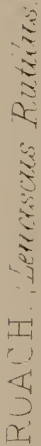

告 

of a smaller description, or gentles may be substituted. The float also should be lighter, and the tackle generally more like that recommended for Roach. Broken worms, and carrion gentles mixed with wet bran, are the two best pond ground baits for Bream that I am acquainted with. Only a small quantity should be thrown in at a time, and with intervals after the first few castings, of not lcss than five minutes. Bream are almost invariably found in large shoals, so that if they are once attracted to a spot, they will consume more ground bait without danger of surfeit than either Barbel or Roach.

The largest Carp Bream I ever saw weighed five pounds and some ounces, but specimens are on record which have nearly doubled this weight. The average "run" of Bream differs very much in different waters. It thrives best in large open lakes, and in slow rivers alternating with "broads" or lagoon-like reaches.

Bream spawn in May, and after scouring for a few weeks return to their usual haunts. Omitting June, when the fish should be left to recover health and strength, the three or four months following the spawning season usually afford the best Bream fishing. 


\section{CHAPTER XXI. \\ ROACH AND RUDD.}

Roach and Rudd are distinct species-Points of difference and similarity. Hybrids amongst fish doubtful. Distinguishing characteristics of Roach and Rudd, and how to be identified. A newv variety of Rudd-Habitats of Roach and Rudd. Spawning season. Best baits and ground baits in running and stagnant waters, and how . to use them. Tackle. Other species of the Roach genus.

WHERE Rudd are found it is almost invariably in waters which are also inhabited by Roach (although the converse of the proposition by no means holds good), and as the two species closely resemble each other both in habits and in the method of fishing for them, baits, \&c., I have bracketed them together.

Roach and Rudd, indeed, have so many striking points of resemblance that the latter were formerly considered by writers on ichthyology to be a "bastard Roach," bred betwixt the true Roach and the Breaman opinion held by, if not originating with, Izaac Walton, who also considered the White Bream or Bream-flat, a cross between the same species. Modern science has, however, exposed the fallacy of this notion, and the three fish are now always recognised as distinct species. 
Indeed, recent ichthyological research has thrown grave doubts upon the existence of any constantly recurring hybrids among fish. Without going into the general question, which would be beyond the scope of this work, I may mention in reference to the case in point, that the Rudd is constantly found in waters in which no Bream exist, and that the Bream-flat has been recognised only in a comparatively few rivers, whilst in hundreds Roach and Bream co-exist plentifully together without either the Bream-flat or the Rudd.

The angler is never likely to be at a loss to distinguish between either of the Breams, and the Roach, or Rudd, the whole type of fish, so to speak, being different ; but between the two latter species I have often known even old fishermen to be uncertain, and therefore I will give a few of the most obvious distinctive marks of the two species.

The prevailing colour of the Roach is silvern, that of the Rudd golden, or silver with a reddish-orangy tint ; the body of the Rudd is a good deal deeper and flatter than that of the Roach, and the head much shorter and more "chubby," being, in fact, little more than three-fifths of the length of that of a Roach of the same length. The most obvious structural difference, however, and one which never varies, is to be found in the relative position of the dorsal or back fin; this in the Roach commences or originates as nearly as possible over the ventral fins; whilst in the Rudd it originates considerably further back. 
By bearing these points in mind the angler need never be in doubt as to which species he has in his creel.

When first caught I should unhesitatingly award to the Rudd the palm for mere brilliancy of colouring over all other British freshwater fish. The reddish gold, which is the prevailing body-colour, varies in the varying shades of light; the eyes and fins are tinted different shades of crimson and orange-scarlet, whilst the gillcovers and sides are of a rich golden yellow. From these peculiarities of colouring it is unnecessary to say that it derives its name. Its specific appellation, erythropthalmus (from the Greek, erythros, red, and oplithalmos, the eye), has a similar origin.

I was so fortunate, a few years ago, as to discover in some ponds near Romford, Essex, a lemon or yellowcoloured variety of the Rudd. In this fish, of which I took several dozen, all the red tints of the Rudd, even including its characteristic red eyes (or more correctly, irides), were replaced by various tints of lemon and bright yellow, the larger the fish, the deeper being the yellow colouring. The specimens-of which some are now in the British Museum - present other, and in some points structural differences.

In their natural habitats the Roach and Rudd differ, inasmuch as whilst the former species thrive and abound equally in ponds and rivers, the latter are comparatively confined to waters of a stagnant character, or lagoon-like expanses connected by rivers, like some of the Norfolk 
broads, in which the Rudd are known to abound. The most remarkable water for Rudd with which I am personally acquainted, is Slapton Ley, in Devonshire, where these fish not only breed in vast numbers, but attain an unusual size, from $I$ to 2 pounds being a weight of common occurrence.

The Rudd spawns in April, or early in May, according to the forwardness of the spring, and the Roach about a month later, when they usually ascend from the lower parts of the rivers, fighting their way up intervening rapids with persistent energy, until they find a suitable spot-usually a weedy shallow-in the higher reaches.

After spawning they repair to the nearest swift gravelly shallows to scour, and subsequently into quieter currents, where they should be fished for until September or October, when they begin to retire for the winter into deep and still waters, preferring usually a gravelly or sandy bottom.

Roach and Rudd will occasionally take most of the baits already described for Bream; paste and gentles. however, are the two best, and of these I have found from experience that gentles are usually both the most killing and the most reliable, taking all waters and weathers throughout the year. They are also much more convenient for use because requiring to be seldom renewed. Many anglers, in fact, go to the opposite extreme, and acting on this circumstance, do not renew the bait nearly often enough. Whenever the gentles 
become dead and sodden, they ought to be renewed. Rudd-and Roach also during cold weather-will often bite freely at the worm ; for which purpose I have found the brandling most successful. As liver gentles are the best general bait for the hook, so carrion gentles are the best ground-bait both for Roach and Rudd. In ponds and still waters they should be used alone, or at any rate mixed with nothing heavier than wet bran; but in running waters, unless in eddies or the gentlest currents, soaked bread or meal should be added, without which it is very difficult to regulate with any degree of nicety the point at which they will reach the ground. The stronger and deeper the stream the stiffer should be the mixture. If gentles in sufficient abundance cannot be obtained, the above ground baits, singly or in combination, are the best substitutes. Meal by itself, or mixed with boiled rice, makes a very fair ground-bait for streams, as it possesses the requisite consistency and weight for withstanding the action of the water; chewed bread-crumb is also a by no means contemptible substitute in ponds and lighter waters. If possible, it is better to bait the place it is proposed to fish beforehand; and on this point, the principle laid down under the head of Barbel and Bream fishing (pp. 247-8) should be observed. Roach being both smaller eaters and commonly congregating in smaller shoals than the lastnamed fish, should be ground baited for with a proportionately smaller quantity of food. In ground 
baiting a swim the day previous, a pint or so of carrion gentles, mixed with about a quart of one or other of the baits above described is about the right quantity. In ground baiting a swim for present fishing, two or three handfuls to begin with will be quite sufficient, smaller quantities being thrown in afterwards. As Roach are easily scared, it will be found the best plan to scatter in frequently at the head of the swim small quantities of bait in broken pieces. If the ground bait is meal or bread, a quantity about equal in bulk to a walnut is about the proper quantity for each "scattering." Whilst Roach are biting, such small pieces may be thrown in with advantage. After every two or three fish hooked, the bait should be dropped immediately in the same place. If gentles alone are used, much smaller quantities will suffice both for preliminary and subsequent ground baiting. For other observations on the subject of baits and ground baits, mode of obtaining and preserving gentles, \&c., see chapter on baits (p. 225).

The tackle and methods of Roach fishing are those already described for ordinary bottom fishing (pp. 219-22), and Nottingham fishing (pp. 222-3), the last named being preferable; and in either case it is of the utmost importance that the tackle and line used should be of the finest. A long, light, stiffish rod is most convenient, and many Roach fishers keep a rod expressly for the purpose, made of light East India cane, or bamboo. The general rod described at p. 5 I, contains, however, a suitable and 
efficient weapon for all practical purposes. For gentles and paste a No. 3 or 4 hook (see p. I I) will be found the most convenient size, a very small piece (about the sixteenth of an inch) of the shank end being nipped off. If the gentles are large, four will be found the best number to bait the above hooks with. They should be made into a "bunchy" looking bait, by the hook being passed through the first three gentles laterally, or across, about the middle. If threaded up to the hook in the more usual way the gentles follow its curve, and form a suspicious-looking half circle of bodies. The point of the hook should be entirely concealed in the fourth gentle, so that when complete no part of the hook should be seen.

The bait should swim three or four inches clear of the bottom in rivers, and in ponds at from about eight inches to a foot from the ground according to the depth. The best depth for a river Roach swim is usually from five to seven feet, over a gravelly or sandy bottom, and the best time to strike a bite is just when the top of the float is disappearing, or is held for a moment level with the top of the water. In order to strike effectually it is advisable to fish with a short line, and the float as nearly under the point of the rod as possible. A violent and sudden darting away of the float usually indicates the bite of a small fish which is generally missed. A heavy Roach rarely makes any great demonstration, but after one or two preliminary "bobs," quietly takes the float down. 


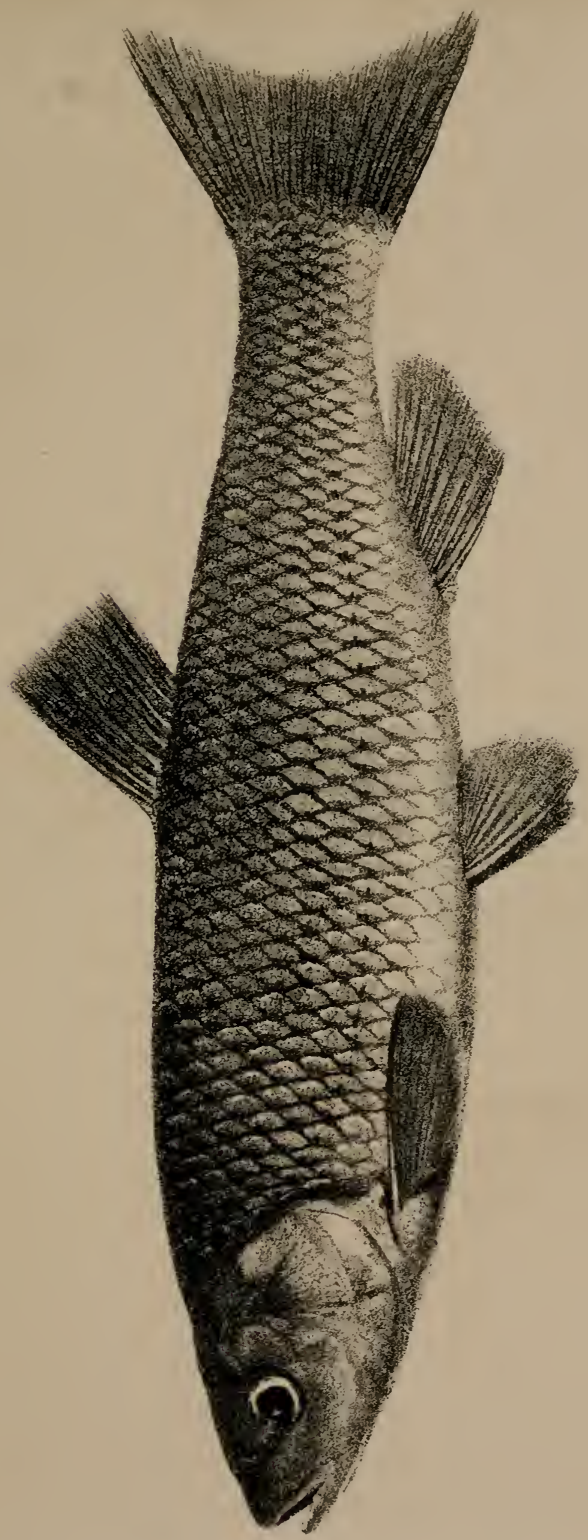



All the foregoing observations on Roach fishing apply equally to fishing for Rudd.

Roach and Rudd will both take a fly occasionally in hot weather, and when basking at the surface. Any small black fly will take if the fish will : but the latter occurrence is so uncertain that fly-fishing for Roach cannot be recommended under ordinary circumstances.

There are three other species belonging to the same gemus as the Roach, viz. the "Double Roach," the "Graining," and the "Azurine," or Blue Roach. These species, however, are either confined to a few particular localities, or are so rarely met with as to pertain rather to the department of the ichthyologist than that of the fisherman. An account of their habits and characteristics will be found in the "Angler-Naturalist." 


\section{CHAPTER XXII. \\ DACE AND CHUB.}

The two species contrasted - Distinguisbing marks - Their habits, haunts, and sporting qualities.

Dace fisking-Baits; ground baits; tackle, \&c. Fly-fishing. Variety of patterns unnecessary-Three typical Trout-fies recommended to be substituted.

Cbub fisbing with the fly; theory of Chub-flies. Useless multiplication of patterns: only one necessary. A nerw pattern described.

Float fisbing-Caterpillars and grasshoppers; live minnows; pith and bullock's brains.

THE bodies of both the Dace and Chub are more cylindrical, or elongated, than those of either the Roach or Rudd, and even without the difference of colouring this characteristic will probably prevent any difficulty arising in their identification. It is not so as regards Dace and Chub inter se, for these species, especially in their earlier growth, so closely assimilate in external appearance as to be constantly confounded. I have now in my mind's eye a tableau which I once witnessed: an enthusiastic young angler and ichthyologist sitting near the river Wey with a volume of "Yarrell's British Fishes," in one hand, a diminutive specimen of the gcruls lenciscus in the other, and in his face a pitiable 
expression of bewilderment as he endeavoured to identify the species of his "captive" by a critical comparison of the relative measurements of the head, body, and fins, according to the ichthyological formulary given in the pages of that scientific, but to the uninitiated, somewhat perplexing volume. Was it a small Chub or a large Dace that he had caught? This was the problem. I forget whether he succeeded at last in solving it; but if the angler will bear in mind the following simple distinguishing characteristic he need never be in a similar dilemma:-The ventral (or belly) fins of the Dace are always greenish with a slight tinge of red, whilst the anal fin has no red about it whatever; in the Chub both these fins are of a brilliant pink colour.

As the Chub grows larger, the chocolate brown, almost black, of its tail-fin becomes more marked, and the whole fish rapidly assumes a bronzed or golden appearance, in place of the prevailing silvery tint which the Dace retains in its original brilliancy to the last.

The Dace is indeed a bright, graceful fish, glancing about in the clear quiet streams with which the southern counties of England especially abound, and which are too often barren of Trout or Salmon. Moreover, it is in full season in October, November, December, and January, when the latter fish are spawning or preparing for the process, and thus a red-lettered day's sport is not unfrequently to be obtained, which would otherwise have 
been a blank in the diary. When hooked, the Dace is one of the gamest fish that swims.

Of the Chub as a "sporting" fish less can be said with truth than of its congener, but on the other hand it grows to a far greater size, and from its being one of the comparatively few species of coarser fish which will take the fly kindly, it is not to be despised. As its specific name-the "Headed Dace"-implies, it is somewhat slow and clumsy in its movements and appearance, though withal a stately and handsome fish when large and in good condition; but I cannot but think that the fashion with old writers of painting the Chub as a sort of water-donkey must have either lacked sufficient foundation, or else that the Chub of our ancestors were somehow different from the Chub with which we are acquainted. Possibly however, the fish of our Metropolitan river, where most of my experience of Chubfishing has been obtained, may be better educated than those of less classical streams. For one thing I can vouch,-that a fish of quicker sight than the Chub does not swim in English waters. The slightest gleam of the rod, the shadow of the swallow flitting over his quiet corner, and down he goes like lead; so quickly, in fact, that the eye is rather conscious he is no longer there than aware of his disappearance. Add to this extreme quickness of perception, the woody nature of the haunts in which he is to be found, and the fact that the successful Chub fisher must be prepared to cast his fly to within 
a few inches of the boughs-often into a space the size of his hat-under penalty of losing either his fish or his tackle, and it will be conceded that the task is no easy one. In fact, in this school not a few of the masters of the craft have passed their apprenticeship. Thus much as to the fish themselves; the idiosyncrasies mentioned will assist the angler in applying the following observations on the method of catching them.

\section{DACE Fishing.}

The Dace will occasionally take all the baits enumerated for Roach and Rudd, especially gentles; but the best bait for them all the year round is a small red worm, the tackle and mode of using it, as well as the method of ground baiting, being identical with that described for Roach fishing. Any of the smaller description of worms, broken into two or three pieces, or carrion gentles, will be found the best ground bait. The haunts of Dace at different seasons, and consequently the best places for catching them, are also very similar to those of the Roach, the only difference that I am aware of being that the Dace affects rather stronger and more rapid waters than the Roach. Indeed, especially during the summer months and towards evening, Dace can be most readily taken with a fly on the swiftest rapids and shallows.

Either of the flies recommended in this book for Trout and Grayling (p. I40), dressed on a No. I or 2 
hook (see p. I I), or a red or biack gnat, will kill Dace if they are disposed to rise. It often happens when Dace are rising shyly that a gentle used on the point of the hook acts as a provocative of appetite.

\section{The Chub.}

Fly-fishing.

Although I have known instances of both Dace and Chub being found in ponds, the river is their common and natural habitat. Unlike the Dace, however, the Chub is rarely taken by bottom fishing throughout the summer, during which period, the fish is to be looked for either on gravelly shallows, especially when they run under bushes and hollow banks, or in back waters, and slow-running streams overhung with bushes and trees. In either of these positions the Chub may be taken with the artificial fly-by far the most killing method of summer fishing-so long as the weather continues warm. The fly-rod (either double or single-handed, according to fancy), and the reel, line, \&c. should be the same as those described for Trout fishing. The mode of working the fly is also similar. When fishing under boughs, the great art is to cast as near to them as may be-or under them, if possible-without getting foul. Indeed I have often found it a good plan when fishing from a boat to let the fly light actually on the fringe of boughs sweeping the stream, the fly thus slipping off into the 
water with a more natural descent, and just in the position where a Chub would be likely to be on the lookout for a caterpillar or cockchafer.

The angler should be slow rather than quick in striking a Chub with the fly-the fish, especially when large, being as I have said, somewhat slow and clumsy in its movements, and having remarkably white lips which are often visible at 10 or 15 yards off as it opens its mouth for the fly. When once hooked, and the first powerful rush for the boughs checked, the Chub very seldom escapes, being remarkably tough and gristly in the jaws and lips, or as it is termed "leathermouthed."

As for all the other species of fly-taking fish, the ingenuity of anglers has contrived a vast variety of artificial lures for the Chub. Of these manifold products of nature and art-or of art without nature-the best are the black and red palmer and the Marlow buzz. These owe their chief killing properties to the fact that they have more legs (hackles) than the rest; and as I have already explained, a propos of Salmon and Trout, the movement and lifelike appearance which legs give are amongst the most important of all the characteristics of an artificial fly. This "movement" is, in the case of Chub flies, of additional importance, owing to the quiet, comparatively stagnant waters in which they are frequently employed. Trout and Salmon flies are, it is true, very commonly used on lakes, where there is no current whatever; but 
then, if they are to be used to any purpose, it is always when the water is curled by a breeze; and more frequently when the sky is clouded ; in fly-fishing for Chub, on the contrary, the calmest of days with the brightest of suns, is the combination of weather most favourable for sport. I have also invariably found a black fly the most kiiling; and this has been the result of my experience - a tolerably long one - not only on bright days, but in dull gloomy weather, and sometimes late into the dusk evening, when it was so dark that to my eyes not only the colour of the fly, but the fly itself was indistinguishable. Appended is the engraving of a Chub fly which fulfils the two conditions explained, and which I myself use-dressed, of course, of different sizes from the beginning to the end of the season, in all weathers, and at all times of the day. I advise my

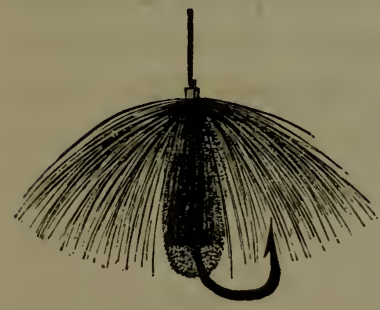

The Sweep. brother anglers to give it a fair trial, and I think they will not be disappointed. The legs are made of black hackle, which should be as long as the body of the fly, and extra thick and bushy; the body of black ostrich herl, and the tail of the same, white or satin-coloured. As it is the fashion amongst anglers to christen their offspring, I have named my sooty-featured nondescript, "the sweep."

The fly shown in the engraving is dressed on a No. 10 
hook of my pattern (see p. I I), and is a fair ordinary size for most waters; one size smaller and one larger will be sufficient to provide for variations. The smaller size should be used when the water is very low and clear, and the larger, when it is high, or when the daylight begins to fade. This is the best time of the whole day for fly-fishing for Chub, as the cockchafers, moths, \&c., on which they principally feed during the summer, are then beginning to come out.

All Chub flies are improved by placing a small piece of a white kid glove-about the size of a large gentleon the bend of the hook. I have never succeeded in making out why this should be; unless indeed it is on the well-approved principle, that "there is nothing like leather." In Chub fishing no more than a single fly should ever be used; and as this is heavy, owing to the plumpness of its body, it should in the largest size be invariably dressed on loops, by which means both the pocket and time of the angler will be saved, and he will be enabled to use a finer collar than he otherwise could. The method of knotting on the fly-loop to the collar is described at p. I6r.

The natural grasshopper-separate, or in combination with gentles-may be used like a fly, and is a very killing bait, or it can be employed instead of gentles on the artificial grasshopper described at p. I4I, with which bait, when cast like a fly, but allowed to sink a foot or two each time, I have had occasionally good sport. 


\section{BotTom Fishing.}

In the spring months a live Minnow is often a very good bait for Chub, used simply with a float and line, and a single hook passed through the upper lip. From this time to October or November, the Chub is better fished for by the fly, or by either of the methods pointed out under the same head.

About this period, however, the fish quits its summer for winter quarters,-quiet swims under willow-beds, amongst roots, by sunken piles, or in any other cover affording good shelter. The occupation of the fly-fisher is now at an end, and that of the bottom-fisher begins. The method of angling may be either the ordinary or Nottingham style, the best swim, tackle, baits, and ground bait, being identical with those recommended for Barbel fishing (p. 246 to p. 248). But by far the most deadly winter bait of all for Chub is "Pith," or the spinal marrow of the bullock or cow, with bullock's brains as ground bait. The method of obtaining, preparing, and using these baits is described at pp. 225-7. For this mode of Chub-fishing the colder the weather the better, provided only that the water is not discoloured. The pith should be used with Nottingham tackle, the most favourable situation being deepish water close to boughs and "rooty" banks. The bait should swim about three or four inches from the bottom, as nearly as may be, the brains being thrown in from time to time above the 


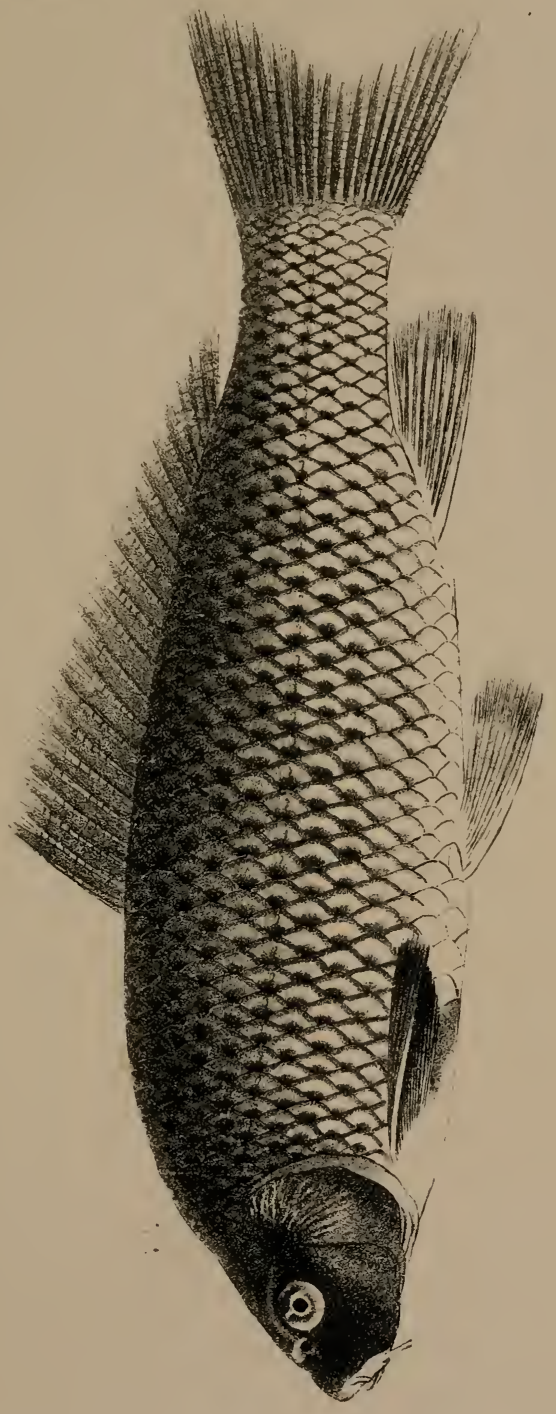



swim. In this mode of fishing it is not advisable to bait any one swim beforehand, as Chub are shy fish, and it is seldom that more than two or three can be taken out of the same place without scaring the rest: consequently it is better to move from place to place, throwing in a small quantity of ground bait at each. By this mode of fishing the largest Chub are to be taken; and when used by skilful hands, I have known a punt-well to be half filled with fish.

The Chub is sometimes locally called the "Chevin." It is the Penci, or Cochgangen, of Wales, and the Skelly, of Scotland. 


\section{CHAPTER XXIII.}

\section{CARP AND TENCII.}

The two species contrasted. Alleged healing powers of Tench. Longevity and growth-rate of Carp. Habits and haunts of the two fish.

Carp and Tench fishing : tackle, baits, ground baits, \&c.

CARP and Tench appear naturally to "go together," like strawberries and cream, or Cod and oyster sauce. Although I have occasionally known waters containing Carp to be destitute of Tench, I cannot call to mind a single instance of the converse of the proposition. Carp and Tench are equally long-lived out of water, their habits and food are similar. They are both to be best fished for with the same baits, at the same seasons, and, so far as bottom fishing is concerned, in precisely the same manner. It is also a curious circumstance, that whilst it is difficult to imagine two fish more opposite in colouring-the Tench being of a very dark olive green, and the common Carp of a golden-bronze colour -yet otherwise, in the general shape and contour of the body they bear so striking a resemblance, that between specimens of the same size a change of coats would be hardly an inconvenience to either. Again, in regard 
to scales, it would be hard to hit upon two fish more dissimilar.

The Carp has the largest scaling of any of the fish composing the group of which it is the type, whilst the scales of the Tench are amongst the smallest, if not actually the most minute of the whole family; and whilst the former fish makes one of the very best Pike live baits that I am acquainted with, the latter, it is affirmed, exerts upon that usually carnivorous gourmand an effect absolutely repellent. Of the truth of this fact, as a fact, there seems to be no reason to doubt, though we are not, of course, bound to put implicit faith in the various theories by which it has at different times been explained. Of these the most universally accepted amongst ancient, and even by some modern authors, appears to be that the Tench is in some way the physician of the water, possessing in the thick slime with which he is covered a natural balsam for the cure of himself and others. Camden, in his "Britannica," says that he has seen the bellies of Pike, which have been rent open, have their gaping wounds presently closed by the touch of the Tench, and by his glutinous slime perfectly healed up. The Pike, in return, it is asserted, refuses to molest his physician, even when most pressed by hunger - a statement in the accuracy of which Oppian, Walton, Holingshed, Bowlker, Salter, Williamson, Hofland, and Fitzgibbon, all acknowledge to more or less faith. 
To try the experiment practically, I once procured some small Tench, and fished with them as live baits for a whole day in some excellent Pike water, without getting a touch. In the evening I put on a small Carp and had a run almost immediately. I also tried some Pike in a stock-pond with the same Tench, but they would not take them; and though left in the pond all night-one on a hook, and one attached to a fine thread -both baits were alive in the morning-some Pike teeth marks, however, being visible on one of them.

Bingley's explanation of the Pike's asserted abstinence is, that the Tench is so fond of mud as to be constantly at the bottom of the water, where the Pike cannot find him. Both theories, however, require confirmation.

The male Tench are distinguished from the females by a very curious and marked difference of the ventral fins. In the females these fins are of the ordinary size and shape, but in the males they are much larger and more muscular, and present almost the appearance of a green concave shell, the concave side being uppermost.

If the Tench is thus remarkable by its characteristics and traditions, the Carp is certainly no less so. The great age to which it is believed to attain, and the cunning and sagacity that has procured it the cognomen of the "Water Fox" have been frequently made the subject of comment by writers on angling. Indeed there are some Carp now in the lakes belonging to the Palace at Fontainbleau which may be fairly said to have 
become historical. The oldest of them have now quite lost their normal colour from their great age, and are very nearly white. There is, moreover, evidence that many of these fish introduced into the ponds at Versailles, \&c., during the reign of Louis the Fourteenth (say 1690), are either still living or were so but a short time before the Revolution of 1830 . Dr. Smith, in his "Tour to the Continent," mentions them, and observes that they had grown white through age. Valenciennes refers to others in the Tuileries, which would also come when called by their names; and Buffon assures us that he had seen in the fosses of the Ponchartrain, Carp which were known to be upwards of a century and a half old.

A year or two ago a series of ponds near Cumberland Lodge, Windsor Park, were run off for the purpose of getting rid of the Jack; and the result of the netting illustrated in a remarkable way the slow growth-rate of the Carp. Thus, nearly all the Carp taken from the Obelisk pond were of a very similar weight, viz. : from $4 \mathrm{lbs}$. to $6 \mathrm{lbs}$. These fish, within the positive knowledge of the Head Fisherman, were fifty years old at least. They had been twice removed during his memory from the different ponds, the last time some thirty-five years previous, when they weighed about 3 lbs. each. Their subsequent growth-rate could not have averaged therefore more than about an ounce a year. Old Carp are very bad breeders, and frequently retain their eggs for 
years, presenting occasionally the appearance of an immense tumour in the region of the abdomen.

During the winter months it is probable that both Carp and Tench retire almost wholly into the mud, or under roots, hollows, and weeds, and at this time they are hardly ever to be taken with a bait. In the summer the former species frequently lie sucking in the weeds, in a sort of lazy state, each suck making a very distinct and unmistakable noise. When not sucking cr basking, Carp usually swim about in shoals near the surface of the water, returning to the bottom to feed.

The Tench spawns, with some variations, about the middle of June, or according to Willoughby, when wheat is in blossom ; Carp usually commencing a little earlier, according to the temperature of the water and forwardness of the season. They deposit their spawn upon and amongst weeds, and are supposed to continue the process for a longer period than any other fresh-water fish, indeed sometimes throughout the entire summer.

Although by no means rarely found in rivers, Carp and Tench are very rarely caught there, and then, according to my experience, it is not when they are being fished for. Indeed fishing for either of these species is at the best but uncertain work, and in the case of rivers usually wholly unprofitable.

Professor Owen, who is a great adept in the art of Carp-fishing in ponds, has been kind enough to give me the result of his experience. 


His practice may be formularized thus :-

I. The summer months are the only time of the year for Carp-fishing, and the best period of the day is between sunrise and about seven o'clock, after which time they usually leave off biting.

2. The best bait is a brandling.

3. He has, however, found the following paste a by no means bad substitute: soft Herring roe, worked up with bread-crumbs and wool.

4. He uses the ordinary bottom-fishing tackle with a light float, and fishes about half a foot off the bottom.

My own experience concurs almost entirely with that of Professor Owen, except as regards paste and bait, with which I never had any sport. I used formerly to use a plain bread-crumb paste, but later experience has convinced me that it was a mistake, and that a wellscoured brandling is the best bait both for Carp and Tench all the year round.

In open waters, however, I employ it in a somewhat different way to that adopted by Professor Owen, placing the shot at about two feet from the bait and allowing the latter to rest, with about six inches of the line, on the bottom. The hook for this purpose should be a No. 7, and the collar of fine round picked gut, stained as recommended at p. 30 . The float should be a light porcupine quill, and it will commonly be found expedient 
to use a reel, as the Carp is remarkably powerful, and without this precaution, the first rush of a heavy fish is very likely to carry away the tackle. A few broken worms thrown in from time to time are the best ground bait ; or whole worms, if the place is to be baited beforehand, in which case the depth also should be very accurately plumbed, so as to avoid any disturbance in the water when the angler comes to fish. Having thrown in the bait, it is the best plan to lay down the rod until there is a bite, and not to strike until the float goes under, or-the more common result-moves steadily away.

The above observations are equally applicable to both Carp and Tench fishing.

In very weedy places this mode of fishing is not practicable, and then the best plan is to fish about midwater, dropping the bait noiselessly in wherever a tempting-looking opening in the weeds presents itself. 


\section{CHAPTER XXIV.}

ON SMALL FISH, PRINCIPALLY USED AS BAITS.

Bleak-How to fish for, with the fly, gentle, and cast-net-How to cook。 Gudgeon and Gudgeon-fishing. Stone Loach-Different species, and how to be distinguished and caught. Miller's Thumb. Minnows and Sticklebacks. All anglers should be Icbthyologists.

\section{BLEAK AND GUdGEON.}

THE Bleak, though I think properly included under this division of my subject, is, in fact, rarely caught by bottom-fishing, properly so called. It is essentially what is termed a "surface-swimmer," and as such should be fished for exclusively at the top. The Gudgeon, on the contrary, is perhaps the most remarkable example amongst sporting fish, of a species haunting and feeding exclusively at the bottom; and I have bracketed the two together because they illustrate in a marked manner the importance to the angler of studying accurately the habits of the fish angled for. It is probable that if a man were to fish for the Bleak from the beginning to the end of the season in the manner described for the Gudgeon, he would not take a single specimen, and vice versâ. 
The Bleak is so common throughout England in most rivers producing Roach and Dace, that any detailed description of its characteristics would be superfluous. Nor is it likely to be confounded with any other fish, as it is the only one of our fresh-water species which in shape is narrow as well as flat-in other words, Spratlike. Bleak derive their name from their shining white* scales, in which, like a girl in her first ball-dress, they seem to be never weary of glancing to and fro, and coquetting with the midges as they flit out their three hours' existence over their native stream. Accordingly, any small fly bearing a sufficient resemblance to these insects will commonly take Bleak in greater or less abundance, especially if a gentle is added on the bookpoint; but the best method of Bleak-fishing is as follows :-Select a light fly-rod and line, a collar of the very finest stained gut, with a No. I hook (see p. I I), and at about two feet from the hook fasten a small round piece of cork, about the size of a large green pea, to act as a sort of float. Choose a swim where Bleak are rising-which if they are there, they will be tolerably sure to do-and having buried the small hook in a single large liver gentle, take a quarter of a handful of bran, and after giving it one quick squeeze under water, so as not quite to soak the whole of it, cast it into the water some ten yards or so from the shore or boat, and imme-

* From a northern word signifying to bleach or whiten—blik, Danish ; blick (Swedish and German) "glance," "glimmer." 
ON SMALL FISH, PRINCIPALLY USED AS BAITS. 28I

diately afterwards throw the bait into the same place, letting it swim quietly down until a bite is perceived. When the swim is finished repeat the cast, using a little more bran now and then as may seem judicious, in order to keep the Bleak together. If, from the rises of the fish, it appears that they are following the bran down the stream, the angler should keep with them, always casting where the most fish are rising. By this means, wherever Bleak are plentiful, a good dish can generally be calculated on, and they will be the finest in the shoal. No shot are necessary, and the style of this fishing generally, approximates to that of artificial fly-fishing. All depends on extreme fineness in the gut and tackle.

I have already mentioned, when alluding to the castnet, that if Bleak are required as baits, soaked bran is the most certain bait for attracting them into any given spot. A small eddy not more than two feet deep is the best water for this purpose.

Bleak dressed and eaten like Whitebait make a very good dish. It is an important point, however, that they should be eaten when quite hot, and that plenty of salt and pepper should be scattered over them whilst they are in process of frying. They spawn in May.

The Gudgeon, although principally interesting to sportsmen as a bait for other fish, has, from its instinctive readiness to bite, and general simplicity of conduct, many devotees amongst the softer sex, who often beat 
their lords hollow in the art. I once forfeited a pair of gloves to a fair angler, who wagered that she would catch ten out of a dozen bites, " nibbles included," and actually did it. Notwithstanding, however, its somewhat feminine reputation, there is no doubt that Gudgeonfishing often exercises a fascination over male minds also; and $\mathrm{I}$ am acquainted with many men who practically confine their angling to the capture of this fish.

Gudgeon are hardly ever seen, unless by an accident, in other than running waters; and here they are to be found - principally on gravel or sand-during the summer, which is the time for taking them. I have seen them in July and August, on the rippling shallows of the Hampshire Avon, literally by thousands, and that often in water little more than enough to cover them. In one throw of the cast-net on such a spot I took last year no less than 98 Gudgeon, most of them very large; and probably a score or two at least escaped in carrying the net over the fifty yards of shallow which intervened between me and the shore.

The ordinary tackle for bottom-fishing should be used for Gudgeon with a medium-sized porcupine-quill float, fine stained gut-line, and a No. 2 or 3 hook (see p. I I).

From 4 to 6 feet of water, where the current is of a medium strength, is the best kind of Gudgeon swim, and the depth should be plumbed accurately, so that the bait may just "dribble" (not drag) along the bottom. 
The best, indeed the only good Gudgeon bait, is the worm, and of worms by far the best is the brandling. Any small worm, however, will do if brandlings cannot be obtained. It will generally be found that the lower half will be better than the whole worm, and that fewer bites will be missed when the hook is thus baited. "The only ground bait which I am acquainted with that is of any use for Gudgeon is small broken worms, mixed with soft clayey mud, which will dissolve rapidly on reaching the bottom, and will cause a thickening or muddying of the water. This result, however, is much better achieved by raking the bottom of the river before, and occasionally during fishing, with a long, heavy iron rake, which is kept by all Thames puntsmen for this purpose. The Gudgeon are attracted by the animalculæ, worms, caddice, \&c., which are turned up in the operation.

While Gudgeon fishing, it is a very good plan to put out a paternoster (see p. 238) for any Pike or Perch which may be roving about, and whose presence would effectually check the "biting" inclination of the smaller fish.

In the lower reaches of a river flounders are not unfrequently taken whilst Gudgeon fishing, the same baits and modes of fishing being best for both fish.

The Gudgeon spawns in May, usually in shallow waters amongst stones. 
STONE LOACH.

The Stone Loach, or "Beardie," though a somewhat slenderer fish, closely resembles the Gudgeon both in shape, size, and colouring, haunting similar waters, and biting at the same bait-a small red worm. The normal position of the Loach is under stones; and here, of course, it is difficult for him either "to take" or be taken by the bait. Consequently, he is of no interest to the angler as a sporting fish. He makes an excellent spinning-bait, however, especially for Lake Trout, in bright weather; and under that head will be found directions for catching him otherwise than by hook and line. For purposes of live-baiting the Loach is useless, being too delicate to survive the slightest exposure either to heat or air.

\section{Miller's Thumb,}

So named from the fancied resemblance of the head of the fish to the proverbial "Thumb of the Miller," is in his habits, baits, \&c., as nearly as may be similar to the last-named species. It is, however, of no use to the angler either for purposes of sport or bait.

\section{MinNows AND STICKLEBACKS,}

Are distributed so widely over most parts of the United Kingdom, and are so well known, as to render description superfluous. A small bit of the tail of any 
small worm on the smallest of hooks, is the best bait for them. Probably, however, few anglers will care to know anything further as to how they may be caught, the former species being of little account except for the purpose of bait, when it can generally be more conveniently caught with the Minnow nets,* and the latter being useless for either purpose.

To the naturalist, on the contrary, these little fish, and especially the Sticklebacks, are more interesting than almost any of the larger species. I daresay it will surprise many of my readers to be told, for example, that the Stickleback, of which our streams and ponds produce six distinct species, are the only British fresh-water fish that build complete nests like birds, in which to deposit their eggs; and that during the subsequent spawning process they display in their diminutive bodies a courage, solicitude, and even affection, almost without a parallel amongst fish. If the Pike is the tyrant of the water, the Stickleback is certainly entitled to be regarded as its knight errant. Now with bated weapons and

* The minnow net is quite peculiar in principle and application, and owes its success to the curiosity which is so strikingly characteristic of the species-males as well as females. It consists of a circular piece of fine net stretched nearly flat over an iron hoop of about two feet in diameter. The hoop is suspended by cords at the sides, like the suspenders of church candle-lamps, and these being attached to a pole the net is dropped horizontally into the water, and suddenly lifted up again when a sufficient number of minnows have congregated over it. Little pieces of red cloth sewn into the net will increase the number of visitors. 
glittering in green and purple he tenderly woos the object of his devotion, or armed cap-à-pie patrols, a watchful sentinel, before her nuptial bower; now he fiercely disputes with rival claimants the possession of some favourite "coign of vantage;" or sheathed in armour of proof and bristling with spines, charges, like a Paladin of old, through the liquid plains in search of other Sticklebacks as pugnacious and more penetrable than himself.

But now that my task is finished, I must not break through the exclusively utilitarian part which in commencing I imposed on myself. It is hard, however-I have often found it very hard-to separate the angler and the ichthyologist,- - not absolutely, of course, because ichthyology in its broadest sense is the very basis of angling; but I mean in those branches of ichthyology which embrace the nicer and less superficial habits and characteristics of fish-life: in the beautiful, in short, as contrasted with the utilitarian.

To such of my readers as I am not now addressing for the first time, I need hardly say that I would have every angler to be an ichthyologist ; a naturalist-that is, so far at any rate as the creatures which form the objects of his own pursuit are concerned.

There are, I know, many little difficulties and drawbacks which deter fishermen from the pursuit of Ichthyology, but these obstacles are not nearly so great as 
they are imagined to be by the uninitiated. Like all other sciences, Ichthyology has of course its own technicalities which must be mastered in the first instance; for if a man is ignorant of the alphabet of a language he can hardly expect to derive much delight from the study of its literature; and the alphabet of science is its technicalities. Again, the markedly, I might say almost ostentatiously, dry and uninviting form in which science delights to expound itself has doubtless been another obstacle. But all these difficulties are to be mastered by a comparatively small application of leisure and perseverance, and even these drawbacks are yearly lessening.

In the "Angler-Naturalist" I have endeavoured by taking myself some little trouble in codifying and simplifying, to save a corresponding labour to others; facts are stated plainly and with an avoidance of unnecessary scientific terms, and I have otherwise done what in me lies to make the subject, which is one naturally full of interest, as little dry and repulsive as possible. To the "Angler-Naturalist,"* therefore, I must refer my readers for those ichthyological peculiarities and characteristics of the different species which are here, not from choice but from necessity, omitted.

The manner in which that attempt at popularizing the subject has been received, gives me good hope that the

* The "Angler-Naturalist : a History of British Fresh Water Fish adapted to Anglers, with a plain Explanation of the Rudiments of Ichthyology." London: George Routledge and Sons. 
time may yet come when a fisherman will not think himself a master of his craft until he is not only a good angler, but also a good ichthyologist ; until he possesses such an amount of scientific attainment as will enable him to read with an intelligent eye the marvels of the beautiful page of Nature that is spread before him,-a page ever open, ever varying.

It has been gravely said that a good angler must also be a good Christian. Without literalizing the assertion, it may well be admitted that there is much in the contemplative character of his pursuit, and in the quiet scenes of beauty with which it brings him face to face, to soften and elevate, as well as to "humanize." The rushing of white water, and the deep greenery of woods and fields, seem incompatible with what is base or sordid. They act like a tonic on mind and body alike, and the fisherman, solitary with his own thoughts, shut out from the world, 'shut in, left alone' with himself and perfection of scenery, can hardly fail to be penetrated with the spirit that haunts solitude and loveliness. A chord is touched that must find an echo in every heart not utterly dead to gentle influences-awakening what is good, silencing what is bad; directing the thoughts into purer channels, and leading them almost instinctively to "look through Nature up to Nature's God."

THE END. 



